Portland State University

PDXScholar

$1-1-1977$

\title{
Citizen participation: individual political behavior and the Federal mandate
}

Rick R. Paulson

Portland State University

Follow this and additional works at: https://pdxscholar.library.pdx.edu/open_access_etds Let us know how access to this document benefits you.

\section{Recommended Citation}

Paulson, Rick R., "Citizen participation: individual political behavior and the Federal mandate" (1977). Dissertations and Theses. Paper 570.

https://doi.org/10.15760/etd.570

This Dissertation is brought to you for free and open access. It has been accepted for inclusion in Dissertations and Theses by an authorized administrator of PDXScholar. Please contact us if we can make this document more accessible: pdxscholar@pdx.edu. 


\section{CITIZEN PARTICIPATION: INDIVIDUAL POLITICAL BEHAVIOR AND THE FEDERAL MANDATE}

by

RICK R. PAULSON
A dissertation submitted to the Faculty of Urban Studies in partial fulfillment of the requirements for the degree of

DOCTOR OF PHILOSOPHY

Portland State University 1977

Copyright (c) 1977 
TO THE OFFICE OF GRADUATE STUDIES AND RESEARCH:

The members of the Committee approve the dissertation of

Rick R. Paulson presented June 22, 1977.
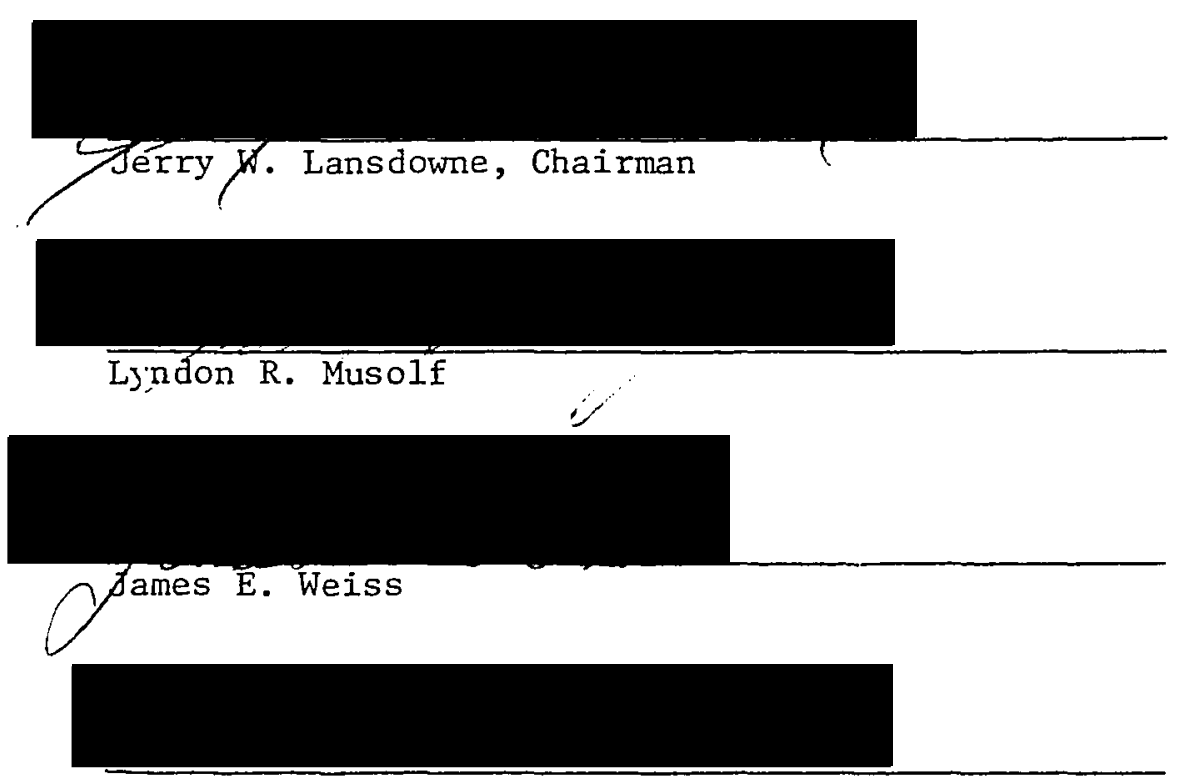

David F. Wrench

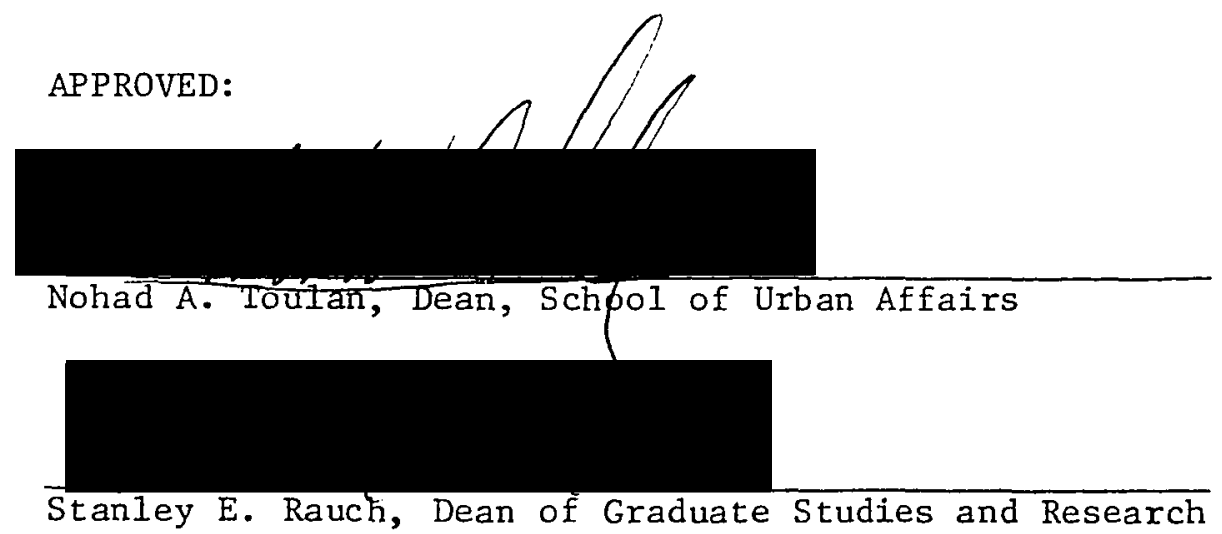


AN ABSTRACT OF THE DISSERTATION OF Rick R. Paulson for the Doctor of Philosophy in Urban Studies presented June 22, 1977.

Title: Citizen Participation: Individual Political Behavior and the Federal Mandate.

APPROVED BY MEMBERS OF THE DISSERTATION COMMITTEE:

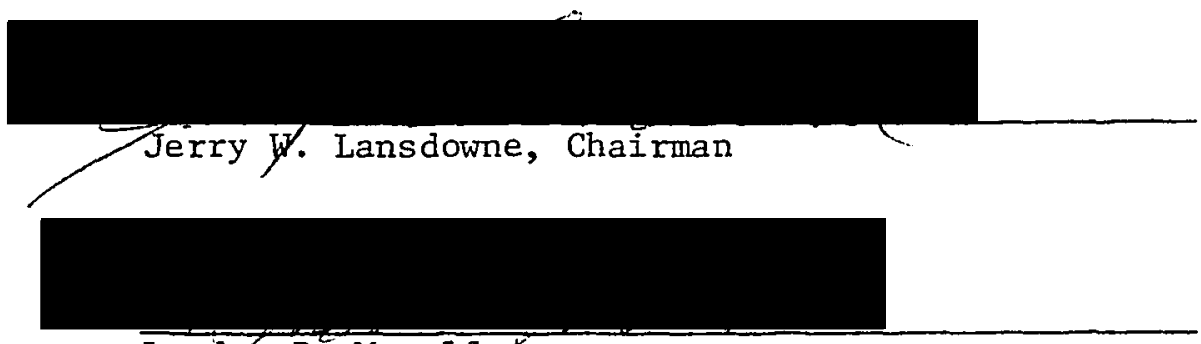

Lyndon R. Musolf

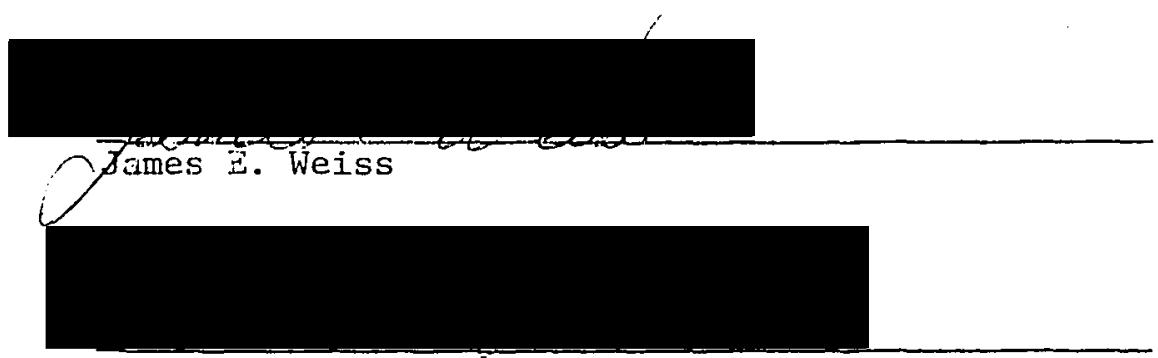

David F. Wrench

Federally mandated citizen participation has been controversial since its inception in 1964. It has been as difficult to implement in practice as it has been to define conceptually. An examination of the literature related to this federally mandated citizen participation uncovers a number of untested assumptions relating to the individual political behavior of those for whom participation is mandated. This literature concentrates on forms of organized group participation, and the direct action of these groups in the planning and policy-making 
process, but it tends to ignore the fact that participation in the organized neighborhood groups advocated is essentially an individual political decision. Also ignored is the substantial body of research and literature related to individual political behavior which generally finds that levels and rates of participation are a function of socio-economic factors. This well established research suggests those for whom participation is mandated--residents of low income and low socio-economic status neighborhoods-are the least likely to become politically active.

The general weakness of this body of research and literature, which is based largely on the electoral process, is that it fails to adequately explain or predict the significant levels of participation actually exhibited by lower income and lower socio-economic status individuals in the War on Poverty, Model Cities, and similar programs. A more holistic model of political behavior based on social-psychological concepts allows a much broader view of the elements which may contribute to this more non-traditional type of political behavior. Such a model has been developed by Robert Lane and others. It suggests perceptual and attitudinal variables which may be especially useful in explaining and/or predicting the participation of lower socio-economic status individuals in these programs. These perceptual and attitudinal variables, and their relationships to political participation, are the focus of the research undertaken in this dissertation.

Through a random sample household interview survey, a study of the perceptual and attitudinal variables associated with resident participation in elections, issues, and neighborhood groups was undertaken in two Low income neighborhoods in the City of Portland, Oregon. The survey results suggest that individuals active in neighborhood groups and issues 
are not necessarily the same individuals highly involved in traditional electoral activity. These survey results indicate a number of perceptual and attitudinal variables significantly associated with participation in neighborhood groups and issues: (1) the perception of the existence of neighborhood problems; (2) salience of perceived neighborhood problems; (3) feelings of personal and/or group efficacy in doing something about the specific problems perceived; (4) perception of the social and political nature of identified neighborhood problems; (5) attitudes toward the value of participation as a desired end in itself; and (6) attitudes toward voting, petitioning, collective action, non-violent protest, and violent protest as approved and effective means to solve neighborhood problems.

The survey results also indicate systematic differences in the perceptual and attitudinal variables associated with the participation of Black and White survey respondents. White participation appears to be much more highly related to the perception of neighborhood problems than Black participation. Whites in the study appear to participate as a means to solve problems they perceive in their neighborhood, while participation seems to be more an end in itself for the Blacks surveyed.

The results of the survey tend to validate important elements of a social-psychological model of political behavior. The results also suggest that more attention needs to be focused on the relationships between individuals' perceptions of their environment and political behavior. 
ACKNOWILEDGMENTS

A dissertation, like any other scholarly work, can only be said to be the work of an individual in a strictly formal sense. In truth, it represents the accumulated input of perhaps hundreds of persons over the period in which it germinates, develops, and is completed. At least this has been my experience. It would be impossible to adequately acknowledge all who have in some way shaped this final product. I would like to single out a few individuals for my special thanks, however.

I must thank Howard Steward and Margaret Hintz, with whom I labored in a few skirmishes in the War on Poverty, for helping me to develop and refine my interest in, and understanding of the problems of, citizen participation. Dennis West provided a graduate seminar experience I shall not soon forget which presented the opportunity and stimulus for formalizing much of what appears in the early chapters of the dissertation. Even then, a11 may have been for nought if not for John Hanson's valuable critique of my early research design proposal. The committee supervising my dissertation has been easy to work with and a great asset. Jerry Lansdowne, Jim Weiss, David Wrench, and Lyndon Musolf have all been receptive to my ideas, both critical and supportive in appropriate amounts, and perhaps unreasonably patient with my efforts to carry the project through to its conclusion. David Wrench has my special gratitude for his assistance in designing the interview questionnaire, and his rigorous critique of my preliminary final draft. 
Finally, I must thank the two people who have made it all possible. Without the support of my parents, both financial and otherwise, this dissertation could not have been completed. Words are never enough, but thanks for your faith, support, and hard cash when I needed it. As is both customary and proper, all those mentioned who have had a part in the development of this dissertation must be cloaked in immunity. I rightly assume full responsibility for what is said and for what is left unsaid in the document which follows, and I will accept whatever criticism or praise it warrants. 
TABLE OF CONTENTS

PAGE

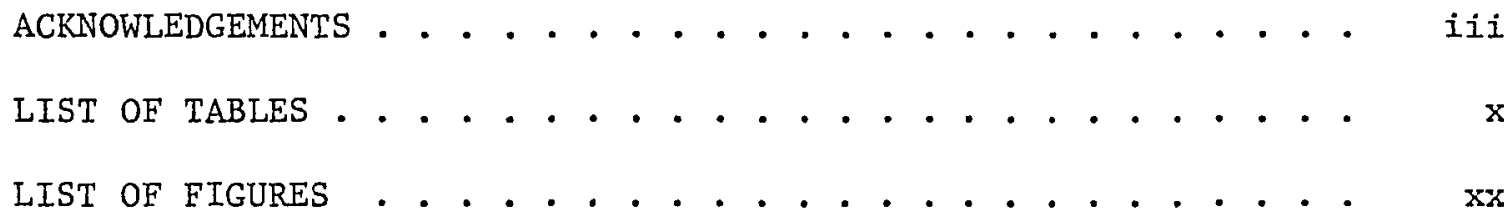

CHAPTER

I INTRODUCTION . . . . . . . . . . . . . . 1

Background . . . . . . . . . . . . . 1

Rationale . . . . . . . . . . . 3

Purpose of the Research ........... 5

Method ................. . 5

Major Findrngs . . . . . . . . . . . 6

Organization . . . . . . . . . . . 6

II THE FEDERAL MANDATE AND CITIZEN PARTICIPATION • . . . 8

Introduction ................ 8

Participation as a Public Issue . . . . . . . 10

The Current Controversy: Antecedents . . . . 12

The Civil Rights Movement

The Discovery of the Ghetto

Changes in Social Welfare Theory and Practice

Governmental Recognition and Legitimization

The Federal Mandate . . . . . . . . .

Social Work Influences

Community Development Influences

Immediate Precursor Programs 
III THE SEARCH FOR DEFINITION . . . . . . . . . . . 31

Introduction ............... . 31

Legislative Intent . . . . . . . . . 32

The Difficult Questions ........... 35

Who Should Participate?

In What Should Citizens Participate?

How Should Citizens Participate?

For What Purpose(s) Should Citizens

Participate?

Unexamined Assumptions . . . . . . . . . .

Assumptions About the Value of Participation as a Goal

Assumptions About the Value of Participation as a Means to Achieve Other Desirable Goals

Citizen Participation and Individual Political

Behavior . . . . . . . . . . .

Individual Political Behavior: The Traditional View

Individual Political Behavior: A More Holistic View

IV PURPOSE AND DIMENSIONS OF THE STUDY . . . . . . . . . 58

Introduction . . . . . . . . . . . . . 58

The Purpose and Dimensions of the Study . . . . 61

Purpose

Major Questions Addressed

Guiding Hypotheses.... . . . . . . 63

$\mathrm{V}$ METHOD ..................... 68

Introduction .............. . 68

The Study Areas ............ 69

The Research Setting

The Survey ireighborhoods: Selection Criteria

Survey Neighborhoods: Selection Process 
Sample Selection . . . . . . . . . . .

Neighborhood Household Random Samples

Pre-selected "Leadership" Samples

Interview Process . . . . . . . . . . 74

Questionnaire Processing . . . . . . . . 75

Data Analysis . . . . . . . . . . 75

Dependent and Independent Variables . . . . . 76

Dependent Variables

Independent Variables

VI PARTICIPATION: THE DEPENDENT VARIABLES . . . . . . 81

Introduction . . . . . . . . . . . . 81

Participation Operationalized . . . . . . 82

Electoral Participation

Group Participation

Issue Participation

Levels of Participation in the Survey

Neighborhoods . . . . . . . . . 84

Participation: New Or 01d Faces? . . . . . 88

Electoral and Issue Participation

Electoral and Group Participation

Issue and Group Participation

Participation: Traditional Explanations . . . . 97

Participation and Age

Participation and Sex

Participation and Socioeconomic Status

Summary . . . . . . . . . . . . 107

VII PARTICIPATION AND THE PERCEPTION OF NEIGHBORHOOD

PROBLEMS . . . . . . . . . . . . . . . . . 114

Introduction . . . . . . . . . . . . . 114

Problem Categories . . . . . . . . . . 115

Measuring Problem Perception . . . . . . . . 117 
Problem Perception: Identification of Problems

Problem Perception: Dimensions of Identified Problems

Problem Perception: Efficacy in Solving Identified Problems

Problem Perception: Salience of Identified Problems

Participation and the Perception of Problems ...

Participation and the Identification of Problems

Participation and the Salience of Identified Problems

Participation and Feelings of Efficacy in Solving Perceived Problems

Participation and the Perception of Problem Dimensions

Summar

VIII PARTICIPATION AND ATTITUDES ABOUT THE VALUE OF

PARTICIPATION . . . . . . . . . . . . . 174

Introduction . . . . . . . . . . . 174

Participation and Attitudes Toward

Participation as a Valued Goal . . . . . . 175

Participation and Attitudes Toward Participation

as a Means to Achieve Other Goals . . . . .

Efficacy of Participation Modes for

Solving Neighborhood Problems

Efficacy of Participation for

Self-Improvement

Summary ................ 203

IX SUMMARY AND CONCLUSIONS . . . . . . . . . . 209

Summary ............... 209

Conclusions . . . . . . . . . . . . 213

Implications . . . . . . . . . . . 218

A SELECTED BIBLIOGRAPHY . . . . . . . . . . . . . . . . 221 
APPENDICES

PAGE

A COMPARABILITY OF SURVEY AREAS . . . . . . . . 238

B BLOCK MAPS OF SURVEY AREAS INDICATING STREETS

AND BLOCK NLMBERS . . . . . . . . . . . 240

Black Neighborhood (Tract 34.02) . . . . 240

White Neighborhood (Tract 21) . . . . . 241

Geographical Relationships Between Survey

Neighborhoods and the Central Business

District . . . . . . . . . . . 242

C INTERVIEW SCHEDULE AND SUBSTITUTION LISTS

FOR SURVEY AREAS . . . . . . . . . . • . 243

Black Neighborhood (Tract 34.02)

Survey List . . . . . . . . . . . 243

Black Neighborhood (Tract 34.02)

Substitution List . . . . . . . . . 244

White Neighborhood (Tract 21)

Survey List . . . . . . . . . . 245

White Neighborhood (Tract 21)

Substitution List.... . . . . . 246

D GENERAL INSTRUCTIONS FOR INTERVIEWERS . . . . . . 247

E IIELD INTERVIEW QUESTIONNAIRE . . . . . . . . 252

F SURVEY COMPLETION RATES . . . . . . . . . . 278 


\section{LIST OF TABLES}

I Types and Rates of Participation in Sample and

Combined Neighborhoods (Expressed in Percent) . .

II Relationships Between Issue Participation and

Electoral Participation for Individual and

Combined Survey Neighborhoods (Expressed

in Percent)................ . . 9 90

III Relationships Between Group Participation and

Electoral and Issue Participation for Indi-

vidual and Combined Survey Neighborhoods

(Expressed in Percent) . . . . . . . . . 94

IV Relationships Between Age and Electoral, Issue, and

Group Participation in Individual and Combined

Survey Neighborhoods (Expressed in Percent) . . . 99

V Significance of the Relationships Between Age and

Electoral, Issue, and Group Participation In

Individual and Combined Survey Neighborhoods . . . 100

VI Relationships Between Sex and Electoral, Issue, and

Group Participation In Individual and Combined

Survey Neighborhoods (Expressed in Percent) . . . 103

VII Significance of the Relationships Between Sex and

Electoral, Issue, and Group Participation in

Individual and Combined Survey Neighborhoods . . . 104 
VIII Relationships Between Socio-Economic Status and

Electoral, Issue, and Group Participation

In Individual and Combined Survey Neighbor-

hoods (Expressed in Percent) . . . . . . . 108

IX Significance of the Relationships Between Socio-

Economic Status and Electoral, Issue, and

Group Participation in Individual and Combined

Survey Neighborhoods . . . . . . . . . 109

X Relationships Between Problem Identification and

Electoral, Issue, and Group Participation For

Individual and Combined Survey Neighborhoods

(Expressed in Percent) . . . . . . . . . . 124

XI Significance of Relationships Between Problem

Identification and Electoral, Issue, and Group

Participation for Individual and Combined

Survey Neighborhoods . . . . . . . . . . 125

XII Relationships Between the Identification of Salient

Housing Problems and Electoral, Issue, and

Group Participation in Individual and Combined

Survey Neighborhoods (Expressed in Percent) . . . 128

XIII Significance of Relationships Between the Identifi-

cation of Salient Housing Prot.1=ms ard Electoral,

Issue, and Group Participation in Individual and

Combined Survey Neighborhoods . . . . . . . . 129 
XIV Relationships Between the Identification of Salient Education Problems and Electoral, Issue, and Group Participation in Individual and Combined Survey Neighborhoods (Expressed in Percent) . . . 130 XV Significance of Relationships Between the Identification of Salient Education Problems and Electoral, Issue, and Group Participation In Individual and Combined Survey Neighborhoods . .

XVI Relationships Between the Identification of Salient Employment Problems and Electoral, Issue, and Group Participation in Individual and Combined Neighborhoods (Expressed in Percent) . . . . . 132

XVII Significance of Relationships Between the Identification of Salient Employment Problems and Electoral, Issue, and Group Participation in Individual and Combined Survey Neighborhoods . . . . . . . . . . 133 XVIII Relationships Between the Identification of Salient Crime and Delinquency Problems and ElectoraI, Issue, and Group Participation in Individual and Combined Survey Neighborhoods (Expressed in Percent) . . . 134 XIX Significance of Relationship Between the Identification of Salient Crime and Delinquency Problems and Electoral, Issue, and Group Participation in Individual and Combined Survey Neighborhoods . . . 
XX Relationships Between the Identification of Salient Police-Community Relations Problems and Electoral, Issue, and Group Participation in Individual and Combined Survey Neighborhoods (Expressed in Percent) ...................

XXI Significance of Relationships Between the Identification of Salient Police-Community Relations Problems and Electoral, Issue, and Group Participation in Individual and Combined Survey NeighborHoods . . . . . . . . . . . . . . .

XXII Relationships Between Neighborhood Rootedness of Individuals and Electoral, Issue, and Group Participation in Individual and Combined Survey Neighborhoods (Expressed in Percent) . . . . .

XXIII Significance of the Relationships Between Neighborhood

Rootedness of Individuals and Electoral, Issue, and Group Participation in Individual and Combined Survey Neighborhoods . . . . . . . 143

XXIV Relationships Between Feelings of Personal Efficacy and Electoral, Issue, and Group Participation In Individual and Combined Survey Neighborhoods (Expressed in Percent) . . . . . . . . . . 147 
XXV Significance of the Relationships Between Feelings of Personal Efficacy and Electoral, Issue, and Group Participation in Individual and Combined Survey Neighborhoods . . . . . . . . . 148 XXVI Relationships Between Feelings of Group Efficacy and Electoral, Issue, and Group Participation in Individual and Combined Survey Neighborhoods (Expressed in Percent) . . . . . . . . .

Significance of the Relationships Between Feelings of Group Efficacy and Electoral, Issue, and Group Participation :in Individual and Combined Neighborhoods . . . . . . . . . . . . .

XXVIII Relationships Between Feelings of Personal Cynicism and Electoral, Issue, and Group Participation in Individual and Combined Survey Neighborhoods (Expressed in Percent) . . . . . . . . .

XXIX Significance of the Relationships Between Feelings of Personal Cynicism and Electoral, Issue, and Group Participation in Individual and Combined Survey Neighborhoods . . . . . . . . . . . . 156 XXX Relationships Between Feelings of Political Cynicism and Electora1, Issue, and Group Participation in Individual and Combined Survey Neighborhoods (Expressed in Percent) . . . . . . . . . . 
XXXI Significance of the Relationships Between Feelings of Political Cynicism and Electoral, Issue, and Group Participation in Individual and Combined Survey Neighborhoods . . . . . . . . . 158 XXXII Relationships Between the Perception of a Personal Vs Social Dimension of Problems and Electoral, Issue, and Group Participation in Individual and Combined Survey Neighborhoods (Expressed in Percent) ................ 160

XXXIII Significance of the Relationships Between the Perception of a Personal vs Social Dimension of Problems and Electoral, Issue, and Group Participation in Individual and Combined Survey Neighborhoods . . . 161 XXXIV Relationships Between the Perception of a Non-Political vs Political Dimension of Problems and Electoral, Issue, and Group Participation in Individual and Combined Survey Neighborhoods (Expressed in Percent) ................... 164 XXXV Significance of the Relationships Between the Perception of a Non-Political vs Political Dimension of Problems and Electoral, Issue, and Group Participation in Individual and Combined Survey Neighborhoods .............. . 165 
XXXVI Relationships Between the Perception of a Local vs

National Dimension of Problems and Electoral, Issue, and Group Participation in Individual and

Combined Survey Neighborhoods (Expressed in Percent) . . . . . . . . . . . . .

XXXVII Significance of the Relationships Between the Perception of a Local vs National Dimension of Problems and Electoral, Issue, and Group Participation in Individual and Combined Survey Neighborhoods......................

XXXVIII Relationships Between Attitudes Toward Participation as

A Valued Goal and Electoral, Issue, and Group

Participation in Individual and Combined Survey

Neighborhoods (Expressed in Percent) . . . . .

Toward Participation as a Valued Goal and

Electoral, Issue, and Group Participation in

Individual and Combined Survey Neighborhoods . . .

XI Relationships Between Attitudes Toward Voting as an

Approved and Effective Mode of Participation and

Electoral, Issue, and Group Participation in

Individual and Combined Survey Neighborhoods

(Expressed in Percent) . . . . . . . . . . 
XLI Significance of the Relationships Between Attitudes Toward Voting as an Approved and Effective Mode of Participation an Electoral, Issue, and Group Participation in Individual and Combined Survey Neighborhoods . . . . . . . . . . . .

XLII Relationships Between Attitudes Toward Petitioning As an Approved and Effective Mode of Participation and Electoral, Issue, and Group Participation in Individual and Combined Survey Neighborhoods (Expressed in Percent) . . . . . .

XLIII Significance of the Relationships Between Attitudes Toward Petitioning as an Approved and Effective Mode of Participation and Electoral, Issue, and Group Participation in Individual and Combined Survey Neighborhoods . . . . . . . . . . 190 XLIV Relationships Between Attitudes Toward Collective Action as an Approved and Effective Mode of Participation and Electoral, Issue, and Group Participation in Individual and Combined Survey Neighborhoods (Expressed in Percent) . . . . . 192 XLV Significance of the Relationships Between Attitudes Toward Collective Action as an Approved and Effective Mode of Participation and Electoral, Issue, and Group Participation in Individual and Combined Neighborhoods . . . . . . . . . 
XIVI Relationships Between Attitudes Toward Non-Violent Demonstrations as an Approved and Effective Mode of Participation and Electoral, Issue, and Group Participation in Individual and Combined Survey Neighborhoods (Expressed in Percent) . . . . . . . . . . . . . . 195

XLVII Significance of the Relationships Between Attitudes Toward Non-Violent Demonstrations as an Approved and Effective Mode of Participation and Electoral, Issue, and Group Participation in Individual and Combined Survey Neighborhoods . . . . . . .

XIVIII Relationships Between Attitudes Toward Violent Demonstrations as an Approved and Effective Mode of Participation and Electoral, Issue, and Group Participation in Individual and Combined Survey Neighborhoods (Expressed in Percent)................ . 198

XLIX Significance of the Relationships Between Attitudes Toward Violent Demonstrations as an Approved and Effective Mode of Participation and Elective, Issue, and Group Participation in Individual Combined Survey Neighborhoods . . . . . . . 
L Relationships Between Attitudes Toward the Efficacy of Participation as a Means for Self-Improvement and Electora1, Issue, and Group Participation In Individual and Combined Survey Neighborhoods (Expressed in Percent) .............

II Significance of the Relationships Between Attitudes Toward the Efficacy of Participation as a Means For Self-Improvement and Electora1, Issue, and Group Participation in Individual and Combined Survey Neighborhoods . . . . . . . . . 202

LII Relationships Between Attitudes Toward Participation as an Approved Means for Self-Improvement and Electoral, Issue, and Group Participation in Individual and Combined Survey Neighborhoods (Expressed in Percent).................. 204

LIII Significance of the Relationships Between Attitudes Toward Participation as an Approved Means for Self-Improvement and Electoral, Issue, and Group Participation in Individual and Combined Survey Neighborhoods . . . . . . . . . . . . 205

LIV Comparability of Survey Areas for Selected 1970 U.S. Census Statistics.............. 238

LV Interview Completion and Refusal Rates in Survey Neighborhoods . . . . . . . . . . . . . . 


\section{LIST OF FIGURES}

FIGURE

1 Possible Response Categories for a Combined

Measure of Problem Identification and

Problem Salience .............. 122

2 Possible Response Categories for a Combined

Measure of Approval and Efficacy of

Participation Modes . . . . . . . . . . 183 
CHAPTER I

INTRODUCTION

BACKGROUND

In 1964, a federal War on Poverty was launched through the Economic Opportunity Act. The one element of this War on Poverty with the most significant and lasting impact was the federal mandate for "maximum feasible participation" of the poor in planning and administering the various programs which comprised the Community Action component of the federal anti-poverty effort.

The federal mandate for participation in these programs proved to be both difficult to implement and highly controversial in its specific applications. The difficulties and the controversy resulted from a lack of any clear or generally agreed upon understanding of just what was meant by "maximum feasible participation". Legislative intent was not clear, either in the minds of those who drafted the legislation, or in the congressional debate which ultimately resulted in the passage of the legislation. As a consequence, an operational definition of the lind of participation mandated by the legislation was never clearly specified.

The experience of those who attempted to implement the federal requirements for participation at the operational or program level can 
be seen as experiments which attempted to define citizen participation in operational terms. They were faced with difficult questions. Who should participate? In what should citizens participate? How should citizens participate? For what purposes should citizens participate? The many answers to such questions became the most controversial part of the War on Poverty--due at least in part to the fact that many of the disadvantaged people and groups whom the War on Poverty was supposed to help were blacks living in the urban ghetto.

In addition to the difficulties encountered in defining citizen participation in operational terms, the need for "maximum feasible participation" in order to win the War on Poverty rested on a set of theories and assumptions which were largely untested. These theories and assumptions relate to the nature of poverty and its causes. They also relate to value of participation as a means to legitimize and bring about social and institutional change. Finally, they relate to the competence and willingness of the participants to engage in the planning and decisionmaking processes.

Those who saw participation (however operationalized) as a significant prescription for the social ills of poveriy believed that the organization and participation of the poor would be a positive strategic step. They also believed that participation required an organizational base in the local community or neighborhood. Even though the specifics were never clear, what is clear is that one essential thing that participation involved was the organization and politicization of local community groups. 
RATIONALE

If the mandate for citizen participation had expired with the war On Poverty, there would be no need to proceed further. That is not the case, however. The federal mandate for citizen participation or citizen involvement has continued in some form throughout the wide range of federal grant-in-aid programs which are implemented at the state and local level. The federal mandate has also had spillover effects to the extent that the involvement of organized groups of citizens in the planning and policy-making process, at the local level in particular, is a pervasive aspect of contemporary society. The problem is that, while not as controversial as they were at the height of the War on Poverty's Community Action programs, the questions relating to participation (Who? How? In What? For What?), are still not clearly answered. Even more important, many of the assumptions which underly the concept of citizen participation remain insufficiently examined.

The literature concerning citizen participation concentrates on organized group participation, but tends to ignore the fact that membership and participation in community or neighborhood organizations is, at base, an individual political decision and act. It tends also to ignore the body of research into political behavior which suggests that rates and types of political behavior vary primarily according to the socioeconomic status of the individual. This body of research into individual political behavior would lead one to predict that people with low income, low education, and low status occupations would be least likely to participate politically, especially in those kinds of activities which demand 
more of the participant. Yet these are precisely the people who are the focus of many programs of citizen participation, and the kinds of activities required are often quite demanding. Little wonder, then, that efforts to organize and involve the poor in planning and decision-making are difficult and often frustrating tasks.

But what of those of low socio-economic status who were organized and mobilized? Significant numbers of the poor did participate in programs under the auspices of the War on Poverty, and other programs such as Model Cities. Many people in low-income neighborhoods continue to be active participants in neighborhood organizations engaged in what is often demanding and highly political activity. The traditional studies of political behavior do not adequately account for this phenomenon. But does this necessarily mean the assumptions and theories underlying the concept of citizen participation are valid? That is one question prompting and guiding the research reported below.

The traditional view of political behavior is based almost exclusiveIy upon studies of voting and/or the electoral process. The type of political behavior represented by citizen participation under the federal mandate is non-traditional in these terms, and is inadequately represented in the studies of political (electoral) behavior. However, there is a body of literature (largely not subjected to empirical examination) which takes a broad social-psychological view of political behavior. Many elements of this social-psychological model of political behavior complement or parallel some of the assumptions in the citizen participation 1iterature. It is these points of congruence that form the basis for this study. 
PURPOSE OF THE RESEARCH

The research reported in the pages to follow seeks to begin to explore the factors associated with low-income resident participation in community organizations and neighborhood associations of the type fostered by the federal mandate. It seeks to determine if factors suggested by both the citizen participation literature and the socialpsychological model of political behavior are significant intervening variables which better predict this kind of participation than do the traditional socio-economic variables. The specific relationships to be examined in the study are: (1) how the identification and perception of neighborhood problems relates to participation; (2) how feelings of individual and group efficacy relate to participation; and (3) how attitudes toward participation as both an end in itself and as a means to achieve other ends relates to participation.

METHOD

The study was conducted in Portland, Oregon in November and December of 1974. It consisted of a random sample household survey in two low-income neighborhoods of that city (thus controlling for socioeconomic status to a significant extent). One neighborhood had a predominantly black population while the other had a predominantly white population. In all other respects the neighborhoods were closely matched. Thus black/white comparisons are quite easily made. 
MAJOR FINDINGS

The findings of the study, which are reported in the pages that follow, are that all three of the factors examined in the study are significantly associated with participation by residents in these two low-income neighborhoods. The relative importance of these factors was different for each neighborhood sample population, however. Participation in the white neighborhood proved to be much more related to the identification and perception of problems, and participation was seen as a means to help solve or ameliorate those perceived problems. Participation in this case was a problem-solving or instrumental activity. In the black neighborhood, on the other hand, participation was more closely related to feelings of individual and group efficacy, and participation was seen as an end in itself. Thus, participation in the black neighborhood tended to be an expressive or symbolic rather than an instrumental activity. Conclusions concerning the reasons for these differences and their implications will be left for the final chapter.

\section{ORGANIZATION}

The research reported below is organized in nine chapters. Chapter II, which follows, discusses the federal mandate for citizen participation. It provides an historical background and context within which the research is properly understood. Chapter III reviews the literature related to citizen participation and political behavior in an attempt to demonstrate both the fuzziness of the concept and the unanswered questions which form the basis for the research project 
undertaken. Chapter IV briefly outlines the purposes and dimensions of the study. Chapter $V$ is devoted to a detailed discussion of the research design and the research methods employed. The next three chapters describe and analyze the results of the research project. Chapter IX summarizes the results, draws some tentative conclusions, and discusses the implications of both the findings and conclusions. 
CHAPTER II

THE FEDERAL MANDATE AND CITIZEN PARTICIPATION

INTRODUCTION

It is one of the basic assumptions of democratic theory that citizens of a democratic society have a right, an opportunity, perhaps even a duty, to participate in the political, economic, and social life of that society. This is one of the principles upon which the United States is founded. As with many principles, however, the ideal which is expressed or implied is seldom completely achieved in practice. Both the rignt to participate and the opportunity to participate have always been subject to qualification. They have been qualified formally through such devices as suffrage laws which politically disenfranchise many citizens. They have also been qualified informally through means such as the distribution of economic resources, social status, and political power.

As with many principles, the right and ability to participate in the social, econonic, and political life of society is generally accepted in the abstract. However, the formal and informal qualifications which determine the actual and specific application of the principle viz a viz various citizens of a society are likely to generate conflict and controversy. This is the case of citizen participation mandated by the 
federal government in a series of programs in the last three decades. A continuing controversy surrounds citizen participation (Who should participate? How? In what? And for what purposes?) for precisely this reason.

It is the purpose of this chapter to describe the context out of which a federal mandate for citizen participation arose, and some of the controversy which resulted. For purposes of clarification at this early point, "citizen participation" under the federal mandate means some form(s) of direct involvement of citizens or groups of citizens in the policy-making and/or planning processes. As we will see, the nature, extent, and content of such involvement has never been clearly specified by those who require participation, nor has it been resolved in practice. Experience with citizen participation under the "maximum feasible participation" provision of the Economic Opportunity Act of 1964 stimulated much of this continuing controversy. The controversy was generated because the phrase "maximum feasible participation" was never clearly defined in the legislation or its resultant programs, nor in subsequent legislation or programs. ${ }^{1}$ Citizen participation remains undefined (or at best unclearly defined) today. ${ }^{2}$

Participation strategies developed in the War on Poverty and Model Cities programs were essentially experiments in defining the concept of citizen participation. They were controversial experiments because they often assaulted the prevailing "accepted" qualifications this society imposes on the right and opportunity of various social, economic, and racial groups to participate. ${ }^{3}$ They were controversial because they attempted to change not only the rules of the game, but often the 
players as well. The result was that participation in the political, economic and social life of the society (or lack of participation on the part of some segments of society) had, by the end of the 1960 's, once again become a significant public issue.

\section{PARTICIPATION AS A PUBLIC ISSUE}

Historically, citizen participation (especially in the sense of political and/or electoral participation) has been a recurring and frequent public issue in this society. The focus of the issue has traditionally been one of extending the electoral franchise to new groups of citizens and expanding their opportunities to participate in the electoral process.

Universal manhood suffrage was not a part of the early colonial or national experience of the United States. Property and religious qualifications disenfranchised many adult white males in many states, as well as all blacks and females. These property and religious restrictions were not generally eliminated until after the turn of the 19 th century. 4

Thomas Jefferson championed a philosophy which vigorously affirmed the rights of the states and their individual citizens. He believed these rights must be protected against encroachments by the federal government. To help achieve these ends, he formed the DemocraticRepublican Party in 1793. Jefferson and his party very early identified itself with the small farmer and entrepreneur. This "party of the little man" and its philosophy of participatory democracy had sufficient appeal to elect Jefferson to the Presidency in $1800 .^{5}$ 
Andrew Jackson revived the philosophy and broadened the power base of the Party in 1828. The "Jacksonian Era" he ushered in produced a movement which campaigned against industrialists and aristocrats and promised to restore the national government to the people. The restoration was to take place through such devices as expanded suffrage, the spoils system, decentralization of government control over money, and a strengthened party system more responsive to the people. 6

The Jeffersonian philosophy and Jacksonian reforms had a significant impact on the opportunities available to citizens for participation in the political system, but it was an impact that was not felt or equally shared by all citizens. Participation of adult black males was not to be guaranteed by law until the Reconstruction Era and the ratification of the Fifteenth Amendment to the U.S. Constitution in 1870. Women. remained disenfranchised.

At about this same time (1870), the Populist Movement urged reforms which would give farmers a greater voice in the national government and a greater share of the economic pie. ${ }^{7}$ Many of the policies of the Populists were subsequenty adopted by the Democratic Party and eventually became law. The effect was one which prepared the way for policies designed to achieve both greater economic equality and popular participation in politics.

Participation again surfaced as an issue with the rise of the Progressive Movement. The Progressive Movement is a name common to a number of reform movements active in the first half of the 20 th century. The Progressives nominated Roosevelt for President in 1912 and drafted a platform that advocated, among a variety of other reforms, the direct 
election of senators, the adoption of the initiative and referendum in formulating legislation, and women's suffrage. 8

While not completely successful at the national level, Progressive reforms were rather widely adopted at the state and local level. This is especially true of those reforms relating to the initiative and referendum, and to a lesser extent, women's suffrage. These reforms significantly expanded the opportunities for participation to those already enfranchised, and helped to pave the way for the ultimate success of the Women's Suffrage Movement. The Nineteenth Amendment to the U.S. Constitution, ratified in 1920, extended participation through the vote to women.

By 1920 most of the legal barriers to participation in the political process had been toppled. Property, religious, race, and sex restrictions had been eliminated. The expanded opportunities for political participation through such reforms as the initiative and referendum, direct election of senators, extension of the franchise, etc., served to effectively remove the issue of citizen participation from the public agenda for a period of some thirty years or more. It was not to become a public issue again until the decade of the 1950's. It is this more contemporary reappearance of the issue of participation and its various dimensions to which we now turn our attention, for this is the focus of the balance of this study.

THE CURRENT CONTROVERSY: ANTECEDENTS

Citizen participation again became a public issue beginning in the mid-1950's. The climax came in the early 1970's, and the fallout 
continues to be felt throughout comtemporary society. In this period, however, the focus of the issue significantly shifted. The focus shifted away from the traditional concern with electoral participation and extension of the franchise, to something quite different. The new focus was upon attempts to bring the disadvantaged, who were legally enfranchised, into the mainstream of the economic, social, and political life of society through modes of participation largely outside of the electoral process.

Before examining the non-traditional and non-electoral modes of participation that were advocated in this revival of the issue of citizen participation (that is the task of Chapter III), we must first describe the circumstances which produced advocacy for them--circumstances which resulted in a federal mandate for citizen participation in federal programs.

The Civil Rights Movement

Beginning in the mid-1950's, a number of forces began to converge which made participation in a generally presumed democratic and open society a public issue of some importance. The first of these forces, and perhaps the most powerful, was the Civil Rights Movement. While much of the early effort in the Civil Rights Movement was directed in a traditional way toward voter registration and other obstacles which prevented blacks from exercising their voting franchise in southern states, it soon broadened both its emphasis and attack.

With the beginning of the Civil Rights Movement, the nation's attention was focused as never before on the struggle of black citizens to enter into the mainstream of society. ${ }^{9}$ Through their demands for 
their full rights as citizens, blacks began to raise the questions of social and economic, as well as political participation (or lack of it), in a society that proclaimed their legal rights on the one hand, and denied them the exercise of those rights on the other.

The Civil Rights Movement helped to point out not only the structured inequality in the society and its effects on the black minority. It also forced the realization that all disadvantaged groups were systematically denied the opportunities for full participation and a voice in shaping their own destiny.

The Discovery of the Ghetto

The Civil Rights Movement was enhanced by a second set of forces. In the decade of the 1950's we "discovered" the black ghetto, and we "discovered" poverty. These two "discoveries" helped to bring the issues and problems raised by the Civil Rights Movement into a sharper focus. They helped to physically locate many of these problems and issues in the festering sores of the inner-city black ghetto.

Post World War II migration patterns played a significant role in the process. The post-war years witnessed the beginning of two distinct migration patterns which continued through the 1960's. These two migration patterns worked to significantly redistribute segments of the population geographically within the society. The first of these was the migration of large numbers of relatively poor, semi-skilled, urban blacks from the cities of the south to the central cities of the north. A similar movement of poor, unskilled, rural blacks also occurred. These blacks moved to the central cities of both the north and south, but tended to concentrate in southern rather than northern cities. 
The second pattern was one of substantial and rapid suburbanization of middle-class whites. They were moving from the cities to which the blacks were moving. They moved not only to escape the emerging problems of the central city, but perhaps more to gain the advantages of suburban living made possible by increasing incomes and federal government incentives.

One critical result of black in-migration to the cities, and white out-migration from them, was the ubiquitous residential segregation of blacks in the core of the nation's central cities. Lacking competitive skills, education, and employment opportunities, blacks found the promise of urban living unfulfilled, and their urban dream too often a ghetto nightmare.

The problems of poverty, unemployment, education, public health, crime and delinquency, and the potential for explosive unrest, etc., were the hallmark of the black ghetto. It was here that the nation's social ills became most concentrated, and thus most visible. It was here that the nation's attention was focused as the Civil Rights Movement reached its peak in the early $1960^{\prime} \mathrm{s}$. The "maximum feasible participation" provision of the economic Opportunity Act of 1964 (and indeed the Act and the War on Poverty itself) can only be completely understood as responses to the black demand, centered in the urban ghetto, for fuller participation in the society. ${ }^{10}$

\section{Changes in Social Welfare Theory and Practice}

A third force combined with the Civil Rights Movement and the problems posed by the urban black ghet to to further emphasize the issue of citizen participation. During the time period of our concern, there 
occurred a "revolution" in social welfare theory and practice. Social welfare agencies, and the professsionals who staffed them, began to view both their clients and their client's problems differently. The emphasis changed from one in which the poor and their problems were viewed as the result of individual maladjustment or pathology which required individual treatment, therapy, and resocialization. Instead, multiple causes of poverty were recognized, and many of the problems faced by the poor were seen to have their roots in the way society and its institutions systematically restricted the opportunities of the poor to solve their problems and better their social, economic, and political position. ${ }^{11}$

This change in theoretical emphasis and social work practice was not a new development. Similar theories had been proposed in the past. As it happened, these theories were persuasively reintroduced and gained widespread acceptance within the social welfare profession at a time when new answers to the pressing problems of the urban ghetto were eagerly sought. This change in emphasis is most clearly evident in the work of Richard Cloward and Floyd Ohlin. ${ }^{12}$ Their influential theory of juvenile delinquency was a significant element in the conversion of the profession, and the application of its basic thesis can be seen in the recognition and elaboration of the concept of a "cycle of poverty" by the social sciences in the early 1960 's.

Clients of social welfare programs--poor blacks and whites--were no longer considered by many professionals to be solely responsible for their problems. Instead, these problems were considered symptomatic of the larger, dominant, white society which restricted the social, political and economic opportunities of the poor. Individual therapy was going out of vogue. Replacing it was a concern with promoting social 
and institutional change to allow the poor to participate in a society which had previously excluded them. ${ }^{13}$

The shift in emphasis focused on the powerlessness and alienation of the poor. Advocates of this view proposed that the best way to open up the opportunity structure to the poor (which would reduce feelings of powerlessness and alienation) was to organize and mobilize the poor. In this way, the poor could capitalize on the political power generated by their numbers. Organized and mobilized poor people could also be effective in undertaking local self-help projects which would increase their stock of skills while decreasing their feelings of powerlessness and alienation. This would ultimately lead to increased social, economic, and political participation, and increased effectiveness and power within society. 14

Proponents also argued for involvement of the poor in planning the various programs which so vitally affected their lives. An assumption was made that participation in the program planning process would also develop needed skills, decrease feelings of powerlessness and alienation, and at the same time, make programs more responsive to their needs.

Thus by the end of the $1950^{\prime}$ s there was substantial agreement within the social welfare profession that poverty had many causes, and that most of them were social and institutional in nature rather than individual. The solution to the problems of poverty and the ghetto involved opening up the opportunity structure. This could best be done by organizing and involving the poor in planning for, making policy in, and operating programs which affect them. This view assumed that participation and feelings of powerlessness and alienation were inversely related. It further assumed that organization and involvement of the poor and 
powerless was an effective means to achieve some measure of social and institutional change (or at least better social and institutional responsiveness) in a pluralistic, democratic society. ${ }^{15}$ We shall return to examine these assumptions more carefully in sections to come. First, we must deal with a final element--governmental recognition of both the issue and the means to resolve the issue.

\section{Governmental Recognition and Legitimization}

The emphases which run through all three of the forces outlined above began to be tied together in an institutional response in the decade of the 1960's. This is most clear in the Ford Foundation "Grey Areas" programs which prceeded and served as a model for subsequent action by the federal government. 16 The "Grey Areas" programs embodied the philosophy represented in the new social welfare theory and practice. They attempted to implement this policy in a coordinated and comprehensive attack on the problems of juvenile delinquency in the urban ghetto. Their emphasis on multiple causation, the need to open up the opportunity structure, the need for a comprehensive attack on the problems of ghetto poverty, and a recognition of the need for participation by the poor were largely carried over into the early federal programs concerned with juvenile delinquency. This emphasis was both complemented and strengthened by the "workable program" requirements of the Urban Renewal Programs authorized by the Housing Act of $1954 .^{17}$ Governmental recognition and legitimization of these various elements reached its peak in the Economic Opportunity Act of 1964, and in the War on Poverty which that act declared. The "maximum feasible participation" requirement of the Economic Opportunity Act of 1964 is the beginning of a continuing mandate for citizen 
participation, now required in some form, in a series of subsequent federal programs.

This federal mandate for citizen participation is the final factor leading to increased concern with participation as a legitimate public issue. The federal mandate is also the stimulus for much of the continuing controversy surrounding the concept of citizen participation. It is this mandate and its history to which we must now turn our attention.

THE FEDERAL MANDATE

When Congress passed the Economic Opportunity Act of 1964, included within its provisions was a clause which said a community action program should be "developed, conducted, and administered with the maximum feasible participation of residents of the areas and group to be served."18 This clause, mandating citizen participation, set into motion a revolution in public social welfare planning. Not only had Congress established a national policy that poverty would be eliminated, but the poor themselves were to have a voice in developing and administering programs to eliminate their poverty. 19

This concept of "maximum feasible participation" did not spring as if by magic from the pens of those who drafted the legislation. It was suggested by the events and forces just described, and it had a lengthy social history. The idea of involving residents in developing programs was not a new one, although its practice was. The roots of the idea reach back as far as the early historical development of the social welfare profession in the United States, and as far back as the principles 
of community development which have characteristically been practiced in the underdeveloped parts of the world. More recently, the idea had been embodied in a number of programs that were immediate precursors of, and models for, the Economic Opportunity Act of 1964.

\section{Social Work Influences}

Within the historical development of social work as a profession, two significant movements can be identified which helped to develop and legitimize the concept of resident participation. Resident participation in this context meant participation of the residents of an area, or participation of groups, to be served by a social welfare program in its planning and operation. The first of these was the Settlement House Movement. The second was the Neighborhood Council Movement.

The Settlement House Movement was perhaps the earliest attempt to foster the concept of neighborhood or citizen participation in planning social welfare programs. The movement was dedicated to helping people work together to meet their own needs, and serious attempts were made to engage area residents in developing solutions to neighborhood problems. 20

The Neighborhood Council Movement represented another, yet complementary, approach to citizen involvement. The neighborhood council functioned as a structure which helped local efforts relate to, and coordinate with, city-wide efforts. At the same time, it was a vehicle through which city-wide services and organizations were integrated into the local area. 21 As a consequence, the neighborhood council not only encouraged local citizen effort and organization, as did the settlement 
houses, it also attempted to relate these efforts to community-wide planning and the overall delivery of services. ${ }^{22}$

Historically, then, both of these movements stressed the involvement of local citizens (many of whom were poor) in planning and developing the social welfare programs and the social services which directly affected their lives. Social work eventually drifted away from what these two movements represented, but they can be seen as historical precedents for the conception of "maximum feasible participation" which was to emerge in 1964.

\section{Community Development Influences}

Citizen participation also has firm and established roots in the principles of community development. There are various approaches to community development, however, one is particularly relevant. Murray Ross describes an "inner resources" approach to community development which stresses the importance of local initiative and grass roots participation. $^{23}$ In this approach, local residents are encouraged to engage in a dialogue which identifies and focuses their concerns, wants, and needs, and defines the solutions to be sought. Assistance can then be obtained from appropriate external and internal sources following this "bottoms up" problem identification, needs assessment and planning process. $^{24}$ Programs and projects are not pre-determined and imposed from above; instead, projects are developed through this slow process of community consensus building, and are assumed to have a relevance and permanence that superimposed projects are not likely to have.

Here again, the idea of involving area residents (including the poor) in the determination of programs relevant to their own particular 
set of circumstances, wants, and needs was an accepted and established concept. In addition, considerable experience had been gained in the developing world regarding the use of this method of identifying and achieving community goals. The problems associated with implementation of this strategy of community development were known as well.

\section{Immediate Precursor Programs}

The conception of OEO's Community Action program and its "maximum feasible participation" requirement was influenced by three programs that closely preceeded it in time. The influences of the Ford Foundation's educational program of the late $1950^{\prime}$ s and early 1960's, and the programs sponsored by the President's Committee on Juvenile Delinquency and Youth Crime were most significant. Less significant in a conceptual sense, but most significant in a legal sense, was the precedent set by the "workable program" requirements for citizen involvement in the Urban Renewal Program established by the Housing Act of 1954.

The Ford Foundation Programs. In the 1950's, the Ford Foundation was concerned by the social problems of the cities and had become interested in two approaches that seemed to offer some solutions-urban renewal and metropolitan governement. By the late 1950's, the Foundation had become disillusioned with both, and was in search of new approaches to solving the problems of the city. 25

In 1960, the Foundation instituted the Great Cities School Improvement Program. A series of grants were made for experimental programs for culturally deprived children. The experience was not terribly successful, leading the Foundation to a conviction that a more comprehensive ap- 
proach was needed. In 1961 the "Grey Areas" programs were developed. 26 They were to be a coordinated effort "to ameliorate slum conditions and to bring slum residents into the mainstream of American 1ife."27

In developing the "Grey Areas" programs, the Foundation was operating on the basis of two major assumptions: (1) that effective community action needed the participation of the groups involved if it was to be successfu1; and (2) that local indigenous leadership was needed to provide a communication link between the planners and the community. ${ }^{28}$ Both elements were considered necessary ingredients. The specifics of how local residents were to participate, however, was never fully clarified. The mode of participation was left to the discretion of individual projects, and varied from project to project. 29

These projects grew out of a concern with the urban condition. As they developed, they came to incorporate a number of programs which were aimed specifically at the problems and needs of young people. The most influential consultants to these youth programs were Richard Cloward and Floyd Ohlin of the Columbia School of Social Work. In 1960 they had published a book which proposed and developed a theory of juvenile delinquency. ${ }^{30}$ They were then attempting to translate the theory into action in the Lower East Side of New York. Their theory argued that delinquency was a response to the frustrations experienced by disadvantaged youths who were denied the opportunity to achieve the ideals of society by legitimate means. Far from being an individual pathological response, delinquency was a rational (though illegitimate) means of acquiring that which society valued. Their solution to the problem of delinquency was a comprehensive attempt to open up the educational and economic opportunities for disadvantaged youths. 
Federal Juvenile Delinquency Programs. The work of Cloward and Ohlin, as they became involved in a research and action program Mobilization for Youth - funded by the National Institute of Mental Health, was especially influential with the President's Committee on Juvenile Delinquency and Youth Crime. This committee was established in 1961. From its programs emerged the concept of "community competence". 31 This the committee defined as a community in which the leaders are 'from the poeple, and one which has sufficient power to affect the decisions of the agencies which provide services to the community. In order to achieve the ideals established by this concept, the various programs of the President's Committee attempted to "involve neighborhood leadership in their own policy formation, and in some measure sought to organize neighborhoods to influence policies of agencies that controlled resources crucial to their needs". 32

Here, as with the Ford Foundation "Grey Areas" projects, the emphasis was on programs in which the residents of the community had an active role. It was not unlikely that the two programs would converge at some point in time, since both shared a common philosophy. Both were concerned about changing the social and institutional environment, rather than the individual. Both emphasized educational and vocational opportunities. Both concentrated on a few demonstration projects and were concerned with objective evaluation of the programs. Both, too, were concerned about developing a local constituency for their approach, not only "by securing a commitment from the leadership of the communities, but by drawing the people to be helped into the planning of their own welfare". 33

Thus by the time the War on Poverty was launched by the Economic Opportunity Act of 1964, there had been, as we have seen, a considerable 
relevant experience with the involvement of local residents in settlement house programs, neighborhood councils, community development programs, as well as the more recent innovations and programs of the Ford Foundation and the President's Committee on Juvenile Delinquency and Youth Crime. A number of blueprints existed which could be drawn together, modified and adapted, and translated into a broad attack on the problems of poverty.

It is not insignificant that many of the architects of the Community Action Program and "maximum feasible participation" were familiar faces in these programs that preceeded the War on Poverty.

Urban Renewal Programs. Finally, the mandate for citizen involvement in federally funded programs had a legal precedent in the Urban Renewal Programs created by the Housing Act of 1954. In order to be eligible for Federal Urban Renewal funds, a city had to demonstrate it had a "workable program" of urban renewa1. 34 This "workable program" had to contain, among other elements, a program for citizen participation in the renewal process. The nature and extent of the participation was not specified, and most cities simply appointed citizens' advisory groups to satisfy the requirement. 35 Nonetheless, a statutory requirement did exist, and the legal precedent was created.

The Economic Opportunity Act of 1964. The federal mandate for citizen participation in federally funded programs, which was weakly stated in the Urban Renewal legislation, was both broadened and strengthened in 1964. The Economic Opportunity Act of that year, and its provisions for "maximum feasible participation," forcefully expressed and 
reaffirmed the mandate. This mandate has continued in nearly all federal grant-in-aid programs since 1964, and has had spillover effects in state and local programs as well.

The mandate has weakened somewnat since its most forceful statement in 1964 , but it remains a very real part of most current federal programs. ${ }^{36}$ The federal requirement for citizen participation was controversial when it burst upon the scene in 1964, and it remains so today though not as explosively controversial as it once was. The reason for the controversy has been the problem of definition. "Maximum feasible participation", and its current permutations, were never clearly defined nor universally accepted. The concepts of "citizen participation" and "citizen involvement" remain fuzzily defined and subject to widely divergent interpretation and definition today. We turn our attention to the meaning of citizen participation mandated by the federal government, and to these questions of interpretation and definition in the next chapter. 


\section{FOOTNOTES}

$I_{\text {The reasons for this lack of definition are most clearly presented }}$ in three excellent works which chronicle the sreation of the Economic Opportunity Act of 1964. See, e.g., Richard Blumenthal, "The Bureaucracy: Anti-Poverty and the Community Action Program" in Alan P. Sindler, ed., American Political Instituions and Public Policy, (Boston: Little, Brown, 1969), pp. 129-179; Daniel P. Moynihan, Maximum Feasible Misunderstanding: Community Action in the War on Poverty, (New York: Free Press, 1969); and, Lillian B. Rubin, "Maximum Feasible Participation: The Origins and Implications", in Susan S. Fainstein and Norman I. Fainstein, eds., The View From Below: Urban Politics and Social Policy, (Boston: Little, Brown, 1972), pp. 98-116.

2 That this is true is an almost inescapable conclusion following a panel on citizen participation in the 1975 Conference on Administration sponsored by the American Society for Public Administration. Panel participants, all representing federal government agencies which mandate some form and level of citizen participation, showed little agreement among themselves as to what citizen participation meant. They also demonstrated little understanding of the practical difficulties involved in the implementation of citizen participation programs.

${ }^{3}$ For example, see Edgar S. Cahn, and Jean C. Cahn, "Maximum Feasible Participation: A General Overview"; and Joseph Wilkins and Barry Passett, "Introduction," both in Edgar S. Cahn and Barry A. Passett, eds., Citizen Participation: A Case Book in Democracy, (Trenton, N.J.: Community Action Training Institute, 1970), pp. 1-64.

4"Suffrage", in Andrew C. McLaughlin, and Albert Bushnell Hart, eds., Cyclopedia of American Government, Vol. III, (Gloucester, Mass.: Peter Smith, 1963), pp. 443-448.

${ }^{5}$ For an excellent review of the history of the Democratic-Republican Party and its philosophy, see Noble E. Cunningham, "The Jeffersonian Republican Party", in Arthur M. Schlesinger, Jr., ed., History of United States Political Parties, (New York: Chelsea House, 1973), pp . 239-272. See also Wilfred E. Binkley, American Political Parties: Their Natural History, (New York: Knopf, 1963), pp. 72-93.

6 The Jacksonian period and the development of the Democratic Party are thoroughly reviewed in Michael F. Holt, "The Democratic Party: 1828$1860^{\prime \prime}$, in Schlesinger, op. cit., pp. 497-536. See also Binkley, op. cit., pp. 120-151. 
7 Even though dated somewhat, the best account of the Populist Movement remains John D. Hicks, The Populist Revolt: A History of the Farmer's Alliance and the Peoples Party, (Minneapolis: University of Minnesota Press, 1931). For a more contemporary critique of Populist reform proposals, see Richard Hofstader, The Age of Reform, (New York: Knopf, 1956).

${ }^{8}$ See, for example, S. J. Duncan-Clark, The Progressive Movement: Its Principles and Its Programme, (Boston: Sma11, Maynard \& Company, 1913). A good concise review of the Progressive Movement is contained in Benjamin Parke De Witt, The Progressive Movement, (Seattle: University of Washington Press, 1968), pp. 3-25.

${ }^{9}$ In both southern and northern states, the Civil Rights Movement was focused to a great extent on urban rather than rural areas. For this reason, it may be considered an urban movement for purposes of this historical account of the development of a federal mandate for citizen participation in federal programs.

${ }^{10}$ For example, see Paul S. Denise, "Some Participation Innovations" in Hans B. C. Spiege1, ed., Citizen Participation in Urban Development: Cases and Programs, Vo1. II, Washington, D.C.: NTL Institute for Applied Behavioral Science, 1969), pp. 7-8; and S. M. Miller and Martin Rein, "Participation, Poverty, and Administration", Public Administration Review, XXIX (January/February, 1969), pp. 15-25.

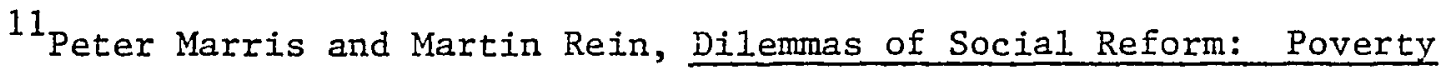
and Community Action in the United States, (New York: Atherton Press, 1967), Pp. 37-40.

12 Their most influential work in this regard is Richard Cloward and Lloyd Ohlin, Delinquency and Opportunity: A Theory of Delinquent Gangs, (Glencoe, III.: Free Press, 1960).

13 Most representative of this "revolution" in theory is the theory of delinquency proposed by Cloward and Ohlin. For an account of the influence of such a theory, see particularly Moynihan, op. cit., pp. 38-59 and 167-203.

${ }^{14}$ See particularly Cahn and Cahn, op. cit., pp. 32-33.

${ }^{15}$ Marris and Rein, op. cit., pp. 33-55.

16The name "Grey Area" was used because the programs were focused on the deteriorating band of territory surrounding the urban core or Central Business District of many major American cities. 
17 One element of a "workable program" was some form of formal citizen input into the planning of renewal projects.

18 U.S. Congress, Economic Opportunity Act of 1964, Public Law 88-452 88th Congress, 2d Sess., 1964, Section 202 (a).

19 The use of the word "poor" here is an arbitrary one. It was arbitrarily defined at the time the legislation was passed, and generally referred to those individuals and families whose income fell below the established poverty level which determined eligibility for participation in many anti-poverty programs. The poverty level was initially fixed at an annual non-farm income of less than $\$ 3000$ for a family of four. This level has been subsequently revised upward a number of times in response to economic conditions.

20 For a history of the Settlement House Movement, see Frank J. Bruno, Trends in Social Work: 1874-1956, (New York: Columbia University Press, 1957) pp. 112-119 and 196-206. See also, Russell H. Kurtz, ed., Social Work Yearbook, 1960, (New York: National Association of Social Workers, 1960), pp. 30-32.

${ }^{21}$ A very good analysis of the Community Council Movement is included in Kurtz, op. cit., pp. 191-198.

22 Ibid.

23 Murray G. Ross, Community Organization: Theory, Principles and Practice, (New York: Harper and Row, 1967), PP. 14-15.

24 Ibid.

${ }^{25}$ Marris and Rein, op. cit., p. 15.

26 The Grey Areas programs of the Ford Foundation are analyzed in a number of sources. See particularly, Marris and Rein, op. cit., pp. 14-20, and Rubin, op. cit., pp. 103-104.

27 Rubin, 으. cit., p. 103 .

28 Ibid., p. 104.

29 Ibid.

${ }^{30}$ Cloward and Ohlin, op. cit.

${ }^{31}$ Rubin, op. cit., p. 105 . 
${ }^{32}$ Melvin Mogulof, "Involving Low-income Neighborhoods in Antidelinquency Programs" Social Work, X (October, 1965), p. 52.

33 Marris and Rein, op. cit., p. 24.

${ }^{34} U$. S. Housing and Home Finance Agency, "Workable Program for Community Development" in Jewel Bellush and Murray Hausknecht, eds., Urban Renewal: People, Politics, and Planning, (Garden City, N.Y.: Anchor Books, 1967), pp. 276-277.

${ }^{35}$ Jewel Bellush and Murray Hausknecht, "Planning, Participation, and Urban Renewal" in Bellush and Hausknecht, op. cit., pp. 278-286.

${ }^{36}$ John Volkman, "An Overview of Decentralization and Citizen Participation", (Portland, Ore.: Center for Urban Education, 1976), pp. 3-4. (Processed.) 
CHAPTER III

THE SEARCH FOR DEFINITION

INTRODUCTION

Once the federal mandate for citizen participation was firmly established in the legislation creating the War on Poverty, the problems of definition quickly arose. Since the definition of "maximum feasible participation" was not specified in the Economic Opportunity Act, a real problem of operationalizing the concept was created for those who were charged with developing programs which required a citizen participation element.

The development of specific programs or strategles of citizen participation in the War on Poverty, Mode1 Cities and subsequent programs demonstrate little agreement about the operational definition of that crucial concept. The definitions elaborated or implied in both the literature and in practice can be placed on a continuum with token or superficial participation at one extreme, and substantial citizen control through a transfer of policy or decision-making power and authority at the other extreme. ${ }^{37}$ Programs or strategies for citizen participation have, likewise, ranged in emphasis from individual, sociotherapeutic, and symbolic activities, to demands for, and accommodations of, community control of programs and institutions. 38 
This disparate variety of operationalized definitions have all found a home within the embrace of "maximum feasible participation" and the continuing federal mandate for citizen participation. Some of them have found this home only after producing considerable strain and confusion. With this the outcome, it is helpful at this point to step back to consider what the authors of the Economic Opportunity Act had in mind when they drafted this provision of the legislation. Why, for example, did they decide to include the "maximum feasible participation" clause? Were they aware of the revolutionary and controversial implications of doing so?

\section{LEGISLATIVE INTENT}

Just as with the concept conceived by the legislation, there seems to be a similar cloud of confusion over the origins and actual intent of the wording of the participation requirement. It is impossible to know exactly how or where the idea developed. ${ }^{39}$ What is more significant, the intent and implications of the clause were also unclear to the authors of the legislation. The authors of the bill--members of a task force appointed by the President to develop an anti poverty program--apparently did not fully discuss the idea in depth, so that its intent was not clearly developed nor its implications fully explored or understood. $^{40}$ However, the intellectual and programmatic progenitors of the idea of local resident participation discussed in Chapter II were both known and generally accepted by most of the task force members--even if only subconsciously. 
Few members of the task force paid any attention to the clause. Those who did tended to think of it as a "safety clause" to prevent segregation in southern programs. It was worded very vaguely to avoid opposition to the bill by southern congressmen. ${ }^{41}$ It seemed to be a very obvious and innocuous requirement.

Confounding this fuzziness created by the task force in the interest of political feasibility, the issue was not publicly debated at any time during its journey through the Congressional machinery. During the five months it took Congress to deliberate and then pass the Economic Opportunity Act, the issue of participation was not addressed in either the comnittee hearings nor on the floor of Congress. 42

Thus, what was to prove to be one of most explosively controversial aspects of the War on Poverty, was never debated either publicly or privately. The intent of the requirement for participation was neither questioned nor clarified. It is curious that with a continuing federal mandate for participation in federal programs, the issue remains unsettled in both concept and practice.

Even after the legislation passed Congress and was signed into law, and as Community Action Programs were underway in many cities, the intent remained unclear. The Office of Economic Opportunity (OEO), which was charged with administering the federal anti-poverty effort, offered little in the way of guidelines. With respect to the most controversial aspect of citizen participation--the participation of the poor in local program policy-making boards, the office resisted pressure for guidelines for nearly two years. The official public position of OEO was that the key to community action was flexibility and local self-determination. ${ }^{43}$ Thus, each local community was initially left to decide 
upon its own operational definition of "maximum feasible participation." Without federal guidelines, the programs at the local level were no more clear about the operational meaning of the concept.

It wasn't until the amendments to the Economic Opportunity Act of late 1966 that Congress addressed itself to the issue. In order to resolve some of the controversy, the legislation was amended to require a minimum proportion of the poor (one-third) on local Community Action Agency boards. These amendments also provided for how these poor representatives were to be selected. They were to be elected by residents who lived in the poverty target areas designated to be served by the local program. ${ }^{44}$ Beyond specifying the minimum proportion and the manner of selection of poor people who would participate, Congress did not go. The role of these citizens and the nature of their participation remains unclearly specified.

What does seem clear, though, is that the operational intent of the clause was never sufficiently clarified, either by the authors of the legislation, by the Congress, or through the experience of the programs themselves. Although there was no unified or single intent, there appear to have been some common goals and a shared philosophy among those who drafted and supported the legislation. ${ }^{45}$

At least in a general sense, there appears to be some agreement that the participation mandated in the legislation involves some transfer of some degree of policy or decision-making power (both political and economic) to the poor. But what kind of a transfer and how much power? Here there was no clear agreement. For those without power and their allies, participation meant a role in policy-making. For those in power and with power who were naturally reluctant to give some 
of it away, participation meant something quite different. Consequently, how and to what extent the poor were to participate, at what levels in the programs, and in what capacities and roles were the hard issues in a controversy debated in virtually every community across the nation. We will turn now to examine the issues of the debate in order to see how, or if, they were resolved.

THE DIFFICULT QUESTIONS

A review of the literature related to citizen participation or citizen involvement under the federal mandate often raises more questions than it answers. The questions most of ten raised in this continuing controversy conveniently fall into four general categories. Questions raised in the first category deal with who should participate. In the second category are questions which address themselves to the issue of "in what" should citizens participate? The third category relates directly to the questions of strategy, and focuses upon how citizens should participate. The final category raises questions of "for what purpose(s)" should citizens participate?

These questions have some obvious political ramifications which add fuel to the debate. They were, and are, often highly political, because the answers proposed in many cases meant the creation of mechanisms for formally and directly including citizens (especially the disadvantaged) in some aspects of the decision-making process. ${ }^{46}$ This was a privilege heretofore enjoyed by relatively few and relatively powerful people and groups in the society. 


\section{Who Should Participate?}

This question surfaced very early in the debate over citizen participation. It pre-dates the mandate for "maximum feasible participation" in the War on Poverty. It is, perhaps, the only question which has been substantially, though not completely, resolved in the long controversy.

Local vs. Areawide Participation. At first, the question revolved around the issue of areawide vs. neighborhood participation. This is especially evident in the case of the urban renewal programs authorized by the Housing Act of 1954.47 The participation requirement of a "workable program" was most often met by a participation program, usually a Citizens Advisory Committee, areawide in scope to counter the threat of ad hoc neighborhood opposition to renewal plans which threatened particular neighborhoods. ${ }^{48}$ This was in keeping with the more communitywide focus of urban renewa1, but did little to give a voice or power to those in the ghet to who were being "renewed" out of their homes.

This part of the "who" question was eventually resolved in favor of neighborhood participation (or at least formal provisions were made for neighborhood participation) as the OEO and Model Cities programs developed. Bowing eventually to pressure from vocal groups of lowincome people and their advocates, guidlines were established which eventually shifted the balance in favor of neighborhood participation. 49

Problems of Representation. Other related questions were not so quickly (or easily) resolved, however. The most important deals with the question of who actually represents the poor in the neighborhoods to be represented. Because of the connected dimensions of race and power, this is a question which remains technically but fundamentally unresolved. 
First, there is a problem of identifying the leaders of the poor. Some argue that the real leaders are unknown to those outside the neighborhood, and are often unknown to those business and professional leaders within the poor community as we11. 50 They point out that if those perceived as leaders by the so called "power structure" are appointed to citizen boards, the real leaders are almost never chosen. This is because the perceived leaders fit the middle-class conception of leadership and the not the conception of leadership held by the neighborhood residents. This is a problem of representativeness inherent in the process of appointing people to serve on advisory boards. Do those perceived as leaders of the poor really represent them? Perhaps they do, but it is equally likely they do not.

The same problem of representation is raised when vocal or militant groups within poor neighborhoods are perceived as leaders, or when they forcefully assume leadership positions as many did in the earlier years of the War on Poverty. In many cases their views, goals, and concerns may be congruent with those of most residents in the neighborhood, but there is evidence to suggest that this is not necessarily the case. 51 The views of a majority of the neighborhood residents may be quite different from those expressed by the vocal or militant group within the neighborhood.

This same kind of question can be raised with respect to the involvement of representatives from organized groups within the poor neighborhoods, in place of involving individuals from the neighborhood at large. Since it appears that a majority of the poor do not belong to voluntary organizations, are those who do belong to such groups, 
and are active in them, representative of those who do not? In many cases they may be, but not necessarily so.

There are some social-psychological assumptions regarding the characteristics of the poor which underlie this question of representation. The poor are generally characterized as apathetic, powerless, and alienated. 52 They are believed to be overwhelmed with the concern for meeting their everyday basic survival needs. ${ }^{53}$ They are believed to be political cynics--feeling that they cannot trust public officials and that they can have little effect on their own lives and circumstances. 54

Using such assumptions, those who raise the question of representation look at those who appear to be upwardly mobile, with some visible middle-class leadership attributes as unrepresentative. They similarly question the representativeness of those who are active members of neighborhood groups, and those who are members of vocal, militant, organizations in the community. 55 Using this kind of argument, they suggest. the only way to get adequate representation is to allow the people of the neighborhood to choose their own leaders of representatives through an election process.

There is a problem with elections, of course. If you accept these assumptions about the basic characteristics of the poor, you are faced with the problems of motivating people to vote, getting people to stand for election, and getting those elected to serve. And if they do serve, do they have the necessary skills to adequately represent the interests of their neighbors in planning programs which will benefit the entire neighborhood. Within the participation formula eventually established by the Office of Econoric Opportunity, ${ }^{56}$ the operation of the community 
action programs appear to demonstrate amply these kinds of problems in their attempts to get even a small number of neighborhood residents to participate in their neighborhood board elections. 57 With so few voting, valid questions of representation can be raised in the case of elections as well, even though the question has been technically resolved in favor of neighborhood elections as a means to select neighborhood representatives in most cases.

Whatever the answer, there remains the underlying complication of power in society. If effective citizen participation requires some redistribution of power, as many argue it does, then the "who" question remains a potentially controversial issue. It is obvious that much of the controversy that has already developed over who should participate is concerned not so much with the more theoretical question of areawide vs. neighborhood participation and representation, but with a more down to earth reaction to the power that has already passed into the hands of the more militant and often radical blacks who have often emerged as the leaders of the poor.

In What Should Citizens Participate?

Identifying Problems vs Controlling Programs. Redistribution of power also complicates the question of what it is that the poor and other citizens are to participate in. In the earlier days of the citizen participation controversy, the identification of issues or problems was seen as the most appropriate and useful way in which citizens could participate. They presumably had some intimate and special knowledge and insight which could be used in the problem identification and goal setting phases of the policy-making/planning process. 58 
Programs were to be designed and operated by the experts. Thus, not only were conflicts between the experts and the unsophisticated citizens avoided, the identification of issues and problems was a "safe" way in which the poor could participate from a power standpoint.

With the development of the War on Poverty and Model Cities programs, the demands for more than this type of paternalistic advisory role were pressed and ultimately sanctioned, then requiring the poor to be represented on program policy-making boards. As the citizen participation movement has continued, the concept of what is to be participated in has expanded to include nearly every phase of the planning and policymaking process. Citizens not only have become involved in identifying problems and goals, they have also become involved planning programs, making policy choices, and in implementing policy and programs as employees of the projects and programs created. The power redistribution implications in such an expansion of citizen role are significant. The controversy has grown as more decision-making and policy-making power ended up in the hands of the poor, especially in the hands of those in the ghetto who demanded community contro1 of programs and institutions. Capacity of Citizens to Participate. Aside from these power considerations which underly the "in what" questions, there is a further debate regarding the resources and capabilities of the poor to assume an expanded role in the planning and policy process. One side of this debate sees the lack of sophistication in the planning process, the orientation to present and personal needs on the part of the poor, the lack of leadership and organizational skills, and the lack of the ability to conceptualize the dimensions of the problems for which solutions must be found, as obstacles which citizen participation poses 
for any program of action. 59 supporters of this argument believe that citizen partipation prolongs the decision-making and planning process too long. The result is most of ten unnecessary conflict between the experts and the citizens, with little constructive action to solve the problems to which the participatory process was addressed. 60

The other side of the debate agrees that the process is costly in terms of time and money, and that some conflict is inevitable. But they believe that citizens (including the poor) do have the ability to plan and make decisions in some sort of partnership with the "power structure" and the professionals of the community. 61 They further believe that the collaborative process of identifying needs, planning programs, and operating programs is the most effective way of ensuring that programs meet the needs of those who are served by them, and that this broad range participation is the only way the poor will be able to both improve their stock of skills and change their condition. 62

Regardless of the arguments, however, it is clear that citizens have demanded and are demanding a greater role in making decisions which affect them. Although the answer to the "in what" question remains incomplete in practice--ranging from issue identification to community control of programs--the directions seem to be leading toward broader decision-making and policy-making roles for citizens in programs which most affect their lives. The specifics of this broader role remains both unclear and controversial, however.

How Should Citizens Participate?

There are a number of levels at which citizens can participate. Sherry Arnstein conceptualizes a "ladder of citizen participation" 
based on the amount of decision-making power in the hands of those who participate. $^{63}$ Some of the ways in which citizens participate are essentially empty ritual or "non-participation" in that no decisionmaking power is actually redistributed in the process. The levels of participation at which power is redistributed are those in which citizens work in a partnership with the decision-makers to arrive at mutually acceptable decisions, or when those in power delegate some or all of the decision-making authority to the citizens. The extreme, of course, is citizen control of programs and institutions.

Assuming that demands of citizen control will not be accommodated for some time yet, ${ }^{64}$ the problem has been one of devising appropriate strategies and programs of participation to achieve some kind of shared decision-making (given the range of tentative answers to the questions of who? and in what?). Essentially the problem is one of devising methods to involve citizens so that their feelings of powerlessness and alienation are overcome while at the same time giving them some power to help construct programs which will meet their needs. This is the problem which appears to be farthest from an accepted solution.

Two major types of strategies or approaches have been used in developing citizen participation programs over the past decade of the federal mandate. One is a community development approach, the other is a social action approach. The two approaches differ in a number of respects, especially in their focus and in their orientation toward conflict and consensus. 
Community Development Approach. The community development approach focuses upon the growth of the individual. It takes a constituency of concerned persons and community leaders and works by trying to unite the community or neighborhood around a particular self-help project. The aim is to develop personal growth and increase skills through successfully completing the self-help projects while working through the system and in partnership with the "power structure". 65 The emphasis is self help, consensus, and personal growth.

Social Action Approaches. Social action or protest strategies focus on shaping social and institutional change through the vehicle of large-scale direct citizen action. The aim is to aggregate citizen power around an issue of concern and to confront the "power structure" with this mass based power so that bargaining with representatives of the community or neighborhood is assured in the decision-making process. ${ }^{66}$ This approach focuses and capitalizes upon conflict, using the power of numbers and the politics of mass protest to gain concessions and accomodation of demands.

Each of these approaches has its strengths and weaknesses, and each of them has had its share of successes and failures. ${ }^{67}$ A problem arose, however, in the use of the social action approach. The conflict generated by organized groups of the poor adopting such strategies (especially poor blacks) stirred the flames of controversy and reinforced many of the arguments against citizen participation. As a result, these strategies may have been counter-productive, and they were totally inappropriate strategies for community-oriented self-help projects. On the other hand, community development strategies often led to frustration when attempting to bring about change in the operation of 
established institutions. This frustration often resulted in increased alienation and/or resort to social action, and the problems were exacerbated rather than ameliorated.

The question of strategy remains unsettled. Of late, however, it seems to be resolved more in favor of consensual community development strategies rather than social action. The social action approach has not completely disappeared, but in keeping with the times, it has become much less frequently used.

For What Purpose(s) Should Citizens Participate?

The three questions examined above are further complicated by a fourth question--that of purpose. It can be fairly implied, for example, that participation in early urban renewal program areawide citizen advisory boards had as its purpose the legitimization and support of specific renewal programs in the face of neighborhood opposition. Others have seen citizen participation as a means of legitimizing social planning, and social reform. 68

Inherent in the community development approaches to citizen participation are self-development, personal growth purposes. In other words, participation has therapeutic effects which are desirable goals in and of themselves. Thus, reduction of feelings of alienation and powerlessness, increasing leadersinip, organizational and other skills were of ten seen as legitimate goals of the process of citizen participation. Perhaps they were as important as the success of the specific project to which participation was addressed.

Often, however, participation was used and intended for less worthy goals. There were many who saw participation as a means to co-opt 
potential opponents of programs and to pacify restless blacks in ghetto neighborhoods. Many programs of citizen participation were little more than empty rituals designed to give the appearance but not the substance of participation in the decision-making process. 69

For others, perhaps for a majority of those concerned with participation, the goal or purpose was the transfer of some meaningful power in the form of decision-making authority to the poor. This could best be done by organizing groups of citizens at the neighborhood level and providing representatives of these groups with specified roles in the planning and policy-making process. The question remained (and remains) of degree and role.

In each case, the question of purpose is inextricably linked with the questions of who, in what, and how. Depending upon purpose, answers to those questions can and do take significantly different form. This question of purpose has not been resolved. All of the purposes mentioned above continue to nervously coexist, with all of their inherent contradictions. Different participants in the same process may have different purposes winich may or may not be achieved or frustrated.

We have come more than a decade since the federal mandate for participation was first established. Yet the operational definition of citizen participation remains unsettled in both theory and practice. The intertwined questions of who, in what, how, and for what purpose are answered in many permutations and combinations--many of them inconsistent and contradictory. The mandate remains, however, and so do the difficulties of implementing the mandate and designing workable strategies for involving citizens. This is not to say that no generalizations can be deduced from these attempts to define and operationalize 
the concept of citizen participation. Citizens have been involved in the planning and policy process in a variety of ways: (1) as members of area-wide or local citizen advisory committees; (2) as members of the policy-making boards that operated the War on Poverty and Model Cities programs and projects; and (3) as participants in a variety of neighborhood organizations which span the range of self-help to protest groups. 70

Through a process of "social choice"--that is, through the aggregate of choices and decisions made over the past decade or more with respect to citizen participation, it has come to mean essentially three things: (1) some form of neighborhood organization; (2) elected and appointed representation of neighborhood groups and organizations on local policy-making and advisory bodies; and (3) jobs for residents of low-income neighborhoods in a variety of programs designed to serve those neighborhoods. 71

UNEXAMINED ASSUMPTIONS

The literature dealing with citizen participation has within it a number of expressed and implied assumptions which have not been adequately examined nor empirically tested in any systematic or rigorous way. It is these assumptions, and their relationship to the body of knowledge concerning individual political behavior (or lack of relationship) which form the basis for the research undertaken. The assumptions will be identified and presented briefly in this section. Their relationship to the body of knowledge concerning political behavior will be addressed in the next section. 
Assumptions About the Value of Participation as a Goal

Participation is assumed in most of the literature to be a desirable goal in and of itself as an end to be achieved. In other words it has expressive or symbolic value apart from what it can accomplish. This is akin to the ancient Greek concept that "citizenship" equals and requires participation. There is, in other words, a citizen duty to participate as a requirement of democracy. Associated with this assumption is a second which holds that people want to participate, to collaborate in a search for the common good. In either case, the capacity to participate is not necessarily assumed. If it does not currently exist, it can be developed as participation proceeds.

Assumption About the Value of Participation as a Means to Achieve Other Desirable Goals

By far, most of the assumptions relate to the value of participation as a means to achieve a number of desirable ends, both in terms of social change favoring the disadvantaged and powerless, and in terms of the therapeutic effects for the individual who participates. There is a further assumption that the capacity for participation exists. This is more than a philosophical question. It is also more than a question of technical competence. 72 Rather, it is an assumption that people know something about their problems, and something about possible solutions to those problems as well.

Participation is assumed to be therapeutic in a variety of ways. It can contribute to feelings of personal and social efficacy as it develops leadership, organizational and other skills. It can serve to increase self-esteem, ego, strength, and the sense of dignity and 
personal woxth or value. In the process, participation can educate and socialize. It can reduce feelings of powerlessness and alienation and help to re-affirm the "social contract." 73

Participation is also assumed to be an effective means to legitimize and bring about social change. People who know their needs and problems, and who are organized at the neighborhood level can use the organizational base to have their interests represented in a pluralistic society. In this manner, participation can give participants a voice in shaping programs and policies that are designed to meet their needs. As a result, power is transferred to the participants who can then more effectively act for their own behalf in the future.

\section{CITIZEN PARTICIPATION AND INDIVIDUAL POLITICAL BEHAVIOR}

The citizen participation literature discussed above concentrates on organized group participation in some form. In other words, it prescribes the organization and the politicization of neighborhood residents as a means to achieve a number of desirable ends. In addition to the weakness outlined with respect to not adequately operationalizing the concept, the literature tends to ignore the fact that membership and participation in neighborhood groups and organizations is, at base, political activity. The decision to join and participate in such groups is an individual political decision. This being the case, a substantial body of literature related to individual political behavior is ignored which may well be relevant. 
Individual Political Behavior: The Traditional View ${ }^{74}$

By far the most significant and well-developed body of knowledge about political behavior is that related to voting behavior and the electoral process. The literature which relates to this body of knowledge tends to consistently arrive at roughly similar conclusions. First, political participation rates and levels, as measured by election campaign and voting activities or by participation in secondary political organizations is neither wiespread nor very high for the population as a whole. 75 The more intense or demanding the political activity, the fewer the number of persons involved. 76

Rates and levels of political (electoral) participation are found to vary systematically with education, income, occupation, race, sex and age. The higher the income, education, and occupation level of the individual, the greater the rate of participation. Males are found to participate at greater rates than females, and whites participate at greater rates than blacks. Finally, people in middle age groups participate at greater rates and levels than do the young or the old.

Participation studies generally conclude that lack of participation is largely a result of apathy. 77 In the case of lower socio-economic groups and non-whites, lack of participation is also partly due to a lack of resources and skills which contribute to feelings of competence, as well as to patterns of socialization which place less emphasis on "citizen duty". 78 For these groups, lack of participation may also result from fear of reprisals, as well as from the realization that the participatory act produces very little benefit for the costs involved. 79

On the basis of this well-developed body of knowledge, it is reasonable to predict that the disadvantaged, with their low incomes, levels 
of education, and low status occupations would not be likely to be very politically active. This is especially true of activities which involve greater levels of commitment and cost than the simple act of voting. This would also be the prediction when adding the considerations of feelings of powerlessness and alienation, and the lack of resources which contribute to feelings of competence, which are the presumed characteristics of the poor.

In fact, these socio-economic factors may account for much of the difficulty experienced in stimulating even moderate rates of participation among the poor in various aspects of the anti-poverty and Model Cities programs. But what of those who did participate? It is here that the narrow electoral focus of the study of political behavior begins to become a liability. The general weakness of this traditional model of political behavior, which relates participation to socio-economic factors, is that it fails to predict the significant levels of participation by low-income and low-SES individuals in anti-poverty, Model Cities, and subsequent programs.

The poor have been successfully organized and politicized in a number of programs in a number of urban areas. The poor have, in fact, been involved in highly politcal, often intense, and sometimes politically risky activity throughout the history of the federal mandate. The type of political activity has been non-traditional, however. It falls outside of the scope of concern of most of the research into political behavior. $^{80}$ In order to adequately account for this phenomenon, we must look elsewhere. 
Individual Political Behavior: A More Holistic View

There is another body of literature related to individual political behavior wich is less developed, and largely untested, but which must be considered relevant. It proposes a much more holistic social-psychological model of politcal behavior. This model of individual political behavior is most throughly developed (conceptually rather than empirically) by Robert Lane. $^{81}$ While Lane's model is focused primarily upon the electoral process, the general model he proposes has potential for much broader application, and is supported in many respects in the social-psychological and psychological 1iterature. 82

The model can be simply outlined. First, it views the individual as an organism which responds to stimuli in the environment. The stimuli in the environment (neighborhood problems, for instance) are perceived by the individual. These stimuli are perceived as political or as nonpolitical according to acquired social and political ideologies. Second, individuals have a core personality and a variety of physiological, psychological, social, economic, political and other needs for which the stimuli may be relevant. Thirdly, if the stimuli are relevant to the core personality and its needs, and if the stimuli are perceived to be political, then political activity of some kind is the resulting behavior. Finally, the type and level of politcal activity chosen by the individual will depend upon a personal cost benefit calculation (even if only intuitively) based on past experience.

The value of this less traditional view of individual political behavior for our purposes here is that it allows for both a much broader range of elements which may contribute to and motivate behavior, and it 
also allows for a much broader range of behavioral responses than voting or other electoral activity.

This body of literature points out the importance of perception, attitudes and values based on learning and experience, and the element of choice, none of which have generally been examined in the traditional studies of political behavior. It also brings us to the heart of the issue and suggests the direction for needed research, in that it focuses upon many of the same elements found in the unexamined assumptions underlying the concept of citizen participation developed under the federal mandate. This common ground and the direction it suggests for research is explored in the next chapter. 
FOOTNOTES

37 The clearest analysis of such a continuum is found in sherry Arnstein, "A Ladder of Citizen Participation", Journal of the American Institute of Planners, XXXV (July, 1969), pp. 216-224.

${ }^{38}$ Ibid. See also, Edmund Burke, "Citizen Participation Strategies", Journal of the American Institute of Planners, XXXIV (September, 1968), pp. 287-294.

${ }^{39}$ Blumenthal, op. cit., pp. 166-168; Moynihan, op. cit., pp. 86-87; and Rubin, op. cit., pp. 99-100 all agree on this point.

40 Ibid.

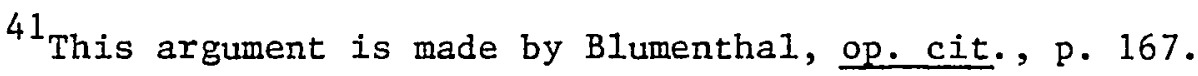

42 According to the Advisory Commission on Intergovernmental Relations, the Community Action Program Title of the Economic Opportunity Act of 1964 and its "maximum feasible participation" requirement were not among the issues addressed by the Congress. See, Advisory Commission on Intergovernmental Relations, Intergovernmental Relations in the Poverty Program: A Commission Report, (Washington, D.C.: U.S. Government Printing Office, 1966), Report No. A-2,9, p. 22. This is also the conclusion of Blumenthal, op. cit., pp. 169-172; Moynihan, op. cit., pp. 89-93; and Rubin, op. cit., p. 99 .

${ }^{43}$ Rubin, op. cit., p. 110 .

${ }^{44}$ Ibid., p. 111 .

${ }^{45}$ Blumentha1, op. cit.

46 The legislation meant that for the first time in American political history, a specific segment of the population had been singled out and directed by law to participate in programs which affected their destiny.

47 The primary citizen participation issue dealt with in the federal Urban Renewal Programs was the question of areawide vs local (or neighborhood) participation. 
${ }^{48}$ This point is made convincingly by James Q. Wilson in his analysis of participation in federal Urban Renewal programs. See, for example, James Q. Wilson, "Planning and Politics: Citizen Participation in Urban Renewal, in James Q. Wilson, ed., Urban Renewal: The Record and the Controversy, (Cambridge, Mass.: MIT Press, 1966), pp. 407-421.

${ }^{49}$ The guidelines developed by the Office of Economic Opportunity in connection with the Community Action Program component of the War on Poverty are especially important in this regard, as are the guidelines established for participation in the Model Cities programs.

50 This is most forcefully argued by Saul Alinsky. See, for example, Saul Alinsky, "Native Leadership" in Hans B. C. Speige1, ed., Citizen Participation in Urban Development: Concepts and Issues, Vol. I, (Washington, D.C.: NTL Institute for Applied Behaviora1 Research, 1968), Pp. 150-162.

${ }^{51}$ See, for example, Neil Gilbert, and Joseph W. Eaton, "Who Speaks for the Poor?", Journal of the American Institute of Planners, XXXVI (November, 1970), pp. 411-416.

52 These characteristics of the poor, and the obstacles they pose for efforts to involve the poor, are analyzed in Francis F. Piven, "Participation of Residents in Neighborhood Community Action Programs", in Speigel, op. cit., Vol. I, pp. 113-127. Another excellent analysis with a similar thrust is found in Harold C. Edelston and Ferne K. Kolodner, "Are the Poor Capable of Planning for Themselves?", in Speigel, op. cit., Vol. I, pp. $225-240$.

\section{${ }^{53}$ Ibid.}

54 The theme of alienation, cynicism, and withdrawal is a thread which runs throughout the literature.

55 Marris and Rein, op. cit., pp. 167-168, effectively sumarize this point of view.

56 The 1967 amendments to the Economic Opportunity Act established firm guidelines for the composition of elected poverty program policy boards. They were to include a minimum of one-third poverty area representatives, a maximum of one-third public officials or their representatives, and the balance to be made up of representatives of the community at large.

57 The generally low level of participation in poverty program boards and elections is analyzed by John H. Strange, "Citizen Participation in Community Action and Model Cities Programs", Public Administration Review, XXXII (Special Issue, October, 1972), pp. 655-669. 
58 This advantage of citizen participation is argued persuasively in Cahn and Cahn, op. cit., pp. 23-24

${ }^{59}$ Edelston and Kolodner, 으. cit.

${ }^{60}$ Ibid.

${ }^{61}$ See, for example, Robert Seaver, "The Dilemma of Citizen Participation", in Speige1, op. cit., Vol. I, pp. 61-71.

${ }^{62}$ Cahn and Cahn, op. cit., and Seaver, op. cit.

${ }^{63}$ Arnstein, 으. cit.

${ }^{64}$ The major area in which demands for community control have been partially accomodated is public education. These efforts have proven highly controversial, and were often less than successful. For a concise review of the issues surrounding community control of the schools, see Marilyn Gittell, "Decentralization and Citizen Participation in Education", Public Administration Review, XXXII (Special Issue, October, 1972), pp. 670-686.

${ }^{65}$ Jack Rothman, "Three Models of Community Organization Practice", in Fred M. Cox, et al., eds., Strategies of Community Organization: A Book of Readings, (Itasca, I11.: F. E. Peacock, 1974) pp. 23-24 and 26-27.

${ }^{66}$ Ibid., pp. $24-25$ and $26-27$.

${ }^{67}$ Burke, op. cit. See also, Roland L. Warren, and Herbert H. Hyman, "Purposive Change in Consensus and Dissensus Situations" in Terry N. Clark, ed., Conmunity Structure and Decision-Making: Comparative Analyses, (San Francisco, Calif.: Chandler Publishing Co., 1968), pp. 407-424.

${ }^{68} \mathrm{~A}$ number of analysts argue this position. The most thorough review of the legitinizing aspects of citizen participation is found in Martin Rein, "Social Planning: The Search for Legitimacy", Journal of the American Institute of Planners, XXXV (July, 1969) pp. 233-243.

${ }^{69}$ See Arnstein, ㅇp. cit., and Burke, op. cit.

${ }^{70}$ In terms of operative strategy.

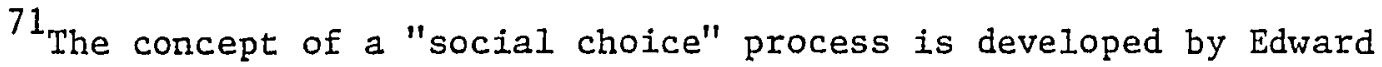
Banfield. See, for example, Edward C. Banfield, Political Influence, (New York: Free Press, 1961), pp. 324-341. 
72 The question of citizen competence is most effectively criticized by Edelston and Kolodner. See Edelston and Kolodner, op. cit.

${ }^{73}$ In arguing the need for participation, Cahn and Cahn are the only analysts who directly connect citizen participation and the "social contract", though this connection is implied elsewhere. See Cahn and Cahn, 오. cit., pp. 32-33.

${ }^{74}$ Theory and research related to traditional political behavior (electoral or voting behavior) has a particularly long history. It is a well developed field of study in the political science discipline. Because of its history and development, several excellent comprehensive summaries are available. Two of the best are Lester Milbrath and $M$. L. Goel, Political Participation: How and Why Do People Get Involved in Politics?, (2nd ed., Chicago: Rand McNally, 1977) and Sidney Verba, and Norman H. Nie, Participation in America: Political Democracy and Social Equality, (New York: Harper \& Row, 1972). These two works form the basis for the brief review presented in the section which follows.

75 Milbrath and Goel, op. cit., p. 23-24, describe the level of political activity in the United States. They conclude that except for the act of voting, most political acts are engaged in by a small minority of the population. Even voting rates suffer in comparison with a number of other nations, reflecting the stricter regulation of voting in the United States through registration requirements. Verba and $\mathrm{Nie,} \mathrm{op.} \mathrm{cit.,} \mathrm{pp.}$ 25-43, generally agree, but suggest that participation is more widespread than a number of previous studies indicate.

I6 Ibid.

${ }^{77}$ If not expressly indicated as a cause of non-participation (especially in the case of non-voting), apathy is at least implied in most of the literature dealing with electoral participation.

78 Milbrath and Goel, op. cit., pp. 49-53.

${ }^{79}$ See, for example, Lester M. Salmon, and Stephen Van Evera, "Fear, Apathy, and Discrimination: A Test of Three Explanations of Political Participation", American Political Science Review, LXVII (December, 1973), pp. 1288-1306.

80 Milbrath and Goel, for example, deal only minimally with protest as a political activity, and their review of the literature related to organizational participation includes primarily traditional voluntary organizations and not the kind of neighbornood organization spawned by the federal mandate for citizen participation. Verba and Nie do not deal with protest activity at all in their examination of participation, and they also deal with organization affiliation in terms of traditional voluntary organizations. 


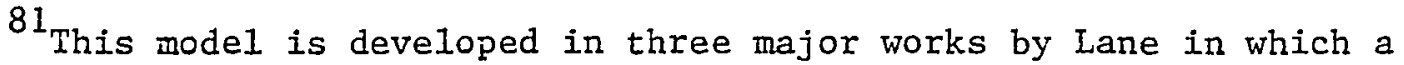
series of in-depth interviews of a very small number of individuals have been used to arrive at generalizations about the nature and dynamics of individual political behavior. There is a clear social-psychological emphasis in these works, and the in-depth interviews approximate psychoanalytic techniques. See, for example, Robert E. Lane, Political Idealogy: Why the American Common Man Believes What He Does, (New York: Free Press, 1962); Political Life: Why People Get Involved In Politics, (New York: Free Press, 1959); and Political Thinking and Consciousness: The Private Life of the Political Mind, (Chicago: Markham Publishing Co., 1969).

82 For example, the stages in the development of the human personality proposed by Erikson complement Lane's analysis. Maslow's needs hierarchy is similarly relevant, and has been found to be useful in understanding political behavior in several studies. See Erik H. Erikson, Childhood and Society, (New York: W. W. Norton, 1963); Abraham Harold Maslow, "A Theory of Human Motivation", Psychological Review, L (July, 1943), pp. 370-396; Knutson, Jeanne Nickell, "Motivation and Political Behavior: An Attempt at Synthesis", (unpublished Ph.D. dissertation, University of Oregon, 1968); and Stanley Allen Renshon, Psychological Needs and Political Behavior: A Theory of Personality and Political Efficacy, (New York: Free Press, 1974). 
CHAPTER IV

PURPOSE AND DIMENSIONS OF THE STUDY

INTRODUCTION

There are, as has been suggested, some important points of congruence between the set of unexamined assumptions which can be reasonably extracted from the review of the citizen participation 1iterature and the incompletely tested social-psychological model of individual political behavior introduced in the last chapter. We have seen that the type of behavior involved, while political, is not traditional electoral behavior. It is neither adequately explained nor predicted by the bulk of the knowledge about individual political behavior. The more holistic model of individual political behavior suggests variables which may be much more useful in an empirical sense for explaining and/or predicting the participation of low-income and low socio-economic status persons in the type of organized neighborhood oriented groups which have come to represent participation under the federal mandate and other contemporary programs.

The weakness of the holistic social-psychological model lies in the fact that it has not been adequately supported or confirmed by empirical evidence. 83 This is a fortunate circumstance in the case of this study, however. An examination of some of the assumptions underlying the concept of citizen participation is a necessary and valid research effort in itself. But the congruence of some of these assumptions and elements of the social-psychological model will allow portions of that 
model to be put to empirical test at the same time.

The common ground just noted suggests and justifies several profitable avenues of needed investigation. First, the citizen participation 1iterature assumes participation to be a societal value and a desirable end in itself. The social-psychological model of individual political behavior suggests the importance of attitudes toward participation in motivating political behavior. What are the attitudes toward the value of participation as a desired social goal? How widely are these attitudes held? Are there systematic differences in attitudes among various segments of the population? Are systematic differences in these attitudes related to systematic differences in participatory behavior? Answers to such questions will help to support or refute the validity of both the assumptions and this element of the social-psychological model of individual political behavior.

The citizen participation literature concentrates most of its attention on participation as a means to achieve a number of other desirable ends. One of the most significant assumptions involved is the one which holds that people experiencing problems know best what those problems are, and perhaps how best to solve them. The model of political behavior suggests the importance of individual perception of stimuli (e.g. neighborhood problems) as an important element associated with political behavior. This being the case, several important questions need to be answered. Are similar or identical problems perceived differently in terms of their nature and importance by different people? Are there systematic differences in perceptions of similar problems among various segments of the population? Are systematic differences 
in these perceptions related to systematic differences in participatory behavior?

The citizen participation literature also assumes that participation has therapeutic value in that it is a means of personal development and self-improvement. The social-psychological model of political behavior suggests that attitudes regarding the value of participation as a means to achieve personal growth and development will vary from individual to individual according to their core needs and past experience. Again, some relevant questions must be posed. What are attitudes regarding participation as a means to achieve personal growth and development? How widely are these attitudes held, and do they vary systematically among segments of the population? Are systematic differences in these attitudes related to systematic differences in behavior?

The literature assumes that participation has value as a means to achieve and/or legitimize social and institutional change and to bring about a solution of problems. The model of behavior suggests that attitudes toward the efficacy and legitimacy of various modes of participation are important elements (based on past experience) in the cost/ benefit calculation which determines the individual behavioral choice in response to relevant political stimuli. What are the attitudes of individuals concerning the efficacy and legitimacy of various modes of participation in bringing about change in solving problems. How widely are these attitudes held, and do they vary systematically among various segments of the population? Are systematic differences in these atti- 
tudes related to systematic differences in participatory behavior?

Finally, the literature assumes a capacity to participate on the part of the poor. The social-psychological behavioral model suggests that the feelings of personal efficacy, or efficacy as part of an organized neighborhood group, are related to political behavior in a similar manner as attitudes concerning the efficacy of various participation modes. Again, a similar set of questions must be posed. Do people feel personally effective or capable of doing something about the problems they perceive? Do they feel effective as a part of a neighborhood group or organization? Do these feelings vary systematically among various segments of the population? Are systematic differences in these feelings related to systematic differences in participatory behavior?

The need for answers to the questions raised above sets the research agenda for this study. In answering them, the validity of many of the assumptions underlying the concept of citizen participation will be put to test. The answers will also serve as an important empirical test of elements of the social-psychological model of individual political behavior which seems to offer a better explanation of this kind of political behavior than does the model developed in the voting studies.

THE PURPOSE AIND DIMENSIONS OF THE STUDY

\section{Purpose}

This study is intended to be exploratory in nature, conducted on a small scale, to begin to examine the relationships suggested in the previous section. While some tentative hypotheses will be used to guide 
the research, the purpose is to uncover relationships and identify those which might profitably be pursued in future research. With this in mind, the purpose of the study is fourfold:

1. The study will examine the factors associated with the lowincome resident participation in black and white neighborhoods of a single city.

2. The study will seek to determine whether the factors suggested by a social-psychological model of individual political behavior (as outlined in the previous section) better explain and predict this participation than do the variables suggested in the traditional political behavior (voting) studies.

3. The study will draw conclusions about the validity of some of the assumptions underlying the concept of citizen participation in light of those factors found to be associated with participation in the type of neighborhood organizations advocated in the literature.

4. The study will draw conclusions about the empirical validity of elements of the social-psychological model of individual political behavior in light of those factors found to be associated with participation in black and white low-income neighborhoods.

\section{Major Questions Addressed}

1. What factors promote, or are associated with, participation in community organizations and neighborhood associations in lowincome neighborhoods? 
a. What factors are associated with participation in community organizations and neighborhood associations in black low-income neighborhoods?

b. What factors are associated with participation in community organizations and neighborhood associations in white low-income neighborhoods?

2. Are the factors which are associated with participation in community organizations and neighborhood associations the same for both black and white low-income neighborhoods? If not, what are the differences, and what factors best account for the differences?

3. Do the same people who participate in community organizations and neighborhood associations also participate in traditional (electoral) political activity? If not, what factors are associated with these differences in participatory behavior?

GUIDING HYPOTHESES

In order to systematize and guide the research, some tentative hypotheses have been constructed. They are hypotheses which can be logically deduced from the argument presented thus far. They are intended only to guide the research, and should not be construed at this point to have a direct or significant theoretical relevance, although the findings of the research may demonstrate the signifigance of some of them for future research. They should be considered "research propositions". 1. Perceptions of problems (stimuli) are significant intervening 
variables associated with individual political behavior.

a. People who perceive neighborhood problems are more likely to participate than those who do not.

b. People who identify problems as salient or relevant to them are more likely to participate than those who do not.

c. People who perceive problems in the neighborhood as political problems are more likely to participate than those who perceive neighborhood problems as non-political problems.

1) People who perceive neighborhood problems as social or societal in nature are more likely to perceive those problems as political than those who perceive neighborhood problems as personal in nature.

2) People who perceive neighborhood problems as social or societal in nature are more likely to participate than those who perceive those problems as personal in nature.

d. People who perceive neighborhood problems as political in nature are more likely to participate in a traditional (electoral) manner if they also perceive those problems as primarily national political problems.

e. People who perceive neighborhood problems as political in nature are more likely to participate in community organizations and neighborhood associations if they also perceive those problems as primarily local political problems. 
f. Perception of problems is more strongly related to neighborhood organization participation than to traditional (electoral) participation.

2. Attitudes toward the value of participation as both an end, and as a means to achieve other ends, are significant intervening variables associated with political behavior.

a. People who believe participation has value as an end in itself are more likely to participate than those who do not.

b. People who feel individually effective are more likely to participate in a traditional (electoral) manner than those who do not.

c. People who feel individually ineffective but who feel effective as a part of a group are more likely to participate in community organizations and neighborhood associations than those who do not.

d. People who feel that the traditional (electoral) forms of participation are effective are more likely to participate in the traditional (electoral) forms of participation than those who do not.

e. People who feel that organized groups are politically effective are more likely to participate in community organizations and neighborhood associations than those who do not.

f. People who feel that the traditional (electoral) forms of political participation are legitimate are more likely 
to participate in those traditional forms than those who do not.

g. People who feel that organized group pressure is legitimate are more likely to participate in community organizations and neighborhood associations than those who do not.

h. People who feel that participation is an effective way in which to improve one's self and increase one's skills are more likely to participate than those who do not.

i. People who feel that participation is a legitimate way in which to improve one's self and increase one's skills are more likely to participate than those who do not.

3. There are systematic differences in perceptions and attitudes between participants and non-participants.

4. There are systematic differences in perceptions and attitudes between those who participate in traditional (electoral) political activities and those who participate in community organizations and neighborhood associations.

These hypotheses will be operationalized as they are introduced and tested in the chapters which discuss the findings of the study. 


\section{FOOTNOTES}

${ }^{83}$ Lane's evidence in support of his theories suffers from the extremely small sample from which he generalized. Except for the studies cited n. 5, ch. III, no studies have been found which address themselves directly to the elements of the model developed by Lane. Indeed, the 1iterature dealing with the psychology of political behavior is overwhelmingly concerned with the personality and/or psychopathology of specific political leaders, and with the political behavior of certain "personality types" (the authoritarian personality, for example). This leaves a decided gap in our understanding of the psychology of political behavior, both in terms of additional theory, and in terms of empirical validation of the model developed by Lane. 
CHAPTER V

METHOD

INTRODUCTION

The study undertaken to accomplish the purposes set forth in the last chapter consisted of a random sample household survey conducted in each of two low-income neighborhoods in the city of Portland, Oregon, in November and December of 1974. Also surveyed was a pre-selected "leadership" sample of people actively involved in neighborhood and community organizations operating within the boundaries of each of the two neighborhoods who lived within the survey neighborhoods.

The two neighborhoods sampled in the study were carefully selected and were matched as closely as possible in terms of their socio-economic characteristics. They differed substantially only in their racial composition. One neighborhood was overwhelmingly white, the other predominately black in racial composition.

Respondents in each of the neighborhood random samples, and in each of the pre-selected "leadership" samples, were administered identical interview questionnaires by trained and experienced interviewers. This method allows for both black/white and participant/non-participant comparative analyses of the two closely matched low-income neighborhoods to be made. 
THE STUDY AREAS

The Research Setting

The research was conducted in the city of Portland, Oregon over a period of three weeks in November and December of 1974. Aside from the advantages of convenience, the city has other advantages which recommend it as the setting for the research. It is an established city of medium size, with a city population of some 383,000 people nested in an SMSA of 1 million. It is the largest city in the state, and has a diversified economy. Its social, economic, and demographic characteristics make the city broadly representative of cities its age and size which have a relatively small black population and no well defined black ghetto.

The city has a relatively small black population which tends to be residentially segregated in an older residential neighborhood made up of single family and converted or subdivided single family residences. This neighborhood is similar in physical characteristics to most other lower income neighborhoods in the city. This similarity in the physical characteristics of the neighborhoods allows for comparisons and matching that would be very difficult to achieve in cities with a well defined black ghetto in the more classic style of tenement structure, etc.

The setting is particularly appropriate for the research undertaken because of its history of citizen involvement in neighborhood associations both past and present. Neighborhood associations of the "citizen improvement league" type existed in many of the city's neighborhoods prior to the establishment of federally mandated citizen participation. The city was the location for both anti-poverty community action programs and Model Cities neighborhood organizations and participation programs. There currently exists a network of neighborhood associations 
recognized and partly supported by the city government to facilitate neighborhood level citizen participation in city planning and policy matters. In short, there exists a substantial history and substantial experience with the kind of participation that is the focus of this study.

The Survey Neighborhoods: Selection Criteria

The two neighborhoods selected for comparison in the study were chosen on the basis of a number of criteria. First, they were both to be low-income neighborhoods. This was required because participation by low-income (or poverty level) residents in neighborhood associations or organization is the model of citizen participation advocated in the federal mandate. It is also the kind of participation unexplained or inadequately predicted by the political participation literature. Thus, this kind of participation becomes a critical dependent variable in the study.

The neighborhoods needed to be low-income neighborhoods for another important reason. The study proposes that variables other than socioeconomic status are important determinants of participatory behavior. By holding socio-economic status constant, a control for SES is provided in the research design and the necessity of statistical manipulation to control for SES is avoided in the data analysis stage. Thus the independent effects of other variables can be assessed more easily. 84

Secondly, the neighborhoods selected for study needed to be as closely matched as possible on a number of critical characteristics:

1. Similar demographic, housing, and socio-economic profiles based on the most current U.S. Census statistics. ${ }^{85}$ 
2. Similar histories of community and neighborhood organization efforts, and the availability of established neighborhood organizations and associations in which to participate.

3. Absence of recent or current overriding neighborhood issues (such as freeway routing controversies, urban renewal projects, etc.).

These three criteria help to ensure the comparability of the neighborhoods with respect to their objective equivalence, and also with respect to the similarity of the types of problems which exist within them--problems which may stimulate or motivate participatory behavior. Finally, the two neighborhoods needed to be different in terms of their racial composition. One neighborhood selected for the study was to be predominately black and the other predominately white ir racial composition. This one difference facilitates black/white comparisons of participants, and perhaps neighborhood organizations as well.

\section{Survey Neighborhoods: Selection Process}

At the time of the study, the City of Portland contained two large inner-city poverty target areeas. These target areas were designated in 1964 for the purposes of anti-poverty program funding. Partially overlaying one of these target areas were the boundaries of the city's Model Cities Program. Partially overlaying the other were the boundaries of the Southeast Uplift Program--a city funded program intended to be roughly equivalent to the federally funded Model Cities Program but for those areas left out of the federal program. 86 Examination of census tracts within these convenient boundaries both narrowed 
the possibilities for choice and guaranteed that many of the selection criteria would be easily met.

Two census tracts in the target area containing the city's black population were first selected as possibilities. They were selected because they were the two census tracts with the highest percentage of black population. (One was $84 \%$ black, the other $77 \%$ black). Demographic, housing and socio-economic profiles for each of these areas were constructed using 1970 U.S. Census tract statistics. (See Appendix A for a table of the census categories used in the profile).

Once the two primary candidates for the black survey neighborhood were identified, a number of census tracts in white sections of each larger target area were similarly profiled and systematically compared with each of the black census tracts. The white tract with the best match overall, and the best match on critical socio-economic' characteristics such as median income, level of education, levels of unemployment, etc. was selected (along with its matched black census tract). The two tracts selected were census tract 34.02 in the Boise neighborhood of the city, and census tract 21 in the Buckman neighborhood of the city. The Boise neighborhood census tract is identified in the balance of the study as the "Black" neighborhood. The Buckman neighborhood census tract is identified in the balance of the study as the "White" neighborhood.

The comparative profiles of the two neighborhoods are detailed in Appendix A. They meet the criteria established in the previous subsection in all essential respects, even though perfect equivalence is not possible. For purposes of the study, they will be considered equivalent. The boundaries of the two neighborhoods and their geographic 
relationship to one another and to the city as a whole are presented in Appendix $B$.

\section{SAMPLE SELECTION}

Neighborhood Household Random Sample

Block statistics from the 1970 U.S. Census of Population and Housing were consulted for each of the survey neighborhoods to determine the number of individual blocks in each neighborhood and the number of housing units in each block. Resource limitations dictated a maximum sample size of about 125 households to be surveyed in each neighborhood. This sample size could be obtained by sampling every 10th household in the Black neighborhood and every 9 th household in the White neighborhood. 87

To draw the samples, a table of random numbers was consulted in order to select the beginning point for identifying the sample households. 88 Once the beginning point was randomly selected for each neighborhood, the survey households were indicated by selecting every 10th household in the Black neighborhood and every 9 th household in the White neighborhood, taking each block in a systematic and continuous order. The sample drawn for each neighborhood is indicated in Appendix C. A list of substitute survey households was randomly selected for each neighborhood in the same manner. It also appears in Appendix $C$.

\section{Pre-selected "Leadership" Samples}

In order to ensure the inclusion of an adequate number of respondents in the survey who had been active in neighborhood organizations 
and associations, a pre-selected sample of these people was identified for each neighborhood and interviewed separately. Reliance on the random sample household survey alone, it was assumed, would include too few participants to make any meaningful participant/non-participant comparisons.

To select this "leadership" sample, a list of neighborhood organizations, associations and community organizations within each neighborhood was compiled. Records of each of these organizations or associations over a period of four years were examined to identify those people who were consistently active. Those who served as officers or board members, committee or task force chairpersons and members, and those who attended a majority of the meetings of each organization were initially selected. This list was further refined by selecting only

those persons with addresses inside either of the survey neighborhoods. An attempt was made to interview $100 \%$ of each of these smaller samples. 89

\section{INTERVIEW PROCESS}

An interview questionnaire was administered to respondents in the random sample of households and the "leadership" samples of each neighborhood. The interview process was completed over a period of three weeks by a tean of trained and experienced interviewers who had been hired for the study. ${ }^{90}$ As much as possible, black interviewers were assigned to the Black neighborhood and white interviewers to the White neighborhood to reduce interviewer bias. ${ }^{91}$ Al1 respondents were 
administered the same questionnaire. (The detailed instructions for the interviewers and the interview questionnaire appear as Appendix $D$ and Appendix $E$ respectively). The interviews were verified for control purposes on a random basis. Approximately one-third of all interviews completed were verified.

QUESTIONNAIRE PROCESSING

The questionnaire items were designed to be closed, forced-choice items in most cases. These items were pre-coded and were simply verified for clarity prior to entering the data on keypunch cards. The few open-ended items were coded by a single person to ensure consistency. Questionnaires which were substantially incomplete, or which had significant sections incomplete were not processed. Questionnaires with small numbers of missing or incomplete items were processed. (These missing items are reflected in the data presentation).

All data from the questionnaires were transferred to computer cards and verified for computer processing. Each questionnaire was coded so that neighborhood was identified. No distinction was made in processing between the random sample questionnaires and "leadership" sample questionnaires. Combining the random sample with the "leadership" sample responses in processing ensured adequate variability in the index items subsequently used for analysis.

DATA ANAIYSIS

The 89 individual items of the interview questionnaire were treated in various combinations as index items. No attempt was made to 
scale items in the questionnaire. Thus the data obtained are of a nominal or ordinal nature depending upon the index. Statistical techniques appropriate to these levels of data are used throughout (Chi Square, Kendall's Tau b or Tau c, and Gamma). Data are presented in cross-tabular form with the appropriate statistics. More sophisticated multivariate statistical techniques were not used, except as otherwise noted, because they were inappropriate for the data at hand. 92

\section{DEPENDENT AND INDEPENDENT VARIABLES}

The questions to be addressed in the study, and the list of "guiding hypotheses", both of which are discussed in the previous chapter, suggest a number of dependent and independent variables which should be considered. In the list that appears below are the dependent and independent variables which are relevant to these questions and hypotheses, and which have some theoretical relevance according to the literature reviewed in Chapter III. These variables will not be operationalized at this point, nor will specific measures be indicated. These tasks will be accomplished for each variable as it is introduced and used in subsequent chapters.

Dependent Variables

Three dependent variables have been selected for use in the study. Each is intended to represent a mode of participation which is conceptually different from the others. Taken together, they represent a range of political activity from traditional electoral activity to nontraditional neighborhood group activity. The three dependent variables are: 
1. Electoral Participation

2. Issue Participation

3. Group Participation

\section{Independent Variables}

The independent variables used in the study fall into two groups. The first group includes those variables suggested by the social-psychological model of political behavior and the assumptions in the citizen participation literature. The second group includes those variables which have been traditionally used to explain political behavior, and those which might logically be useful for control purposes, or for purposes of refining the examination of the relationships between the dependent variables and the primary independent variables. The two groups of independent variables are:

\section{Primary Group}

1. Identification or Perception of Neighborhood Problems

2. Housing Problem Identification and Salience

3. Education Problem Identification and Salience

4. Enployment Problem Identification and Salience

5. Crime and Delinquency Problem Identification and Salience

6. Police-Community Relations Problem Identification and Salience

7. Feelings of Personal Efficacy in Solving Identified Problems

8. Feelings of Group Efficacy in Solving Identified Problems

9. Perception of a Personal vs Social Dimension of Identified Problems

10. Perception of a Local vs ivational Dimension of Identified Problems

11. Perception of a Non-political vs Political Dimension of Identified Problems 
12. Attitudes Toward the Value of Participation as an End in Itself

13. Attitudes Toward Voting as an Approved and Effective Means of Solving Neighborhood Problems

14. Attitudes Toward Petitioning as an Approved and Effective Means of Solving Neighborhood Problems

15. Attitudes Toward Collective Action as an Approved and Effective Means of Solving Neighborhood Problems

16. Attitudes Toward Non-Violent Demonstrations as an Approved and Effective Means of Solving Neighborhood Problems

17. Attitudes Toward Violent Demonstrations as an Approved and Effective Means of Solving Neighborhood Problems

18. Attitudes Toward Participation as an Effective Means of Self-Improvement

19. Attitudes Toward Participation as an Approved Means of Self-Improvement

Secondary Group

1. Age

2. Sex

3. Socio-Economic Status

4. Neighborhood Rootedness

5. Feelings of Personal Cynicism

6. Feelings of Political Cynicism 
FOOTNOTES

${ }^{84}$ By holding SES constant, the influence of variation in level of SES on participation is physically controlled. This affords greater simplicity in subsequent data analysis than does statistical control of SES. For a discussion of the process of controlling for the influence of variables, see Hubert M. Blalock, Jr., Social Statistics, (2nd. Ed., New York: McGrawHil1, 1972), pp. 303-312. See also, Fred N. Kerlinger, Foundations of Behavioral Research: Educational and Psychological Inquiry, (New York: Holt, Rinehart and Winston, 1964), pp. 284-286.

${ }^{85}$ At the time of the study, statistics from the 1970 U.S. Census of Population and Housing were available. These statistics were used in matching the two survey neighborhoods.

${ }^{86}$ The Southeast Uplift Program was administered by the local urban renewal agency, the Portland Development Commission. It had a locally elected policy board, but limited funds and staffing. Its programs and program impact was thus substantially less than that of the Portland Model Cities Program.

87 This was determined by dividing approximately 140 clusters of , one household (which with the expected completion rate would result in roughly a sample of 125 households) into the number of households in each neighbornood.

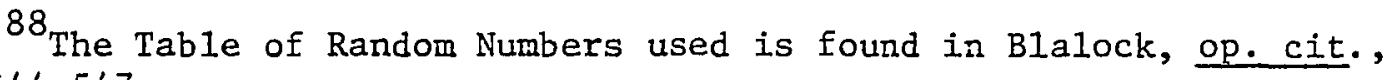
pp. 544-547.

${ }^{89}$ In each neighborhood, only one of the identified persons refused to be interviewed, and all others were successfully interviewed.

90 The interviewers were otbained from a pool of experienced interviewers employed by a local public opinion research firm. They were paid at a rate per hour roughly equivalent to that paid by the public opinion research firm.

${ }^{91}$ Interviewer bias is generally not a problem for most items in a questionnaire. However, bias has been found to increase for questions relating to political and personal efficacy, attitudes toward the police, neighborhood conditions, and race relations. Since most of these areas were included in the questionnaire, it was decided to attempt to minimize this potential interviewer bias through careful assignment of black and white interviewers. This was especially important in the White survey neighborhood, and probably contributed to the low refusal rate in the interview process in that neighborhood. For a discussion of interview 
bias as it relates to survey research in poverty areas, see, John $B$. Lansing, Stephen B. Whithey, and Arthur C. Wolfe, Working Papers on Survey Research in Poverty Areas, (Ann Arbor, Mich.: University of Michigan, 1971), pp. iii-iv.

92 Had the sample been substantially larger, and had the questionnaire items related to reported behavior rather than attitudes and perceptions, then some justification might be said to exist for using multivariate statistical techniques with the ordinal level data. Since this was not the case, it was decided to forego these more powerful techniques in favor of those clearly justified by the level of the data collected in the study. 


\section{CHAPTER VI}

\section{PARTICIPATION: THE DEPENDENT VARIABLES}

\section{INTRODUCTION}

Participation is a term which has been used rather loosely up to this point. This is partly due to the difficulties with operationalizing the term noted in the literature review, and partly due to the fact that the most appropriate time for specifics is in the detailed description of the study and its findings. We have now reached that appropriate point.

In the preceding chapters a distinction was made between traditional electoral forms or modes of participation and the non-traditional modes of participation represented by neighborhood organization and direct involvement of neighborhood representatives in the planning or policy process. This distinction is the basis for the selection of the dependent variables used in the study. Three dependent variables were selected for the study: (1) traditional electoral participation; (2) participation in neighborhood and community organizations and associations of the type fostered by the federal mandate; and (3) participation in local public issues which conceptually represents an intermediate type of participation. It is non-traditional in the sense of being other than electoral activity, but it may be either individual or group activity. Each of these variables is operationalized in turn below. 
PARTICIPATION OPERATIONALIZED

\section{Electoral Participation}

For purposes of this study, electoral participation is defined by a simple additive index adapted from indices developed by Woodward and Roper, and by Milbrath. ${ }^{93}$ Respondents were asked nine questions about their participation and political activities in the election campaign which had concluded some three weeks prior to the study. The nine questions comprising this index are the first nine questions of the Survey Questionnaire in Appendix E. They were designed to measure activity in the electoral process, by seeking answers to the following:

1. Did you talk to people and try to show them why they should vote for one of the political parties, candidates or ballot measures?

2. Did you give any money or buy tickets or anything to help the campaign for one of the political parties, candidates or ballot measures?

3. Did you go to any political meetings, rallies, dinners or anything like that where the candidates for office or ballot measures were discussed?

4. Did you do any other work for one of the political parties, candidates or ballot measures like telephoning, addressing envelopes or taking campaign literature door-to-door?

5. Do you belong to any political club or oganization?

6. Did you wear a campaign button or put a bumper sticker on your car or put a sign on your lawn?

7. Are you registered to vote?

8. Have you voted in an election in the past four years?

9. Did you vote in this last election?

Respondents scored one point for each positive answer and zero points for each negative answer or don't know answer. Thus an index of electoral participation ranging from 0-9 points was easily tabulated. 
For analytic purposes, this index was collapsed into three ordinal categories representing high, medium, and low levels of political activity or participation in the recent election. 94

\section{Group Participation}

Group participation was measured by an index developed specifically for the study. Respondents were first read a list identifying a number of community and neighborhood organizations available in their own neighborhood in which they could participate. They were then asked a series of five questions relating to their familiarity with, and participation in, any of the listed organizations and associations. The questions were as follows: (Refer to questions 10-14 in Appendix E).

1. Do you know about any of these groups or organizations?

2. Have you attended meetings of any of these groups or organizations?

3. Have you taken part in activities or programs sponsored by any of these groups or organizations?

4. Have you ever voted in an election to choose the leaders of any of these groups or organizations?

5. Have you been a leader, or have you served on a committee in any of these groups or organizations?

Respondents were again scored, with a positive response tallying one point and a negative or don't know response counting zero points. Thus a simple additive index of group participation ranging. from $0-5$ points was created. For ease of analysis, this index was also collapsed into three ordinal categories representing low, medium, and high levels of participation and activity in neighborhood and community organizations and associations of the type advocated in the citizen participation Iiterature. 
Issue Participation

It is possible for people to be politically active in yet another way. They may become involved in some specific neighborhood or community issue. Such activity is outside the traditional electoral process, but it is not necessarily group activity. It may be either group or individual activity, or perhaps both. As such, it represents an intermediate type of political behavior.

In order to measure issue participation or activity, a series of questions were asked of respondents after first defining for them what taking an active part in an issue meant. Respondents were asked: (Refer to questions $15-17$ in Appendix E).

1. Have you taken an active part in any local government, community or neighborhood issue during the past two or three years?

2. What was the issue?

3. What did you do? (Five alternative activities were listed.)

Respondents scored one point for a positive response to the first question, one point for each issue to a maximum of three issues, 95 and one point for each specific activity to a maximum of five. This produced an addive index of issue participation ranging for 0-8 points. As with the other two dependent variables, this index was collapsed into three ordinal categories ranging from low to high participation in local public issues.

LEVELS OF PARTICIPATION IN THE SURVEY NEIGHBORHOODS

Using the three measures of participation just described, some initial findings can now be presented as kind of a baseline prior to 
the introduction and discussion of the independent variables used in this study. TABLE I indicates the percentage of respondents in each survey neighborhood and in the combined survey neighborhoods who fall into the three level of participation categories for each type of participation.

The table allows some interesting preliminary comparisons to be made. First, with respect to electoral participation, the overall level of electoral activity appears to be substantial. Some two-thirds of the respondents in each survey neighborhood report being involved in the past election campaign at moderate or high levels. This supports Nie and Verba's contention that the level of political activity is more substantial than generally assumed in the literature. ${ }^{96}$ The table also shows a significantly higher level of participation in the electoral process on the part of respondents in the Black survey neighborhood. The percentage of Black neighborhood respondents in the high category is more than $40 \%$ greater than that of the White neighborhood respondents, while the percentage of respondents in the low category is identical. This would seem to indicate that residents in the Black survey neighborhood are more highly politicized than their White survey neighborhood counterparts--at least with respect to traditional electoral activity. This may well be due to a concern for voter registration in the Civil Rights Movement and in OEO and Model Cities programs in the Black survey neighborhood that did not manifest itself in the White survey neighborhood. 97

Second, when examining issue participation, the overall level of participation drops significantly. Less than half of the respondents 
TABLE I

TYPES AND RATES OF PARTICIPATION IN SAMPLE AND COMBINED NEIGHBORHOODS (EXPRESSED IN PERCENT)

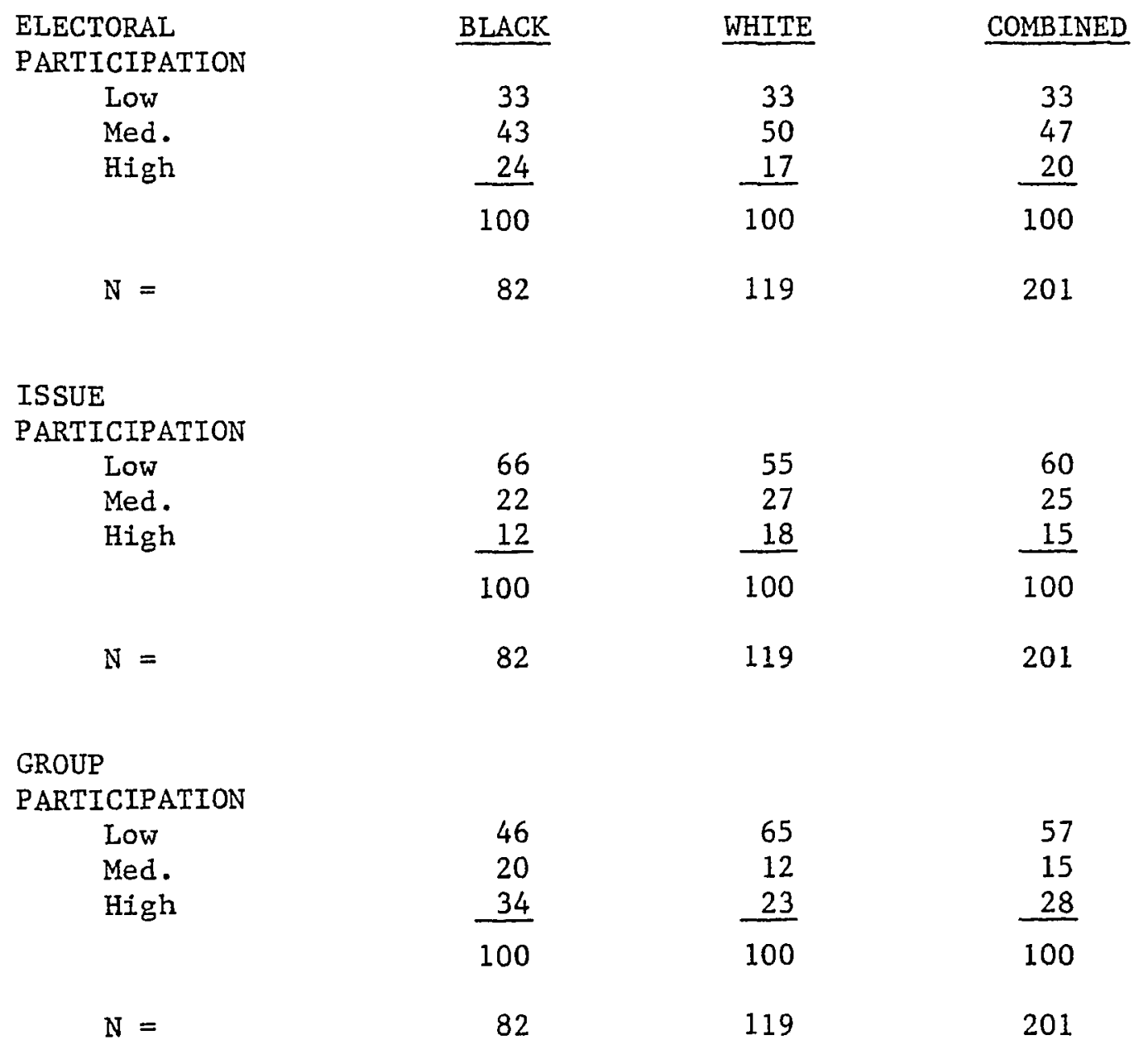


in each survey neighborhood are involved at moderate or high levels. This drop in participation level is particularly notable in the Black survey neighborhood where the low category increases by $100 \%$ and the moderate and high categories each decrease by roughly $50 \%$. In the White survey neighborhood, the low category increases by $67 \%$. All of this increase is at the expense of the moderate category, because the percentage of respondents who are nighly active remains the same for issue participation as for electoral participation. These results may be interpreted to suggest that participation in the White neighborhood is much more a problem or issue oriented instrumental activity than is the case in the Black survey neighborhood. This is an area that will be more directly addressed at a later point.

Finally, with regard to group participation, the reverse of the situation encountered with issue participation is generally true. Overall participation is much lower in the White survey neighborhood, even though the percentage of respondents highly active increased to its highest level. Respondents in the Black neighborhood are substantially more involved in neighborhood groups and organizations. This further reflects the successful mobilization and politicization of residents in the Black survey neighborhood. This does not necessarily invalidate the interpretation that participation in the Black survey neighborhood is less problem or issue oriented and instrumental. Participation in neighborhood groups and organizations can be a symbolic or social activity just as well as a problem solving or instrumental activity. Looking only at the dependent variables, then, there do appear to be some systematic differences in the levels of participation between the Black and White survey neighborhoods. We will explore these differ- 
ences in the ensuing chapters, but a few more initial comparisons must first be made. The three dependent variables have been selected because they are both conceptually different and important to the study. But are they systematically different? One of the research questions addressed in the study is whether the same people who participate in neighborhood organizations and groups are the same people who are active in traditional electoral activities. If so, then group participation may be just another manifestation of the factors which are associated with electoral behavior. In this case, the higher status residents in the community may well be its political actives, as is predicted in much of the traditional political behavior literature. If different people are involved, then other explanatory factors must be identified.

\section{PARTICIPATION: NEW OR OLD FACES}

\section{Electoral and Issue Participation}

In order to test whether substantially the same individuals are the high participants in both electoral and issue activities, two approaches were taken. The first is pernaps the easiest and most direct. Spearman and Kenda11 Rank Order Correlation Coefficients were calculated for the pair of dependent variables to see how strongly they were associated with one another. 98 The correlations between electoral participation and issue participation proved to be quite consistent for the two survey neighborhoods. Kendall Rank Order Correlation Coefficients range from a low of .513 for the White survey neighborhood to a high of .544 for the Black survey nelghborhood. The Spearman Rank Order Correlation Coefficients, which are less conservative, range from a low of .550 for 
the White survey neighborhood to a high of .587 for the Black survey neighborhood. While these measures of association show a moderately strong relationship between the two variables, they allow us to conclude that the two variables are measuring different but related dimensions of participation. It is also reasonable to conclude that substantially different individuals participating in each set of activities cannot be ruled out.

In order to look at the relationship in more detail, a bivariate crosstabulation of electoral participation by issue participation was calculated. That crosstabulation and its related statistics can be seen in TABLE II. If the same individuals were involved at similar levels in both kinds of participation, the table would show a perfect linear relationship. There would only be participants indicated in the diagonal running from top left to bottom right of the table. The Tau $b$ which measures the strength and direction of linear relationships would be +1.00 . The Gamma, which indicates the strength and direction of both linear and curvilinear relationships would also be $+1.00 .^{99}$ This is not the case, however. Strong, positive linear or curvilinear relationships are the result in both Black and White survey neighborhoods, as well as for the combined neighborhoods. But without a careful examination of the table, this relationship could be overstated. A quick calculation of some row and column percentages bring several important differences to 1ight.

In the Black survey neighborhood, only $45 \%$ of those scoring in the highest category of electoral participation score in the highest category of issue participation. Yet $90 \%$ of those who score highest in 
TABLE II

RELATIONSHIPS BETWEEN ISSUE PARTICIPATION AND ELECTORAL PARTICIPATION FOR INDIVIDUAL AND COMBINED SURVEY NEIGHBORHOODS (EXPRESSED IN PERCENT)

BLACK NEIGHBORHOOD

Issue Participation

ELECTORAL
PARTICIPATION
LOW
Medium
High

Ch1 Square:

$$
\begin{aligned}
& 37.305 \\
& \text { d.f. }=4
\end{aligned}
$$$$
\text { Signif. }=.000
$$

Tau $b=+.544$

Gamma $=+.832$

WHITE NEIGHBORHOOD

Issue Participation

$\begin{array}{rrr}\text { Low } & \text { Med. } & \text { High } \\ 27.7 & 4.2 & 0.8 \\ 26.1 & 18.5 & 5.9 \\ 1.7 & 4.2 & 10.9\end{array}$

Chi Square:

$$
\begin{aligned}
& 50.272 \\
& \text { d.f. }=4 \\
& \text { Signif. }=.000
\end{aligned}
$$

Tau $\mathrm{b}=+.513$

Gamma $=+.774$
COMBINED NEIGHBORHOODS

Issue Participation

Low Med. High

$$
\begin{aligned}
& \begin{array}{lll}
28.9 & 3.5 & 0.5
\end{array} \\
& 27.9 \quad 15.4 \quad 4.0 \\
& \begin{array}{lll}
3.0 & 6.0 & 10.9
\end{array} \\
& N=201
\end{aligned}
$$

Chi Square:

$$
82.218
$$$$
\text { d.f. }=4
$$$$
\text { Signif. }=.000
$$

Tau b $=+.515$

Gamma $=+.780$ 
issue participation also score highest in electoral participation. In the moderate categories, only half of those who exhibit moderate levels of issue participation also exhibit moderate levels of electoral activity. Only one quarter of the electoral moderates are also issue participation moderates. These figures and the percentage figures for each cell indicated in the table suggest two things. First, in the Black survey neighborhood, few people are involved in public issue activity. (As we concluded from TABLE I.) Second, those few who are involved tend to be some of the same individuals who are highly involved in electoral activity, but those who are highly involved in electoral activity are probably not also highly involved in public issues.

Considerably different results are obtained in the case of the White survey neighborhood, which is reflected in the table for comblned neighborhoods as well. In the White survey neighborhood, $65 \%$ of those who are high level electoral actives are also highly active in public issues. However, only $62 \%$ of those highly active in public issues exhibit high levels of electoral activity. A similar situation exists for the moderate levels of each type of participation. $69 \%$ of those moderately active in issues are also moderately active electorally. $37 \%$ of those moderately active electorally are also moderately active in public issues. This suggests that while there is some considerable overlap, significant numbers of those moderately or highly active in public issues are different individuals than those who are moderately or highly involved in electoral activity.

The differences between the Black and White survey neighborhoods are substantial, but taken together, they suggest fairly strongly that the participants in these two kinds of participation tend to be the 
same persons. We must keep in mind, however, that issue participation represents an intermediate type. It may be more closely related to individual electoral activity than to group activity. This is especially true of the respondents in the Black survey neighborhood. It remains to be determined whether similar relationships exist between electoral and group participation.

\section{Electoral and Group Participation}

The same procedure was used to determine if the individuals active in neighborhood groups were the same individuals active in traditional electoral activity. Spearman and Kendall Rank Order Correlation Coefficients were calculated for electoral and group participation. The Kendall Rank Order Correlation Coefficients ranged from a low of .366 for the White survey neighborhood, to a high of .581 for the Black survey neighborhood. The less conservative Spearman Correlation Coefficient ranged from a low of .394 for the White survey neighborhood, to a high of .629 for the Black survey neighborhood. These relationships are interesting in at least two regards. First, they tend to reinforce the impressions gained in the examination of the correlation between electoral and issue participation in the case of the Black survey neighborhood. By both statistical measures, electoral participation is moderately strongly related to group participation--slightly more strongly than is the case with electoral and issue participation. This tends to suggest that substantial numbers of participants in each type of activity are the same people.

Second, these measures of association are much weaker in the case of the White survey neighborhood. This provides some evidence from 
which to conclude that the specialization of activity found with respect to electoral and issue participation in this neighborhood is also true for group participation--perhaps even more so.

Again, it is necessary to look at the relationships in more detail to determine whether or not they are confirmed. TABLE III presents a bivariate crosstabulation and related statistics for electoral participation and group participation for each of the survey neighborhoods. An examination of these tables show the initial impression to be only partially confirmed.

For the Black survey neighborhood, the Tau $b$ and Gamma statistics indicate strong positive linear or curvilinear relationships between the two measures of participation. These relationships are about the same magnitude as those found in TABLE II for electoral and issue participation. This is misleading in one important respect, however. Calculating row and column percentages produces an important difference. Whereas $90 \%$ of all those highly active in issues were also highly active electoral participants, only $64 \%$ of those highly active in neighborhood groups are also electoral actives. On the other hand, where on 1 y $45 \%$ of those highly active in electoral activities were also highly active in issues, we see a full $90 \%$ of electoral actives also highly active in neighborhood groups.

These figures, and the total percentages for each cell of the table, suggest two things. First, in the Black survey neighborhood, the overall level of participation in neighborhood groups is much greater than the level of participation in issues, and it is nearly as great as for electoral activity. Second, a substantial percentage of those highly involved in neighborhood groups tend to be different indi- 
TABLE III

RELATIONSHIPS BETWEEN GROUP PARTICIPATION AND ELECTORAL AND ISSUE PARTICIPATION FOR INDIVIDUAL AND COMBINED SURVEY NEIGHBORHOODS (EXPRESSED IN PERCENT)

\section{BLACK NEIGHBORHOOD}

Group Participation

\begin{tabular}{lrrr} 
ELECTORAL & Low & Med. & High \\
PARTICIPATION & & & \\
Low & 25.6 & 4.9 & 2.4 \\
Medium & 19.5 & 13.4 & 9.8 \\
High & 1.2 & 1.2 & 22.0 \\
& \multicolumn{3}{c}{$\mathrm{N}=82$}
\end{tabular}

Chi Square:

43.380

d.f. $=4$

Signif. $=.000$

Tau $\mathrm{b}=+.581$

Gamma $=+.803$

ISSUE

PARTICIPATION

Low
Medium
High

$\begin{array}{lll}45.1 & 12.2 \quad 8.5\end{array}$

$\begin{array}{lll}1.2 & 7.3 & 13.4\end{array}$

$\begin{array}{lll}0.0 & 0.0 & 12.2\end{array}$

$\mathrm{N}=82$

Chi Square:

44.196

d.f. $=4$

Signif. $=.000$

Tau $\mathrm{b}=+.644$

Gamma $=+.911$

\section{WHITE NEIGHBORHOOD}

Group Participation

Low Med. High

$\begin{array}{rlr}27.7 & 2.5 & 2.5 \\ 31.9 & 7.6 & 10.9 \\ 5.0 & 1.7 & 10.1 \\ & & \\ & N & =119\end{array}$

Chi Square: 22.818 d.f. $=4$ Signif. $=.000$

Tau $\mathrm{b}=+.336$

Gamma $=+.614$

$\begin{array}{rrr}50.4 & 3.4 & 1.7 \\ 12.6 & 6.7 & 1.7 \\ 1.7 & 1.7 & 14.3 \\ & & \end{array}$

Chi Square: 66.641 d.f. $=4$ Signif. $=.000$

Tau $\mathrm{b}=+.646$

Gamma $=+.878$

\section{COMBINED NEIGHBORHOODS}

Group Participation

Low Med. High

$$
\begin{array}{rrr}
26.9 & 3.5 & 2.5 \\
26.9 & 10.0 & 10.4 \\
3.5 & 1.5 & 14.9 \\
\multirow{3}{3}{N=201}
\end{array}
$$

Chi Square: 65.485

d.f. $=4$ Signif. $=.000$

Tau $b=+.457$

Gamma $=+.698$

$$
\begin{aligned}
& \begin{array}{lll}
48.3 & 7.0 & 4.5
\end{array} \\
& 8.0 \quad 7.0 \quad 10.0 \\
& \begin{array}{lll}
1.0 & 1.0 & 13.4
\end{array} \\
& \mathrm{~N}=201
\end{aligned}
$$


viduals than those highly involved in electoral activity, even though most of those highly involved electorally are also highly active in neighborhood groups. Thus we can see some specialization of political activity which must be explained.

The specialization of activity is even more striking in the case of the White survey neighborhood. The Tau b and Gamma statistics both indicate much weaker linear or curvilinear relationships between electoral and group participation measures. Only $43 \%$ of those highly active in neighborhood groups are also highly active electoral participants. Only $60 \%$ of the electoral actives are also group actives. This suggests substantial specialization of activity, with predominantly different individuals highly involved in each type of activity. This specialization is further reflected in the moderate categories of each type of activity. Only $15 \%$ of the electoral moderates are also group participation moderates, while $64 \%$ of the group participation moderates are also electoral moderates.

Thus we can see in the relationship between electoral and group participation specialization of activity similar to that found for electoral and issue participation. This is especially pronounced in the White survey neighborhood, but it is clearly evident in the Black survey neighborhood as well. This suggests that indeed the people who are highly active in neighborhood groups are often different individuals than those who are active in traditional electoral modes of participation.

\section{Issue and Group Participation}

It was suggested earlier that issue participation in the Black survey neighborhood may be more closely related to electoral participa- 
tion than to group participation. Conversely, the moderate levels of issue participation specialization found in the White survey neighborhood may indicate that issue participation is more related to group participation than to electoral activity. In order to test these propositions, the relationships between issue and group participation were also examined. Spearman and Kendall Rank Order Correlation Coefficients proved to be of little assistance. They are identical for both statistical measures and for both survey neighborhoods. A careful examination of the crosstabulations of the two variables presented in Table. III, however, tends to support this explanation of the differences noted. While the tables and their related statistics for the different survey neighborhoods show very strong, positive relationships between issue and group participation, only $36 \%$ of those highly active in groups in the Black survey neighborhood are highly active in neighborhood issues. In the White survey neighborhood, $60 \%$ of those highly active in neighborhood groups are also highly active in issues. In the Black survey neighborhood, only $37 \%$ of those moderately active in groups are also moderately active in issues, while $57 \%$ of those in the White survey neighborhood moderately active in neighborhood groups are also moderately active in issues. Thus, even though the association is very strong between issue and group participation in each neighborhood, those highly or moderately involved in groups in the White survey neighborhood are nearly twice as likely to be highly or moderately involved in issues as their counterparts in the Black survey neighborhood. This lends some support to the proposition that issue participation is more an individual activity related to traditional electoral activity in the Black survey neighborhood, and more a group activity in the White survey neighborhood. 
PARTICIPATION: TRADITIONAL EXPLANATIONS

The literature related to individual political behavior suggests socio-economic status, sex, age, and race to be the primary factors associated with participation. We have already seen that race is a factor in the equation, and the radical differences in level of participation will continue to be examined as we explore further. Age, sex, and socio-economic status will be briefly considered as they relate to participation at this point for two reasons. First, these factors may help refine our understanding of who participates in the various types of political activity under investigation, and how the participants in each arena might differ from one another. Second, these are theoretically relevant variables which must be initially examined as benchmarks against which the explanatory or predictive utility of the independent variables used in the study must be evaluated. We will examine each of these variables in turn in the remainder of this chapter.

\section{Participation and Age}

Respondents in the survey were not asked to indicate their age. Instead, the interviewers were asked to estimate as closely as possible which of three age categories the respondents fit. The three categories were: (1) Under 30; (2) 30-55; and (3) Over 55. (See Appendix E; the final page). These three broad categories were chosen because the literature suggests those in the middle years--roughly $30-55$ years of age--are more likely to participate than people in either lower or higher age groups. 100 While interviewer judgment of the age of the 
respondents may provide a rather crude measure of age, it is sufficient for our purposes since the categories are quite broad. Thus the need for precision is lessened, and the already lengthy survey instrument could be shortened by observing rather than asking a respondent's age. TABLES IV and $V$ indicate the relationships between age group measured in this manner and the three types of participation in each of the survey neighborhoods. Looking at TABLE $V$, which summarizes the statistics related to the contingency tables in TABLE IV, the first thing that must be said about the relationships is that they are moderately strong in only the Black survey neighborhood. This is the case even though the Chi Square statistics all show a statistically significant, or nearly significant, relationship between age and participation of all types in each neigborhood. 101 For the White and combined survey neighborhoods, age is comparatively weakly associated with all three types of participation.

Second, the strongest relationship in the Black survey neighborhood is between age group and electoral participation. This is precisely what we would expect according to the literature. The relationship in the case of the White survey neighborhood shows no strength at all for either the Tau b or Gamma statistics which measure the strength and direction of association between two variables. Thus, age is not a variable which explains or predicts participation very successfully in the White survey neighborhood, even though a slightly stronger association between age and participation is noted in the case of issue participation.

Third, it is significant that the relationships are positive in the Black survey neighborhood and negative in the case of the White survey 
TABLE IV

RELATIONSHIPS BETWEEN AGE AND ELECTORAL, ISSUE, AND GROUP PARTICIPATION IN INDIVIDUAL AND COMBINED SURVEY NEIGHBORHOODS (EXPRESSED IN PERCENT)

\section{BLACK NETGHBORHOOD}

Age Groups

\section{WHITE NEIGHBORHOOD}

Age Groups

COMBINED NEIGHBORHOODS

Age Groups

ELECTORAL

PARTICIPATION

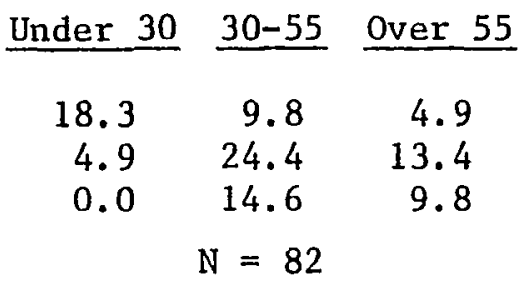

ISSUE

PARTICIPATION

$\begin{array}{lrrr}\text { Low } & 20.7 & 28.0 & 17.1 \\ \text { Medium } & 2.4 & 14.6 & 4.9 \\ \text { High } & 0.0 & 6.1 & 6.1 \\ & & \mathrm{~N}=82 & \end{array}$

GROUP

PARTICIPATION

$\begin{array}{lrcr}\text { Low } & 18.3 & 18.3 & 9.8 \\ \text { Medium } & 3.7 & 11.0 & 4.9 \\ \text { High } & 1.2 & 19.5 & 13.4 \\ & & \mathrm{~N}=82 & \end{array}$

\begin{tabular}{rrrr} 
Under 30 & & $30-55$ & Over 55 \\
\cline { 1 - 1 } 12.6 & & 10.1 & 10.1 \\
11.8 & & 16.8 & 21.8 \\
6.7 & & 8.4 & 1.7 \\
& $N=119$ &
\end{tabular}

$\begin{array}{rrr}17.6 & 13.4 & 24.4 \\ 8.4 & 10.9 & 7.6 \\ 5.0 & 10.9 & 1.7 \\ & \mathrm{~N}=119\end{array}$

$\begin{array}{rrr}21.0 & 17.6 & 26.1 \\ 5.9 & 2.5 & 3.4 \\ 4.2 & 15.1 & 4.2 \\ & \mathrm{~N}=119\end{array}$

\begin{tabular}{|c|c|c|}
\hline Under 30 & $30-55$ & Over 55 \\
\hline 14.9 & 10.0 & 8.0 \\
\hline 9.0 & 19.9 & 18.4 \\
\hline 4.0 & 10.9 & 5.0 \\
\hline \multicolumn{3}{|c|}{$N=201$} \\
\hline
\end{tabular}

$\begin{array}{rrr}18.9 & 19.4 & 21.4 \\ 6.0 & 12.4 & 6.5 \\ 3.0 & 9.0 & 3.5 \\ & \mathrm{~N}=201\end{array}$

$\begin{array}{rrr}19.9 & 17.9 & 19.4 \\ 5.0 & 6.0 & 4.0 \\ 3.0 & 16.9 & 8.0 \\ & \mathrm{~N}=201\end{array}$




\section{TABLE V}

SIGNIFICANCE OF THE RELATIONSHIPS BETWEEN AGE AND ELECTORAL, ISSUE AND GROUP PARTICIPATION IN INDIVIDUAL AND COMBINED SURVEY NEIGHBORHOODS

ELECTORAL PARTICIPATION

AND AGE GROUP

Chi Square:

$$
\begin{aligned}
& \text { Blk. }=24.833 \text { Signif. }=.000 \text { d.f. }=4 \\
& \text { Wht. }=8.968 \text { Signif. }=.062 \text { d.f. }=4 \\
& \text { Comb. }=18.056 \text { Signif. }=.001 \text { d.f. }=4
\end{aligned}
$$

ISSUE PARTICIPATION

AND AGE GROUP

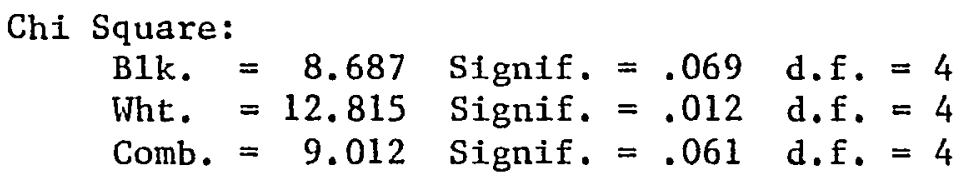

GROUP PARTICIPATION

AND AGE GROUP

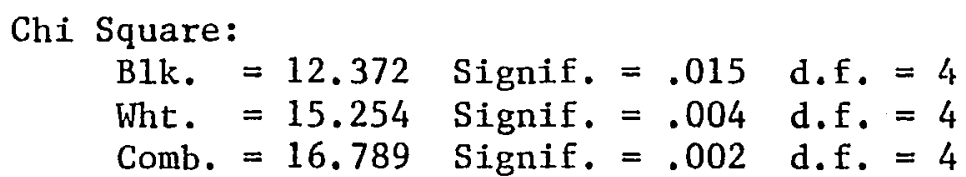

Tau b:

$$
\begin{aligned}
& \text { Blk. }=+.300 \\
& \text { Wht. }=-.065 \\
& \text { Comb. }=+.078
\end{aligned}
$$

Gamma :

$$
\begin{aligned}
& \text { B1k. }=+.579 \\
& \text { Wht. }=-.035 \\
& \text { Comb. }=+.214
\end{aligned}
$$

Tau b:

B1k. $=+.210$
Wht. $=-.134$

Comb. $=-.011$
Gamma :

$$
\begin{aligned}
& \text { BIk. }=+.374 \\
& \text { Wht. }=-.208 \\
& \text { Comb. }=-.019
\end{aligned}
$$

Gamma :

$$
\begin{aligned}
& \text { Blk. }=+.463 \\
& \text { Wht. }=-.107 \\
& \text { Comb. }=+.126
\end{aligned}
$$


neighborhood (even if only slightly so). This indicates that participants in the former neighborhood tend to be older than their counterparts in the latter neighborhood. This is confirmed by an examination of the crosstabulations presented in TABLE IV.

In the Black survey neighborhood, $60 \%$ of those who are highly active electoral participants are in the 30-55 age group. There are none in the under 30 category, and the remaining $40 \%$ are in the over 55 age group. In the White survey neighborhood, $40 \%$ are under 30 years of age, while only $10 \%$ are in the over 55 category. The remaining $50 \%$ are in the $30-55$ age group.

For issue participation, White survey neighborhood participants tend to be somewhat older, with only $29 \%$ of the highly active respondents in the under 30 age group. $62 \%$ are in the 30-55 category, with the remainder over 55. But again, these participants are younger than their Black survey neighborhood counterparts. Half of the respondents in that neighborhood are in each of the two higher age group categories.

The same pattern holds in the case of group participation. $58 \%$ of the highly active Black survey neighborhood respondents are in the 30-55 age group. $39 \%$ are in the over 55 category, and for the first time, we see some respondents in the under 30 age group. In the White survey neighborhood, $64 \%$ of the actives are in the $30-55$ age group with $18 \%$ in each extreme category.

From this analysis we can conclude several things. First, there is a systematic difference in the age of participants in the two survey neighborhoods. Those active in all types of participation in the Black survey neighborhood tend to be older than their counterparts in the White survey neighborhood, though there is a slight tendency for group partici- 
pants in the Black survey neighborhood to more closely resemble their younger White survey neighborhood counterparts. Second, while most participants in each neighborhood and for each type of participation are in the 30-55 age group predicted in the literature, there are significant numbers of older people involved in all types of participation in the Black survey neighborhood in spite of the fact that the population profile of the area shows it to have an age structure more heavily skewed toward the younger age groups than is the case of the White survey

neighborhood population. 102 The White survey neighborhood, with its older population, has significant numbers of younger people involved in all types of participatory activity, and far fewer of its older residents actively involved. Finally, participation is strongly associated with age only in the Black survey neighborhood, and primarily in the case of electoral participation. The association between age and participation in the White survey neighborhood shows little strength, and can be disregarded.

\section{Participation and Sex}

Interviewers were asked to record the sex of each respondent on the last page of the questionnaire. (See Appendix E). This allows us to determine both how strongly sex is associated with our three measures of participation, and whether systematic differences in the sex of active participants exist between the two survey neighborhoods. TABLES VI and VII allow us to examine these relationships.

The literature suggests that males are more politically active than females. Thus, we can reasonably expect a higher proportion of males to be highly active in the three types of participatory activity than 


\section{TABLE VI}

RELATIONSHIPS BETWEEN SEX AND ELECTORAL, ISSUE, AND GROUP PARTICIPATION IN INDIVIDUAL AND COMBINED SURVEY NEIGHBORHOODS (EXPRESSED IN PERCENT)

\section{BLACK NEIGHBORHOOD}

Sex

ELECTORAL

PARTICIPATION

Low

Medium

High

ISSUE

PARTICIPATION

Low

Medium

High

GROUP

PARTICIPATION
Low
Medium
High

$\mathrm{N}=82$

$\begin{array}{rr}43.9 & 22.0 \\ 14.6 & 7.3 \\ 7.3 & 4.9 \\ & \\ N=82\end{array}$

$15.9 \quad 3.7$

$18.3 \quad 15.9$

\section{WIITE NEIGHBORHOOD}

Female Male

$\begin{array}{rr}17.6 & 15.1 \\ 22.7 & 27.7 \\ 9.2 & 7.6\end{array}$

$\mathrm{N}=82$

$$
\text { Sex }
$$

$\mathrm{N}=119$

31.1

$10.9 \quad 16.0$

$7.6 \quad 10.1$

$\mathrm{N}=119$

$12.4 \quad 12.4$

$7.5 \quad 8.0$

$\mathrm{N}=201$
$33.6 \quad 31.1$
$3.4 \quad 8.4$
$12.6 \quad 10.9$
$N=119$

\section{COMBINED NEIGHBORHOODS}

Sex

Female Male

$\begin{array}{rr}20.9 & 11.9 \\ 24.4 & 22.9 \\ 10.9 & 9.0 \\ & N=201\end{array}$

$\begin{array}{rr}32.8 & 24.4 \\ 8.5 & 6.5 \\ 14.9 & 12.9\end{array}$

$\mathrm{N}=201$ 


\section{TABLE VII}

SIGNIFICANCE OF THE RELATIONSHIPS BETWEEN SEX AND ELECTORAL, ISSUE, AND GROUP PARTICIPATION IN INDIVIDUAL AND COMBINED SURVEY NEIGHBORHOODS

ELECTORAL PARTICIPATION

AND SEX

Chi Square:

B1k. $=2.895$ Signif, $=.235$ d.f. $=2$

Wht. $=1.022$ Signif. $=.600$ d.f. $=2$

Comb. $=2.330$ Signif. $=.312$ d.f. $=2$
Tau c:

$$
\begin{aligned}
& \text { B1k. }=+.190 \\
& \text { Wht. }=+.022 \\
& \text { Comb. }=+.085
\end{aligned}
$$

Gamma :

B1k. $=+.319$

Wht. $=+.036$

Comb. $=+.136$

ISSUE PARTICIPATION

AND SEX

Chi Square:

B1k. $=.174$ Signif. $=.917$ d.f. $=2$

Wht. $=2.515$ Signif. $=.284$ d.f. $=2$

Comb. $=2.596$ Signif. $=.273$ d.f. $=2$
Tau c:

$$
\begin{aligned}
& \text { B1k. }=+.029 \\
& \text { Wht. }=+.140 \\
& \text { Comb. }=+.113
\end{aligned}
$$

Gamma :

$$
\text { B1k. }=+.062
$$

Wht. $=+.234$

Comb. $=+.201$

GROUP PARTICIPATION

AND SEX

Chi Square:

Blk. $=3.676$ Signif. $=.159$ d.f. $=2$

Wht. $=2.823$ Signif. $=.244$ d.f. $=2$

Comb. $=.226$ Signif. $=.893$ d.f. $=2$
Tau c:

B1k. $=+.121$

Wht. $=+.033$

Comb. $=+.030$
Gamma :

B1k. $=+.211$

Wht. $=+.065$

Comb. $=+.056$ 
females. An examination of TABLE VII shows this to be the case. However, none of the relationships among the three types of participation and sex are either statistically significant or very strong for either survey neighborhood. Thus, sex of the respondents adds very little to our understanding of participation in these neighborhoods, except that rates of participation for males in both neighborhoods is higher than for females.

The interpretation of the crosstabulations in TABLE VI must be made carefully. At first glance, they seem to run counter to the conclusions drawn above. It is true that there are more women in the high and moderate participation categories than men in the Black survey neighborhood. This reflects the fact that there are substantially fewer male respondents than female in the Black survey neighborhood sample. The percentage of women who are highly or moderately active is lower than the percentage of men who are highly or moderately active. This same caution applies in the case of the White survey neighborhood, where the balance of male/female respondents is nearly equal, and in the combined neighborhood, where female respondents are again in the majority.

\section{Participation and Socio-economic Status}

As indicated in Chapter V, the research design was intended to control for the effects of socio-economic status by holding it constant. Two closely matched low-income neighborhoods were selected for this purpose. Even so, a perfect match is not possible, and some variation in such critical areas as income, education, and occupation might reasonably be expected within each survey neighborhood. An index of socio-economic status was included in the questionnaire to allow an 
examination of the effects of this variation within each of the matched neighborhoods.

Each respondent was asked questions about his or her level of education and the level of education of the main wage earner of the household if different. (Refer to questions 52 and 53 in Appendix E). Respondents were also asked to Indicate their level of household income during the past year. (Refer to question 55 in Appendix E). They were also asked to identify the specific occupation or type of work engaged in by the main wage earner of the household. (Refer to question 51 in Appendix E). The occupation specified was coded with an occupational prestige score developed and used in the National Opinion Research Center's annual social survey. 103 A composite index of socio-economic status was then calculated using these three measures. The score for each measure was standardized by dividing the score by the number of categories which comprised the measure. This standardized score for each of the three measures were then summed for all cases for which there were no missing observations to produce the composite index. ${ }^{104}$ The categories of the composite index were then collapsed for ease of analysis into high, medium and low categories. Caution must be exercised in interpreting this index. The three categories of the index of socio-economic status indicate degrees of variation within low socioeconomic neighborhoods. Thus, respondents who score in the high category in this sample would not necessarily (and probably would not) fall into a similar category if they were included in a sample drawn to represent a cross-section of the general population.

With this caution in mind, we can turn to examine the relationships between socio-economic status and participation. These relationships 
are summarized in TABLES VIII and IX. These two tables suggest two important conclusions. First, there is not as much variation in socioeconomic status within the Black survey neighborhood as there is within the White survey neighborhood. Second, what variation there is in the Black survey neighborhood is neither strongly nor statistically significantly associated with any of the three types of participation. We do find a moderately strong and statistically significant relationship between socio-economic status and all three types of participation in the White survey neighborhood. White participants are more likely to be highly active in each of the three types of participatory activities if their socio-economic status is higher relative to that of their neighbors. Thus, we cannot refect the proposition supported in the literature that SES is the most significant factor associated with participation in the case of our White survey neighborhood. We do, have some basis to seriously question this assertion in the case of our Black survey neighborhood.

\section{SUMMARY}

In examining three types of participation in both Black and White survey neighborhoods, we find that participation levels overall are higher than might be predicted by those who have studied electoral behavior. Participation levels are as high or higher for respondents in the Black survey neighborhood than for their white survey neighborhood counterparts, with the exception of participation in neighborhood issues. Black participation in neighborhood issues is significantly lower, suggesting participation may be less a means than an end in itself 


\section{TABLE VIII}

RELATIONSHIPS BETWEEN SOCIO-ECONOMIC STATUS AND ELECTORAL, ISSUE, AND GROUP PARTICIPATION IN INDIVIDUAL AND CONBINED SURVEY NEIGHBORHOODS (EXPRESSED IN PERCENT)

ELECTORAL

PARTICIPATION

Low

Mediurn

High

ISSUE

PARTICIPATION

Low
Medium
High

High

GROUP

PARTICIPATION

Low
Medium
High

$$
\begin{array}{crc}
42.6 & 16.7 & 0.0 \\
14.8 & 9.3 & 1.9 \\
11.1 & 3.7 & 0.0 \\
\mathrm{~N}=54 & \text { Missing }=28
\end{array}
$$

BLACK NEIGHBORHOOD

Socio-Economic Status

\section{WHITE NEIGHBORHOOD}

$$
\begin{gathered}
\text { Socio-Economic } \\
\text { Status }
\end{gathered}
$$

Low Med. High

$\begin{array}{lll}16.7 & 5.6 & 0.0\end{array}$

$29.6 \quad 18.5 \quad 0.0$

$\begin{array}{lll}22.2 & 5.6 & 1.9\end{array}$

$\mathrm{N}=54$ Missing $=28$

$\begin{array}{rrl}\text { Low } & \text { Med. } & \text { High } \\ 24.3 & 6.8 & 1.0 \\ 24.3 & 24.3 & 2.9 \\ 6.8 & 6.8 & 2.9 \\ N=103 & \text { Missing }=16\end{array}$

$\begin{array}{rrr}36.9 & 17.5 & 2.9 \\ 16.5 & 7.8 & 1.0 \\ 1.9 & 12.6 & 2.9\end{array}$$$
\mathrm{N}=103 \text { Missing }=16
$$

COMBINED NEIGHBORHOODS

$$
\begin{aligned}
& \text { Socio-Economic } \\
& \text { Status } \\
& \text { Low Med. High } \\
& \begin{array}{lll}
21.7 & 6.4 & 0.6
\end{array} \\
& \begin{array}{lll}
26.1 & 22.3 & 1.9
\end{array} \\
& \begin{array}{lll}
12.1 & 6.4 & 2.5
\end{array} \\
& \mathrm{~N}=157 \text { Missing }=44
\end{aligned}
$$

$\begin{array}{rrr}38.9 & 17.2 & 1.9 \\ 15.9 & 8.3 & 1.3 \\ 5.1 & 9.6 & 1.9\end{array}$

$\mathrm{N}=157$ Missing $=44$

$$
\begin{array}{rrr}
24.1 & 13.0 & 0.0 \\
16.7 & 3.7 & 0.0 \\
27.8 & 13.0 & 1.9 \\
N=54 & \text { Missing }=28
\end{array}
$$

$$
\begin{array}{rrr}
43.7 & 18.4 & 4.9 \\
6.8 & 4.9 & 0.0 \\
4.9 & 14.6 & 1.9
\end{array}
$$

$\mathrm{N}=103$ Missing $=16$

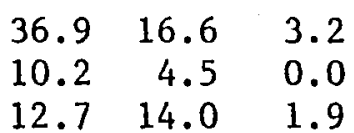

$\mathrm{N}=157$ Missing $=44$ 
SIGNIFICANCE OF THE RELATIONSHIPS BETWEEN SOCIO-ECONOMIC STATUS AND ELECTORAL, ISSUE, AND GROUP PARTICIPATION IN INDIVIDUAL AND COMBINED SURVEY NEIGHBORHOODS

ELECTORAL PARTICIPATION

AND SOCIO-ECONOMIC STATUS

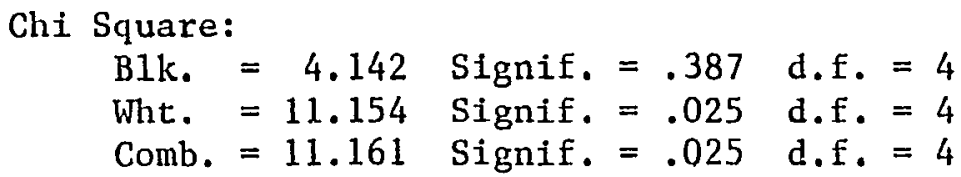

ISSUE PARTICIPATION

AND SOCIO-ECONOMIC STATUS
Tau b:

B1k. $=-.001$

Wht. $=+.266$

Comb. $=+.157$
Gamma :

B1k. $=-.002$

Wht. $=+.446$

Comb. $=+.273$

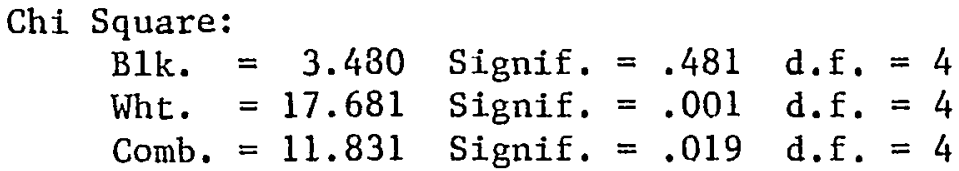

GROUP PARTICIPATION

AND SOCIO-ECONOMIC STATUS

Chi Square:

Blk. $=2.391$ Signif. $=.664$ d.f. $=4$
Wht. $=13.801$ Signif. $=.008$ d.f. $=4$
Comb. $=7.470$ Signif. $=.113$ d.f. $=4$

Tau b:

$$
\begin{aligned}
& \text { B1k. }=+.017 \\
& \text { Wht. }=+.270 \\
& \text { Comb. }=+.142
\end{aligned}
$$

Gamma :

$$
\begin{aligned}
& \text { Blk. }=+.032 \\
& \text { Wht. }=+.474 \\
& \text { Comb. }=+.254
\end{aligned}
$$


for participants in this neighborhood. The data also suggests successful mobilization and politicization of both blacks and whites in lowincome neighborhoods--especially in the case of neighborhood group participation.

Winile respondents in the Black survey neighborhood are less likely to participate in neighborhood issues, those who do are likely to be the same individuals who are highly active electorally. There are almost no high issue actives in the Black survey neighborhood who are not also highly active electorally. White survey respondents, on the other hand, are both more significantly involved in neighborhood issues, and appear somewhat more specialized in their participatory activity. A significantly smaller percentage of White survey neighborhood respondents who are highly active in neighborhood issues are also high electoral actives. This specialization becomes more pronounced for both Black and White survey respondents in the case of neighborhood group participation. Substantial numbers of neighborhood group participants in both neighborhoods are not also highly active electoral participants. Further, there is a higher percentage of $\mathrm{Black}$ survey neighborhood respondents than White who are highly active in neighborhood groups but not also highly active in neighborhood issues. This lends some support to the proposition that the Black survey neighborhood respondents may value group participation more as an end than as a means to achieve other ends. Participants in the Wnite survey neighborhood tend to be younger than their Black counterparts, though most participants tend to be in the predicted middle age range in both neighborhoods. This is in spite of an age structure skewed toward the older end of the range in the White survey neighborhood and skewed toward the younger end of the range 
in the Black survey neighborhood. In both neighborhoods, the percentage of males who participate is higher than the percentage of females who participate, though this does not seem to be a significant factor. Variations in socio-economic status are both more pronounced and strongly associated with participation in the White survey neighborhood. Socioeconomic status variation within the Black survey nelghborhood appears to have little impact on participatory behavior.

We have demonstrated, then, that for the three types of participation examined in this study, systematic differences do exist between Black and White survey neighborhoods. We have also found that to some extent, different individuals are involved in the most highly active categories of each type of participatory activity. Finally, we have found that the traditional variables used to explain political behavior-age, sex, and socio-economic status--are only partially useful for this purpose in the case of these two low-income neighborhoods. With these benchmarks as a beginning point, it is now appropriate to begin to investigate those other variables suggested by both the citizen participation literature and its assumptions, and by the socialpsychological model of political behavior. Perhaps these variables lead to a better understanding of the differences and similarities encountered thusfar in our examination of participation in black and white low-income neighborhoods. 
FOOTNOTES

${ }^{93}$ See Julian I. Woodward, and Elmo Roper, "Political Activity of American Citizens", American Political Science Review, XLIV (December, 1950), pp. 872-885; and Lester W. Milbrath, Political Participation: How and Why Do People Get Involved in Politics?, lst. ed., (Chicago: Rand McNally, 1965), pp. 155-156.

${ }^{94}$ Those who scored $0-2$ points were considered low level participants. Those who scored 3-5 points were considered medium level participants. High level participants were those who scored $6-9$ points.

${ }^{95}$ Previous research has suggested that people tend to become involved in a single issue, rather than a great number of issues. The data in this study generally confirm those findings, but there were several respondents who reported being involved in as many as four issues. For this reason, the index was expanded to include the higher level of issue activity represented by these respondents.

${ }^{96}$ Verba and Nie, op. cit., pp. 25-43.

${ }^{97}$ The White survey neighborhood respondents were no less politicized, they simply manifest their politicization in more issue or problem oriented ways--notably by participation in neighborhood issues and neighborhood groups.

98 Both the Spearman and Kendall Rank Order Correlation Coefficients require the use of rankings rather than the absolute value of variables. Both are appropriate for use with ordinal level data. The chief difference between them is that the Kendall coefficients are slightly more meaningful when there are a large number of tied ranks, and when a fairly large number of cases are classified into a small number of categories. In general, the absolute value of the Kendall coefficient (which ranges from +1.0 to -1.0 as does the Spearman coefficient) tends to be smaller than Spearman coefficient. For a discussion of these two statistical measures, see Norman H. Nie, et a1., SPSS: Statistica1 Package for the Socia1 Sciences, (2nd. ed., New York: McGraw-Hi11, 1975), pp. 288-289. See also Blalock, op. cit., pp. 416-421.

${ }^{99}$ Nie, et a1. , op. cit., pp. 228-229.

100 Milbrath and Goe1, op. cit., pp. 114-116. 
${ }^{101}$ It is customary in the social sciences to use a level of statistical. significance of .05 . (The significance level refers to the probability of rejecting a set of assumptions when they are in fact true. A.05 level of significance would mean there are five chances in one hundred that a true assumption will be rejected). This level of significance will be the one used in this study. However, because of the exploratory nature of this study, a .10 level of significance (while not reported significant in the text) may be considered by the reader to be a reasonable level of statistical significance.

102 The skewed nature of the two neighborhood sample populations can be clearly seen in Appendix A, TABLE LIV.

103 National Data Program for the Social Sciences, Codebook for the Spring 1972 General Social Survey, (Chicago: National Opinion Research Center, University of Chicago, July 1972), pp. 87-99 and 105-106.

104 Many respondents refused to answer the question related to household income. Because of this missing observation, their position on the index of socio-economic status could not be calculated. 
CHAPTER VII

\section{PARTICIPATION AND THE PERCEPTION \\ OF NEIGHBORHOOD PROBLEMS}

\section{INTRODUCTION}

The citizen participation literature suggests that residents of local communities or neighborhoods have some special insight into the problems they face in their particular environment--both in terms of what those problems are, and what the causes and solutions might be as well. The social-psychological model of political behavior discussed in Chapter IV points to perception of neighborhood problems (stimuli in the environment) as an important element in the calculus of participatory behavior. Accordingly, the major portion of the research undertaken was concerned with the questions of how different people perceive common or similar problems in their neighborhoods, and how these perceptions relate to their participation in elections, issues and neighborhood groups.

It is important at the outset to be very clear about what is and is not intended in this examination of problem perception and participation. What clearly is not intended is an examination of the accuracy of individual's perceptions and the relationship of accurate vs inaccurate perception to behavior. Given the highly subjective and individually unique nature of perception, this would surely be an impossible task. What is being examined, however, is whether individuals perceive a problem, and if so, do they perceive the problem differently than their neighbors do. Regardless of how individuals personally define a problem, the fact that 
they perceive a problem, and perceive it differently than their neighbors, should be related to the behavioral actions they take. In attempting to uncover differences in perception of common or similar problems among residents of the two survey neighborhoods, our interest is in the ways in which they perceive the broad dimensions of those problems they identify. For example, do they perceive the problems as personal or social problems? Are they seen as local or national problems? Are they defined as nonpolitical or political problems? Again, the point is not that they perceive these dimensions of the problems they identify accurately, but that they perceive the various dimensions of problems in some ways and not others.

\section{PROBLEM CATEGORIES}

The identification and selection of problem categories about which to question respondents in the study was a subjective perceptual task for the researcher as well as for the respondents. Different backgrounds and experience sets made this portion potentially risky with respect to bias built into the research design, and thus the ultimate validity of the specific problem areas or categories used in the study might easily be jeopardized. In order to make the choice, two basic assumptions were first made to provide some guidance. First, it was assumed that U.S. Census statistics and other available survey data would provide sound "objective" data upon which a preliminary identification of problems in the two neighborhoods could be based. (For example, significantly higher rates of unemployment, crime, substandard housing, etc., than for the city as a whole.) second, it was assumed that the broad problem categories initially selected for examination would be the same for both 
neighborhoods, since the close matching of the two survey neighborhoods was intended to produce survey neighborhoods as nearly identical as possible. Thus, they should exhibit yery similar problems.

Armed with some preliminary idea of the problem categories which might be of value in the study, the choice was both verified and refined through discussion with the program staff of the relevant OEO and Model Cities agencies in each neighborhood, and through the results of a previously conducted comunity survey which had attempted to define the problems of poverty.

In 1969, as part of their program planning for the following year, OEO Community Action Programs operating in each survey neighborhood had engaged in what was known as a "Bottom Up" planning process. 105 This consisted of a series of "town hall" type meetings held in each neighborhood which were designed to identify those factors which residents believed to be the causes of poverty. From this series of neighborhood meetings emerged a rather lengthy list of problems and causes which was compiled in a ballot. A general commity meeting was then held, and residents were asked to rank the ten most significant items on the ballot. The results of this balloting produced problem groupings very similar to those which had been initially identified for possible use in the study. With this supporting evidence from the neighborhood residents, five problem categories were selected for use in the study. They are: (1) housing; (2) education; (3) employment; (4) crime and delinquency; and (5) police-commity relations. Further support for the use of these problem categories can be found in the Kerner Commission report on the causes of the domestic violence which erupted in the late 1960's. The 
Kerner Commission identified nearly identical problem categories in their explanation of the factors which led to ghetto disburbances. 106

MEASURING PROBLEM PERCEPTION

\section{Problem Perception: Identification of Problems}

Respondents in each neighborhood were read a statement as part of the interview questionnaire. The statement indicated that over the years, a number of problems had been said to exist in their neighborhood, and they would be asked some questions about how they saw their neighborhood and its problems. Following the statement, a series of questions were then asked about each of the five problem categories in turn. These questions first described a broad-ranging set of examples of what might be considered a problem in each specific category. After describing the range of what might possibly be defined as a problem in the category, the question then asked whether they thought any of those kinds of things were a problem in their neighborhood. If they responded affirmatively, they were considered to have perceived and identified a problem in that category--regardless of how they might have defined the problem specifically. It is the set of yes or no answers to this question about each problem category which forms the index of problem identification used in the study. Respondents scored one point for each "yes" answer, and zero points for each "no" answer. Thus, the ordinal index has values which range from zero to five points. The index was later collapsed into 1ow, medium, and high categories for ease of analysis. (The specific questions which make up this index are numbers $18,24,30,36$ and 42 in Appendix E.) 
Problem Perception: Dimensions of Identified Problems

For each problem category for which a problem was identified by the respondent, a series of follow-up questions were asked about how they perceived the dimensions of those problems. They were asked to select one of four Likert Scale type choices for each of the following questions:

1. Some say these ... are personal problems that should be handled by the individual. Others say they are social problems that should be handled by government. If you had to choose one of four possibilities, would you say these ... problems are: ...?

2. Some people say these ... problems are local problems. Others say they are national problems. If you had to choose one of four possibilities, would you say these ... problems are: ...?

3. Some people say these ... problems are not a political matter or responsibility. Others say they are a political matter or responsibility. If you had to choose one of four possibilities, would you say these ... problems are: ...?

(Refer to questions $19-21,25-27,31-33,37-39$, and 43-45 in Appendix E for the specific questions which make up each index subsequently created.)

Each of the questions above were designed to measure the range of perception along a particular dimension. The first dimension is the personal vs social nature of a given problem. The second measures perception of a local vs national problem dimension. The final question measures perception of a non-political vs political dimension of neighborhood problems.

By calculating the average score based on the number of problem categories for which a problem was identified and these questions were answered (the questions were not asked in those cases where a problem was not identified in any specific category) three separate composite 
measures were created. The first, which is an index measuring the personal vs social dimension, has four categories representing the range of perception along this dimension of problems: (1) personal problems; (2) both, but more personal; (3) both, but more social; and (4) social problems. The second composite index measures the local vs national dimensions and has the following similar categories: (1) local problems; (2) both, but more local; (3) both, but more national; and (4) national problems. The final composite measure measures the range of perception of the non-political vs political nature of problems, and has the following categories: (1) non-political problems; (2) both, but more nonpolitical; (3) both, but more political; and (4) political problems.

\section{Problem Perception: Efficacy in Solving Identified Problems}

For each problem category for which a respondent perceived or identified a problem, further questions were asked to determine how effective the respondent thought he or she was in doing anything to solve that problem. Feelings of efficacy have been identified as important factors associated with political behavior in several studies. Such feelings are also suggested by the social-psychological model of political behavior to be important elements. However, most studies which examine feeling of efficacy and their relationship to political behavior do so only in a very generalized sense. ${ }^{107}$ They focus on general feelings of personal efficacy rather than relating feelings of efficacy to a specific problem or set of problems. It may well be that feelings of efficacy vary from the general to the specific, and they may also vary from one specific problem to another. For these reasons, the measures 
of efficacy used in this study are related directly to the specific neighborhood problems identified by each respondent in the study.

For each problem category in which a problem was identified, respondents were asked two questions about how effective they felt they were in doing anything about those problems:

1. Are these ... problems the kinds of things you feel you can personally do something about as an individual?

2. Are these ... problems the kinds of things you feel you could do something about as part of a group of concerned neighbors working together?

The first question was designed to measure feeling of personal efficacy. The second question was designed to measure group efficacy, or the increased feeling of efficacy which may result from collective action of the type advocated in the federal mandate. (Refer to questions 22, 23, $28,29,34,35,40,41,46$ and 47 in Appendix $E$ for the specific questions used to construct the measures of personal and group efficacy.)

A composite index measuring feelings of personal efficacy and a similar index measuring feelings of group efficacy was created by calculating the average score for the number of times each question was asked and answered in the affirmative. Respondents scored one point for a "yes" answer, and zero points for a "no" answer. Each resulting index ranged from zero to five points, and was subsequently collapsed into low, medium, and high categories for ease of analysis.

\section{Problem Perception: Salience of Identified Problems}

A number of studies have suggested that the salience of issues (in most cases political campaign issues) to the Individual are important elements motivating political behavior. ${ }^{108}$ The social-psychological 
model of behavior used in this study also suggests that the relevance and importance of stimuli (neighborhood problems) to the individual and his needs is an important factor in the decision to participate. Thus, it was decided that a measure of the salience of identified neighborhood problems might be especially useful in refining an understanding of the relationships between problem perception and participation.

To measure the salience of the various problem categories for respondents in the survey, each of the individuals interviewed was given a set of five cards. Each card indicated one of the problem areas which had been covered in the previous sections of the interview. (Interviewers were instructed to offer to read the cards for the respondents if it appeared they were having difficulty understanding what was written on them.) The respondents were asked to select the three cards which indicated problem areas most important to them. They were then asked to rank order the three cards in terms of their importance. The three problem categories and their rank order were recorded by the interviewer. (Refer to question 48 in Appendix E.)

With a rank ordering of problem categories, and a record of the responses to the set of questions related to problem identification, it is possible to create an index for each of the problem categories which allows a much more detailed examination of the perception and identification or problems than is possible with the composite index of problem identification discussed earlier. For each problem category index, respondents can be placed into one of four categories. These possible categories are indicated in Figure 1 below. 


$$
\begin{gathered}
\text { Salience of Problem Category } \\
\text { Low }
\end{gathered}
$$

Identification

of

Problems

$\begin{array}{ccc}\text { No } & 1 & 2 \\ \text { Yes } & 3 & 4\end{array}$

Figure 1. Possible response categories for a combined measure of problem identification and problem salience.

While the categories of these measures are nominal in the strict sense of the word, it is reasonable to assume some order in the way in which the categories relate to participation. In the case of the two extreme categories ( 1 and 4 ), the order is readily seen. Those who perceive no problems in a problem area which is of low salience should be less likely to participate than those who perceive a salient problem. The two mixed categories present something of a problem, however. Are people more likely to act if they perceive no immediate problem in an area which is salient for them (for example to prevent a problem from arising in the future), or are they more likely to act on a perceived problem which is of low salience? The social-psychological model of political behavior would suggest that the perception of a problem is the primary ingredient, with the salience of that perceived problem an important, but secondary consideration. It could also be argued, however, that the salience of a potential problem area could lead the individual to more readily identify a problem than he or she might if the problem area was less salient. It was decided that the key to order is problem identification, rather than problem area salience, for purposes of this study. Accordingly, an index was created which measures 
both the identification, and salience of problems in each problem area used in the study. Each index is assumed to be ordinal in nature, with the order as indicated in Figure 1.

\section{PARTICIPATION AND THE PERCEPTION \\ OF PROBLEMS}

Participation and the Identification of Problems

One of the "guiding hypotheses" in Chapter IV was that people who identify problems in their neighborhoods are more likely to participate than those who do not. In order to test that proposition, the composite index of problem identification discussed in the previous section was crosstabulated with each of the measures of participation for each survey neighborhood sample. These crosstabulations and their related statistics are summarized in TABLES $\mathrm{X}$ and $\mathrm{XI}$.

An examination of TABLE $X$ shows the hypothesized relationship to be the case. Those who score highest on the index of problem identification also tend to score the highest on all three measures of participation. This is especially evident in the case of group participation in both neighborhoods.

An examination of TABLE XI allows some conclusions to be made about the strength and statistical significance of the observed relationships. First, the relationship is not statistically significant for electoral participation according to the Chi Square statistic for any of the neighborhoods. However, it is possible to calculate the significance of the Tau b statistic (it is primarily for this reason that the Tau $b$ and Tau c statistics are reported in the tables) even though these 
TABLE $X$

RELATIONSHIPS BETWEEN PROBLEM IDENTIFICATION AND ELECTORAL, ISSUE, AND GROUP PARTICIPATION FOR INDIVIDUAL AND COMBINED SURVEY NEIGHBORHOODS (EXPRESSED IN PERCENT)

\section{BLACK NEIGHBORHOOD}

Problem

Identification

ELECTORAL

PARTICIPATION

Low

High

ISSUE

PARTICIPATION

Low
Medium
High

High

GROUP

PARTICIPATION

Low
Medium
High

\section{WHITE NEIGHBORHOOD}

Problem

Identification

\begin{tabular}{rrr} 
Low & Med. & High \\
7.6 & 9.2 & 16.0 \\
6.7 & 16.8 & 26.9 \\
0.0 & 3.4 & 13.4 \\
\multirow{3}{*}{$N=119$}
\end{tabular}

$11.9 \quad 16.4 \quad 31.3$

$2.5 \quad 6.0 \quad 16.4$

$\begin{array}{lll}0.0 & 1.5 & 13.9\end{array}$

$\mathrm{N}=119$

$\mathrm{N}=201$

COMBINED NEIGHBORHOODS

Identification

Low Med. High

$\begin{array}{lll}6.5 & 8.5 & 17.9\end{array}$

$\begin{array}{lll}7.5 & 11.9 & 27.9\end{array}$

$\begin{array}{lrr}0.5 & 3.5 & 15.9\end{array}$

$\mathrm{N}=201$
$\begin{array}{lll}9.8 & 7.3 & 29.3\end{array}$
$\begin{array}{lll}3.7 & 3.7 & 12.2\end{array}$
$\begin{array}{lll}1.2 & 4.9 & 28.0\end{array}$
$\mathrm{N}=82$
$\begin{array}{lll}11.8 & 25.2 & 27.7\end{array}$
$\begin{array}{lll}1.7 & 1.7 & 8.4\end{array}$
$\begin{array}{lll}0.8 & 2.5 & 20.2\end{array}$
$\mathrm{N}=119$
$\begin{array}{lll}10.9 & 17.9 & 28.4\end{array}$
$\begin{array}{lll}2.5 & 2.5 & 10.0\end{array}$
$\begin{array}{lll}1.0 & 3.5 & 23.4\end{array}$
$\mathrm{N}=201$




\section{TABLE XI}

SIGNIFICANCE OF RELATIONSHIPS BETWEEN PROBLEM IDENTIFICATION AND ELECTORAL, ISSUE AND GROUP PARTICIPATION FOR INDIVIDUAL AND COMBINED SURVEY NEIGHBORHOODS

ELECTORAL PARTICIPATION

AND PROBLEM IDENTIFICATION

Chi Square:

$\begin{array}{lll}\text { B1k. }=3.577 & \text { Signif. }=.466 & \text { d.f. }=4 \\ \text { Wht. }=8.423 & \text { Signif. }=.077 & \text { d.f. }=4 \\ \text { Comb. }=9.028 & \text { Signif. }=.060 & \text { d.f. }=4\end{array}$

ISSUE PARTICIPATION

AND PROBLEM IDENTIFICATION

Chi Square:

$\begin{array}{lll}\text { Blk. }=5.771 & \text { Signif. }=.217 & \text { d.f. }=4 \\ \text { Wht. }=14.665 & \text { Signif. }=.005 & \text { d.f. }=4 \\ \text { Comb. }=16.925 & \text { Signif. }=.002 & \text { d.f. }=4\end{array}$

GROUP PARTICIPATION

AND PROBLEM IDENTIFICATION

Chi Square:

Blk. $=4.701$ Signif. $=.319$ d.f. $=4$
$=17.216$ Signif. $=.002$ d.f. $=4$

Wht. $=17.216$ Signif. $=.002$ d.f. $=4$

Comb. $=20.137$ Signif. $=.001$ d.f. $=4$
Tau b:

B1k. $=+.119$
Wht. $=+.198$
Comb. $=+.166$

Tau b:

Blk. $=+.177$

Wht. $=+.319$

Comb. $=+.253$

Gamma :

Blk. $=+.389$

Wht. $=+.555$

Comb. $=+.479$
Tau b:

Blk. $=+.179$

Wht. $=+.331$

Comb. $=+.278$
Gamma :

B1k. $=+.324$

Wht. $=+.616$

Comb. $=+.506$ 
significance levels are not indicated in the tables. ${ }^{109}$ The Tau b indicates a statistically significant linear relationship between problem identification and all three measures of participation in the case of the White and combined survey neighborhoods. The Chi Square statistic also shows a significant relationship in the case of both issue and group participation for these neighborhoods. While none of the Chi Square statistics are significant for the Black survey neighborhood, the Tau b is statistically significant for both issue and group participation. Second, there are important differences in the strength of the observed relationships. Both the Tau b and the Gamma show the relationships to be quite strong for both the White and combined survey neighborhood respondents. While these relationships are moderately strong in the case of the Black survey neighborhood, they are considerably weaker than those found in the other two survey neighborhoods. The identification of problems is a weaker predictor of political participation in the Black survey neighborhood than the White. This appears to be true for all these types of participation.

Thirdly, the relationships noted are weakest in the association of problem identification and electoral participation, becoming much stronger for issue and group participation. This is as it should be, since electoral activity is only rarely directly focused on problems. Elections are a very indirect means of problen solving under the best circumstances. We have found, then, that the identification of neighborhood problems is both strongly and significantly related to participation. This is especially true in the White survey neighborhood, and especially true for the non-traditional modes of participation represented by the issue 
and group participation measures. The same general relationships are found in the Black survey neighborhood, but they are considerably weaker and less significant, suggesting that participation is less motivated by its potential efficacy in solving problems for participants in that neighborhood.

\section{Participation and the Salience of Identified Problems}

The results of the examination of overall problem identification and participation detailed just above, suggest that the relationships to be found between each of the individual measures of problem salience and participation are similar, and perhaps more pronounced. What we find, however, is a case where the whole seems to be greater than the sum of its individual parts. In retrospect, this should not be terribly surprising. A single perceived problem, taken alone, appears less likely to prompt high levels of political activity on a sustained basis, even if it is salient, than the perception that a number of salient problems exist in the neighborhood.

Nonetheless, we can see in TABLES XII through XXI the same generaI pattern of relationships observed in the case of the composite measure of problem identification. People who perceive a given salient problem are more likely to participate than those who do not perceive a salient problem. These relationships are not as strong as those observed in the case of overall problem identification, since each individual problem salience measure contributes less to participation than when combined with others in the context of the neighborhood, but the same general pattern is still clearly evident. 
TABLE XII

RELATIONSHIPS BETWEEN THE IDENTIFICATION OF SALIENT HOUSING PROBLEMS AND ELECTORAL, ISSUE, AND GROUP PARTICIPATION IN INDIVIDUAL AND COMBINED SURVEY NEIGHBORHOODS (EXPRESSED IN PERCENT)

\section{BLACK NEIGHBORHOOD}

Ident. of Problems

Salient Housing

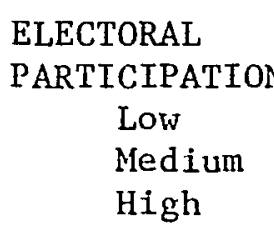

ISSUE

PARTICIPATION

Low

High

GROUP

PARTICIPATION

Low

Medium

High

$$
\begin{aligned}
& \underline{D 11} \quad \underline{\mathrm{D} 2^{1}} \quad \mathrm{D}^{1} \quad \underline{D 4}^{1} \\
& \begin{array}{llll}
5.4 & 0.0 & 14.9 & 10.8
\end{array} \\
& \begin{array}{llll}
6.8 & 5.4 & 21.6 & 9.5
\end{array} \\
& \begin{array}{llll}
2.7 & 0.0 & 10.8 & 12.2
\end{array} \\
& N=74 \quad \text { Missing }=8
\end{aligned}
$$$$
\begin{array}{rrrr}
14.9 & 4.1 & 32.4 & 13.5 \\
0.0 & 1.4 & 6.8 & 14.9
\end{array}
$$$$
\begin{array}{llll}
0.0 & 0.0 & 8.1 & 4.1
\end{array}
$$$$
\mathrm{N}=74 \quad \text { Missing }=8
$$

$\begin{array}{llll}9.5 & 2.7 & 21.6 & 10.8\end{array}$

$\begin{array}{llll}2.7 & 2.7 & 5.4 & 8.1\end{array}$

$\begin{array}{llll}2.7 & 0.0 & 20.3 & 13.5\end{array}$

$\mathrm{N}=74$ Missing $=8$

\section{WHITE NEIGHBORHOOD}

Ident. of Problems

Salient Housing

$$
\begin{aligned}
& \underline{\mathrm{D}^{1}} \quad \underline{\mathrm{D} 2^{1}} \quad \underline{\mathrm{D} 3^{1}} \quad \underline{\mathrm{D}} 4^{1} \\
& \begin{array}{lllll}
5.1 & 3.4 & 14.4 & 9.3
\end{array} \\
& \begin{array}{llll}
11.0 & 1.7 & 13.6 & 24.6
\end{array} \\
& \begin{array}{llll}
0.8 & 0.0 & 9.3 & 6.8
\end{array} \\
& \mathrm{~N}=118 \text { Missing }=1
\end{aligned}
$$

$\begin{array}{rrrr}11.0 & 5.1 & 20.3 & 18.6 \\ 5.1 & 0.0 & 8.5 & 13.6 \\ 0.8 & 0.0 & 8.5 & 8.5\end{array}$

$\mathrm{N}=118$ Missing $=1$

$\begin{array}{rrrr}14.4 & 4.2 & 25.4 & 20.3 \\ 1.7 & 0.8 & 3.4 & 5.9 \\ 0.8 & 0.0 & 8.5 & 14.4\end{array}$

$\mathrm{N}=118$ Missing $=1$

\section{COMBINED NEIGHBORHOODS}

Ident. of Problems

Salient Housing

$$
\begin{array}{lrrrr}
\text { D1 }^{1} & \text { D2 } & & \text { D3 } & \text { D4 } \\
5.3 & 2.1 & 14.6 & 9.9 \\
9.4 & 3.1 & 16.7 & 18.8 \\
1.6 & 0.0 & 9.9 & 8.9 \\
N= & 192 & \text { Missing }=9
\end{array}
$$

$\begin{array}{rrrr}12.5 & 4.7 & 25.0 & 16.7 \\ 3.1 & 0.5 & 7.8 & 14.1 \\ 0.5 & 0.0 & 8.3 & 6.8\end{array}$

$\mathrm{N}=192$ Missing $=9$

$\begin{array}{rrrr}12.5 & 3.6 & 24.0 & 16.7 \\ 2.1 & 1.6 & 4.2 & 6.8 \\ 1.6 & 0.0 & 13.0 & 14.1\end{array}$

$\mathrm{N}=192$ Missing $=9$

${ }^{1}$ 1 = Problem Not Identified and Low Salience; $\mathrm{D} 2=$ Problem Not Identified but High Salience; $\mathrm{D} 3=$ Problem Identified But Low Salience; D4 = Problem Identified and High Salience. 
SIGNIFICANCE OF RELATIONSHIPS BETWEEN THE IDENTIFICATION OF SALIENT HOUSING PROBLEMS AND ELECTORAL, ISSUE, AND GROUP PARTICIPATION IN INDIDIVIDUAL AND COMBINED SURVEY NEIGHBORHOODS

ELECTORAL PARTICIPATION

AND IDENTIFICATION OF SALIENT HOUSING PROBLEMS

Chi Square:

$$
\begin{array}{lll}
\text { Blk. }=8.207 & \text { Signif. }=.223 & \text { d.f. }=6 \\
\text { Wht. }=12.310 & \text { Signif. }=.055 & \text { d.f. }=6 \\
\text { Comb. }=7.835 & \text { Signif. }=.250 & \text { d.f. }=6
\end{array}
$$

Tau c:

$$
\begin{aligned}
& \text { B1k. }=+.076 \\
& \text { Wht. }=+.114 \\
& \text { Comb. }=+.096
\end{aligned}
$$

Gamma :

$$
\begin{aligned}
& \text { B1k. }=+.119 \\
& \text { Wht. }=+.184 \\
& \text { Comb. }=+.155
\end{aligned}
$$

ISSUE PARTICIPATION

AND IDENTIFICATION OF SALIENT HOUSING PROBLEMS

Chi Square:

$$
\begin{aligned}
& \text { B1k. }=15.906 \text { Signif. }=.014 \text { d.f. }=6 \\
& \text { Wht. }=9.745 \text { Signif. }=.136 \text { d.f. }=6 \\
& \text { Comb. }=18.796 \text { Signif. }=.005 \text { d.f. }=6
\end{aligned}
$$

Tau c:

$$
\begin{aligned}
& \text { B1k. }=+.280 \\
& \text { Wht. }=+.157 \\
& \text { Comb. }=+.205
\end{aligned}
$$

Gamma :

$$
\begin{aligned}
& \text { Blk. }=+.549 \\
& \text { Wht. }=+.269 \\
& \text { Comb. }=+.367
\end{aligned}
$$

\section{GROUP PARTICIPATION}

AND IDENTIFICATION OF SALIENT HOUSING PROBLEMS

Chi Square:

$$
\begin{array}{lll}
\text { B1k. }=8.201 & \text { Signif. }=.224 & \text { d.f. }=6 \\
\text { Wht. }=11.216 & \text { Signif. }=.082 & \text { d.f. }=6 \\
\text { Comb. }=16.931 & \text { Signif. }=.010 & \text { d.f. }=6
\end{array}
$$

Tau c:

Blk. $=+.168$

Wht. $=+.231$

Comb. $=+.201$
Gamma :

Blk. $=+.269$

Wht. $=+.453$

Comb. $=+.351$ 
TABLE XIV

RELATIONSHIPS BETWEEN THE IDENTIFICATION OF SALIENT EDUCATION PROBLEMS AND ELECTORAL, ISSUE, AND GROUP PARTICIPATION IN INDIVIDUAL AND COMBINED SURVEY NEIGHBORHOODS

(EXPRESSED IN PERCENT)

\section{BLACK NETGHBORHOOD}

Ident. of Salient

Education Problems

\begin{tabular}{|c|c|c|c|c|}
\hline ELECTORAL & $\mathrm{DI}^{1}$ & $\underline{\mathrm{D} 2}{ }^{1}$ & $\mathrm{D}^{1}$ & D4 \\
\hline \multicolumn{5}{|l|}{ PARTICIPATION } \\
\hline Low & 6.8 & 2.7 & 14.9 & 6.8 \\
\hline Medium & 6.8 & 6.8 & 9.5 & 20.3 \\
\hline \multirow[t]{2}{*}{ High } & 2.7 & 0.0 & 12.2 & 10.8 \\
\hline & \multicolumn{2}{|c|}{$N=74$} & Missing & $=8$ \\
\hline \multicolumn{5}{|l|}{ ISSUE } \\
\hline \multicolumn{5}{|l|}{ PARTICIPATION } \\
\hline Low & 9.5 & 9.5 & 24.3 & 21.6 \\
\hline Medium & 6.8 & 0.0 & 5.4 & 10.8 \\
\hline \multirow[t]{2}{*}{ High } & 0.0 & 0.0 & 6.8 & 5.4 \\
\hline & \multicolumn{3}{|c|}{$N=74$} & $=8$ \\
\hline \multicolumn{5}{|l|}{ GROUP } \\
\hline \multicolumn{5}{|l|}{ PARTICIPATION } \\
\hline Low & 6.8 & 8.1 & 14.9 & 14.9 \\
\hline Medium & 5.4 & 1.4 & 6.8 & 5.4 \\
\hline High & 4.1 & 0.0 & 14.9 & 17.6 \\
\hline
\end{tabular}

\section{WHITE NEIGHBORHOOD}

Ident. of Salient Education Problems

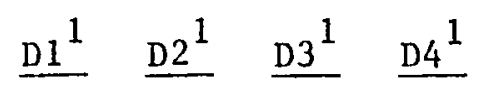

$$
\begin{array}{rrrr}
14.5 & 1.7 & 11.1 & 5.1 \\
17.9 & 5.1 & 12.0 & 15.4 \\
2.6 & 0.9 & 4.3 & 9.4
\end{array}
$$$$
\mathrm{N}=117 \text { Missing }=2
$$

$$
\begin{array}{rrrr}
24.8 & 4.3 & 16.2 & 9.4 \\
7.7 & 3.4 & 6.0 & 10.3 \\
2.6 & 0.0 & 5.1 & 10.3 \\
N=117 & \text { Missing }=2
\end{array}
$$

$$
\begin{array}{rrrr}
27.4 & 5.1 & 18.8 & 12.8 \\
3.4 & 1.7 & 2.6 & 4.3 \\
4.3 & 0.9 & 6.0 & 12.8 \\
& & & \\
N & = & 117 & \text { Missing }=2
\end{array}
$$

\section{COMBINED NEIGHBORHOODS}

$$
\begin{aligned}
& \text { Ident. of Salient } \\
& \text { Education Problems } \\
& \underline{\mathrm{D}^{1}} \quad \underline{\mathrm{D} 2^{1}} \quad \mathrm{D}^{1} \quad \mathrm{D}^{1} \\
& \begin{array}{llll}
11.5 & 2.1 & 12.6 & 5.8
\end{array} \\
& \begin{array}{llll}
13.6 & 5.8 & 11.0 & 17.3
\end{array} \\
& \begin{array}{rrrr}
2.6 & 0.5 & 7.3 & 9.9
\end{array} \\
& \mathrm{~N}=191 \quad \text { Missing }=10
\end{aligned}
$$

${ }^{1} 1$ = Problem Not Identified and Low Salience; $\mathrm{D} 2$ = Problem Not Identified But High Salience; D3 = Problem Identified But Low Salience; D4 = Problem Identified and High Salience. 


\section{TABLE XV}

SIGNIFICANCE OF RELATIONSHIPS BETWEEN THE IDENTIFICATION OF SALIENT EDUCATION PROBLEMS AND ELECTORAL, ISSUE, AND GROUP PARTICIPATION IN INDIVIDUAL AND COMBINED SURVEY NEIGHBORHOODS

ELECTORAL PARTICIPATION

AND IDENTIFICATION OF SALIENT EDUCATION PROBLEMS

Chi Square:

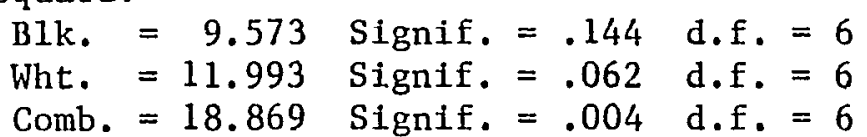

Tau c:

B1k. $=+.165$

Wht. $=+.226$

Comb. $=+.211$
Gamma :

B1k. $=+.241$

Wht. $=+.342$

Comb. $=+.310$

ISSUE PARTICIPATION

AND IDENTIFICATION OF SALIENT EDUCATION PROBLEMS

Chi Square:

$$
\begin{array}{lll}
\text { Blk. }=9.591 & \text { Signif. }=.143 & \text { d.f. }=6 \\
\text { Wht. }=17.299 & \text { Signif. }=.008 & \text { d.f. }=6 \\
\text { Comb. }=16.418 & \text { Signif. }=.012 & \text { d.f. }=6
\end{array}
$$

GROUP PARTICIPATION

AND IDENTIFICATION OF SALIENT EDUCATION PROBLEMS

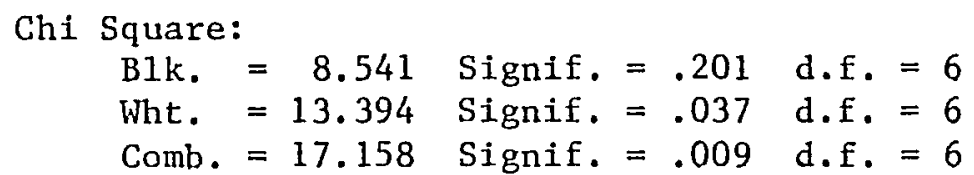

Tau c:

B1k. $=+.100$
Wht. $=+.290$

Comb. $=+.202$

Tau c:

B1k. $=+.149$

Wht. $=+.245$

Comb. $=+.231$
Gamma :

B1k. $=+.190$

Wht. $=+.445$

Comb. $=+.332$
Gamma :

B1k. $=+.225$

Wht. $=+.430$

Comb. $=+.370$ 
TABLE XVI

RELATIONSHIPS BETWEEN THE IDENTIFICATTON OF SALIENT EMPLOYMENT PROBLEMS AND ELECTORAL, ISSUE, AND GROUP PARTICIPATION IN INDIVIDUAL AND COMBINED NEIGHBORHOODS

(EXPRESSED IN PERCENT)

BLACK NEIGHBORHOOD

Ident. of Salient Employment Problems

\section{ELECTORAL \\ PARTICIPATION

Low
Medium
High

ISSUE

PARTICIPATION

Low
Medium
High

GROUP

$\begin{array}{lllrr}\text { Low } & 0.0 & 6.8 & 21.6 & 16.2 \\ \text { Medium } & 0.0 & 2.7 & 6.8 & 9.5 \\ \text { High } & 2.7 & 1.4 & 16.2 & 16.2 \\ & & & \\ & \mathrm{~N}= & 74 & \text { Missing }=8\end{array}$

$$
\begin{array}{llll}
\text { D1 } & \text { D2 } & \text { D3 } & \text { D4 } \\
1.4 & 2.7 & 10.8 & 16.2 \\
0.0 & 6.8 & 20.3 & 16.2 \\
1.4 & 1.4 & 13.5 & 9.5
\end{array}
$$

$\begin{array}{llll}0.0 & 6.8 & 20.3 & 16.2\end{array}$

$\mathrm{N}=74$ Missing $=8$

$\begin{array}{rrrr}0.0 & 9.5 & 27.0 & 28.4 \\ 2.7 & 1.4 & 9.5 & 9.5 \\ 0.0 & 0.0 & 8.1 & 4.1\end{array}$

$\mathrm{N}=74$ Missing $=8$
PARTICIPATION

$1_{D 1}=$ Problem Not Identified and Low Salience; D2 = Problem Not Identified But High Salience; D3 = Problem Identified But Low Salience; D4 = Problem Identified and High Salience.
WHITE NEIGHBORHOOD

Ident. of Salient

Employment Problems

\section{COMBINED NEIGHBORHOODS}

Ident. of Salient Employment Problems

$$
\begin{aligned}
& \underline{\mathrm{D}}^{1} \quad \underline{\mathrm{D}}^{1} \quad \underline{\mathrm{D}}^{1} \quad \underline{\mathrm{D}}^{1} \\
& \begin{array}{llll}
5.1 & 3.4 & 10.2 & 13.6
\end{array} \\
& \begin{array}{llll}
7.6 & 5.1 & 19.5 & 18.6
\end{array} \\
& \begin{array}{llll}
1.7 & 0.0 & 6.8 & 8.5
\end{array} \\
& \mathrm{~N}=118 \text { Missing }=1
\end{aligned}
$$$$
\underline{\mathrm{D} 1^{1}} \quad \underline{\mathrm{D} 2^{1}} \quad \underline{\mathrm{D} 3^{1}} \quad \underline{\mathrm{D} 4^{1}}
$$$$
\begin{array}{llll}
3.6 & 3.1 & 10.4 & 14.6
\end{array}
$$$$
\begin{array}{llll}
4.7 & 5.7 & 19.8 & 17.7
\end{array}
$$$$
\begin{array}{llll}
1.6 & 0.5 & 9.4 & 8.9
\end{array}
$$$$
\mathrm{N}=192 \text { Missing }=9
$$

$$
\begin{array}{rrrr}
11.0 & 5.9 & 17.8 & 20.3 \\
1.7 & 2.5 & 12.7 & 10.2 \\
1.7 & 0.0 & 5.9 & 10.2
\end{array}
$$$$
\begin{array}{llll}
6.8 & 7.3 & 21.4 & 23.4
\end{array}
$$$$
\begin{array}{llll}
2.1 & 2.1 & 11.5 & 9.9
\end{array}
$$

$\begin{array}{lrrr}1.0 & 0.0 & 6.8 & 7.8\end{array}$

$$
\mathrm{N}=118 \text { Missing }=1
$$

$N=192$ Missing $=9$

$$
\begin{array}{rrrr}
12.7 & 6.8 & 18.6 & 26.3 \\
0.8 & 0.8 & 7.6 & 2.5 \\
0.8 & 0.8 & 10.2 & 11.9
\end{array}
$$$$
\mathrm{N}=118 \text { Missing }=1
$$ 
SIGNIFICANCE OF RELATIONSHIPS BETWEEN THE IDENTIFICATION OF SALIENT EMPLOYMENT PROBLEMS AND ELECTORAL, ISSUE, AND GROUP PARTICIPATION IN INDIVIDUAL AND COMBINED SURVEY NEIGHBORHOODS

ELECTORAL PARTICIPATION

AND IDENTIFICATION OF SALIENT EMPLOYMENT PROBLEMS

Chi Square:

Blk. $=4.531$ Signif. $=.605$ d.f. $=6$
Wht. $=3.442$ Signif. $=.752$ d.f. $=6$
Comb. $=4.934$ Signif. $=.552$ d.f. $=6$

Comb. $=4.934$ Signif. $=.552$ d.f. $=6$

ISSUE PARTICIPATION

AND IDENTIFICATION OF SALIENT EMPLOYMENT PROBLEMS

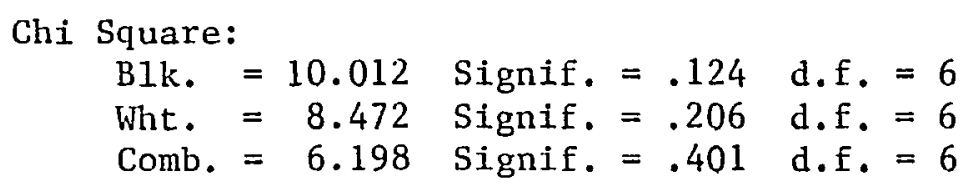

GROUP PARTICIPATION

AND IDENTIFICATION OF SALIENT EMPLOYMENT PROBLEMS

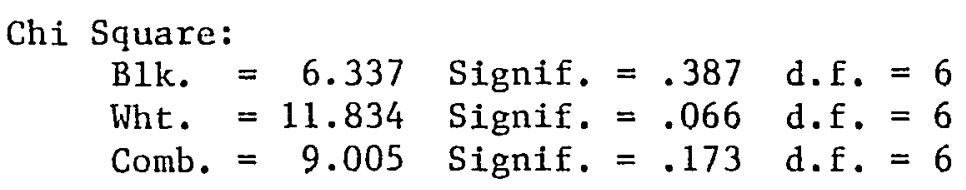

Tau c:

$$
\begin{aligned}
& \text { BIk. }=-.077 \\
& \text { Wht. }=+.055 \\
& \text { Comb. }=+.010
\end{aligned}
$$

Gamma :

Blk. $=-.128$

Wht. $=+.090$

Comb. $=+.017$
Tau c:
B1k. $=-.024$
Wht. $=+.156$
Comb. $=+.082$

Gamma :

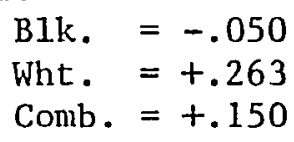

Gamma :

B1k. $=+.107$

Wht. $=+.216$

Comb. $=+.189$ 


\section{TABLE XVIII}

RELATIONSHIPS BETWEEN THE IDENTIFICATION OF SALIENT CRIME AND DELINQUENCY PROBLEMS AND ELECTORAL, ISSUE, AND GROUP PARTICIPATION IN INLIVIDUAL AND COMBINED SURVEY NEIGHBORHOODS

(EXPRESSED IN PERCENT)

BLACK NEIGHBORHOOD

Ident. of Salient Crime $\&$ Del. Problems

\begin{tabular}{|c|c|c|c|c|}
\hline ELECTORAL & $\underline{\mathrm{D} 1}{ }^{1}$ & $\mathrm{D}^{1}$ & $\mathrm{D} 31$ & $\mathrm{D} 4^{1}$ \\
\hline PARTICIPATION & & & & \\
\hline Low & 4.1 & 4.1 & 10.8 & 12.2 \\
\hline Medium & 9.5 & 1.4 & 17.6 & 14.9 \\
\hline High & 1.4 & 0.0 & 12.2 & 12.2 \\
\hline
\end{tabular}

ISSUE

PARTICIPATION

Low
Medium
High

GROUP

PARTICIPATION

Low
Medium
High

$\begin{array}{rrrr}8.1 & 5.4 & 24.3 & 27.0 \\ 6.8 & 0.0 & 9.5 & 6.8 \\ 0.0 & 0.0 & 6.8 & 5.4\end{array}$

$\mathrm{N}=74 \quad$ Missing $=8$
WHITE NEIGHBORHOOD

Ident. of Salient Crime \& Del. Problems

\begin{tabular}{|c|c|c|c|}
\hline $\mathrm{DI}^{1}$ & $\mathrm{D} 2^{1}$ & $\mathrm{D}^{1}$ & $\mathrm{D} 4^{1}$ \\
\hline 4.2 & 5.1 & 8.5 & 14.4 \\
\hline 2.5 & 3.4 & 27.1 & 17.8 \\
\hline 0.8 & 0.0 & 8.5 & 7.6 \\
\hline
\end{tabular}

5.1

1.7

$\begin{array}{lll}7.6 & 15.3 & 27.1\end{array}$

$\begin{array}{llll}0.8 & 0.0 & 11.9 & 5.1\end{array}$

$\mathrm{N}=118 \quad$ Missing $=1$

\section{COMBINED NEIGHBORHOODS}

Ident. of Salient Crime $\&$ De1. Problems

\begin{tabular}{|c|c|c|c|}
\hline$D 1^{1}$ & $\mathrm{D} 2^{1}$ & $\mathrm{D} 3^{1}$ & $D 4^{1}$ \\
\hline 4.2 & 4.7 & 9.4 & 13.5 \\
\hline 5.2 & 2.6 & 23.4 & 16.7 \\
\hline 1.0 & 0.0 & 9.9 & 9.4 \\
\hline
\end{tabular}

$\begin{array}{rrrr}6.3 & 6.8 & 18.8 & 27.1 \\ 3.6 & 0.5 & 14.1 & 7.3 \\ 0.5 & 0.0 & 9.9 & 5.2\end{array}$

$\mathrm{N}=192 \quad$ Missing $=9$

${ }^{1}$ D1 $=$ Problem Not Identified and Low Salience; $\mathrm{D} 2=$ Problem Not Identified But High Salience; D3 = Problem Identified, But Low Salience; D4 = Problem Identified and High Salience.

$$
\begin{array}{rrrr}
6.3 & 6.8 & 19.3 & 24.5 \\
2.1 & 0.5 & 6.3 & 5.7 \\
2.1 & 0.0 & 17.2 & 9.4 \\
& & & \\
N= & 192 & \text { Missing }=9
\end{array}
$$


TABLE XIX

SIGNIFICANCE OF RELATIONSHIP BETWEEN THE IDENTIFICATION OF SALIENT CRIME AND DELINQUENCY PROBLEMS AND ELECTORAL, ISSUE, AND GROUP PARTICIPATION IN INDIVIDUAL AND COMBINED SURVEY NEIGHBORHOODS

\section{ELECTORAL PARTICIPATION}

AND IDENTIFICATION OF SALIENT CRIME AND DELINQUENCY PROBLEMS

Chi Square:

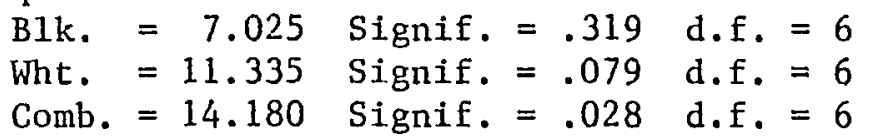

ISSUE PARTICIPATION

AND IDENTIFICATION OF SALIENT CRIME AND DELINQUENCY PROBLEMS

Chi Square:

Blk. $=7.270$ Signif. $=.297$ d.f. $=6$

Wht. $=17.665$ Signif. $=.007$ d.f. $=6$

Comb. $=19.788$ Signif. $=.003$ d.f. $=6$
Tau c:

BIk. $=+.097$

Wht. $=+.067$

Comb. $=+.077$
Gamma :

B1k. $=+.150$

Wht. $=+.113$

Comb. $=+.126$

GROUP PARTICIPATION

AND IDENTIFICATION OF SALIENT CRIME AND DELINQUENCY PROBLEMS

Chi Square:

B1k. $=4.083$ Signif. $=.666$ d.f. $=6$

Wht. $=21.139$ Signif. $=.002$ d.F. $=6$

Comb. $=15.523$ Signif. $=.017$ d.f. $=6$
Tau c:

Blk. $=-.016$
Wht. $=-.060$

Comb. $=-.038$
Gamma :

$\mathrm{B} 1 \mathrm{k} .=-.033$

Wht. $=-.105$

Comb. $=-.070$
Tau c:

B1k. $=+.108$

Wht. $=-.056$

Comb. $=-.002$
Gamma :

B1k. $=+.173$

Wht. $=-.113$

Comb. $=-.004$ 


\section{TABLE XX}

RELATIONSHIPS BETWEEN THE IDENTIFICATION OF SALIENT POLICE-COMMIUNITY RELATIONS PROBLEMS AND ELECTORAL, ISSUE, AND GROUP PARTICIPATION IN INDIVIDUAL AND COMBINED SURVEY NEIGHBORHOODS (EXPRESSED IN PERCENT)

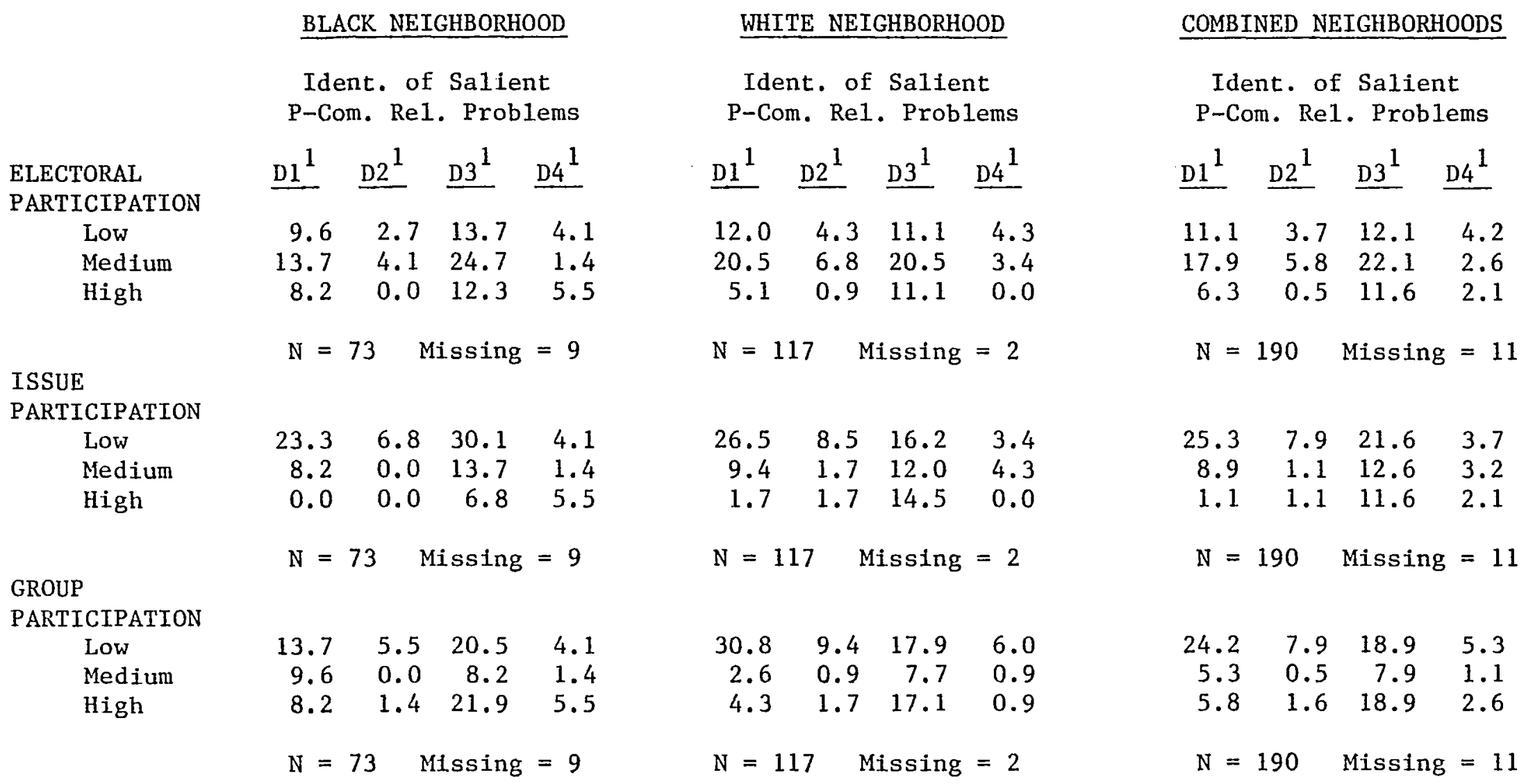

${ }^{1} 1$ = Problem Not Identified and Low Salience; $D 2=$ Problem Not Identified But High Salience; $\mathrm{D} 3=$ Problem Identified But Low Salience; $\mathrm{D} 4$ = Problem Identified and High Salience. 
TABLE XXI

SIGNIFICANCE OF RELATIONSHIPS BETWEEN THE IDENTIFICATION OF SALIENT POLICE-COMMUNITY RELATIONS PROBLEMS AND ELECTORAL, ISSUE, AND GROUP PARTICIPATION IN INDIVIDUAL AND COMBINED SURVEY NEIGHBORHOODS

ELECTORAL PARTICIPATION

AND IDENTIFICATION OF SALIENT POLICE-COMMUNITY RELATIONS PROBLEMS

Chi Square:

B1k. $=5.820$ Signif. $=.444$ d.f. $=6$

Wht. $=7.554$ Signif. $=.273$ d.f. $=6$

Comb. $=7.318$ Signif. $=.293$ d.f. $=6$
Tau c:

$\mathrm{B} 1 \mathrm{k} .=+.056$

Wht. $=+.014$

Comb. $=+.032$
Gamma :

$$
\begin{aligned}
& \text { B1k. }=+.090 \\
& \text { Wht. }=+.023 \\
& \text { Comb. }=+.053
\end{aligned}
$$

ISSUE PARTICIPATION

AND IDENTIFICATION OF SALIENT POLICE-COMMUNITY RELATIONS PROBLEMS
Chi Square:
B1k. $=16.913$ Signif. $=.010$ d.f. $=6$
Wht. $=22.324$ Signif. $=.001$ d.f. $=6$
Comb. $=21.471$ Signif. $=.002$ d.f. $=6$

Tau c:

$$
\begin{aligned}
& \text { B1k. }=+.233 \\
& \text { Wht. }=+.247 \\
& \text { Comb. }=+.232
\end{aligned}
$$

Gamma :

Blk. $=+.474$
Wht. $=+.410$
Comb. $=+.415$

GROUP PARTICIPATION

AND IDENTIFICATION OF SALIENT POLICE-COMMUNITY RELATIONS PROBLEMS

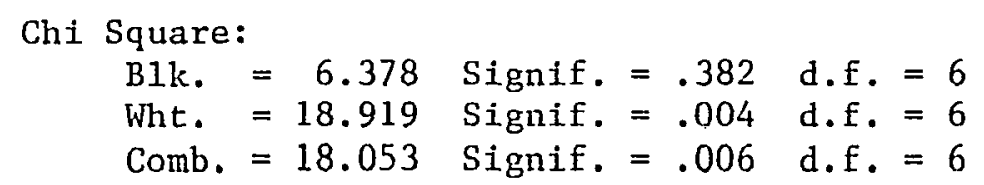
Tau c:
Blk. $=+.112$
Wht. $=+.222$
Comb. $=+.186$

Gamma :

$$
\begin{aligned}
& \text { Blk. }=+.186 \\
& \text { Wht. }=+.422 \\
& \text { Comb. }=+.327
\end{aligned}
$$


The identification of a sallent problem is more strongly associated with participation in the White survey neighborhood for the issue and group modes of participation with only two exceptions. Housing problem salience shows a stronger relationship with issue participation in the Black survey neighborhood than the White. Crime and delinquency problem salience appears to be more important a factor in group participation in the Black neighborhood as well. In both neighborhoods, perception of a salient problem is more strongly associated with issue and group participation than with electoral participation.

Housing. While it is true the relationships are not as strong as initially expected, this does not mean that they are necessarily insignificant. In the case of housing, for example, (TABLES XII and XIII) the relationship between the identification of a salient housing problem and both issue and group participation produces Kendall's Tau c statistics which are strong enough to be statistically significant for both the Black and White sample populations. Combining the two neighborhood samples produces statistically significant Chi Squares as well.

Education. The relationships between the identification of salient education problems and participation (TABLES XIV and XV) exhibit similar levels and patterns of significance. The Kendall's Tau $c$ shows the relationship to be statistically significant for electoral participation in both survey neighborhoods. This is the only instance where a statistically significant relationship is found between electoral participation and the identification of a salient problem. This may reflect the fact that educational policy is determined by a directly elected and reasonably accessible local school board. The Tau c statistic is 
also significant for the White survey neighborhood relationships between the identification of salient education problems and both issue and group participation. Combining the two neighborhood samples again produces significant Chi Squares for all measures of participation.

Police-Community Relations. The relationships between the identification of salient police-community relations problems and participation in both individual and combined survey neighborhoods (TABLES XX and XXI) are seen to fall into the same general pattern. Both the Chi Square and Tau $c$ indicate a statistically significant relationship between this problem salience measure and issue participation for each neighborhood sample. The Tau $c$ is significant in all cases for group participation, and significant Chi Squares are found for both White and combined survey neighborhood populations. Again, electoral participation is neither strongly nor significantly associated with the identification of a salient problem.

Employment and Crime and Delinquency. The remaining two problem salience measures (TABLES XVI through XIX) present us with mixed results. In both cases, the relationships are very weak. The mixture of slightly positive and slightly negative relationships tends to indicate that the identification of salient problems in these two areas has little to do with participatory behavior. This is probably due to the fact that of the five problem areas examined, these two areas are less visibly affected by citizen action. Thus the connection between action and the solution of these two problems is much less clear than for the other three problem areas. 
Problem Identification, Salience, and Neighborhood Roots. When examining the relationships between the perception or identification of salient neighborhood problems and participation, there is one additional element--neighborhood rootedness--which must be considered, since it serves to shape or condition perceptions. It is reasonable, therefore, to consider the effects of neighborhood roots on both perception and participation before moving on to examine other aspects of participatory behavior.

Studies have shown, for example, that those who have stronger and deeper roots in the community (i.e., those who have lived in the community for five years or more) tend to participate more in the life of the community. 110 Deeper roots in the neighborhood should logically relate to the identification and salience of problems, since the individual is more familiar with his or her environment, and probably has a bigger stake or interest in the neighborhood environment as well. Both of these aspects of neighborhood rootedness may, therefore, be important elements in the calculus of participatory activity.

Four items in the interview questionnaire were included to allow some measurement of the individual respondent's roots in the neighborhood. Respondents were asked whether they owned or rented their residence. Resident homeowners were assumed to have stronger roots in the neighborhood than renters. Respondents were then asked how long they had been living at their current address. If they had been living at their current address for five years or more, it was assumed tha the respondent had stronger roots in the neighborhood than more recent arrivals. For those who had been living at their current address for 
less than five years, two further questions were asked relating to the number of times they had moved in the past five years, and the location of their previous address. Of the more recent arrivals, it was assumed that those who had moved the least number of times and who had a previous address in the same neighborhood may have stronger roots than others.

A simple composite index of neighborhood rootedness was created by first coding the responses to each of the questions either "low" or "high". One point was assigned to "high" responses, and zero points to "low" responses. To form the index, the points for each question were summed, and the total was divided by the number of questions answered. (Two of the questions were not asked of those who had resided in the neighborhood for more than five years.) The resulting index ranged in value from zero to one. This range of values was subsequently collapsed into "low" and "high" categories for ease of analysis. (The specific questions which compromise this composite index are questions 56 through 59 in Appendix E.) We find in TABLES XXII and KXIII, that neighborhood rootedness is indeed related to participation. This relationship is especially strong for respondents in the Black survey neighborhood, where the level of resident homeownership is higher. Those who have stronger roots in the neighborhood, according to this measure, tend to be more highly active in all modes of participation in both the individual and combined neighborhoods. The Chi Square statistics are significant for all types of participation in both the Black and combined survey neighborhoods, and the Kendall's Tau c statistics are significant for all observed relationships.

Having confirmed the relationship between participation and neighborhood rootedness, the question of the impact of strong neighborhood roots on problem perception remains. To test the proposition that neighborhood 
TABLE XXII

RELATIONSHIPS BETWEEN NEIGHBORHOOD ROOTEDNESS OF INDIVIDUALS AND ELECTORAL, ISSUE, AND GROUP PARTICIPATION IN INDIVIDUAL AND COMBINED SURVEY NEIGHBORHOODS (EXPRESSED IN PERCENT)

COMBINED NEIGHBORHOODS

$\begin{array}{lrr} & \begin{array}{c}\text { BLACK NEIGHBORHOOD } \\ \text { Neighborhood } \\ \text { Rootedness }\end{array} \\ \text { ELECTORAL } & \text { LOW } & \text { High } \\ \text { PARTICIPATION } & 28.0 & 4.9 \\ \text { LOW } & 19.5 & 23.2 \\ \text { Medium } & 6.1 & 18.3 \\ \text { High } & \mathrm{N}=82\end{array}$

WHITE NEIGHBORHOOD

Neighborhood

Rootedness

Low $\quad \underline{\text { High }}$

26.16 .7

$31.1 \quad 19.3$

$10.9 \quad 5.9$

$$
\mathrm{N}=119
$$

$$
\begin{array}{rr}
41.2 & 14.3 \\
16.8 & 10.1 \\
10.1 & 7.6 \\
N= & 119
\end{array}
$$

$$
\begin{array}{rr}
47.1 & 17.6 \\
9.2 & 2.5 \\
11.8 & 11.8 \\
N= & 119
\end{array}
$$

Neighborhood

Rootedness

$$
\begin{array}{rr}
\text { Low } & \text { High } \\
26.9 & 6.0 \\
26.4 & 20.9 \\
9.0 & 10.9 \\
\text { N }=201
\end{array}
$$

$$
\begin{array}{rr}
41.8 & 17.9 \\
12.9 & 11.9 \\
7.5 & 8.0 \\
N=201
\end{array}
$$

GROUP

Medium

High
$35.4 \quad 11.0$
$9.8 \quad 24.4$

$$
\mathrm{N}=82
$$


SIGNIFICANCE OF THE RELATIONSHIPS BETWEEN NEIGHBORHOOD ROOTEDNESS OF INDIVIDUALS AND ELECTORAL, ISSUE AND GROUP PARTICIPATION IN INDIVIDUAL AND COMBINED SURVEY NEIGHBORHOODS

ELECTORAL PARTICIPATION

AND NEIGHBORHOOD ROOTEDNESS OF INDIVIDUALS

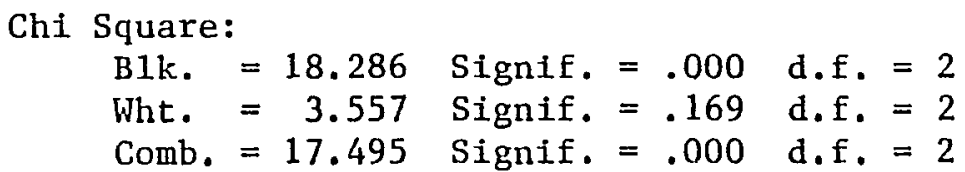

ISSUE PARTICIPATION

AND NEIGHBORHOOD ROOTEDNESS OF INDIVIDUALS
Tau c:

$$
\begin{aligned}
& \text { B1k. }=+.501 \\
& \text { Wht. }=+.138 \\
& \text { Comb. }=+.298
\end{aligned}
$$

Gamma :

$$
\begin{aligned}
& \text { Blk. }=+.701 \\
& \text { Wht. }=+.260 \\
& \text { Comb. }=+.484
\end{aligned}
$$

Chi Square:

$\begin{array}{llll}\text { BIk. }=7.944 & \text { Signif. }=.019 & \text { d.f. }=2 \\ \text { Wht. }=2.767 & \text { Signif. }=.251 & \text { d.f. }=2 \\ \text { Comb, }=7.832 & \text { Signif. }=.020 & \text { d.f. }=2\end{array}$

Tau c:

Blk. $=+.297$

Wht. $=+.147$

Comb. $=+.192$
Gamma :

Blk. $=+.547$
Wht. $=+.275$
Comb. $=+.346$

\section{GROUP PARTICIPATION}

AND NEIGIBORHOOD ROOTEDNESS OF INDIVIDUALS

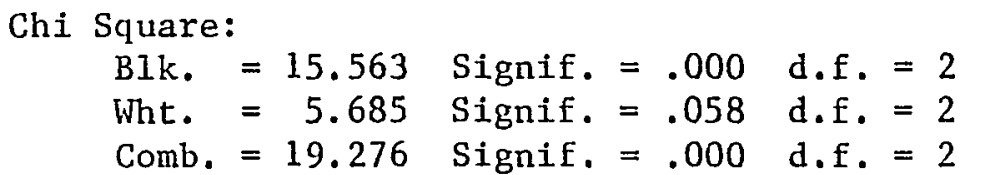

Tau c:

Blk. $=+.460$

Wht $=+.152$

Comb. $=+.302$
Gamma :

Blk. $=+.651$

Wht. $=+.322$

Comb. $=+.511$ 
rootedness affects the identification and the salience of neighborhood problems as they relate to participation, a second set of crosstabulations between participation and each of the problem salience measures were produced for those cases where neighborhood rootedness measured high on our index. With this statistical control for neighborhood rootedness applied, the strength of the relationships between the identification of salient problems and participation was generally observed to increase--in some cases substantially. This tends to confirm our contention that for those with stronger roots in the neighborhood, the connection between participation and the identification of salient problems is greater than for those with weaker roots in the neighborhood. This appears to be especially true for respondents in the Black survey neighborhood.

We can conclude several things from the results of this analysis and problem salience and participation. The conclusions both complement and reinforce the impressions gained in earlier portions of study. Even though each individual measure of the identification of a salient problem contributes less to participatory behavior than when combined with others in a composite measure, the results generally conform to those found for the composite measure. In three of the five problem categories, participation is found to be moderately or moderately-strongly associated with the identification of a salient problem. These relationships are again stronger and more significant for the white survey neighborhood than for the Black survey neighborhood, and the relationships continue to be more important for issue and group participation than for electoral participation. This connection between the identification of salient problems and participation appears to be most sig- 
nificant in those problem areas where concrete and visible results are more likely to follow from specific citizen action. The relationships also tend to be stronger for those with the strongest roots in the neighborhood, a factor which is especially evident in the responses in the Black survey neighborhood.

Participation and Feelings of Efficacy in Solving Perceived Problems Feelings of efficacy in solving problems perceived in the neighborhood are suggested by our model of political behavior to be an important element in the individual decision to participate. Assuming a problem is identified wich is salient to the individual, some assessment of efficacy in doing something about the problem logically precedes any specific action. If the individual believes he or she can do nothing to affect the problem perceived, participatory action is much less likely to occur than in the case in which the individual believes he or she can have some impact. (This is less likely to be true if participation is primarily seen as a symbolic or social activity rather than as an instrumental or problem-solving activity.) Thus, feelings of efficacy on the part of the individual, as they relate to both the perception of problems and participation to solve them must be examined in order to refine our understanding of the ways in which the perception of neighborhood problems is associated with participation.

As mentioned earlier in this chapter, two different but related measures of feelings of efficacy were used in the study. Both are directly tied to the problems perceived by the survey respondents. The first, feelings of personal efficacy, measures the extent to which the individual feels he or she can personally do something as an individual 
to affect the problem or problems he or she identifies. The second measures feelings of group efficacy. Regardless of how personally effective or ineffective an individual feels, he or she may feel a different sense of efficacy (probably greater) as part of an organized group which attempts to affect the identified problem. Each of these measures of feelings of efficacy were examined with respect to their association with participation and their impact on the previously established relationships between problem salience and participation.

Feelings of Personal Efficacy. The composite index of feelings of personal efficacy and the three types of participation were first crosstabulated. These crosstabulations and a summary of their related statistics are presented in TABLES XXIV and XXV. These tables confirm that feelings of personal efficacy are both strongly and significantly associated with all types of participation. A majority of respondents in each neighborhood do not feel personally effective in solving the problems they dientify, but those who do feel personally effective are more likely to participate than those who do not.

The distribution of respondents among the various levels of the index of feelings of personal efficacy is very similar for both survey neighborhood populations. The relationships observed are also equally true of respondents in both the Black and White survey neighborhoods for each of the two non-traditional types of participation. The association of electoral participation and feelings of personal efficacy is somewhat weaker for respondents in both survey neighborhoods, but remains nearly as strong for Black survey neighborhood respondents. This reflects the lessened direct connection between electoral participation and solution of neighborhood problems, but it also indicates that feelings of personal efficacy are more important for electoral participation 
TABLE XXIV

RELATIONSHIPS BETWEEN FEELINGS OF PERSONAL EFFICACY AND ELECTORAL, ISSUE, AND GROUP PARTICIPATION IN INDIVIDUAL AND COMBINED SURVEY NEIGHBORHOODS (EXPRESSED IN PERCENT)

\section{BLACK NEIGHBORHOOD}

Feelings of Personal Efficacy

ELECTORAL

PARTICIPATION

Low

Medium

High

\section{ISSUE \\ PARTICIPATION \\ Low \\ Medium \\ High}

GROUP

PARTICIPATION

Low

Medium

High

(Not Ascertained $=1$ )

\section{WHITE NEIGHBORHOOD}

Feelings of Personal Efficacy

$\begin{array}{rcc}\text { Low } & \text { Med. } & \text { High } \\ 24.4 & 4.2 & 4.2 \\ 25.2 & 12.6 & 6.7 \\ 5.0 & 4.2 & 6.7 \\ & \text { N }=119 & \end{array}$

(Not Ascertained $=8$ )

$\begin{array}{rll}38.7 & 7.6 & 5.0 \\ 11.8 & 9.2 & 3.4 \\ 4.2 & 4.2 & 9.2 \\ & N=119 & \end{array}$

(Not Ascertained $=8$ )

$\begin{array}{rrr}34.1 & 11.0 & 1.2 \\ 11.0 & 3.7 & 3.7 \\ 12.2 & 11.0 & 11.0 \\ & \mathrm{~N}=82 & \end{array}$

$($ Not Ascertained $=1)$

$\begin{array}{rcc}41.2 & 11.8 & 5.9 \\ 5.0 & 3.4 & 3.4 \\ 8.4 & 5.9 & 8.4 \\ & \mathrm{~N}=119\end{array}$

$($ Not Ascertained $=8$ )

\section{COMBINED NEIGHBORHOODS}

Feelings of Personal Efficacy

Low Med. High

$\begin{array}{rcr}23.4 & 5.5 & 3.5 \\ 26.4 & 10.9 & 6.5 \\ 6.0 \quad 6.5 & 7.0 \\ \mathrm{~N}=201 & \end{array}$

(Not Ascertained $=9$ )

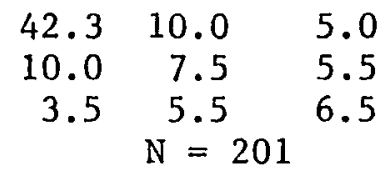

( Not Ascertained $=8$ )

$\begin{array}{rcr}38.3 & 11.4 & 4.0 \\ 7.5 & 3.5 & 3.5 \\ 10.0 & 8.0 & 9.5 \\ & \mathrm{~N}=201\end{array}$

(Not Ascertained $=8$ ) 
SIGNIFICANCE OF THE RELATIONSHIPS BETWEEN FEELINGS OF PERSONAL EFFICACY AND ELECTORAL, ISSUE, AND GROUP PARTICIPATION IN INDIVIDUAL AND COMBINED SURVEY NEIGHBORHOODS

ELECTORAL PARTICIPATION

AND FEELINGS OF PERSONAL EFFICACY

Chi Square:

$\begin{array}{lll}\text { B1k. }=11.445 & \text { Signif. }=.076 & \text { d.f. }=6 \\ \text { Wht. }=18.789 & \text { Signif. }=.004 & \text { d.f. }=6 \\ \text { Comb. }=23.615 & \text { Signif. }=.001 & \text { d.f. }=6\end{array}$

ISSUE PARTICIPATION

AND FEELINGS OF PERSONAL EFFICACY

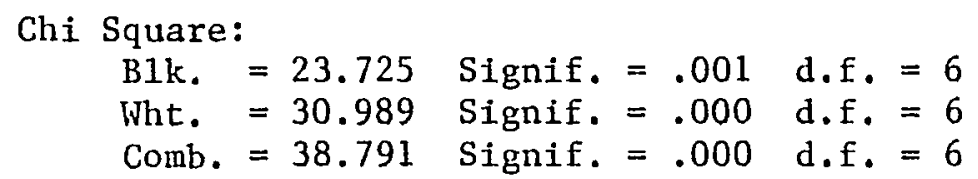

\section{GROUP PARTICIPATION}

AND FEELINGS OF PERSONAL EFFICACY

Chi Square:

$\begin{array}{lll}\text { B1k. }=17.961 & \text { Signif. }=.006 & \text { d.f. }=6 \\ \text { Wht. }=15.537 & \text { Signif. }=.016 & \text { d.f. }=6 \\ \text { Comb. }=26.731 & \text { Signif. }=.000 & \text { d.f. }=6\end{array}$

'Tau b:

$$
\begin{aligned}
& \text { Blk. }=+.280 \\
& \text { Wht. }=+.175 \\
& \text { Comb. }=+.219
\end{aligned}
$$

Gamma :

Blk. $=+.436$

Wht. $=+.276$

Comb. $=+.344$

Tau b:

$$
\begin{aligned}
& \text { B1k. }=+.346 \\
& \text { Wht. }=+.364 \\
& \text { Comb. }=+.347
\end{aligned}
$$

Gamma :

$$
\begin{aligned}
& \text { B1k. }=+.530 \\
& \text { Wht. }=+.542 \\
& \text { Comb. }=+.527
\end{aligned}
$$

Tau b:

B1k. $=+.329$

Wht. $=+.311$

Comb. $=+.316$
Gamma :

B1k. $=+.506$

Wht. $=+.507$

Comb. $=+.497$ 
in the Black survey neighborhood than in the White neighborhood.

The effect of these feelings of personal efficacy on the previously established relationships between participation and the identification of salient problems was also examined for each specific problem category. Participation and each measure of the identification of a salient problem were crosstabulated for those cases where the respondent felt he or she could personally do something about the problem. In most cases, the observed relationship was stronger than the original without the statistical control for feelings of personal efficacy. This indicates that those who feel they can do something when they perceive a problem are more likely to participate than those who do not.

Feelings of Group Efficacy. Feelings of group efficacy are observed to be similarly related to participation in TABLES XXVI and XXVII. Again, the distribution of respondents among the three levels of the index of feelings of group efficacy is nearly the same for both sample populations. A considerably higher proportion of all respondents feel they can do something about the problems they identify as part of a group than as an individual. These relationships between participation and feelings of group efficacy, as reflected in the Kendall's Tau statistics, are significant and moderately strong in all cases. They are especially strong in the case of the Black survey neighborhood. Where we earlier found feelings of personal efficacy to be equally important for participation in both Black and White survey neighborhoods, we find here that feelings of group efficacy are substantially more important for the Black survey neighborhood respondents who are issue and group participants than they are for their White neighborhood counterparts. 
TABLE XXVI

RELATIONSHIPS BETWEEN FEELINGS OF GROUP EFFICACY AND ELECTORAL, ISSUE, AND GROUP PARTICIPATION IN INDIVIDUAL AND COMBINED SURVEY NEIGHBORHOODS (EXPRESSED IN PERCENT)

\section{BLACK NEIGHBORHOOD}

Feelings of Group Efficacy

ELECTORAL
PARTICIPATION
LOW
Mediun
High

ISSUE

PARTICIPATION

Low

High

Low Med. High

$11.0 \quad 4.9 \quad 17.1$

$\begin{array}{lll}14.6 & 8.5 & 18.3\end{array}$

$1.2 \quad 3.7 \quad 19.5$

$\mathrm{N}=82$

(Not Ascertained $=1$ )
WHITE NEIGHBORHOOD

Feelings of

Group Efficacy

$\begin{array}{rlr}\text { Low } & \text { Med. } & \text { High } \\ 10.1 & 5.0 & 16.0 \\ 10.1 & 5.9 & 31.9 \\ 0.0 & 4.2 & 12.6 \\ \mathrm{~N} & =119 & \end{array}$

(Not Ascertained = 5)
COMBINED NEIGHBORHOODS

Feelings of

Group Efficacy

$$
\begin{array}{rll}
\text { Low } & \text { Med. } & \text { High } \\
10.4 & 5.0 & 16.4 \\
11.9 & 7.0 & 26.4 \\
0.5 & 4.0 & 15.4 \\
\mathrm{~N} & =201
\end{array}
$$

(Not Ascertained $=6$ ) $\begin{array}{rlr}14.3 & 5.9 & 31.9 \\ 5.9 & 4.2 & 16.0 \\ 0.0 & 5.0 & 12.6 \\ N & =119\end{array}$

(Not Ascertained $=5$ ) $\begin{array}{rlr}17.9 & 8.5 & 30.8 \\ 5.0 & 3.5 & 15.9 \\ 0.0 & 4.0 & 11.4 \\ & N=201\end{array}$

(Not Ascertained $=6$ )

GROUP

PARTICIPATION

Low

Medium
High

$$
\begin{array}{rll}
19.5 & 9.8 & 15.9 \\
4.9 & 1.2 & 13.4 \\
2.4 & 6.1 & 25.6 \\
& N=82
\end{array}
$$

$($ Not Ascertained $=1)$ $\begin{array}{rlr}16.8 & 7.6 & 36.1 \\ 0.0 & 2.5 & 9.2 \\ 3.4 & 5.0 & 15.1 \\ \mathrm{~N} & =119\end{array}$

(Not Ascertained $=5$ )

$$
\begin{array}{rlr}
17.9 & 8.5 & 27.9 \\
2.0 & 2.0 & 10.9 \\
3.0 & 5.5 & 19.4 \\
\mathrm{~N} & =201
\end{array}
$$

(Not Ascertained $=6$ ) 
SIGNIFICANCE OF THE RELATIONSHIPS BETWEEN FEELINGS OF GROUP EFFICACY AND ELECTORAL, ISSUE, AND GROUP PARTICIPATION IN INDIVIDUAL AND COMBINED NEIGHBORHOODS

ELECTORAL PARTICIPATION

AND FEELINGS OF GROUP EFFICACY

Chi Square:

$\begin{array}{lll}\text { Blk. }=9.619 & \text { Signif. }=.142 & \text { d.f. }=6 \\ \text { Wht. }=10.654 & \text { Signif. }=.100 & \text { d.f. }=6 \\ \text { Comb. }=15.415 & \text { Signif. }=.017 & \text { d.f. }=6\end{array}$

ISSUE PARTICIPATION

AND FEELINGS OF GROUP EFFICACY

Chi Square:

$\begin{array}{lll}\text { B1k. }=8.999 & \text { Signif. }=.174 & \text { d.f. }=6 \\ \text { Wht. }=10.734 & \text { Signif. }=.097 & \text { d.f. }=6 \\ \text { Comb. }=16.361 & \text { Signif. }=.012 & \text { d.f. }=6\end{array}$

GROUP PARTICIPATION

AND FEELINGS OF GROUP EFFICACY

\section{Chi Square:}

Blk. $=15.573$ Signif. $=.016$ d. f. $=6$

Wht. $=10.121$ Signif. $=.120$ d.f. $=6$

Comb. $=17.801$ Signif. $=.007$ d.f. $=6$
Tau b:

Blk. $=+.184$

Wht. $=+.199$

Comb. $=+.189$

Tau b:

B1k. $=+.290$

Wht. $=+.133$

Comb. $=+.197$

Tau b:

$\mathrm{B} 1 \mathrm{k} .=+.363$

Wht. $=+.149$

Comb. $=+.229$
Gamma :

B1k. $=+.291$

Wht. $=+.333$

Comb. $=+.312$
Gamma :

$\mathrm{B} 1 \mathrm{k} .=+.544$

Wht $=+.231$

Comb. $=+.351$ 
The effect of these feelings of group efficacy on the previously established relationships between the identification of salient problems and participation is similar to that found in the case of feelings of personal efficacy, but it is more pronounced for both issue and group participation. Those who identify a problem which is salient for them are more likely to participate if they also feel effective in doing something about that problem as part of a group.

Efficacy and Cynicism. If participation is an empty ritual, and if individuals perceive problems which are salient to them but feel nothing can be done about those problems, they may become alienated and cynical in time. Cynicism implies an active rejection of political behavior, and it has been found in a number of studies that persons who are either personally or politically cynical are less likely to be politically involved. $^{111}$ For these reasons, it is important to briefly examine the relationships between cynicism and feelings of efficacy, and between cynicism and participation.

Two measures of cynicism were included in the study. They were adapted for use from scales of personal and political cynicism developed by Campbell and by Agger, et al. ${ }^{112}$ Ten questions in the interview questionnaire were included to allow measurement of these two concepts. To measure personal cynicism, respondents were asked to indicate how strongly they agreed or disagreed with the following four statements: (Refer to questions $64,66,67$ and 68 in Appendix E.)

1. It is safest to assume that all people have a vicious streak and it will come out if given the chance.

2. Barnum was very wrong when he said there was a sucker born every minute. 
3. The biggest difference between most criminals and other people is that criminals are stupid enough to get caught.

4. Generally speaking, people won't work hard unless they are forced to do so.

Political cynicism was defined by the extent to which respondents agreed or disagreed with an additional set of six statements: (See Appendix E, questions $63,65,69,70,71$ and 72.$)$

1. In order to get nominated, most candidates for political office have to make basic compromises and undesirable commitments.

2. Money is the most important factor influencing public policies.

3. Politicians spend most of their time getting re-elected or re-appointed.

4. A large number of city and county politicians are political hacks.

5. People are very frequently manipulated by politicians.

6. Politicians represent the general interest more frequently than they represent the special interests.

An index for each type of cynicism was created from the responses to these statements by averaging the scores for each set of statements after re-coding the items which were stated in reverse form. This produced an index which ranged from one (least cynical) to six (most cynical) for both personal and political cynicism. Each index was subsequently collapsed into low, medium, and high categories for ease of analysis.

Both measures of cynicism were found to be related to feelings of personal and group efficacy. Those who felt more effective--either personally or as part of a group--in dealing with perceived problems were less cynical than those who felt less effective. This was especially true of respondents in the Black survey neighborhood. 
Having established the connection between cynicism and feelings of efficacy, the relationships between cynicism and participation were examined. The results are summarized in TABLES XXVIII through XXXI. These tables show both personal and political cynicism to be more pronounced among the Black survey population. It is also observed to be negatively related to participation in that neighborhood sample. Those who are less cynical tend to participate more frequently. These relationships are fairly strong, and the Tau statistics are significant, even though the Chi Squares are not.

Respondents in the White survey neighborhood tend to be less cynical than their Black counterparts, and those who feel less personally cynical are more active participants. This relationship is statistically significant for both electoral and group participation. Political cynicism does not appear to be associated with participation in the White survey neighborhood, since the relationships observed exhibit little or no strength.

Participation and the Perception of Problem Dimensions

In addition to ways in wich participation relates to the identification of problems, their salience, and feelings of efficacy in doing something about those problems, it may also be related to the general ways in which people define the problems they perceive. If there are differences in the ways in which common problems are perceived and defined, the nature and dimensions of those definitions may be important for understanding participatory behavior.

The range of examples used in the problem identification portions of the survey questionnaire suggest three conceptual dimensions of the 
TABLE XXVIII

RELATIONSHIPS BETWEEN FEELINGS OF PERSONAL CYNICISM AND ELECTORAL, ISSUE, AND GROUP PARTICIPATION IN INDIVIDUAL AND COMBINED SURVEY NEIGHBORHOODS (EXPRESSED IN PERCENT)

\section{BLACK NEIGHBORHOOD}

Feelings of

Personal Cynicism

$\begin{array}{lrrr}\text { ELECTORAL } & \text { Low } & \text { Med. } & \text { High } \\ \text { PARTICIPATION } & & & \text {. } \\ \text { Low } & 2.2 & 8.9 & 13.3 \\ \text { Medium } & 0.0 & 28.9 & 17.8 \\ \text { High } & 2.2 & 20.0 & 6.7 \\ & \mathrm{~N}=45 & \text { Missing }=37\end{array}$

ISSUE

PARTICIPATION

Low
Medium
High

$\begin{array}{lll}2.2 & 37.8 & 28.9\end{array}$

$\begin{array}{lll}0.0 & 11.1 & 6.7\end{array}$

$\begin{array}{lll}2.2 & 8.9 & 2.2\end{array}$

$\mathrm{N}=45 \quad$ Missing $=37$
WHITE NEIGHBORHOOD

Feelings of

Personal Cynicism

Low Med. High

$\begin{array}{lll}4.3 & 18.8 & 7.2\end{array}$

$\begin{array}{lll}4.3 & 43.5 & 5.8\end{array}$

$\begin{array}{lll}4.3 & 10.1 & 1.4\end{array}$

$\mathrm{N}=69$ Missing $=50$

COMBINED NEIGHBORHOODS

\begin{tabular}{l}
\multicolumn{3}{c}{ Feelings of } \\
Political \\
$\begin{array}{llr}\text { Low } & \text { Med. } & \text { High } \\
3.5 & 14.9 & 9.6 \\
2.6 & 37.7 & 10.5 \\
3.5 & 14.0 & 3.5 \\
=114 & \text { Missing }=87\end{array}$
\end{tabular}

$\mathrm{N}=114$ Missing $=87$

$$
\begin{array}{ccc}
3.5 & 42.1 & 16.7 \\
2.6 & 14.0 & 3.5 \\
3.5 & 10.5 & 3.5 \\
N=114 & \text { Missing }=87
\end{array}
$$

GROUP

PARTICIPATION

$$
\begin{aligned}
& \text { Low } \\
& \text { Medium }
\end{aligned}
$$$$
\begin{array}{lll}
0.0 & 17.8 & 22.2
\end{array}
$$$$
\begin{array}{lll}
2.2 & 17.8 & 4.4
\end{array}
$$$$
2.2 \quad 22.2 \quad 11.1
$$$$
\mathrm{N}=45 \quad \text { Missing }=37
$$

$\begin{array}{rrr}2.6 & 37.7 & 14.9 \\ 2.6 & 12.3 & 1.8 \\ 4.4 & 16.7 & 7.0\end{array}$

$N=114$ Missing $=87$ 


\section{TABLE XXX}

RELATIONSHIPS BETWEEN FEELINGS OF POLITICAL CYNICISM AND ELECTORAL, ISSUE, AND GROUP PARTICIPATION IN INDIVIDUAL AND COMBINED SURVEY NEIGHBORHOODS (EXPRESSED IN PERCENT)

BLACK NEIGHBORHOOD

Feelings of

Political Cynicism

ELECTORAL
PARTICIPATION
Low
Medium
High

ISSUE

PARTICIPATION

Low

Medium

$\mathrm{High}$

Low Med. High

$\begin{array}{lll}0.0 & 8.8 & 20.6\end{array}$

$\begin{array}{lll}0.0 & 11.8 & 35.6\end{array}$

$\begin{array}{lll}0.0 & 11.8 & 11.8\end{array}$

$\mathrm{N}=34$ Missing $=48$
WHITE NEIGHBORHOOD

Feelings of

Political Cynicism

Low Med. High

$\begin{array}{lll}1.4 & 16.7 & 13.9\end{array}$

$0.0 \quad 25.0 \quad 30.6$

$\begin{array}{lll}2.8 & 2.8 & 6.9\end{array}$

$\mathrm{N}=72$ Missing $=47$
COMBINED NEIGHBORHOODS

Feelings of

Political Cynicism

Low Med. High

$0.9 \quad 14.2 \quad 16.0$

$\begin{array}{lll}0.0 & 20.8 & 32.1\end{array}$

$\begin{array}{lll}1.9 & 5.7 & 8.5\end{array}$

$\mathrm{N}=106$ Missing $=95$ $\begin{array}{rrr}0.0 & 14.7 & 47.1 \\ 0.0 & 11.8 & 11.8 \\ 0.0 & 5.9 & 8.8\end{array}$

$N=34$ Missing $=48$ $\begin{array}{lll}1.4 & 27.8 & 27.8\end{array}$

$\begin{array}{lll}0.0 & 13.9 & 12.5\end{array}$

$\begin{array}{lll}2.8 & 2.8 & 11.1\end{array}$

$\mathrm{N}=72 \quad$ Missing $=47$
$0.9 \quad 23.6 \quad 34.0$

$\begin{array}{lll}0.0 & 13.2 & 12.3\end{array}$

$\begin{array}{lll}1.9 & 3.8 & 10.4\end{array}$

$\mathrm{N}=106 \quad$ Missing $=95$

GROUP

PARTICIPATION

Low

Medium

$0.0 \quad 11.8 \quad 35.3$

$\begin{array}{lll}0.0 & 5.9 & 8.8\end{array}$

High

$\begin{array}{lll}0.0 & 14.7 & 23.5\end{array}$

1.430 .6 .31 .9

$\begin{array}{lll}1.4 & 6.9 & 6.9\end{array}$

$\begin{array}{lll}1.4 & 6.9 & 12.5\end{array}$

$0.9 \quad 24.5 \quad 33.0$

$\begin{array}{lll}0.9 & 6.6 & 7.5\end{array}$

$\mathrm{N}=34$ Missing $=48$

$\mathrm{N}=72$ Missing $=47$

$\mathrm{N}=106$ Missing $=95$ 


\section{TABLE XXXI}

SIGNIFICANCE OF THE RELATIONSHIPS BETWEEN FEELINGS OF POLITICAL CYNICISM AND ELECTORAL, ISSUE, AND GROUP PARTICIPATION IN INDIVIDUAL AND COMBINED SURVEY NETGHBORHOODS

ELECTORAL PARTICIPATION

AND FEELINGS OF POLITICAL CYNICISM

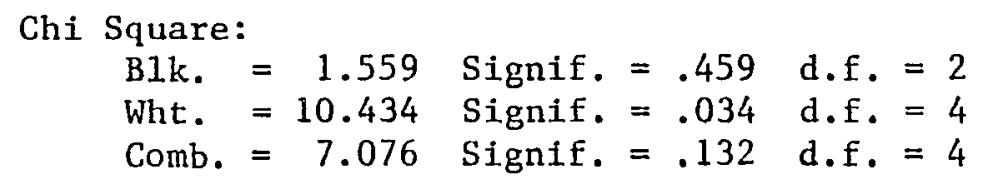
Tau b:

Blk. $=-.138^{1}$
Wht. $=+.065$
Comb. $=+.019$

Gamma :

B1k. $=-.238$

Wht. $=+.112$

Comb. $=+.033$

\section{ISSUE PARTICIPATION}

AND FEELINGS OF POLITICAL CYNICISM

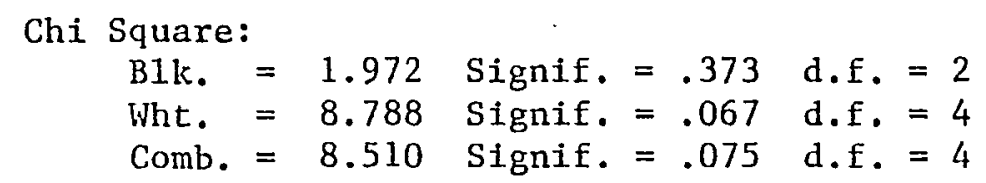
Tau b:

$$
\begin{aligned}
& \text { B1k. }=-.197^{1} \\
& \text { Wht. }=+.050 \\
& \text { Comb. }=-.026
\end{aligned}
$$

Gamma :

$$
\begin{aligned}
& \text { B1k. }=-.377 \\
& \text { Wht. }=+.088 \\
& \text { Comb. }=-.047
\end{aligned}
$$

GROUP PARTICIPATION

AND FEELINGS OF POLITICAL CYNICISM

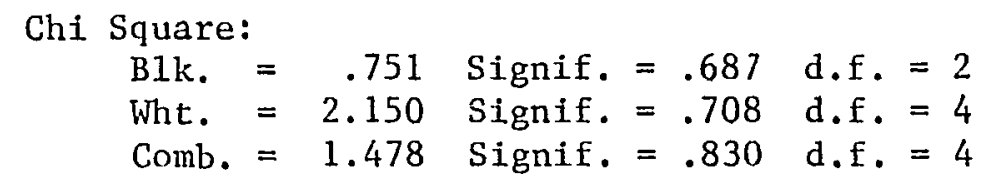
Tau b:

$$
\begin{aligned}
& \text { B1k. }=-.135^{1} \\
& \text { Wht. }=+.026 \\
& \text { Comb. }=+.009
\end{aligned}
$$

Gamma :

Blk. $=-.245$

Wht. $=+.048$

Comb. $=+.016$

\footnotetext{
$1_{\text {Tau }} \mathrm{c}$ is used for the Black Neighborhood sample because no values were encountered in column one.
} 
various problems used in the study which bear some scrutiny. It was proposed in the "guiding hypotheses" section of Chapter IV that people who perceive problems as political problems rather than non-political problems are more likely to participate. It was further suggested that perceiving a problem in social rather than personal terms was likely to result in a political definition of that problem, and thus to higher rates of participation. Finally, it was suggested that perception of problems along a local-national dimension would help to determine the mode of participatory action taken by the individual. We sha1l examine each of these propositions or hypotheses in this final section of the Chapter.

Personal vs Social Dimension of Problems. It is reasonable to assume that people who perceive problems as social or societal problems which ought to be acted upon by government are more likely to undertake political activities than those who believe neighborhood problems to be the personal problems of individuals which should be handled privately. We see in TABLES XXXII and XXXIII some support for this proposition. TABLE XXXII indicates that a majority of respondents in both survey neighborhoods perceive the problems they identify in their neighborhoods in social rather than personal terms. This perception of the social nature of neighborhood problems is positively associated with both issue and neighborhood group participation for both survey neighborhoods. Thus, people who perceive problems in social terms are more likely to participate in neighborhood issue and groups than those who perceive the same problems in personal terms. The relationship between electoral participation and perception of the personal vs social problem dimension of problems is observed to be inconsistent. It is slightly negative for the Black survey neighborhood respondents, and slightly positive for White survey neigh- 
TABLE XXXII

RELATTONSHIPS BETWEEN THE PERCEPTION OF A PERSONAL VS SOCIAL DIMENSION OF PROBLEMS AND ELECTORAL, ISSUE, AND GROUP PARTICIPATION IN INDIVIDUAL AND COMBINED SURVEY NEIGHBORHOODS (EXPRESSED IN PERCENT)

\section{BLACK NEIGHBORHOOD}

Personal vs Social Problem Perception

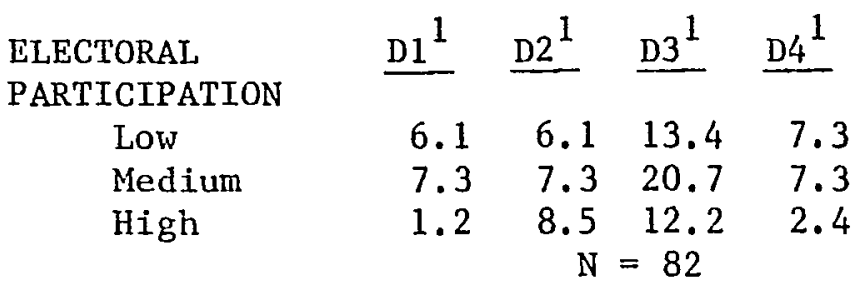

ISSUE

PARTICIPATION

LOW

Medium

High

$\begin{array}{rrrr}13.4 & 11.0 & 29.3 & 12.2 \\ 0.0 & 7.3 & 11.0 & 3.7 \\ 1.2 & 3.7 & 6.1 & 1.2 \\ & \mathrm{~N}=82\end{array}$

GROUP

PARTICIPATION

$\begin{array}{lrrrr}\text { Low } & 9.8 & 9.8 & 19.5 & 7.3 \\ \text { Medium } & 2.4 & 3.7 & 9.8 & 3.7 \\ \text { High } & 2.4 & 8.5 & 17.1 & 6.1 \\ & & \mathrm{~N}=82\end{array}$

WHITE NEIGHBORHOOD

Personal vs Social

Problem Perception

$$
\begin{aligned}
& \underline{\mathrm{D}^{1}} \quad \underline{\mathrm{D} 2^{1}} \quad \mathrm{D}^{1} \quad \mathrm{D4}^{1} \\
& \begin{array}{llll}
5.9 & 6.7 & 15.1 & 5.0
\end{array} \\
& \begin{array}{llll}
10.1 & 11.8 & 21.8 & 5.9
\end{array} \\
& \begin{array}{llll}
0.0 & 0.8 & 11.8 & 4.2
\end{array}
\end{aligned}
$$

(Not Ascertained $=1)$

$$
\begin{array}{rrrr}
12.6 & 12.6 & 24.4 & 5.9 \\
3.4 & 5.9 & 11.8 & 5.0 \\
0.0 & 0.8 & 12.6 & 4.2 \\
& \mathrm{~N}=119
\end{array}
$$

(Not Ascertained = 1)

$$
\begin{array}{rrrr}
12.6 & 14.3 & 27.7 & 10.1 \\
2.5 & 0.8 & 5.9 & 1.7 \\
0.8 & 4.2 & 15.1 & 3.4 \\
\multicolumn{4}{c}{\mathrm{N}=119} \\
\text { (Not Ascertained = } & \text { ) }
\end{array}
$$

\section{COMBINED NEIGHBORHOODS}

Personal vs Social

Problem Perception

$$
\begin{array}{lrrr}
\underline{\mathrm{D}}^{1} & \underline{\mathrm{D} 2}{ }^{1} & \underline{\mathrm{D}^{1}} & \underline{\mathrm{D}^{1}} \\
6.0 & 6.5 & 14.4 & 6.0 \\
9.0 & 10.0 & 21.4 & 6.5 \\
0.5 & 4.0 & 11.9 & 3.5 \\
\mathrm{~N}=201 & \\
\text { (Not Ascertained }=1 \text { ) }
\end{array}
$$

$$
\begin{array}{rrrr}
12.9 & 11.9 & 26.4 & 8.5 \\
2.0 & 6.5 & 11.4 & 4.5 \\
0.5 & 2.0 & 10.0 & 3.0
\end{array}
$$

(Not Ascertained $=1$ )

$$
\begin{array}{rrrr}
11.4 & 12.4 & 24.4 & 9.0 \\
2.5 & 2.0 & 7.5 & 2.5 \\
1.5 & 6.0 & 15.9 & 4.5 \\
& \mathrm{~N}=201 &
\end{array}
$$

(Not Ascertained $=1$ )

$\mathrm{l}_{\mathrm{D} 1}=$ Personal Problems; D2 = Both, But More Persona1; D3 = Both, But More Social, D4 = Social Problems 


\section{TABLE XXXIII}

SIGNIFICANCE OF THE RELATIONSHIPS BETWEEN THE PERCEPTION OF A PERSONAL VS SOCIAL DIMENSION OF PROBLEMS AND ELECTORAL, ISSUE, AND GROUP PARTICIPATION IN INDIVIDUAL AND COMBINED SURVEY NEIGHBORHOODS

ELECTORAL PARTICIPATION

AND PERCEPTION OF A PERSONAL VS SOCIAL DIMENSION OF PROBLEMS

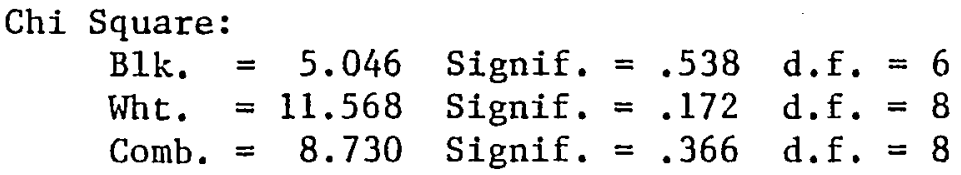

ISSUE PARTICIPATION

AND PERCEPTION OF A PERSONAL VS SOCIAL DIMENSION OF PROBLEMS
Tau c:

$$
\begin{aligned}
& \text { B1k. }=-.029 \\
& \text { Wht. }=+.128 \\
& \text { Comb. }=+.065
\end{aligned}
$$

Gamma :

$$
\text { Blk. }=-.042
$$

Wht. $=+.207$

Comb. $=+.101$
Gamma :

Blk. $=+.036$

Wht. $=+.383$

Comb. $=+.249$

GROUP PARTICIPATION

AND PERCEPTION OF A PERSONAL VS SOCIAL DIMENSION OF PROBLEMS

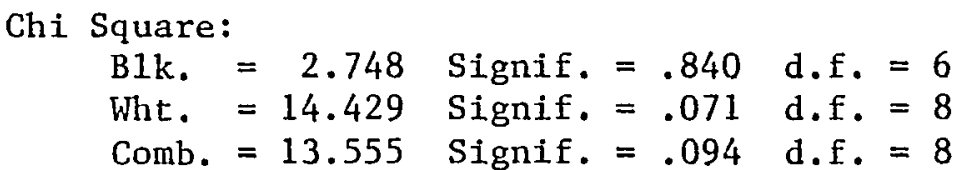

Tau c:

B1k. $=+.097$

Wht. $=+.096$

Comb. $=+.101$
Gamma :

B1k. $=+.150$

Wht. $=+.187$

Comb. $=+.174$ 
borhood respondents.

In general, though the relationships tend to be as predicted, they are not terribly strong. Only the relationship between issue participation and the measure of the personal vs social dimension of problems yields reasonably strong and significant results, and this is only the case in the White survey neighborhood sample. The results do tend to lend some support to the hypothesis, however. This suggests that this may be an area worthy of future exploration with a more sophisticated measure of how people perceive this dimension of problems they identify in their neighborhoods, and how this perception relates to participation. Personal/Social and Non-political/Political Perception of Problems. Perhaps more important than the direct contribution of a perception of the personal vs social dimension of problems to participation is the relationship between the perception of this dimension of problems and the subsequent or concurrent perception of those same problems in political or non-political terms. We proposed earlier in Chapter IV that individuals who perceive problems in social rather than personal terms are more likely to also perceive those problems in political rather than non-political terms. This second related perception is presumed to be more directly related to participation.

Crosstabulation of measures of these two dimensions confirms this association. The relationship between perception of problems in social terms and perception of problems in political terms is quite pronounced. The statistical relationships between the two measures are uniformly strong and uniformly significant for both individual and combined survey neighborhoods. This strongly supports the contention that people who 
perceive problems in social terms are much more likely to also perceive those problems in political terms. This appears to be especially true of Black survey neighborhood respondents. Non-political vs Political Dimension of Problems. A summary of the crosstabulations of participation with the index measuring the perception of a non-political vs political dimension of problems is presented in TABLES XXXIV and XXXV. We observe first in TABLE XXXIV, that a majority of respondents in the survey neighborhood perceive problems in political rather than non-political terms. The percentage of Black survey neighborhood respondents who do so is substantially greater than we find in the case of White survey neighborhood respondents. Further, the table indicates a positive relationship bewteen the perception of problems in political terms and all types of participation in all survey neighborhoods. The strength and significance of the observed relationships is summarized in TABLE XXXV. A familiar pattern is observed in this summary. The strength of the relationships and their significance tends to be more pronounced in the White survey neighborhood sample. The Tau c statistics are all significant, and the Chi Square are. statistically significant in the case of issue and group participation as well. The relationship between issue participation and the perception of problems in political terms is more pronounced than the other relationships, but all observed relationships except those for electoral participation in the Black survey neighborhood are moderately strong. These relationships are reasonable evidence in support of our hypothesis that perceiving problems in political terms is more likely to lead to participation than perceiving problems in non-political terms. 
TABLE XXXIV

RELATIONSHIPS BETWEEN THE PERCEPTION OF A NON-POLITICAL DIMENSION OF PROBLEMS AND ELECTORAL, ISSUE, AND GROUP PARTICIPATION IN INDIVIDUAL AND COMBINED SURVEY NEIGHBORHOODS (EXPRESSED IN PERCENT)

\section{BLACK NEIGHBORHOOD}

Non-Pol. vs Political Problem Perception

\begin{tabular}{|c|c|c|c|c|}
\hline ELECTORAL & $\mathrm{D} 1^{1}$ & $\mathrm{D} 2^{1}$ & D $3^{1}$ & $\underline{D 4^{1}}$ \\
\hline PARTICIPATION & & & & \\
\hline Low & 7.3 & 2.4 & 17.1 & 6.1 \\
\hline Medium & 8.5 & 6.1 & 17.1 & 11.0 \\
\hline High & 0.0 & $\begin{array}{r}7.3 \\
\mathrm{~N}\end{array}$ & $\begin{aligned} & 9.8 \\
= & 82\end{aligned}$ & 7.3 \\
\hline
\end{tabular}

ISSUE

PARTICIPATION

$\begin{array}{lrrrr}\text { Low } & 14.6 & 7.3 & 30.5 & 13.4 \\ \text { Medium } & 1.2 & 6.1 & 7.3 & 7.3 \\ \text { High } & 0.0 & 2.4 & 6.1 & 3.7\end{array}$

GROUP

PARTICIPATION

$\begin{array}{lrrrr}\text { Low } & 12.2 & 4.9 & 23.2 & 6.1 \\ \text { Medium } & 2.4 & 2.4 & 8.5 & 6.1 \\ \text { High } & 1.2 & 8.5 & 12.2 & 12.2\end{array}$

High

\section{WHITE NEIGHBORHOOD}

Non-Pol. vs Political Problem Perception

$$
\begin{aligned}
& \underline{\mathrm{D} 1^{1}} \quad \underline{\mathrm{D} 2^{1}} \quad \underline{\mathrm{D} 3^{1}} \quad \underline{\mathrm{D} 4^{1}} \\
& \begin{array}{rrrr}
8.4 & 9.2 & 8.4 & 5.9
\end{array} \\
& \begin{array}{llll}
12.6 & 11.8 & 18.5 & 6.7
\end{array} \\
& \begin{array}{llll}
0.0 & 2.5 & 8.4 & 5.9
\end{array} \\
& \mathrm{~N}=119
\end{aligned}
$$

$$
\begin{array}{rrrr}
16.8 & 15.1 & 15.1 & 7.6 \\
4.2 & 7.6 & 7.6 & 6.7 \\
0.0 & 0.8 & 12.6 & 4.2
\end{array}
$$

(Not Ascertained $=2$ )

$$
\begin{array}{rrrr}
16.8 & 18.5 & 16.0 & 12.6 \\
2.5 & 1.7 & 5.0 & 1.7 \\
1.7 & 3.4 & 14.3 & 4.2 \\
\multicolumn{4}{c}{\mathrm{N}=119} \\
\text { (Not Ascertained }=2 \text { ) }
\end{array}
$$

\section{COMBINED NEIGHBORHOODS}

Non-Pol. vs Politica1 Problem Perception

$$
\begin{aligned}
& \underline{\mathrm{DI}^{1}} \quad \underline{\mathrm{D} 2^{1}} \quad \underline{\mathrm{D} 3^{1}} \quad \underline{\mathrm{D} 4^{1}} \\
& \begin{array}{llll}
8.0 & 6.5 & 11.9 & 6.0
\end{array} \\
& \begin{array}{rrrr}
10.9 & 9.5 & 17.9 & 8.5
\end{array} \\
& \begin{array}{llll}
0.0 & 4.5 & 9.0 & 6.5
\end{array}
\end{aligned}
$$

( Not Ascertained $=2$ )

\begin{tabular}{rrrr}
15.9 & 11.9 & 21.4 & 10.0 \\
3.0 & 7.0 & 7.5 & 7.0 \\
0.0 & 1.5 & 10.0 & 4.0 \\
\multicolumn{4}{c}{$\mathrm{N}=201$} \\
(Not Ascertained $=$ & 2)
\end{tabular}

$$
\begin{array}{rrrr}
14.9 & 12.9 & 18.9 & 10.0 \\
2.5 & 2.0 & 6.5 & 3.5 \\
1.5 & 5.5 & 13.4 & 7.5 \\
& \mathrm{~N}=201
\end{array}
$$

(Not Ascertained $=2$ ) 
SIGNIFICANCE OF THE RELATIONSHIPS BETWEEN THE PERCEPTION OF A NON-POLITICAL VS POLITICAL DIMENSION OF PROBLEMS AND ELECTORAL, ISSUE, AND GROUP PARTICIPATION IN INDIVIDUAL AND COMBINED SURVEY NEIGHBORHOODS

\section{ELECTORAL PARTICIPATION}

AND PERCEPTION OF A POLITICAL VS NON-POLITICAL DIMENSION OF PROBLEMS

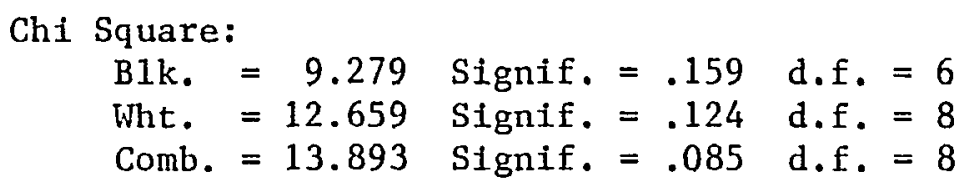

Gamma :

$$
\begin{aligned}
& \text { Blk. }=+.123 \\
& \text { Wht. }=+.295 \\
& \text { Comb. }=+.229
\end{aligned}
$$

ISSUE PARTICIPATION

AND PERCEPTION OF A POLITICAL VS NON-POLITICAL DIMENSION OF PROBLEMS

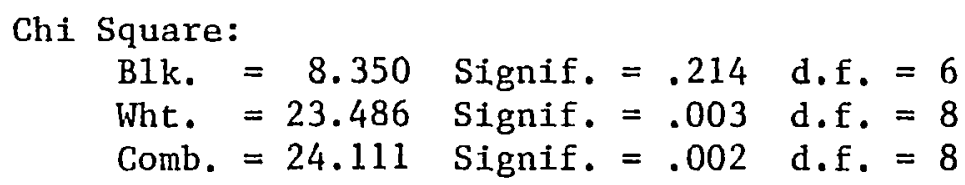

GROUP PARTICIPATION

AND PERCEPTION OF A POLITICAL VS NON-POLITICAL DIMENSION OF PROBLEMS
Chi Square:

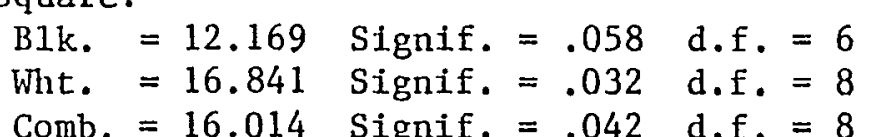

Tau c:

Blk. $=+.203$

Wht. $=+.157$

Comb. $=+.192$
Gamma :

B1k. $=+.222$

Wht. $=+.421$

Comb. $=+.327$
Gamma :

Blk. $=+.299$

Wht. $=+.273$

Comb. $=+.306$ 
Local vs National Dimension of Problems. Our "guiding hypotheses" in Chapter IV proposed that individuals who perceived problems as being local rather than national in nature, would be more likely to participate in neighborhood issues and neighborhood groups. If they perceive problems to be national in nature, it was suggested that they are more likely to participate in traditional electoral activities. The evidence summarized in TABLES XXXVI and XXXII fails to adequately support either of these hypotheses.

As TABLE XXXVI indicates, roughly an equivalent majority of each sample population perceive the problems they identify in their neighborhoods in national rather than local terms. This perception is positively related to all types of participation, and is strongest for issue and group participation in the White survey neighbornood.

The strength and significance of the relationships is summarized in TABLE XXXVII. Here we find moderate and significant relationships only In the case of issue participation in the White survey neighborhood. The balance of the relationships show less strength. This is particularly true of the Black survey neighborhood sample, where the relationships show little or no association between the perception of a local vs national dimension of problems and participation.

While the results of the analysis do not lend support to the two hypotheses, it is still possible that the postulated relationships may exist. In de-briefing interviewers in the study it was learned that the set of questions which make up the index of perception of a local vs national problem dimension presented some difficulty. This is because the problem areas used in the study were broad enough to be considered 
TABLE XXXVI

RELATIONSHIPS BETWEEN THE PERCEPTION OF A LOCAL VS NATIONAL DIMENSION OF PROBLEMS AND ELECTORAL, ISSUE AND GROUP PARTICIPATION IN INDIVIDUAL AND COMBINED SURVEY NEIGHBORHOODS (EXPRESSED IN PERCENT)

BLACK NEIGHBORHOOD

Local vs National

Problem Perception

ELECTORAL

PARTICIPATION

$\begin{array}{lrrrr}\text { Low } & 6.1 & 4.9 & 12.2 & 9.8 \\ \text { Medium } & 11.0 & 4.9 & 17.1 & 9.8 \\ \text { High } & 0.0 & 11.0 & 3.7 & 9.8 \\ & & \mathrm{~N}=82 & \end{array}$

ISSUE

PARTICIPATION

$\begin{array}{lrrrr}\text { Low } & 15.9 & 11.0 & 19.5 & 19.5 \\ \text { Medium } & 0.0 & 4.9 & 9.8 & 7.3 \\ \text { High } & 1.2 & 4.9 & 3.7 & 2.4 \\ & & \mathrm{~N}=82\end{array}$

GROUP

PARTICIPATION

\begin{tabular}{lrrrr} 
Low & 12.2 & 6.1 & 12.2 & 15.9 \\
Medium & 2.4 & 3.7 & 9.8 & 3.7 \\
High & 2.4 & 11.0 & 11.0 & 9.8 \\
& \multicolumn{4}{c}{$\mathrm{B}=82$}
\end{tabular}

\section{WHITE NEIGHBORHOOD}

Local vs National

Problem Perception

$$
\begin{aligned}
& \underline{\mathrm{D} 1^{1}} \quad \underline{\mathrm{D} 2^{1}} \quad \underline{\mathrm{D} 3^{1}} \quad \underline{\mathrm{D} 4^{1}} \\
& \begin{array}{llll}
5.9 & 6.7 & 14.3 & 5.0
\end{array} \\
& \begin{array}{llll}
9.2 & 14.3 & 15.1 & 11.8
\end{array} \\
& \begin{array}{llll}
0.8 & 6.7 & 5.0 & 4.2
\end{array} \\
& \mathrm{~N}=119
\end{aligned}
$$

(Not Ascertained = 1)

$$
\begin{array}{rrrr}
12.6 & 13.4 & 21.8 & 6.7 \\
2.5 & 7.6 & 5.0 & 11.8 \\
0.8 & 6.7 & 7.6 & 2.5 \\
& \mathrm{~N}=119 &
\end{array}
$$

(Not Ascertained $=1)$

$$
\begin{array}{rrrr}
14.3 & 16.0 & 21.0 & 12.6 \\
0.8 & 2.5 & 5.0 & 3.4 \\
0.8 & 9.2 & 8.4 & 5.0 \\
& \mathrm{~N}=119 &
\end{array}
$$

(Not Ascertained $=1$ )
COMBINED NEIGHBORHOODS

$$
\begin{aligned}
& \text { Local vs National } \\
& \text { Problem Perception } \\
& \begin{array}{rlrrr}
\mathrm{D}^{1} & \text { D2 } & \text { D3 }{ }^{1} & \multicolumn{1}{c}{\text { D4 }^{1}} \\
6.0 & 6.0 & 13.4 & 7.0 \\
10.0 & 10.4 & 15.9 & 10.9 \\
0.5 & 8.5 & 4.5 & 6.5 \\
& \mathrm{~N}= & 201 &
\end{array}
\end{aligned}
$$$$
\text { (Not Ascertained }=1 \text { ) }
$$

$$
\begin{array}{rrrr}
13.9 & 12.4 & 20.9 & 11.9 \\
1.5 & 6.5 & 7.0 & 10.0 \\
1.0 & 6.0 & 6.0 & 2.5 \\
& \mathrm{~N}= & 201 &
\end{array}
$$

(Not Ascertained = 1)

$$
\begin{array}{rrrr}
13.4 & 11.9 & 17.4 & 13.9 \\
1.5 & 3.0 & 7.0 & 3.5 \\
1.5 & 10.0 & 9.5 & 7.0 \\
& \mathrm{~N}=201 &
\end{array}
$$

(Not Ascertained $=1$ )

${ }^{1}{ }_{D 1}=$ Local Problems; D2 = Both, But More Local; D3 = Both, But More Nationa; D4 = Nationa1 Problems. 
SIGNIFI(AANCE OF THE RELATIONSHIPS BETWEEN THE PERCEPTION OF A LOCAL VS NATIONAL DIMENSION OF PROBLEMS AND ELECTORAL, ISSUE, AND GROUP PARTICIPATION IN INDIVIDUAL AND COMBINED SURVEY NEIGHBORHOODS

ELECTORAL PARTICIPATION

AND PERCEPTION OF A LOCAL VS NATIONAL DIMENSION OF PROBLEMS

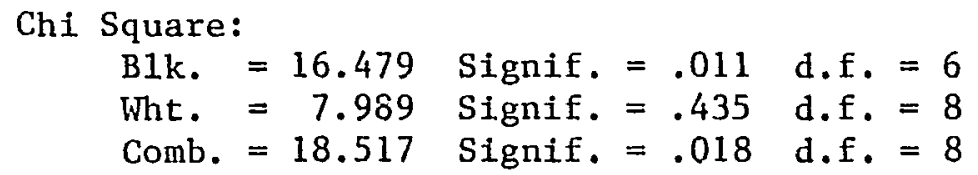

ISSUE PARTICIPATION

AND PERCEPTION OF A LOCAL VS NATIONAL DIMENSION OF PROBLEMS

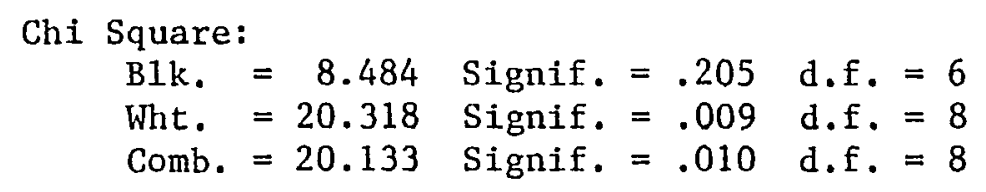

GROUP PARTICIPATION

AND PERCEPTION OF A LOCAL VS NATIONAL DIMENSION OF PROBLEMS

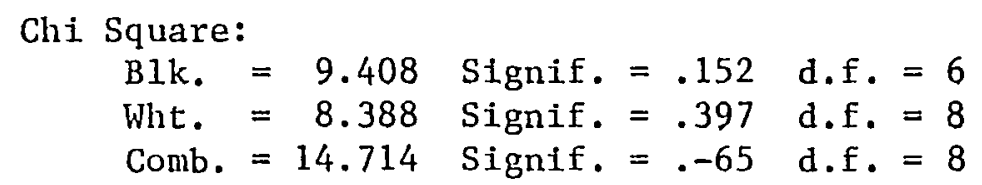

Tau c:

$$
\begin{aligned}
& \text { B1k. }=+.030 \\
& \text { Wht. }=+.049 \\
& \text { Comb. }=+.043
\end{aligned}
$$

Gamma :

$$
\begin{aligned}
& \text { B1k. }=+.041 \\
& \text { Wht. }=+.072
\end{aligned}
$$$$
\text { Comb. }=+.062
$$
Tau e:
B1k. $=+.054$
Wht. $=+.152$
Comb. $=+.107$

Gamma :

Blk. $=+.097$

Wht. $=+.228$

Comb. $=+.172$

$$
\begin{array}{ll}
\text { Tau c: } & \\
\text { B1k. } & =+.024 \\
\text { Wht. } & =+.105 \\
\text { Comb. } & =+.083
\end{array}
$$

Gamma :

$$
\begin{aligned}
& \text { B1k. }=+.034 \\
& \text { Wht. }=+.187 \\
& \text { Comb. }=+.130
\end{aligned}
$$


primarily national problems with a local manifestation. These are also the sort of broad problems or issues covered in the mass communication media, especially television. Since most of the survey respondents get their information from television, it is reasonable to assume this to be a factor in their perception of issues and problems. A more carefully designed and refined measure of this problem dimension--one which considers neighborhood vs community issues and problems, perhaps--may produce results in support of the hypotheses.

\section{SUMMARY}

We have seen in this analysis of the relationships between the perception of problems and participation that participation, especially the more non-traditional issue and group types of participation advocated by the federal mandate, is strongly associated with how individuals perceive problems in their neighborhoods in a number of ways. First, the identification of neighborhood problems has been observed to be strongly and significantly linked to individual participation in neighborhood issues and groups, particularly among the White survey neighborhood respondents. The more problems people perceive in their neighborhoods, the more likely they are to become involved.

Second, we have seen by examining the salience of five specific problem areas that problem salience is also related to participation in three of the five problem areas studied. People who perceive a salient problem are, therefore, more likely to participate than those who do not perceive a problem or who perceive a problem that is not salient to them. Salient problems which by their nature can be perhaps more visibly and immediately affected by citizen action appear to motivate people to 
become involved at the neighborhood level than other types of problems. Although the identification of a single salient problem appears to be less strongly associated with participation than does the perception of many problems in the context of the neighborhood, the importance of salient problems must, nonetheless, be appreciated in the calculus of individual participation. This would be especially true if several salient problems are believed by the individual to exist concurrently in his or her neighborhood.

Third, we again observe differences in the importance of these factors in the participatory behavior of our Black and White survey neighborhood populations. Nearly all of the relationships between the perception of problems and participation in the Black survey neighborhood are both weaker and less significant than those found in the White survey neighborhood. This reinforces our earlier observation that participation by residents of this neighborhood is not as highly related to the perception of problems as participation by the White survey neighborhood respondents. However, Black survey neighborhood respondents who have strong roots in their neighborhood--as homeowners and/or longtime residents--are more likely to respond to their perception of neighborhood problems by participating than their neighbors with weaker connections to the neighborhood. In the White survey neighborhood, where the percentage of resident homeowners is smaller according to the U.S. Census statistics (see Appendix A), neighborhood roots appear to be less related to problem identification, problem salience, or participation. Fourth, people who feel they can do something about the specific problems they perceive in their neighborhoods--either personally, or as part of a group-are more likely to become involved in neighborhood 
issues and neighborhood groups. The added support of the neighborhood group is observed to be especially important among Black survey neighborhood respondents. Further, these feelings of efficacy are important for the relationships between participation and the identification of salient neighborhood problems. Those who perceive a salient problem are more likely to follow up that perception with action if they also feel they can do something about that problem. Feelings of helplessness in the face of problems may lead to cynical attitudes and withdrawal from active involvement. In our study, cynical attitudes were more prevalent in the Black survey neighborhood sample, and were a factor in the participatory behavior of these respondents.

Finally, people who define the problems they perceive in political rather than non-political terms are more likely to participate than those who do not. This dimension of neighborhood problems is closely related to the perception of the problems in social, rather than personal terms. Those who believe the problems they perceive to be social or societal in nature are more likely to define the problems as political, and are more likely to participate as a result. Black survey neighborhood respondents were found to perceive problems in political terms more often than their White survey neighborhood counterparts, but this perception appears to be less important for their subsequent action or lack of action. This may well be a reflection of the lower feelings of efficacy and greater cynicism found among respondents in the Black survey neighborhood.

We can reasonably conclude from these findings that the perception of neighborhood problems is related in various ways to individual political participation. This is especially true of the types of non- 
traditional political participation represented by neighborhood issue and group participation--types of participation not adequately explained or predicted by the traditional studies of electoral behavior. There is much less of a relationship observed between problem perceptions and traditional electoral participation than we found in the case of issue and group participation. These findings also tend to confirm the value or utility of the perceptual variables suggested by the social-psychological model of political behavior. They are found to increase our understanding of citizen involvement in neighborhood issues and groups in these two low-income neighborhoods.

As important as the perceptions of problems may be in the individual decision to consider becoming involved in political activity, we are still left with the question of what actions are likely to result. Here we must begin to consider how the individual evaluates political participation. Is it a valuable process? Is it an effective process? Answers to these questions, and questions about the efficacy and legitimacy of specific participatory activities, are part of an assessment made by the individual as he or she decides whether or not to take some specific action We will examine how these assessments are related to participation in the next chapter which considers individuals' attitudes about the value of participation. 
FOOTNOTES

${ }^{105}$ Interview with Howard Steward, Project Director, Portland Action Committees Together, Inc., July, 1970; and Interview with Irma Hepburn, Portland Metropolitan Steering Committee, July, 1974.

${ }^{106}$ Report of the National Advisory Commission on Civil Disorders, (New York: New York Times Co., 1968), pp. 135-150.

107 Milbrath and Goel, op. cit., pp. 57-61 and 157-158; Verba and Nie, op. cit., p. 187.

108 Especially true of studies which attempt to relate public opinion. to political (voting) behavior. The salience of issues about which opinions are asked is found to be an important factor in the subsequent behavior of the individual. The importance of elections is also seen to be related to higher levels of participation. See, for example, Milbrath and Goel, op. cit., pp. 138-139.

${ }^{109}$ The significance level of the Tau $b$ and Tau $c$ statistics is included in the output of the crosstabulations generated by the SPSS statistical package used in computer processing of the data. These significance level figures are not presented in the tables for purposes of clarity of presentation in the table layout. To include them would have unnecessarily cluttered the table.

110

Milbrath and Goel, op. cit., pp. 113-114.

111 Ibid., pp. 61-74. See also, John S. Jackson, III, "Alienation and Black Political Participation", Journal of Politics, XXXV (November, 1973), pp. 849-885.

${ }^{112}$ These two scales are cataloged in John P. Robinson, Jerrold G. Rusk, and Kendra B. Head, eds., Measures of Political Attitudes, (Ann Arbor, Mich.: Survey Research Center, University of Michigan, 1968), Pp. 479-481. 


\section{CHAPTER VIII}

\section{PARTICIPATION AND ATTITUDES ABOUT \\ THE VALUE OF PARTICIPATION}

\section{INTRODUCTION}

of the assumptions expressed or implied in the citizen participation 1iterature, most deal in one way or another with the value of participation. Some believe participation to have intrinsic value as an end in itself, regardless of what might be accomplished through participation. Others, as we have seen in Chapters III and IV, believe participation to have value primarily as a means to achieve a number of desirable ends: the self-improvement of the individual participant; the solution of neighborhood problems; the legitimization of plans, policies, and programs; the creation of social change; etc.

Citizen participation in practice may accomplish some of all or some of none of these worthy goals, but a necessary question remains largely unanswered. What does participation mean to those to whom participation programs have been addressed? It is our contention, based upon elements of the social-psychological model of political behavior introduced in Chapter III, that the attitudes of potential participants toward participation--both as means and end--are significantly associated with their decision to become involved or not. Attitudes toward the value of participation as an end, for example, may relate to an individual's feelings of citizen duty and his subsequent willingness or desire to participate. Attitudes toward the value of participation as a means to achieve other 
ends may significantly figure into the cost/benefit calculation which influences both the individual's decision to participate, and the mode of participation ultimately chosen. This chapter will examine such attitudes, and will assess their importance in the participatory behavior of respondents in the two neighborhood sample populations included in this study.

\section{PARTICIPATION AND ATTITUDES TOWARD PARTICIPATION AS A VALUED GOAL}

One of the arguments used by proponents of citizen participation for its justification is that participation is an essential ingredient of a healthy democratic society. Assumed in this argument is a requirement that in order to be healthy, the democratic society must both allow and encourage participation by all segments of the society. Also assumed is a willingness on the part of the populace to perform their citizen duty to participate. This willingness to participate, and the feelings of citizen duty to participate, are assumed to be characteristic of the lower as well as the upper strata of the society. The problem is seen as one of lack of opportunity and a surplus of obstacles to participation on the part of lower status citizens of the society. We must at this point begin to examine some of these assumptions in order to more fully understand the participatory behavior of lower income individuals.

Attitudes toward participation as a valued social goal logically relate to feelings of citizen duty and a willingness to participate. If people feel that participation is not of value, then they are less likely to feel a duty or willingness to participate. The question to be examined here is whether there are significant relationships between the partici- 
pation of low-income residents in our two survey neighborhoods and their attitudes about the value of particlpation as a desirable goal in society. As outlined in Chapter IV, one of the "guiding hypotheses" or research propositions of the study is that people who believe that participation is a valued goal apart from what it might accomplish are more likely to participate than those who do not.

In order to test this proposition, a measure of the attitudes toward participation as a valued goal must first be specified. Questions 74 through 77 of the interview questionnaire (see Appendix E) were included to allow such a measurement.

Respondents were asked how strongly they agreed or disagreed with five statements about the importance or value of participation. While no attempt was made to scale the five items, they were designed so that it was progressively "harder" for respondents to agree. The five statements are as follows:

1. All citizens have a right to participate in deciding issues that affect them.

2. People should participate in deciding issues that are important to them.

3. Participation by people in decisions that affect them is more important than what decisions are made.

4. Participation by people in decisions that affect them is important even if the decisions are harder to make and might be delayed for longer periods of time.

5. Participation by people in decisions that affect them is important even if the decisions made might be wrong.

Calculating the average of the Likert Scale scores for the five items produces an index of attitudes toward participation as a valued goal ranging from one (most valued as a goal) to six (least valued as a goal). The index was subsequently collapsed into three categories for ease of analysis. 
The relationships between the attitudes of respondents toward participation as a valued goal and their participatory behavior are summarized in TABLES XXXVIII and XXXIX. The data in these two tables indicate a widely shared attitude that participation is a valued social or societal goal, but they also indicate that this attitude is strongly associated with participation only among our Black survey neighborhood respondents.

In TABLE XXXVIII, we see that fully $90 \%$ of the respondents in the Black survey neighborhood score high on the index measuring attitudes toward participation as a valued goal. Of these, three-quarter are moderately or highly involved in electoral activity, half are moderately or highly active in neighborhood issues, and nearly two-thirds are similarly involved in neighborhood groups. Virtually all of those who are among the most highly active in each type of participation also score high on the index of attitudes toward participation as a valued goal.

These relationships are clearly reflected in the statistical summary in TABLE XXXIX. The Gammas all indicate very strong and positive relationships exist. This is especially pronounced for electoral and group participation, but much less so for issue participation. Since issue participation is logically a less symbolic or expressive activity, this is not surprising. The Chi Squares indicate nearly significant statistical relationships exist in only the case of electoral and group participation, as do the Tau statistics, which are not as strong as the Gammas, but are strong enough to be statistically significant in both cases.

These tables indicate a much different situation exists for the White survey neighborhood respondents. Again, most (84\%) of the respondents scored high on the index measuring attitudes toward participation as a vaiued goal, but these attitudes are not related to participation in 
TABLE XXXVIII

RELATIONSHIPS BETWEEN ATTITUDES TOWARD PARTICIPATION AS A VALUED GOAL AND ELECTORAL, ISSUE AND GROUP PARTICIPATION IN INDIVIDUAL AND COMBINED SURVEY NEIGHBORHOODS (EXPRESSED IN PERCENT)

BLACK NEIGHBORHOOD

Participation As

A Valued Goal

ELECTORAL

PARTICIPATION

Low

Medium

High

\begin{tabular}{|c|c|c|}
\hline Low & Med. & High \\
\hline$\overline{0.0}$ & $\overline{6.2}$ & 23.1 \\
\hline 0.0 & 3.1 & 41.5 \\
\hline 0.0 & 0.0 & 26.2 \\
\hline
\end{tabular}

ISSUE

PARTICIPATION

Low
Medium
High

$\begin{array}{lll}0.0 & 7.7 & 55.4 \\ 0.0 & 1.5 & 23.1 \\ 0.0 & 0.0 & 12.3\end{array}$

$\mathrm{N}=65$ Missing $=17$

GROUP

PARTICIPATION

Low

Medium

High
WHITE NEIGHBORHOOD

Participation As

A Valued Goal

$\frac{\text { Low }}{0.0} \frac{\text { Med. }}{7.1} \frac{\text { High }}{28.6}$

$0.0 \quad 4.8 \quad 36.9$

$\begin{array}{lll}1.2 & 2.4 & 19.0\end{array}$

$\mathrm{N}=84$ Missing $=35$
COMBINED NEIGHBORHOODS

\section{Participation As \\ A Valued Goal}

\begin{tabular}{|c|c|c|}
\hline Low & Med. & High \\
\hline 0.0 & 6.7 & 26. \\
\hline 0.0 & 4.0 & 38.9 \\
\hline 0.7 & 1.3 & 22 \\
\hline
\end{tabular}

$\mathrm{N}=149$ Missing $=52$

\section{$0.0 \quad 6.0 \quad 40.5$ \\ $\begin{array}{lll}0.0 & 4.8 & 26.2\end{array}$ \\ $\begin{array}{lll}1.2 & 3.6 & 17.9\end{array}$}

$\mathrm{N}=84$ Missing $=35$ $\begin{array}{lll}0.0 & 6.7 & 47.0\end{array}$

$\begin{array}{lll}0.0 & 3.4 & 24.8\end{array}$

$\begin{array}{lll}0.7 & 2.0 & 15.4\end{array}$

$\mathrm{N}=149$ Missing $=52$
$\begin{array}{lll}0.0 & 7.7 & 33.8\end{array}$
$0.0 \quad 1.5 \quad 21.5$
$0.0 \quad 0.0 \quad 35.4$
$\begin{array}{lll}0.0 & 9.5 & 51.2\end{array}$
$\begin{array}{lll}0.0 & 2.4 & 8.3\end{array}$
$1.2 \quad 2.4 \quad 25.0$
$\mathrm{N}=65 \quad$ Missing $=17$
$\mathrm{N}=84$ Missing $=35$

$\begin{array}{lll}0.0 & 8.7 & 43.6\end{array}$

$\begin{array}{lll}0.0 & 2.0 & 14.1\end{array}$

$\mathrm{N}=149$ Missing $=52$ 
SIGNIFICANCE OF THE RELATIONSHIPS BETWEEN ATTITUDES TOWARD PARTICIPATION AS A VALUED GOAL AND ELECTORAL, ISSUE, AND GROUP PARTICIPATION IN INDIVIDUAL AND COMBINED SURVEY NEIGHBORHOODS

ELECTORAI, PARTICIPATION

AND ATTITUDES TOWARD PARTICIPATION AS A VALUED GOAL

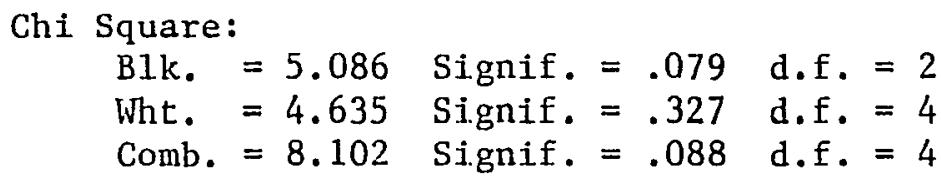

ISSUE PARTICIPATION

AND ATTITUDES TOWARD PARTICIPATION AS A VALUED GOAL

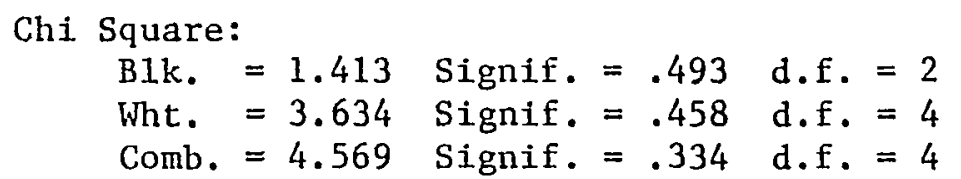

GROUP PARTICIPATION

AND ATTITUDES TOWARD PARTICIPATION AS A VALUED GOAL

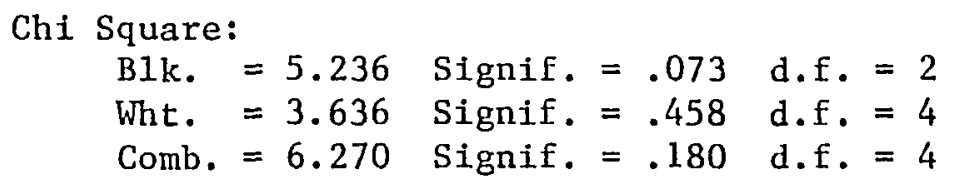

Tau b:

$$
\begin{aligned}
& \text { B1k. }=+.170^{1} \\
& \text { Wht. }=+.051 \\
& \text { Comb. }=+.134
\end{aligned}
$$

Gamma :

$$
\begin{aligned}
& \text { B1k. }=+.750 \\
& \text { Wht. }=+.122 \\
& \text { Comb. }=+.344
\end{aligned}
$$

$$
\begin{aligned}
\text { Tau b: } & \\
\text { B1k. } & =+.176^{1} \\
\text { Wht. } & =+.015 \\
\text { Comb. } & =+.125
\end{aligned}
$$$$
\text { Gamma : }
$$$$
\text { Blk. }=+.809
$$$$
\text { Wht. }=+.039
$$$$
\text { Comb. }=+.351
$$ 
the same ways we observed among the Black survey neighborhood respondents. The data in TABLE XXXIX indicate little or no relationship between these attitudes and participation in either the case of electoral activity or neighborhood group activity. Further, the negative association observed in the case of issue participation suggests that those individuals who see participation as an end in itself are less likely to participate in attempts to affect the resolution of neighborhood issues.

What these data appear to suggest fairly convincingly is that viewing participation as a valued goal is an important factor associated with participation among respondents on our Black survey neighborhood. For those in our White survey neighborhood, something other than participation itself is the goal, and while participation is viewed by most as a valued goal, this attitude bears little direct relationship to their participatory behavior.

\section{PARTICIPATION AND ATTITUDES TOWARD PARTICIPATION} AS A MEANS TO ACHIEVE OTHER GOALS

As indicated earlier, by far most of the assumptions expressed or implied in the citizen participation literature relate to the value of participation as an effective means of bringing about a broad range of desirable ends or goals. There was neither the time nor the resources to consider the value of participation as an effective means to achieve this entire range of goals proposed in the literature. Instead, two will be considered which follow naturally from the thrust of the research and analysis thus far. We will consider first the value of participation as a means to bring about the solution of perceived neighborhood problems, and second, the value of participation as a means of self-improvement. 
More specifically, we will examine how individuals' attitudes toward participation as a means to achieve other goals (ie. to solve problems in their neighborhoods or to improve their stock of skills to solve neighborhood problems) relates to their level of involvement in the three types of participatory activity which is the focus of this study. This approach is taken for several reasons. First, such attitudes are suggested by the social-psychological model of political behavior to be important variables in the cost/benefit calculation which determines participation. Second, by focusing on the solution of problems or increasing the skills needed to solve neighborhood problems as the "ends" which participation is to achieve, we maintain a necessary link to the analysis already presented. Finally, to assess the actual impact or efficacy of participation merits a research effort much too ambitious to attempt given the limited scope and resources of the present research effort.

Efficacy of Participation Modes for Solving Neighborhood Problems

In order to measure the attitudes of respondents toward participation as a means to achieve other goals, two sets of five similar and related questions were asked of each respondent. In the first set, individuals were asked to indicate how effective or ineffective they felt each of five types or modes of participation were as means of affecting decisions designed to bring about the solution of neighborhood problems--regardless of whether they believed any of the modes of participation to be right or wrong. The five modes of participation were chosen so that they ranged from most traditional to most non-traditional. They included voting, petitioning, collective action, protest, and violence. 
In the second set of questions, respondents were asked how strongly they approved or disapproved these same modes of participation as a means of affecting decisions about the solution of neighborhood problems. They were asked to evaluate the appropriateness of these modes of participation regardless of how effective or ineffective they believed any of them to be. The specific questions which make up the measure are indicated below: (Refer to questions 78 through 87 in Appendix E.)

In order to solve neighborhood problems, decisions have to be made about what to do. There are many ways people can help get decisions made that they approve, and to stop decisions they are against. In the next five questions I would like you to tell me how effective you feel some of these ways are-megardless of whether you feel they are right or wrong.

1. Some people feel voting is very effective. Others feel it is not effective at all. Do you feel voting is: ...?

2. Some people feel that things like writing letters to officials, signing or circulating petitions, or speaking out at public hearings are very effective. Others feel these kinds of things are not effective at all. Do you feel these kinds of things are: ...?

3. Some people feel joining with others and working together as a group is very effective. Others feel it is not effective at a11. Do you feel joining a group and working together is: ...?

4. Some people feel organized, peaceful demonstrations and picketing are very effective. Others feel they are not effective at all. Do you feel peaceful demonstrations and picketing are: ...?

5. Some people feel violent demonstration and rioting are very effective. Others feel they are not effective at all. Do you feel violent demonstrations and rioting are: ...?

Just as you feel that some of these ways to help get decisions made are more effective than others, you may also feel that some of them are right or wrong--regardless of how effective you feel they are. In the next five questions I would like to ask you how strongly you approve or do not approve of these ways to get decisions made. 
1. Some people approve of voting. Others do not. Do you approve very strongly, somewhat, very little, or not at all?

2. Some people approve of things like writing letters to officials, signing or circulating petitions, or speaking out at public hearings. Others do not. Do you approve of these kinds of things very strongly, somewhat, very little, or not at all?

3. Some people approve of joining with others and working together as a group. Others do not. Do you approve of joining a group and working together very strongly, somewhat, very little, or not at all?

4. Some people approve of organized, peaceful demonstrations and picketing. Others do not. Do you approve of peaceful demonstrations and picketing very strong$1 \mathrm{y}$, somewhat, very little, or not at all?

5. Some people approve of violent demonstrations and rioting. Others do not. Do you approve of violent demonstrations and rioting very strongly, somewhat, very little, or not at all?

If we were to dichotomize the four responses to each question into categories representing either effective/not effective or approved/not approved, the responses for a given mode of participation could fall into one of four possible categories. These categories are indicated in Figure 2.

Efficacy of Participation Mode Effective Not Effective

Approval of

Participation

Mode

Approved $\quad 1$

Not Approved 3 4

Figure 2. Possible response categories for a combined measure of approval and efficacy of participation modes. 
These categories are considered in the study to form an index measuring attitudes toward each of the modes of participation as approved and effective means of affecting decisions which are aimed at the solution of neighborhood problems.

While the categories of the index created are formally nominal categories, it is not unreasonable to assume some order among them as they relate to participatory behavior. Certainly it is reasonable, for example, to assume that those modes which are both approved and believed to be effective are likely to be used more often than those which are neither approved nor considered effective. A cost/benefit calculation would clearly favor the first case over the second, all other things being equal. It is also reasonable to assume that modes which are approved but not seem as effective are more likely to be used than those which are believed to be effective but not approved. The psychic costs of the former case are far less than in the latter case, even though the potential benefits may well be less as well. For these reasons, the response categories of the index for each participation mode are assumed to be ordered as indicated in Figure 2. An examination of the data tend to confirm the validity of this assumption.

In the tables that follow, the relationships between participatory behavior and attitudes toward these various modes of participation as approved and effective means to affect problem-solving decisions are clear. The most traditional form of participation--electoral behavior-is strongly associated with attitudes toward voting as an approved and effective mode of participation. Issue and group activity are clearly related to attitudes toward the value of the less traditional modes of participation, with the exception of violent demonstrations or rioting which are neither widely approved nor believed to be effective. 
Voting: The relationships between participation and attitudes toward voting as an approved and effective mode of participation are summarized in TABLES XL and XLI. The data in these tables indicate a very strong relationship exists between electoral activity and attitudes toward voting among all survey respondents. Respondents in the White survey neighborhood tend to approve of voting as much as their Black survey neighborhood counterparts, but they evaluate the efficacy of voting somewhat higher. As we can observe in TABLE XL, $73 \%$ of the respondents in the white survey neighborhood feel voting is an effective means of affecting problemsolving decisions, while $62 \%$ of the Black survey neighborhood respondents hold a similar view. For each neighborhood sample, however, those who both approve voting and find it to be effective are more active electorally than those who do not. This relationship is both very strong and statistically significant, as reflected in TABLE XII.

The influence of these attitudes is observed to carry over to the other types of participatory activity for the Black survey neighborhood respondents. This is not true of respondents in the White survey neighborhood, where attitudes toward voting show little or no association with issue or group participation. This difference may be a further reflection of the attitudes found among the Black survey neighborhood respondents that participation is desirable regardless of what it can accomplish (and regardless of how effective it might be in the process.)

Petitioning. Petitioning, as defined in the study, is a mode of participation which can be considered transitional in nature. Writing letters to officials can be considered a traditional electoral activity. ${ }^{113}$ Signing or circulating petitions may also be considered traditional 
TABLE XL

RELATIONSHIPS BETWEEN ATTITUDES TOWARD VOTING AS AN APPROVED AND EFFECTIVE MODE OF PARTICIPATION AND ELECTORAL, ISSUE, AND GROUP PARTICIPATION IN INDIVIDUAL AND COMBINED SURVEY NEIGHBORHOODS (EXPRESSED IN PERCENT)

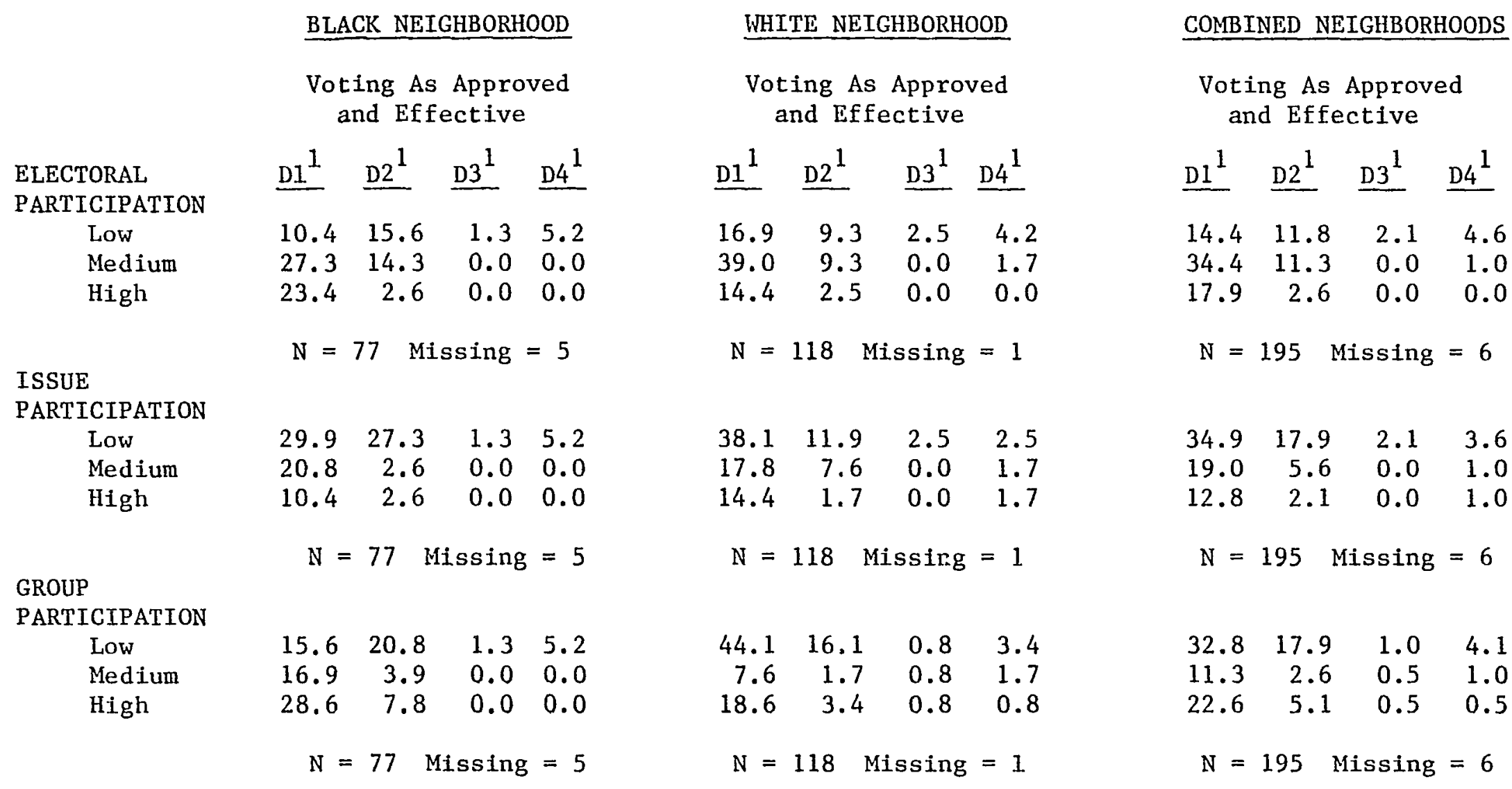

${ }^{1} \mathrm{D} 1=$ Approved and Effective; $\mathrm{D} 2$ = Approved But Not Effective; $\mathrm{D} 3$ = Not Approved But Effective; D4 = Not Approved and Not Effective. 


\section{TABLE XLI}

SIGNIFICANCE OF THE RELATIONSHIPS BETUEEN ATTITUDES TOWARD VOTING AS AN APPROVED AND EFFECTIVE MODE OF PARTICIPAT'ION AND ELECTORAL, ISSUE, AND GROUP PARTICIPATION IN INDIVIDUAL AND COMBINED SURVEY NEIGHBORHOODS

ELECTORAL PARTICIPATION

AND ATTITUDES TOWARD VOTING AS AN APPROVED AND EFFECTIVE MODE OF PARTICIPATION

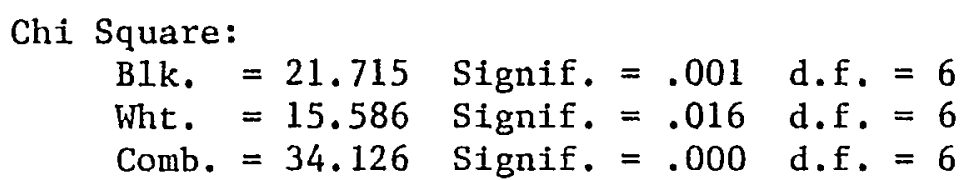

ISSUE PARTICIPATION

AND ATTITUDES TOWARD VOTING AS AN APPROVED AND EFFECTIVE MODE OF PARTICIPATION

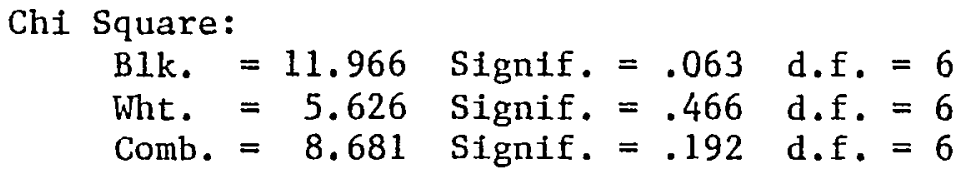

Gamma :

$$
\begin{aligned}
& \text { Blk. }=-.728 \\
& \text { Wht. }=-.519 \\
& \text { Comb. }=-.605
\end{aligned}
$$

Gamma : Blk. $=-.684$
Wht. $=-.092$
Comb. $=-.329$
Gamma :

$$
\begin{aligned}
& \text { B1k. }=-.640 \\
& \text { Wht. }=-.108 \\
& \text { Comb. }=-.339
\end{aligned}
$$


electoral activity, but it could just as easily be part of involvement in a neighborhood issue or group. The same might be said for testimony at a public hearing. In any case, it is reasonable to expect that people who approve of petitioning as a mode of participation and who also find if to be effective would be more active than those who do not.

We see in TABLES XIII and XIIII, that nearly equal percentages of respondents in both neighborhoods approve petitioning. The same percentages of respondents in each neighborhood (48\%) also find petitioning an effective means of affecting decisions aimed at solving problems in their neighborhoods. In both neighborhoods, those who approve petitioning are more active than those who do not, and those who both approve petitioning and feel it is effective are observed to be the most active.

The data summarized in TABLE XIIII indicate attitudes toward petitioning as an approved and effective mode of participation are strongly and significantly associated with all three measures of participatory behavior. The association is the strongest for issue and group participation among the White survey respondents. It is strongest for group participation among the Black survey neighborhood respondents, but it is nearly as strong for electoral participation. This may indicate that petitioning is less traditionally focused in the White survey neighborhood sample population than it is among the Black survey neighborhood respondents.

Collective Action. It is reasonable to expect attitudes toward collective action as an approved and effective means of affecting problemsolving decisions to be closely associated with the level of involvement in neighborhood groups. A similar relationship might also be expected in the case of issue involvement, since such involvement may be either individual or group in nature. TABLES XLIV and XLV, which summarize the 


\section{TABLE XLII}

RELATIONSHIPS BETWEEN ATTITUDES TOWARD PETITIONING AS AN APPROVED AND EFFECTIVE MODE OF PARTICIPATION AND ELECTORAL, ISSUE, AND GROUP PARTICIPATION IN INDIVIDUAL AND COMBINED SURVEY NEIGHBORHOODS (EXPRESSED IN PERCENT)

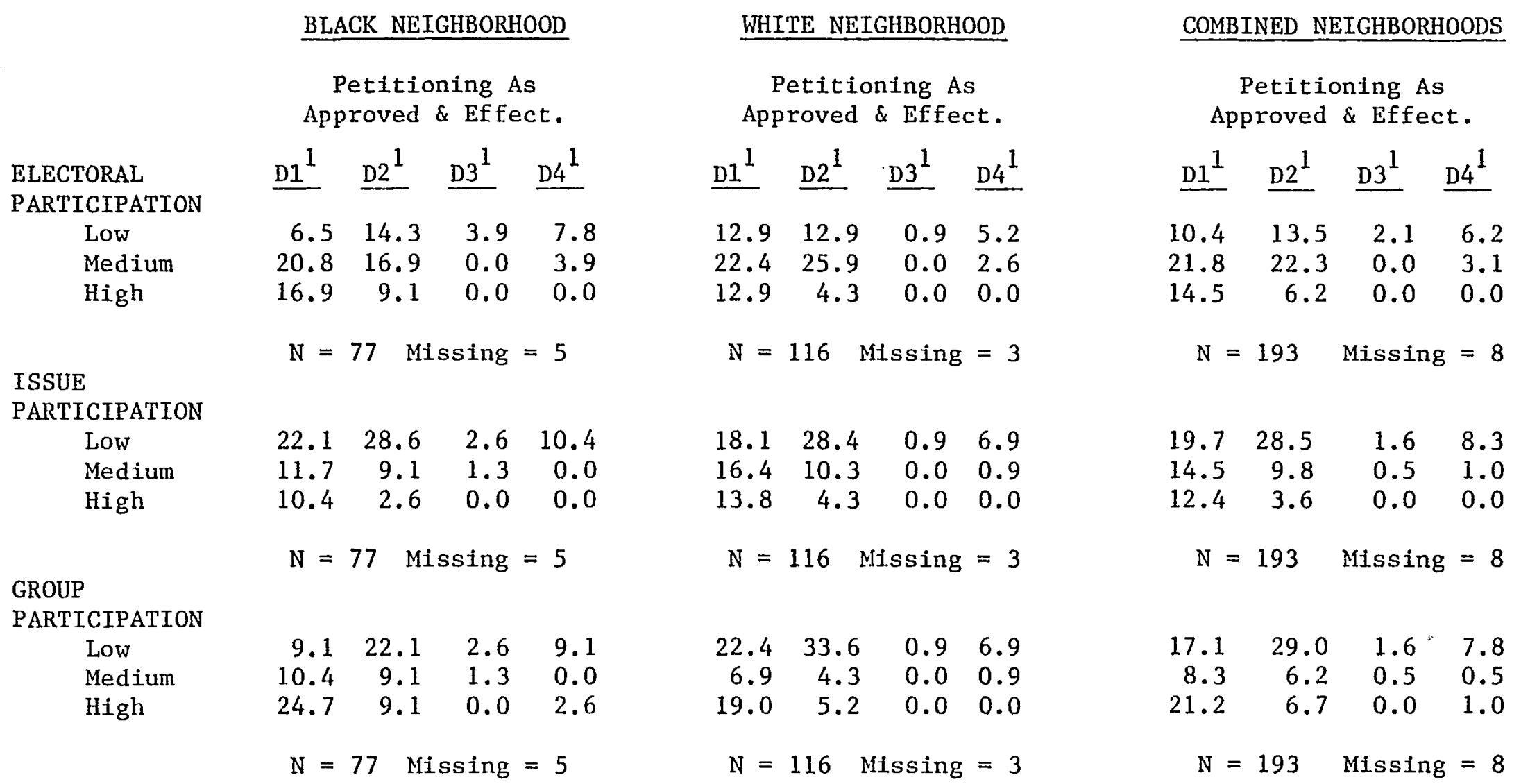

$1_{D 1}=$ Approved and Effective; D2 = Approved But Not Effective; D3 = Not Approved But Effective; D4 = Not Approved and Not Effective. 
SIGNIFICANCE OF THE RELATIONSHIPS BETWEEN ATTITUDES TOWARD PETITIONING AS AN APPROVED AND EFFECTIVE MODE OF PATICIPATION AND ELECTORAL, ISSUE, AND GROUP PARTICIPATION IN INDIVIDUAL AND COMBINED SURVEY NEIGHBORHOODS

ELECTORAL PARTICIPATION

AND ATTITUDES TOWARD PETITIONING AS AN APPROVED AND EFFECTIVE MODE OF PARTICIPATION

Chi Square:

$$
\begin{array}{lll}
\text { B1k. }=17.711 & \text { Signif. }=.007 & \text { d.f. }=6 \\
\text { Wht. }=13.673 & \text { Signif. }=.034 & \text { d.f. }=6
\end{array}
$$$$
\text { Comb. }=29.003 \text { Signif. }=.000 \text { d.f. }=6
$$

Tau c:

$$
\begin{aligned}
& \text { B1k. }=-.364 \\
& \text { Wht. }=-.203 \\
& \text { Comb. }=-.271
\end{aligned}
$$

Gamma :

$$
\begin{aligned}
& \text { B1k. }=-.527 \\
& \text { Wht. }=-.378 \\
& \text { Comb. }=-.469
\end{aligned}
$$

\section{ISSUE PARTICIPATION}

AND ATTITUDES TOWARD PETITIONING AS AN APPROVED AND EFFECTIVE MODE OF PARTICIPATION

Chi Square:

BIk. $=8.503$ Signif. $=.204$ d.f. $=6$
Wht. $=15.762$ Signif. $=.015$ d.f. $=6$
Comb. $=23.650$ Signif. $=.000$ d.f. $=6$

Tau c:

B1k. $=-.236$

Wht. $=-.296$

Comb. $=-.277$
Gamna :

Blk. $=-.482$

Wht. $=-.567$

Comb. $=-.539$

GROUP PARTICIPATION

AND ATTITUDES TOWARD PETITIONING AS AN APPROVED AND EFFECTIVE MODE OF PARTICIPATION

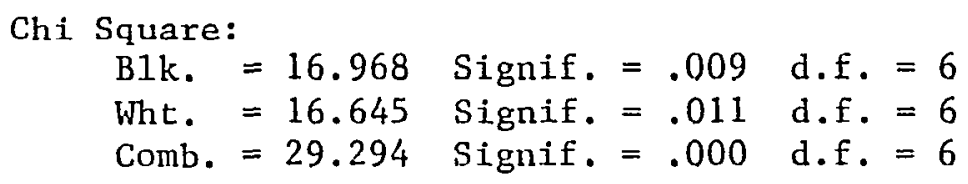

Tau c:

$$
\begin{aligned}
& \text { B1k. }=-.370 \\
& \text { Wht. }=-.285 \\
& \text { Comb. }=-.308
\end{aligned}
$$
Gamma :
B1k. $=-.583$
Wht. $=-.615$
Comb. $=-.568$


relationships between these attitudes and participation justify these expectations. Those who approve of collective action are more likely to become involved in neighborhood groups and issues than those who do not. Those who both approve of collective action and find it an effective means of affecting decisions are most likely to become highly involved in neighborhood issues and groups.

These relationships are observed to hold for both individual and combined survey neighborhoods. As the data in TABLE XLV indicate, the association between attitudes toward collective action and participation in neighborhood groups and issues is quite strong. All of the Tau c statistics are significant for these relationships, and the Chi Squares in every case except issue participation in the White survey neighborhood indicate statistically significant relationships as well. As expected, the association between attitudes toward collective action and electoral participation are weaker, but the same relationship is observed, and it is still quite pronounced in the case of the Black survey neighborhood respondents.

Protest. Non-violent demonstrations and picketing are modes of participation that are characteristic of both neighborhood issue and group involvement. Studies have shown that fewer people approve of protest as a mode of participation, but that blacks are more likely to approve of, and engage in, protest activities than whites. ${ }^{114}$ The data summarized in TABLES XLVI and XLVII support the first but not the second of these previous findings. We see in TABLE XLVI that considerably fewer of the survey respondents either approve of protest or find it an effective means of affecting decisions which seek to solve neighborhood problems. The percentages of the survey respondents who do approve of protest is nearly identical for both survey neighborhoods, however, and there is 


\section{TABLE XLIV}

RELATIONSHIPS BETWEEN ATTITUDES TOWARD COLLECTIVE ACTION AS AN APPROVED AND EFFECTIVE MODE OF PARTICIPATION AND ELECTORAL, ISSUE, AND GROUP PARTICIPATION IN INDIVIDUAL AND COMBINED SURVEY NEIGHBORHOODS (EXPRESSED IN PERCENT)

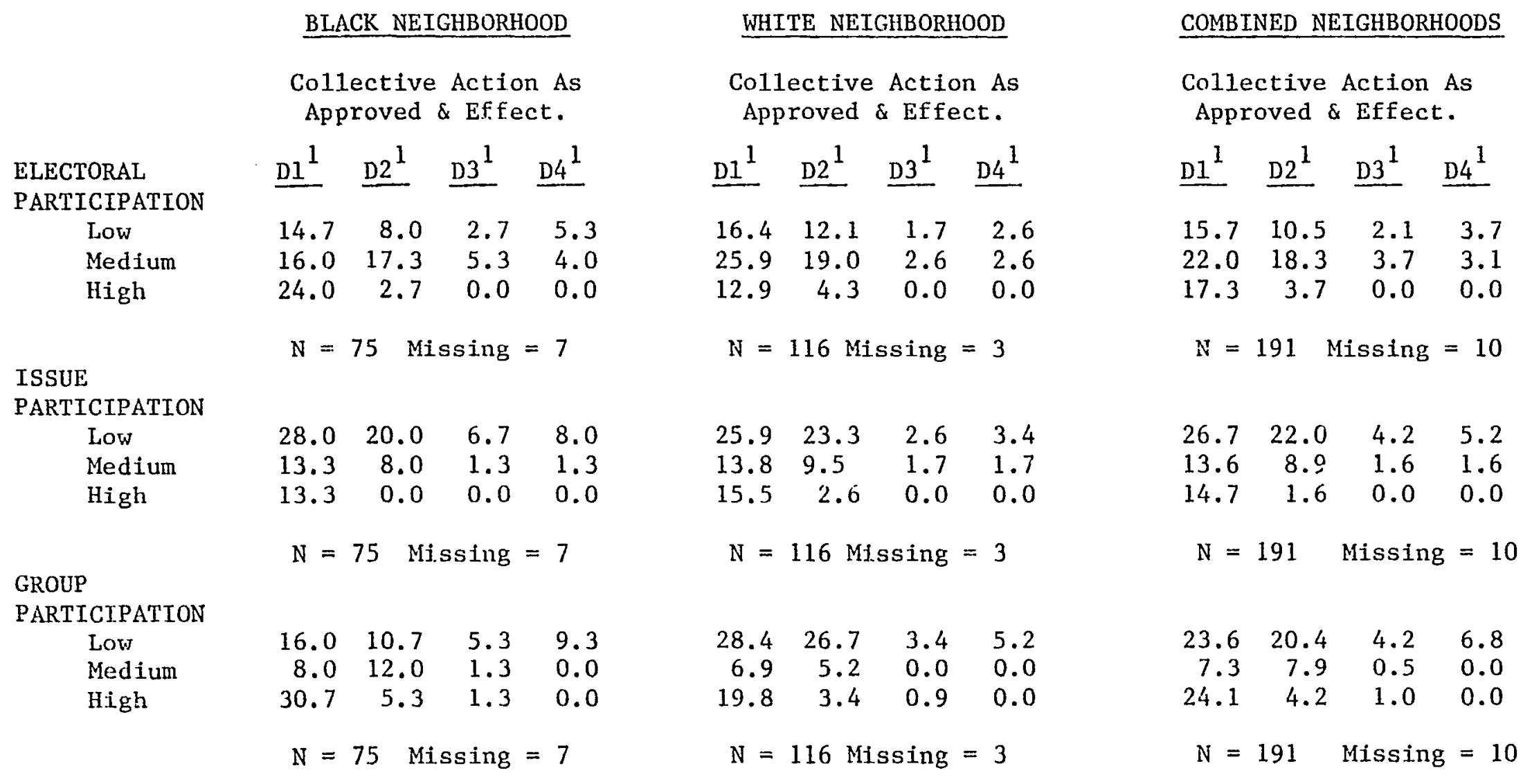

$I_{D 1}=$ Approved and Effective; $D 2$ = Approved But Not Effective; $D 3$ = Not Approved But Effective; D4 = Not Approved and Not Effective. 
TABLE XLV

SIGNIFICANCE OF THE RELATIONSHIPS BETWEEN ATTITUDES TOWARD COLLECTIVE ACTION AS AN APPROVED AND EFFECTIVE MODE OF PARTICIPATION AND ELECTORAL, ISSUE, AND GROUP PARTICIPATION IN INDIVIDUAL AND COMBINED NEIGHBORHOODS

\section{ELECTORAL PARTICIPATION}

AND ATTITUDES TOWARD COLLECTIVE ACTION AS AN APPROVED AND EFFECTIVE MODE OF PARTICIPATION

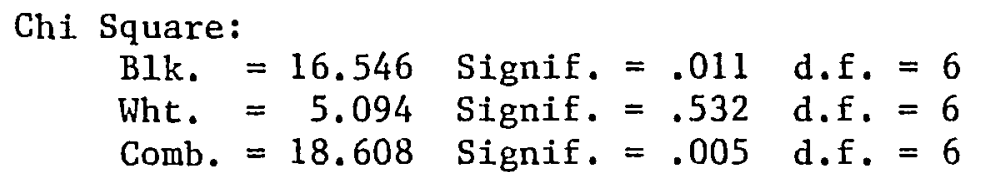
Tau c:
B1k. $=-.280$
Wht. $=-.130$
Comb. $=-.188$

Gamma :

B1k. $=-.456$

Wht. $=-.251$

Comb. $=-.339$

\section{ISSUE PARTICIPATION}

AND ATTITUDES TOWARD COLLECTIVE ACTION AS AN APPROVED AND EFFECTIVE MODE OF PARTICIPATION

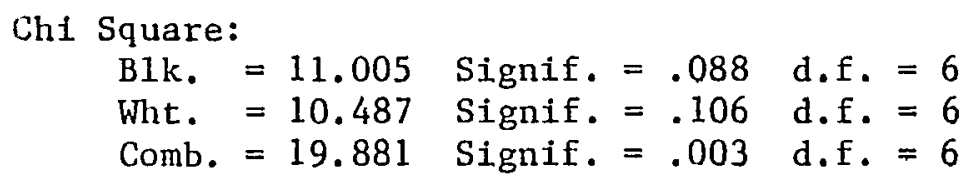
Tau c:
Blk. $=-.250$
Wht. $=-.188$
Comb. $=-.215$
Gamina :
Blk. $=-.536$
Wht. $=-.375$
Comb. $=-.437$

GROUP PARTICIPATION

AND ATTITUDES TOWARD COLLECTIVE ACTION AS AN APPROVED AND EFFECTIVE MODE OF PARTICIPATION

Chi Square:

$\begin{array}{lll}\text { Blk. }=24.282 & \text { Signif. }=.000 & \text { d.f. }=6 \\ \text { Wht. }=14.087 & \text { Signif. }=.029 & \text { d.f. }=6\end{array}$

Comb. $=32.001$ Signif. $=.000$ d.f. $=6$

\section{Tau c:}

BIk. $=-.377$

Wht. $=-.240$

Comb. $=-.280$
Gamma :

B1k. $=-.601$

Wht. $=-.550$

Comb. $=-.539$ 
little or no difference between the two neighborhood samples with respect to the percentage who find protest an effective participation mode.

The statistical relationships produced by crosstabulating the various measures of participatory behavior with attitudes toward protest activity are summarized in TABLE XLVII. These data indicate moderately strong relationships exist between issue participation and the attitudes, and between group participation and the attitudes toward protest. Those who approve of protest and who find it effective are more likely to become actively involved in neighborhood issues and groups than those who do not. This is slightly more true of issue participation than participation in groups.

Among White survey neighborhood respondents, little relationship between electoral participation and attitudes toward protest is observed. This is not the case among the Black survey neighborhood respondents, however. Attitudes toward protest are found to be very similarly related to all three measures of participatory behavior for the Black survey neighborhood respondents. The pattern of the relationships observed among both survey neighborhood sample populations between attitudes toward protest and both issue and group participation is very similar, though the relationships are slightly stronger among the Black survey neighborhood respondents.

Violence. Significantly fewer respondents in the survey approved violent demonstrations or rioting as a means of affecting problem-solving decisions. Even fewer respondents felt violence was effective. As the data in TABLE XLVIII indicate, Black survey neighborhood respondents are more likely to approve of violence as a mode of participation. White survey neighborhood respondents, while they are less likely to approve 
TABLE XLVI

RELATIONSHIPS BETWEEN ATTITUDES TOWARD NON-VIOLENT DEMONSTRATIONS AS AN APPROVED AND EFFECTIVE MODE OF PARTICIPATION AND ELECTORAL, ISSUE, AND GROUP PARTICIPATION IN INDIVIDUAL AND COMBINED SURVEY NEIGHBORHOODS (EXPRESSED IN PERCENT)

\section{BLACK NEIGHBORHOOD}

Non-Violent Dem. As Approved \& Effect.

ELECTORAL
PARTICIPATION
LOW
Medium
High

ISSUE

PARTICIPATION

Low
Medium
High

GROUP

PARTICIPATION
WHITE NEIGHBORHOOD

Non-Violent Dem. As Approved \& Effect.

$$
\begin{array}{rrrrr}
\mathrm{D1}^{1} & \underline{\mathrm{D} 2}{ }^{1} & & \mathrm{D}^{1} & \underline{\mathrm{D}^{1}} \\
9.5 & 12.1 & 0.9 & 10.3 \\
13.8 & 19.8 & 1.7 & 15.5 \\
6.9 & 6.9 & 0.0 & 2.6 \\
\mathrm{~N}= & 116 & \text { Missing }=3
\end{array}
$$$$
\begin{array}{rrrr}
10.3 & 25.0 & 2.6 & 17.2 \\
9.5 & 7.8 & 0.0 & 10.3 \\
10.3 & 6.0 & 0.0 & 0.9
\end{array}
$$$$
\mathrm{N}=116 \text { Missing }=3
$$

$\begin{array}{rrrr}14.7 & 26.7 & 1.7 & 21.6 \\ 5.2 & 4.3 & 0.9 & 1.7 \\ 10.3 & 7.8 & 0.0 & 5.2 \\ & & \\ N= & 116 & \text { Missing }=3\end{array}$

Low

Medium

High

$\begin{array}{rrrr}7.9 & 15.8 & 2.6 & 17.1 \\ 6.6 & 7.9 & 2.6 & 3.9 \\ 13.2 & 15.8 & 3.9 & 2.6 \\ & \\ N= & 76 & \text { Missing }=\end{array}$

$$
\begin{array}{rrrr}
14.5 & 23.7 & 6.6 & 19.7 \\
5.3 & 11.8 & 2.6 & 3.9 \\
7.9 & 3.9 & 0.0 & 0.0 \\
& \\
N= & 76 & \text { Missing }=6
\end{array}
$$

$l_{D 1}=$ Approved and Effective; $D 2$
Not Approved and Not Effective. D4 $=$ Not Approved and Not Effective.

\section{COMBINED NEIGHBORHOODS}

Non-Violent Dem. As Approved \& Effect.

$\underline{\mathrm{D} 1^{1}} \quad \underline{\mathrm{D} 2^{1}} \quad \underline{\mathrm{D} 3^{1}} \quad \underline{\mathrm{D} 4^{1}}$

$\begin{array}{llll}8.3 & 10.4 & 1.6 & 12.5\end{array}$

$\begin{array}{llll}13.0 & 19.8 & 2.6 & 12.0\end{array}$

$\begin{array}{llll}7.8 & 8.9 & 1.0 & 2.1\end{array}$

$\mathrm{N}=192$ Missing $=9$

$\begin{array}{rrrr}12.0 & 24.5 & 4.2 & 18.2 \\ 7.8 & 9.4 & 1.0 & 7.8 \\ 9.4 & 5.2 & 0.0 & 0.5\end{array}$

$\mathrm{N}=192$ Missing $=9$ $\begin{array}{llll}12.0 & 22.4 & 2.1 & 19.8\end{array}$

$\begin{array}{llll}5.7 & 5.7 & 1.6 & 2.6\end{array}$

$\mathrm{N}=192$ Missing $=9$ $\begin{array}{llll}11.5 & 10.9 & 1.6 & 4.2\end{array}$ 
TABLE XLVII

SIGNIFICANCE OF THE RELATIONSHIPS BETWEEN ATTITUDES TOWARD NON-VIOLENT DEMONSTRATIONS AS AN APPROVED AND EFFECTIVE MODE OF PARTICIPATION AND ELECTORAL, ISSUE, AND GROUP

PARTICIPATION IN INDIVIDUAL AND COMBINED SURVEY NEIGHBORHOODS

ELECTORAL PARTICIPATION

AND ATTITUDES TOWARD NON-VIOLENT DEMONSTRATIONS AS AN APPROVED AND EFFECTIVE MODE OF PARTICIPATION

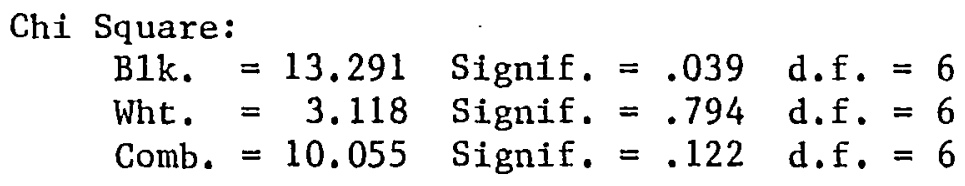
Tau c:
Blk. $=-.286$
Wht. $=-.087$
Comb. $=-.166$

ISSUE PARTICIPATION

AND ATTITUDES TOWARD NON-VIOLENT DEMONSTRATIONS AS AN APPROVED AND EFFECTIVE MODE OF PARTICIPATION

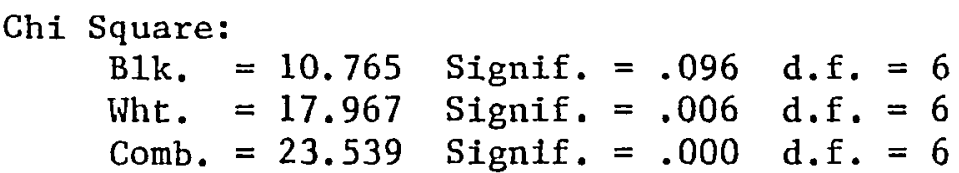

Tau c:

Blk. $=-.231$
Wht. $=-.232$
Comb. $=-.230$
Gamma :

B1k. $=-.423$

Wht. $=-.376$

Comb. $=-.389$

GROUP PARTICIPATION

AND ATTITUDES TOWARD NON-VIOLENT DEMONSTRATIONS AS AN APPROVED AND EFFECTIVE MODE OF PARTICIPATION

Chi Square:

Blk. $=9.545$ Signif. $=.145$ d.f. $=6$

Wht. $=8.144$ Signif. $=.228$ d.f. $=6$

Comb. $=14.152$ Signif. $=.028$ d.f. $=6$
Tau c:

B1k. $=-.261$

Wht. $=-.169$

Comb. $=-.198$
Gamma :

$\mathrm{Blk} .=-.376$

Wht. $=-.318$

Comb. $=-.324$ 
of violence, tend more often to find it effective than their Black survey neighborhood counterparts. Virtually none of the survey respondents both approve violence and find it effective, and in Black survey neighborhood virtually none of the respondents who do not approve of violence find it effective.

We can conclude from TABLE XLIX that attitudes toward violence as an approved mode of participation are related to participatory behavior only among the Black survey neighborhood respondents, and only with respect to issue and group participation for these individuals. The data show little or no relationship between attitudes toward violence and the participatory behavior of the White survey neighborhood respondents. This is most likely due to the fact that so few of these respondents approve of violent demonstrations as a mode of participation. Thus the psychic costs of such participatory behavior on the part of these respondents would be high.

\section{Efficacy of Participation for Self-Improvement}

As indicated earlier, many proponents of citizen participation assume participation to have some therapeutic value. Many believe participation increases the skills and competence of those who participate. Thus it contributes to personal growth and self-development or improvement. Regardless of how effective participation may actually be in achieving these goals, the attitudes of potential participants regarding the efficacy of participation for self-improvement and increasing the skills needed to cope with neighborhood problems may be important elements in the decision to participate. Individuals who may feel participation is not terribly effective for other purposes may still participate because of the personal development potential of doing so. 
TABLE XLVIII

RELATIONSHIPS BETWEEN ATTITUDES TOWARD VIOLENT DEMONSTRATIONS AS AN APPROVED AND EFFECTIVE MODE OF PARTICIPATION AND ELECTORAL, ISSUE, AND GROUP PARTICIPATION IN INDIVIDUAL AND COMBINED SURVEY NEIGHBORHOODS (EXPRESSED IN PERCENT)

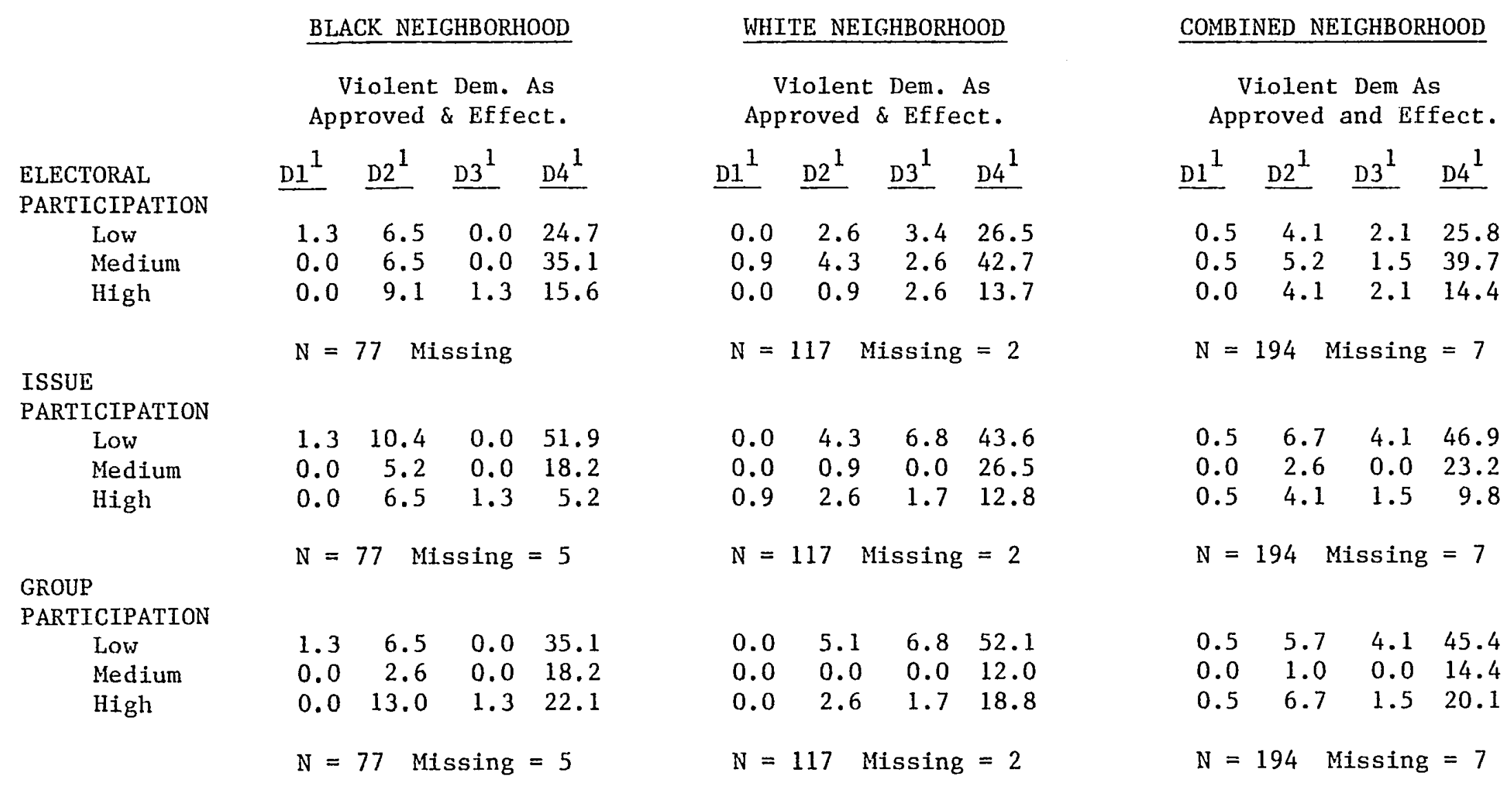

$1_{\mathrm{D} 1}=$ Approved and Effective; $\mathrm{D} 2$ = Approved But Not Effective; $\mathrm{D} 3$ = Not Approved But Effective; D4 = Not Approved and Not Effective. 
TABLE XLIX

SIGNIFICANCE OF THE RELATIONSHIPS BETWEEN ATTITUDES TOWARD VIOLENT DEMONSTRATIONS AS AN APPROVED AND EFFECTIVE MODE OF PARTICIPATION AND ELECTIVE, ISSUE, AND GROUP PARTICIPATION

IN INDIVIDUAL COMBINED SURVEY NEIGHBORHOODS

ELECTORAL PARTICIPATION

AND ATTITUDES TOWARD VIOLENT DEMONSTRATIONS AS AN APPROVED AND EFFECTIVE MODE OF PARTICIPATION

$\begin{aligned} & \text { Chi Square: } \\ & \text { Blk. }=8.068 \text { Signif. }=.233 \text { d.f. }=6 \\ & \text { Wht. }=3.249 \text { Signif. }=.777 \text { d.f. }=6 \\ & \text { Comb. }=5.347 \text { Signif. }=.501 \text { d.f. }=6\end{aligned}$
Tau c:

Blk. $=-.074$
Wht. $=-.001$
Comb. $=-.035$
Gamma :

$$
\begin{aligned}
& \text { Blk. }=-.187 \\
& \text { Wht. }=-.005 \\
& \text { Comb. }=-.105
\end{aligned}
$$

ISSUE PARTICIPATION

AND ATTITUDES TOWARD VIOLENT DEMONSTRATIONS AS AN APPROVED AND EFFECTIVE MODE OF PARTICIPATION

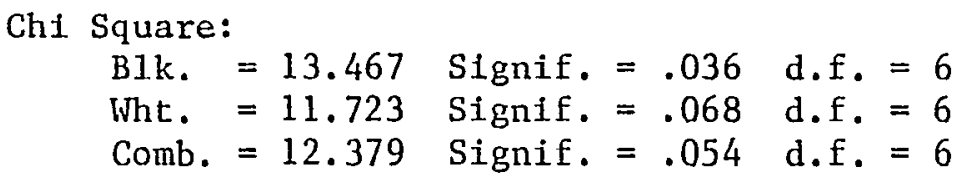

Tau c:

$$
\begin{aligned}
& \text { Blk. }=-.144 \\
& \text { Wht. }=-.008 \\
& \text { Comb. }=-.051
\end{aligned}
$$

Gamma :

$$
\begin{aligned}
& \text { B1k. }=-.415 \\
& \text { Wht. }=-.030 \\
& \text { Comb. }=-.170
\end{aligned}
$$

GROUP PARTICIPATION AND ATTITUDES TOWARD VIOLENT DEMONSTRATIONS AS AN APPROVED AND EFFECTIVE MODE OF PARTICIPATION

Chi Square:

B1k. $=8.117$ Signif. $=.230$ d.f. $=6$

Wht. $=6.831$ Signif. $=.337$ d.f. $=6$

Comb. $=10.237$ Signif. $=.115$ d.f. $=6$
Tau c:

$\mathrm{B} 1 \mathrm{k} .=-.134$

Wht. $=-.006$

Comb. $=-.065$
Gamma :

B1k. $=-.356$

Wht. $=-.028$

Comb. $=-.216$ 
The final two questions of the interview questionnaire (see Appendix E) allow some assessment of attitudes toward the value of participation as a means of self-improvement among the sample populations:

1. Do you feel that getting involved in community and neighborhood affairs is an effective way to improve yourself and increase your skills?

2. Do you approve of getting involved in community and neighborhood affairs as a way to improve yourself and increase your skills?

The respondents were asked to answer these two questions with a "yes" or "no" answer.

We see, in TABLES $L$ and LI, that those who feel participation in neighborhood and community affairs is an effective means of self-improvement are more likely to participate than those who do not. This is true for all kinds of participation and for both individual and combined survey neighborhood sample populations. Participatory behavior among the Black survey respondents is more strongly associated with feelings that participation is an effective means for self-improvement, particularly involvement in neighborhood issues and groups. Electoral activity is less strongly associated with feelings that participation is an effective means for self-improvement for both survey neighborhood sample respondents. Except for issue and group participation among the Black survey neighborhood respondents, these relationships are neither very strong nor significant. (The tau is significant in both cases.) They do indicate, nonetheless, that attitudes toward the efficacy of participation as a means for self-improvement are associated with the participatory behavior of individuals who were interviewed in the study. 
TABLE L

RELATIONSHIPS BETWEEN ATTITUDES TOWARD THE EFFICACY OF PARTICIPATION AS A MEANS FOR SELF-IMPROVEMENT AND ELECTORAL, ISSUE, AND GROUP PARTICIPATION IN INDIVIDUAL AND COMBINED SURVEY NEIGHBORHOODS (EXPRESSED IN PERCENT)

\begin{tabular}{lcc} 
& \multicolumn{2}{c}{ BLACK NEIGHBORHOOD } \\
\cline { 2 - 3 } ELECTORAL & Yes & No \\
PARTICIPATION & 22.1 & 10.4 \\
LOW & 24.7 & 16.9 \\
Medium & 20.8 & 5.2 \\
High & $\mathrm{N}=77$ & Missing $=5$
\end{tabular}

WHITE NEIGHBORHOOD

$\begin{array}{cc}\text { Yes } & \text { No } \\ 18.8 & 13.7 \\ 29.9 & 20.5 \\ 12.0 & 5.1 \\ N=117 & \text { Missing }=2\end{array}$

ISSUE

PARTICIPATION

Low
Medium
High

High

GROUP

PARTICIPATION

Low
Medium
High

$\begin{array}{cc}39.0 & 24.7 \\ 16.9 & 6.5 \\ 11.7 & 1.3 \\ N=77 & \text { Missing }=5\end{array}$

30.8

18.8

23.9

11.1

$\mathrm{N}=117$ Missing $=2$

8.5

6.8

$\mathrm{N}=77$ Missing $=5$

$\begin{array}{rr}24.7 & 18.2 \\ 15.6 & 5.2 \\ 27.3 & 9.1 \\ =77 & \text { Missing }=5\end{array}$

$\begin{array}{lr}35.0 & 29.1 \\ 10.3 & 1.7 \\ 15.4 & 8.5\end{array}$

$\mathrm{N}=117$ Missing $=2$
COMBINED NEIGHBORHOOD

$\begin{array}{lr}\text { Yes } & \text { No } \\ 20.1 & 12.4 \\ 27.8 & 19.1 \\ 15.5 & 5.2\end{array}$

$\mathrm{N}=194$ Missing $=7$

$$
\mathrm{N}=77 \text { Missing }=5
$$

\footnotetext{
$\mathrm{N}=117$ Missing $=2$
} 
TABLE LI

SIGNIFICANCE OF THE RELATIONSHIPS BETWEEN ATTITUDES TOWARD THE EFFICACY OF PARTICIPATION AS A MEANS FOR SELF-IMPROVEMENT AND ELECTORAL, ISSUE, AND GROUP PARTICIPATION IN INDIVIDUAL AND COMBINED SURVEY NEIGHBORHOODS

ELECTORAL PARTICIPATION

AND ATTITUDES TOWARD PARTICIPATION AS AN EFFECTIVE MEANS FOR SELF-IMPROVEMENT
Tau c:

B1k. $=-.083$

Wht. $=-.073$

Comb. $=-.080$
Gamma :

B1k. $=-.144$

Wht. $=-.126$

Comb. $=-.137$

\section{ISSUE PARTICIPATION}

AND ATTITUDES TOWARD PARTICIPATION AS AN EFFECTIVE MEANS FOR SELF-IMPROVEMENT

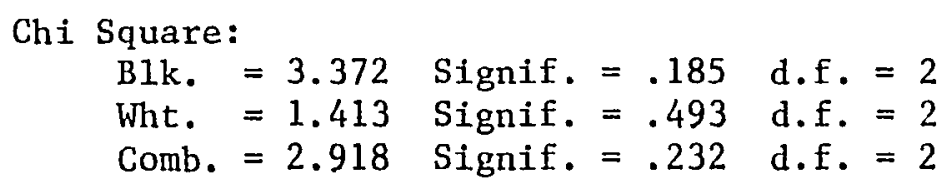

Tau c:
Gamma :

$$
\begin{aligned}
& \text { Blk. }=-.412 \\
& \text { Wht. }=-.148 \\
& \text { Comb. }=-.226
\end{aligned}
$$

Wht. $=-.083$

Comb. $=-.118$

GROUP PARTICIPATION

AND ATTITUDES TOWARD PARTICIPATION AS AN EFFECTIVE MEANS FOR SELF-IMPROVEMENT

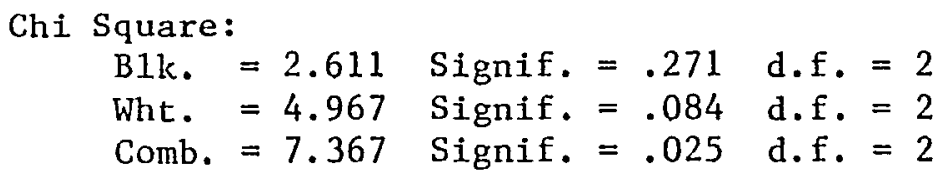

Tau c:

$\mathrm{B} 1 \mathrm{k} .=-.171$

Wht. $=-.130$

Comb. $=-.156$
Gamma :

B1k. $=-.302$

Wht. $=-.266$

Comb. $=-.291$ 
Whether people approve participation as a means of self-improvement appears to have little to do with their decision to participate. A slightly larger percentage of the White Survey neighborhood respondents approve participation as a means for self-improvement as indicated in TABLE LII. TABLE LIII indicates that this approval is somewhat related to the participation of these individuals in neighborhood groups and in electoral activities, but these relationships are not very strong, and none are significant. Approval of participation as a means for selfimprovement shows little or no association with any type of participatory behavior on the part of respondents in the Black survey neighborhood.

\section{SUMMARY}

We have seen that attitudes toward the value of participation are strongly associated with the participatory behavior of individuals surveyed. Those who believe participation has intrinsic value as an end or goal in itself are more likely to participate than those who do not. This is particularly true of respondents in the Black survey neighborhood, where participation appears to be more an end than a means to achieve other ends.

Those who believe various modes of participation are approved and effective means to achieve other ends are more likely to participate than those who do not, but only up to a point. The most costly mode of participation in terms of its psychic costs and its risk--violent demonstrations--is less likely to be approved or found effective, and these attitudes are not observed to be significantly associated with the measures of participatory behavior used in the study. 
TABLE LII

RELATIONSHIPS BETWEEN ATTITUDES TOWARD PARTICIPATION AS AN APPROVED MEANS FOR SELF-IMPROVEMENT AND ELECTORAL, ISSUE, AND GROUP PARTICIPATION IN INDIVIDUAL AND COMBINED SURVEY NEIGHBORHOODS

(EXPRESSED IN PERCENT)

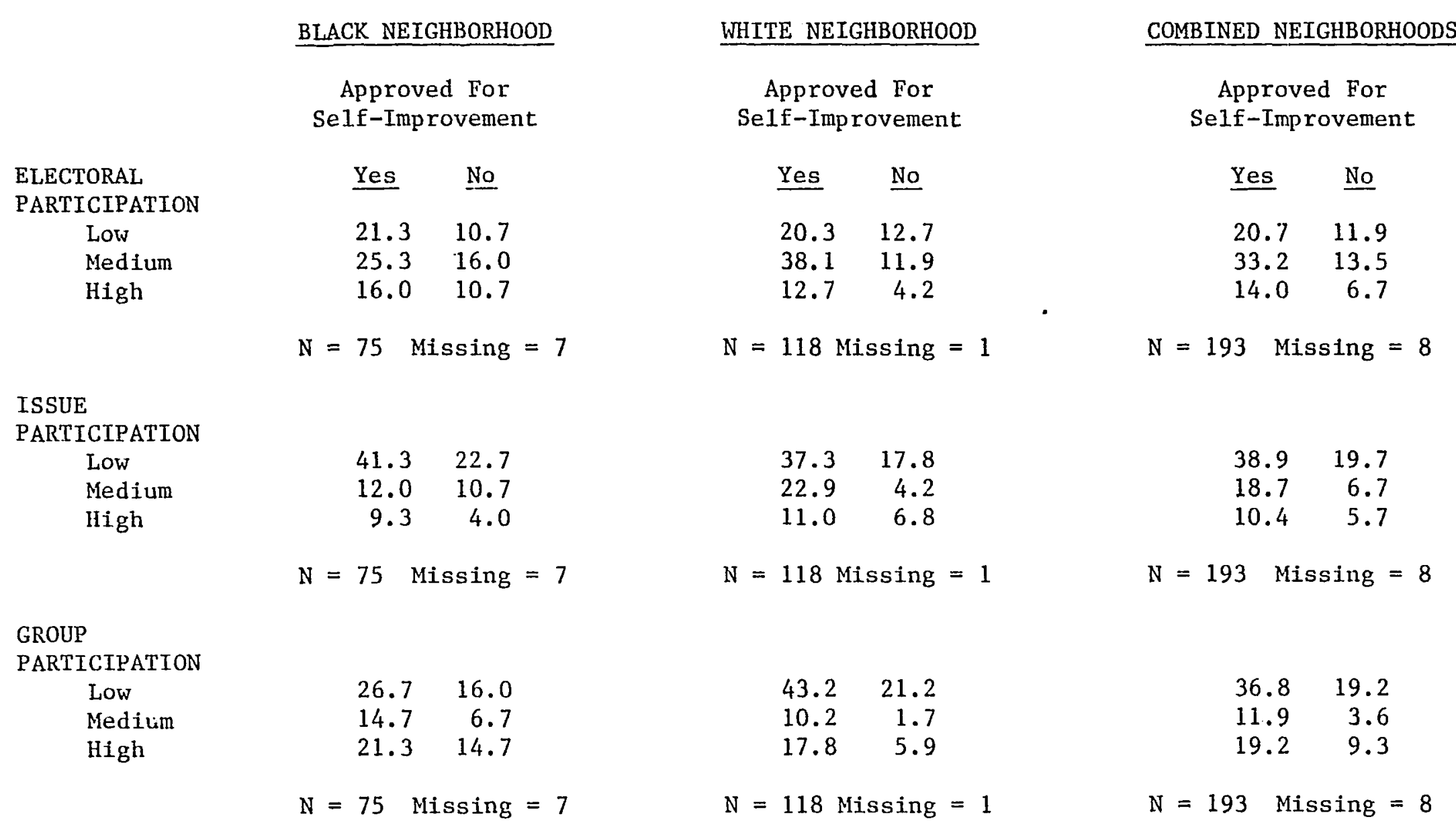


TABLE LIII

SIGNIFICANCE OF THE RELATIONSHIPS BETWEEN ATTITUDES TOWARD PARTICIPATION AS AN APPROVED MEANS FOR SELF-IMPROVEMENT AND ELECTORAL, ISSUE, AND GROUP PARTICIPATION IN INDIVIDUAL AND COMBINED SURVEY NEIGHBORHOODS

ELECTORAL PARTICIPATION

AND ATTITUDES TOWARD PARTICIPATION AS AN APPROVED MEANS FOR SELF-IMPROVEMENT

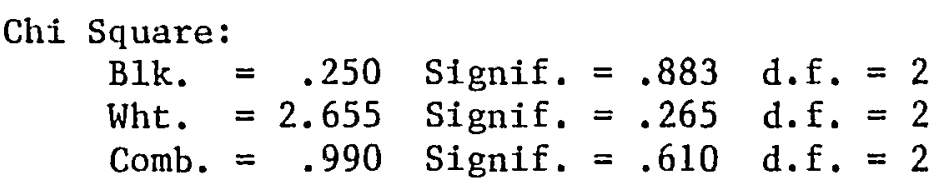

Tau c:

$$
\begin{aligned}
& \text { B1k. }=+.057 \\
& \text { Wht. }=-.123 \\
& \text { Comb. }=-.043
\end{aligned}
$$

Gamma :

$$
\begin{aligned}
& \text { B1k. }=+.093 \\
& \text { Wht. }=-.240 \\
& \text { Comb. }=-.078
\end{aligned}
$$

ISSUE PARTICIPATION

AND ATTITUDES TOWARD PARTICIPATION AS AN APPROVED MEANS FOR SELF-IMPROVEMENT

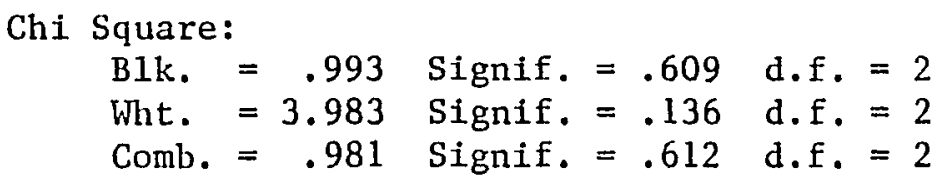

GROUP PARTICIPATION AND ATTITUDES TOWARD PARTICIPATION AS AN APPROVED MEANS FOR SELF-IMPROVEMENT

Chi Square:

Blk. $=.387$ Signif. $=.824$ d.f. $=2$

Wht. $=2.256$ Signif, $=.324$ d.f. $=2$

Comb. $=1.298$ Signif. $=.522$ d.f. $=2$
Tau c:

B1k. $=+.026$

Wht. $=-.093$

Comb. $=-.031$
Gamma :

$$
\text { B1k. }=+.057
$$

Wht. $=-.069$

Comb. $=-.042$
Gamma :

Blk. $=+.044$

Wht. $=-.230$

Comb. $=-.062$ 
Traditional participation in the form of electoral activity is most strongly associated with attitudes regarding traditional modes of participation as approved and effective. Those who approve these modes and find them effective are more likely to be highly involved in electoral activity. The same relationship between non-traditional political behavior and attitudes toward non-traditional modes of participation exists. Those who approve of petitioning, collective action, or non-violent protest, and who find them effective, are more likely to become involved in issues and neighborhood groups than those who do not. This is true of both Black and White survey neighborhood respondents.

Attitudes toward participation as a means for self-improvement are less significantly related to actual participation. Those who feel participation is an effective means of self-improvement are more likely to participate than those who do not, but the relationships observed are not very strong. Approval of participation as a means for self-improvement, on the other hand, appears to make very little difference in the participation of respondents in the study.

We can conclude from the data presented that attitudes toward the value of participation as both a means and an end are important for understanding the political behavior of the respondents surveyed in these two low-income neighborhoods. Attitudes toward participation as a desirable goal seem especially important for understanding participation in the Black survey neighborhood. Attitudes toward various modes of participation with regard to their approval and efficacy as means to achieve other ends are also important for understanding participation. We have seen that approval of a particular mode is more important for participation than evaluations of its efficacy, though the coincidence of approval 
and efficacy are most likely to lead the individual to higher levels of participatory activity.

From these data we can also reach some conclusions about many of the assumptions expressed or implied in the citizen participation literature. We have found that there is widespread approval of participation as an end and as a means to achieve other ends (with the excpetion of violent demonstrations as an approved mode of participation). This approval is related to the decisions of individuals to become involved. There is much less widespread agreement that participation is particularly effective as a means of affecting decisions which are aimed at the solution of neighborhood problems. Thus, participation is socially approved as a means and end. This is consistent with the assumptions in the literature. On the question of efficacy of participation, there appears to be some reasonable doubt in the minds of many of our survey respondents.

Finally, we can conclude from the data that the elements suggested by the social-psychological model of political behavior do provide us with a greater understanding of the participatory behavior in low-income, low-SES neighborhoods. To the extent this is true, relevant portions of that model are empirically supported by the results of this study.

Having examined attitudes toward the value of participation, the final task remaining is one which relates the various research findings back to the theory and the questions with which we began. In the final chapter we will turn to this task as conclusions and their implications are drawn from the data gathered in the study. 


\section{FOOTNOTES}

$113 \mathrm{~A}$ question related to this specific activity is often included in measures of traditional electoral participation.

${ }^{114}$ Milbrath and Goel, op. cit., pp. 14-15, 68-71, and 95-96. 
CHAPTER IX

SUMMARY AND CONCLUSIONS

SUMMARY

At the risk of being overly repetitious, the results of the study can be summarized. We have found that both the Black and White neighborhood populations surveyed in the study have been successfully politicized and politically mobilized. Overall, the levels of political participation are higher than might be expected. This participation manifests itself somewhat differently in the two sample populations, with Black survey neighborhood respondents more highly involved in traditional electoral activity than their White survey neighborhood counterparts, and the White survey neighborhood respondents, for their part, more significantly involved in neighborhood issues.

The White survey neighborhood respondents tend to be somewhat more specialized in their participatory behavior as well. Those who are involved in neighborhood groups are more clearly different people than those who are active in electoral activities in the White survey neighborhood. This is less the case in the Black survey neighborhood. Thus, the variables traditionally used to explain and predict political participation are only partially useful in explaining the issue and group participation of our survey respondents, especially those within the White survey neighborhood. 
The most active participants in both neighborhoods tend to be males, but the active participants in the White survey neighborhood tend to be younger than their Black survey neighborhood counterparts. This tendency is especially pronounced when considering the fact that the population distributions of the two neighborhoods with respect to age tend to be skewed in opposite directions--the White survey neighborhood population is older, while the Black survey neighborhood population is younger.

We also find that those who are the most active participants in the White survey neighobrhood tend to exhibit somewhat higher levels of socioeconomic status than their neighbors. There is less variation in socioeconomic status among respondents in the Black survey neighborhood, and what variation there is shows little relationship to particpation.

We have also found that the ways in which people perceive problems in their neighborhoods are significantly related to the political behavior they exhibit. Perceiving problems in the nieghborhood environment is strongly and significantly associated with political participation-especially participation in neighborhood issues and groups. This appears to be particularly true of those problems which are determined by the individual to be salient, and particularly true of those problems which are potentially more immediately and visibly affected by citizen action.

Again, some systematic differences were observed between the Black and White survey neighborhood populations. Black survey neighborhood participation was found to be consistently and substantially less problem or issue related than White survey neighborhood participation, except for those Black survey respondents who had strong roots in their neighborhood. Participation of these individuals was rough1y as related to problems and issues as for their White survey neighborhood counterparts. 
Neighborhood roots were less strongly related to participation in the White survey neighborhood.

Assuming a problem is identified wich is salient to the individual, some feeling that something can be done about the problem is an important element in the calculus of participation. Feelings of efficacy with regard to specific identified problems, is importantly associated with participation in both survey neighborhoods. The Black survey neighborhood respondents appear to feel less effective than respondents in the White survey neighborhood, and the increased feelings of efficacy that accompany membership in a neighborhood organization are especially important in the participation of the Black survey respondents. These feelings of efficacy are related to feelings of cynicism. The Black survey respondents, feeling less effective on the whole, tend to be more cynical than their White survey counterparts. In either case, cynicism reduces political activity.

The existence of problems is not the only thing perceived. Individuals also perceive or define for themselves the nature and dimensions of those problems. Two such dimensions were found to be significantly associated with participation. Problems perceived as social rather than personal or individual in nature increase the likelihood of participation. This is due to their connection with a political dimension. A problem defined or perceived in social terms is very likely to also be perceived in political rather than non-political terms. Our results show clearly that problems defined or perceived to be political problems are strongly and significantly associated with participation. This is less true among Black survey neighborhood respondents- a reflection of their lower feelings of efficacy and greater cynicism as compared to the White survey respondents. 
Finally, we have found that attitudes toward the value of participation are significantly associated with the political behavior of the individual. Most Black and White survey neighborhood respondents believe participation to have value as a desired goal. The association of these feelings with participation is particularly striking among Black survey respondents. This is further and substantial evidence that participation among Black survey neighborhood respondents may be an end in itself, perhaps having a symbolic or expressive value more than an instrumental orproblem-solving value.

The problem-solving value of participation cannot be discounted, however. Attitudes toward the value of specific participation modes as approved and effective means to influence problem-solving decisions is associated with participation in both sample populations. Those who approve a mode of participacion and believe it to be effective are more likely to participate. This relationship is seen both in the case of traditional electoral modes of participation as they are associated with electoral participation, and in the case of non-traditional participation as it is associated with attitudes toward the more non-traditional modes of participation. This is only true up to a point, however. There appears to be a threshold (which is different for sample populations within each of the survey neighborhoods) above which the psychic and other costs of engaging in a particular mode of participation which is neither approved nor deemed effective (or both) becomes too great. Increased participation does not result once this threshold is reached.

The value of participation as a means for self-improvement of the individual, a notion popular in the literature related to participation, appears less important as an element in the actual behavior of indivi- 
dua1s. There is some relationship between participatory behavior and belief that participation is an effective means for self-improvement, but the relationship is not very pronounced.

Having summarized the findings of the study which are detailed in the preceding chapters, we must now try to make some sense out of what we have found--aside from the intrinsic value of each particular finding. We will turn our attention to this task in the final two sections of this chapter.

\section{CONCLUSIONS}

There is always a danger of over-generalizing on the basis of evidence whicis is insufficient to support the generalizations. At the same time, to be overly cautious does not do justice to the effort that has gone into a research effort of the magnitude undertaken here. We sha11 attempt to tread a middle ground.

It must first be re-emphasized that the research reported above is clearly exploratory in nature. The results, and the conclusions drawn from them, are properly considered to be only suggestive rather than definitive in nature. No claims for generalization beyond this specific research are being made. A similar study of the two neighborhoods considered here may produce different results if undertaken at a different time. Different results may well be obtained in a similar study undertaken in a city with different characteristics as well--a city containing a larger black population proportion and/or a well developed ghetto, for example, and/or a city with a different social and political environment for and history of citizen involvement. Any decision about the extent to 
which these results and conclusions may apply in general must await the evidence of further research. With this necessary caveat aside, we can come to some reasonable conclusions about some of the factors associated with individual participation in elections, neighborhood issues, and neighborhood groups in the two low-income and low-SES neighborhoods surveyed in this study. We can also reach some cautiously suggestive conclusions about the empirical validity and utility of the social-psychological model of political behavior, and about some of the assumptions underlying the concept of citizen participation.

First, we can conclude that a number of factors other than socioeconomic status are significantly assoicated with political participation in these two neighborhoods--especially participation in neighborhood issues and groups. We have identified six factors: (1) perception of the existence of neighborhood problems; (2) salience of perceived neighborhood problems; (3) feelings of efficacy in doing something about the specific problems perceived in the neighborhood; (4) perceptions of the nature and dimensions of the identified neighborhood problems; (5) attitudes toward participation as a valued goal; and, (6) attitudes toward various participation modes as approved and effective means to solve neighborhood problems. All are factors found to be strongly and significantly associated with the political behavior of respondents in the study.

Second, since the factors listed above are all suggested by the social-psychological model of individual political behavior to be important, we can conclude there is some reasonable empirical evidence in support of some critical elements of that model. Problem perception in all its various aspects is found to be significantly associated with political behavior, particularly participation in neighborhood issues 
and groups. Feelings of efficacy, and attitudes toward the value of specific participation modes as approved and effective means of solving neighborhood problems, relate to the individual cost/benefit calculation which precedes and shapes the decision to participate. As as suggested by the model, both are found in this study to be significantly associated with participation.

Third, the factors we find related to political behavior in the two survey neighborhoods seem to be more strongly and significantly associated with participation of these low-income, low-SES residents than do the traditional variables used to explain and predict electoral behavior. This is especially true in the case of issue and group participation-the kinds of participation generally not considered in the traditional body of literature. This is especially important, because data in the study reflect the fact that those persons involved in issues and groups are not necessarily the same persons active in a traditional electoral manner. This empirical evidence provides us with a reasonable basis to conclude that the variables suggested by the social-psychological model of individual political behavior do indeed better explain and predict the participatory behavior of our respondents than the SES variables suggested in the voting studies.

Fourth, while we cannot reach any conclusions about the objective validity of the assumptions underlying the concept of citizen participation, we can reach some conclusions about the congruence of the attitudes and perceptions of our respondents with these assumptions. Individuals may not accurately perceive what their problems are, for example, but they do perceive neighborhood problems that are important to them, and as a result tend to be more willing and more likely to become in- 
volved at the neighborhood level to do something about them. Similarly, their actual competence to effectively deal with the neighborhood problems they face may be very much in doubt, but significant numbers of our respondents believe they can be effective, and this belief is related to their actual behavior. Many of our respondents believe participation to have value as a means of solving neighborhood problems. Their participation is related to these beliefs, regardless of their objective validity. The respondents are less convinced of the value of participation as a means for self-improvement. Perhaps they believe it to be less important than do some of those who partially justify citizen participation on the basis of its presumed therapeutic value.

Finally, and perhaps the most important conclusion than can be reached on the basis of the evidence of this study, systematic differences in the factors associated with participation are demonstrated to exist between the Black and White survey neighborhood respondents. We can conclude on the basis on these differences that the participation of respondents in White survey population is much more problem and issue related than participation of the Black survey population. Respondents in the White survey neighborhood appear to value and use participation as a means to solve problems they identify in their neighborhood. Respondents in the Black survey neighborhood, on the other hand, appear to value and use participation more as an end in itself. For these respondents, participation appears to be much more of an expressive activity--one with symbolic value more than concrete practical value.

Charles Hamilton perceives three types of political action characteristic of the Black political struggle which provide a helpful framework for understanding these differences. The first type of political 
action he calls the Politics of Protest. Here, participatory action is aimed at correcting blatant racial injustices within the political system and acquiring indivisible benefits not previously equally available. The second type he calls the Politics of Participation. Here the group seeks to maximize its political status based on the group's numerical proportion of the electorate by removing barriers to access, and by sharing at least symbolically in the divisible benefits of society. The third is the Politics of Governance, which he describes as the exercise of dominant political power or community control in pursuit of a real and equitable share of the divisible benefits of society. 115

If we consider these three types of participation as stages of political development, then our findings with respect to the participatory orientations of our two sample populations begin to take on additional meaning. Using this framework, the Black survey neighborhood respondents, at least at the time of the study, might be characterized as engaging in the Politics of Participation. That is, they are conscious of their minority role, and they appear relatively content for the time being with removing barriers to access. They participate to make some gains which are sometimes symbolic, but their participation seems to exhibit less concern with the outcomes that with the process. The White survey neighborhood respondents, being unencumbered by many of the barriers faced by their Black counterparts, or by a minority consciousness or role, have apparently already moved into a stage of political development roughly equivalent to the Politics of Governance. 


\section{IMPLICATIONS}

There are some rather obvious practical and strategic implications which can be drawn from our final conclusion. It would be reasonable to expect, for example, that respondents $i_{i k}$ the Black survey neighborhood might be more easily mobilized, at least in the short term, by appeals focusing on the value of participation, the opportunity to participate, and on a sense of citizen duty. Ultimately, the participation of these lower income blacks is likely to be increased only by participatory experiences which give them a greater sense of efficacy. White survey neighborhood respondents, on the other hand, have a greater sense of efficacy. They might be more easily mobilized by appeals which identify and stress the need for solutions to specific problems, the relevence of the problem to the individual, and the impact the individual participant can potentially have on the solution of the problem.

Another implication can be drawn from the final conclusion. The Black survey neighborhood respondents, at present, may be satisfied with specific programs of citizen involvement if they are perceived as open and accessible, even though their minority status means they will not always have a major impact on the outcomes of policy process. It also seems likely that the Black survey respondents, since their current participation is relatively more oriented toward process than outcome, might be more easily manipulated than their White survey neighborhood counterparts who appear to be at least as concerned with outcome as with process. If we were to compare the two groups of respondents in terms of Arnstein's ladder of citizen participation, the White survey population, at present, 
would seem to be relatively less satisfied that the Black with a position on the ladder which does not represent some substantial degree of citizen control in an open and accessible policy process. 116

Strategy aside, the most important implications to be drawn from the research have to do with theory and research. Perceptions of problems and their relationship to political participation is largely unexplored territory. The results of this exploratory research effort suggest this to be an area of research worthy of considerable attention. The same can be said for the more specific conceptualization of political efficacy used in this study, especially as it relates to the perceived costs and benefits of a given participatory action. Attitudes toward the value of participation as both an end and as a means merit similar attention, since they too are related to the individual cost/benefit calculation which determines the level and mode of participation. As we have seen in this study, both these feelings of efficacy and attitudes toward participation are significant correlates of political behavior which might be profitably explored in more depth.

Finally, the results of this research suggest that much more rigorous and specifically focused research should be undertaken to begin to empirically validate a social-psychological model of political behavior. It appears, on the basis of this research, that the model is both useful for understanding political behavior and empirically supported. The model deserves a great deal more attention, and the rewards following from such attention in terms of contributions to understanding political behavior appear substantial. 
FOOTNOTES

115 Charles V. Hamilton, "Racial, Ethnic, and Social Class Politics and Administration", Public Administration Review, XXXII (Special Issue, October, 1972), pp. 638-648.

${ }^{116}$ Arnstein, ㅇp. cit. 


\section{A SELECTED BIBLIOGRAPHY}

\section{BOOKS}

Abcarian, Gilbert, and Soule, John W. (eds.) Social Psychology and Political Behavior: Problems and Prospects, Columbus, Ohio: Charles E. Merri11, 1970.

Agger, Robert E., Goldrich, Daniel, and Swanson, Bert E. The Rulers and the Ruled, New York: John Wiley \& Sons, 1964.

Alford, Robert R. Bureaucracy and Participation, Chicago: Rand McNally, 1969.

Alinsky, Saul David. Citizen Participation and Community Organization in Planning and Urban Renewal, Chicago: Industrial Areas Foundation, 1962 .

Altshuler, Alan A. Community Control: The Black Demand for Participation in Large American Cities, New York: Pagasus, 1970.

Ashford, Douglas E. Ideology and Participation, Beverly Hills, Calif.: Sage Pub1ications, 1972.

Babbie, Ear1 R. Survey Research Methods, Belmont Calif.: Wadsworth Publishing Co., Inc., 1973.

Banfield, Edward C. Political Influence, New York: The Free Press, 1961.

Banfield, Edward C., and Wilson, James Q. City Politics, New York: Vintage Books, 1963.

Backstrom, Charles H., and Hursh, Gerald D. Survey Research, Evanston, I11.: Northwestern University Press, 1963.

Berelson, Bernard R., Lazarsfeld, Paul F., and McPhee, Wm. N. Voting, Chicago: University of Chicago Press, 1954.

Binkley, Wilfred E. American Political Parties: Their Natural History, New York: Alfred A. Knopf, 1963.

Blalock, Hubert M., Jr. Causal Inferences in Nonexperimental Research, Chapel Hil1, N.C.: University of North Carolina Press, 1964. 1972 .

- Social Statistics, 2nd. ed., New York: McGraw-Hill Book Co., 
Bloomberg, Warner, Jr., and Schmandt, Henry J. (eds.) Urban Poverty: Its Social and Political Dimensions, Beverly Hills, Calif.: Sage Publications, 1970.

Bone, Hugh A., and Ranney, Austin. Politics and Voters, New York: McGraw-Hi11 Book Co., 1963.

Bowen, Don R. Political Behavior of the American Public, Columbus, Ohio: Charles E. Merrill, 1968.

Bruno, Frank J. Trends in Social Work: 1874-1956, New York: Columbia University Press, 1957.

Burdick Eugene, and Broadbeck, Arthur J. (eds.) American Voting Behavior, Glencoe, I11.: The Free Press of Glencoe, 1959.

Cahn, Edgar S., and Passett, Barry A. (eds.) Citizen Participation: A Casebook in Democracy, Trenton, N.J.: New Jersey Community Action Training Institute, 1970.

Campbe11, Angus, et al. The American Voter, New York: John Wiley \& Sons, 1964.

Clark, Kenneth, and Hopkins, Jeanette. A Relevant War Against Poverty: A Study of Community Action Programs and Observable Social Change, New York: Harper and Row, 1969.

Cloward, Richard A., and Onlin, Lloyd E. Delinquency and Opportunity: A Theory of Delinquent Gangs, New York: The Free Press, 1960.

Conway, M. Margaret, and Feigert, Frank B. Political Analysis: An Introduction, Boston: Allyn and Bacon, 1972.

Dah1, Robert. Modern Political Analysis, Englewood Cliffs, N.J.: Prentice-Ha11, Inc., 1970. - Who Governs?, New Haven, Conn.: Yale University Press, 1961.

Davies, James C. Human Nature in Politics: The Dynamics of Political Behavior, New York: John Wiley \& Sons, 1968.

Davies, J. Clarence III. Neighborhood Groups and Urban Renewal, New York: Columbia University Press, 1966.

Dawson, Richard, Prewitt, Kenneth, and Dawson, Karen S. Political Socialization, 2nd. ed., Boston: Little, Brown and Company, 1977.

Denzin, Norman K. Sociological Methods: A Sourcebook, Chicago: Aldine Publishing Co., 1970.

Di Palma, Giuseppe. Apathy and Participation: Mass Politics in Western Societies, New York: The Free Press, 1970.

De Witt, Benjamin Parke. The Progressive Movement, Seattle, Wash.: University of Washington Press, 1968. 
Donovan, John C. The Politics of Poverty, New York: Pegasus, 1967.

Downs, Anthony. An Economic Theory of Democracy, New York: Harper and Row, 1957.

Dowse, Robert, and Hughes, John A. Political Sociology, New York: John Wiley \& Sons, 1972.

Duncan-Clark, S. J. The Progressive Movement: Its Principles and Its Programe, Boston: Smal1, Maynard, and Company, 1913.

Edelman, Murray. Politics as Symbolic Action: Mass Arousal and Quiescence, Chicago: Markham Publishing Co., 1971.

- The Symbolic Uses of Politics, Urbana, I11.: University of IIIinois Press, 1964.

Etzioni, Amitai. Demonstration Democracy, New York: Gordon and Breach, 1970.

Erikson, Erik H. Childhood and Society, New York: W. W. Norton, 1963.

Eulau, Heinz, Eldersveld, Samuel J., and Janowitz, Morris, (eds.) Political Behavior, Glencoe, I11.: The Free Press of Glencoe, 1956.

Eysenck, H. J. The Psychology of Politics, New York: Frederick A. Praeger, 1955.

Fainstein, Norman I., and Fainstein, Susan S. Urban Political Movements: The Search for Power by Minority Groups in American Cities, Englewood Cliffs, N.J.: Prentice-Ha11, Inc., 1974.

Farquharson, Robin. Theory of Voting, New Haven, Conn.: Yale University Press, 1969.

Free, Lloyd A., and Cantril, Hadley. The Political Beliefs of Americans: A Study of Public Opinion, Brunswick, N.J.: Rutgers University Press, 1967.

Frieden, Bernard, and Morris, Robert. (eds.) Urban Planning and Social Policy, New York: Basic Books, 1968.

Gamson, William A. Power and Discontent, Homewood, I11.: Dorsey Press, 1968.

Ganley, Albert C. The Progressive Movement: Traditional Reform, New York: Macmillan Company, 1964.

Gans, Herbert J. The Levittowners: Ways of Life and Politics in a New Suburban Cormunity, New York: Pantineon Books, 1967. 
Goode, William J., and Hatt, Paul K. Methods in Social Research, New York: McGraw-Hill Book Co., 1954.

Greenberg, Stanley B. Politics and Poverty: Modernization and Response in Five Poor Neighborhoods, New York: John Wiley \& Sons, 1974.

Greenstein, Fred I. Personality and Politics: Problems of Evidence, Inference, and Conceptualization, Chicago: Markham Publishing Co., 1969.

Hicks, John D. The Populist Revolt: A History of the Farmer'a Alliance and the Peoples Party, Minneapolis, Minn.: University of Minnesota Press, 1931.

Hofstader, Richard. The Age of Reform, New York: Alfred A. Knopf, 1956.

Hunter, Floyd. Community Power Structure: A Study of Decision Makers New York: Anchor Books, 1963.

Hutcheson, John D., and Steggert, Frank X. Organized Citizen Participation in Urban Areas, Atlanta, Ga.: Center for Research in Social Change, Emory University, 1970.

Hyman, Herbert H. Political Socialization, New York: The Free Press, 1969.

Jones, E. Terrence. Conducting Political Research, New York: Harper and Row, 1971.

Katz, Edward M., and Hyman, Herbert H. Urban Planning for Social Welfare: A Model Cities Approach, New York: Praeger Publishers, 1970.

Kerlinger, Fred N. Foundations of Behavioral Research: Educational and Psychological Inquiry, New York: Holt, Rinehart and Winston, 1964.

Kirkpatrick, Samuel A., and Pettit, Lawrence K. (eds.) The Social Psychology of Political Life, Belmont, Calif.: Duxbury Press, 1972.

Knutson, Jeanne N. (ed.) Handbook of Political Psychology, San Francisco, Calif.: Jossey-Bass Publishers, 1973. - The Human Basis of the Polity, Chicago: Aldine-Atherton, 1972.

Kramer, Daniel C. Participatory Democracy: Developing Ideals of the Political Left, Cambridge, Mass.: Schenkman Publishing Co., 1972.

Kramer, Ralph M. Participation of the Poor: Comparative Community Case Studies in the War on Poverty, Englewood Cliffs, N.J.: PrenticeHa11, Inc., 1969.

Kurtz, Russell H. (ed.) Social Work Yearbook, 1960, New York: National Association of Social Workers, 1960. 
Lane, Robert. Political Ideology: Why the Common Man Believes What He Does, New York: The Free Press, 1962.

- Political Life: Why People Get Involved in Politics, Glencoe,

II1.: The Free Press, 1959.

- Political Thinking and Consciousness: The Private Life of the Political Mind, Chicago: Markham Publishing Co., 1969.

Lane, Robert E., and Sears, David O. Public Opinion, Englewood Cliffs, N.J.: Prentice-Ha11, Inc., 1964.

Lane, Ruth. Political Man: Toward A Conceptual Base, Beverly Hills, Calif.: Sage Publications, 1973.

Lansing, John B., Withey, Stephen B., and Wolfe, Arthur C. Working Papers On Survey Research in Poverty Areas, Ann Arbor, Mich.: Survey Research Center, Institute for Social Research, University of Michigan, 1971.

Lasswel1, Harold D. The Analysis of Political Behavior: An Empirical Approach, Hamden, Conn.: Archon Books, 1966.

Lipset, Seymour Martin. Political Han: The Social Bases of Politics, Garden City, N.Y.: Doubleday and Co., 1963.

Lipsky, Michael. Protest in City Politics: Rent Strikes, Housing, and Power of the Poor, Chicago: Rand McNally, 1970.

Lowi, Theodore J. The End of Liberalism: Ideology, Policy, and the Crisis of Public Authority, New York: W. W. Norton, 1969.

McKenzie, Richard B. and Tullock, Gordon. The New World of Economics: Explorations into the Human Experience, Homewood, I11.: Richard D. Irwin, Inc., 1975.

McLaughlin, Andrew C., and Hart, Albert Bushne11. (eds.). Cyclopedia of American Government, Vol. III, Gloucester, Mass.: Peter Smith, 1963.

Manheim, Jaral B. The Politics Within, Englewood Cliffs, N.J.: Prentice-Ha11, Inc., 1975.

Marris, Peter, and Rein, Martin. Dilemmas of Social Reform, New York: Atherton Press, 1967.

Milbrath, Lester W. Political Participation: How and Why Do People Get Involved in Politics?, lst ed., Chicago: Rand lícNally, 1965.

Milbrath, Lester W., and Goel, M. L. Political Participation: How and Why Do People Get Involved in Politics?, 2nd. ed., Chicago: Rand McNa1ly College Publishing Co., 1977. 
Mitche11, William C. Why Vote:, Chicago: Markham Publishing Co., 1971.

Moynihan, Daniel Patrick. Maximum Feasible Misunderstanding: Community Action in the War on Poverty, New York: The Free Press, 1969.

Murakami, Y. Logic and Social Choice, New York, Dover Publications, 1968.

Nachmias, David, and Nachmias, Chava. Research Methods in the Social Sciences, New York: St. Martin's Press, 1976.

Nie, Norman H., et al. SPSS: Statistical Package for the Social Sciences, 2nd. ed., New York: McGraw-Hill Book Company, 1975.

Pateman, Carole. Participation and Democratic Theory, New York: Cambridge University Press, 1970.

Pennock, J. Roland, and Chapman, John W. (eds.) Participation in Politics, New York: Lieber-Atherton, Inc., 1975.

Pranger, Robert J. The Eclipse of Citizenship: Power and Participation in Contemporary Politics, New York: Holt, Rinehart and Winston, 1968.

Rai, Kul B., and Blydenburgh, John C. Political Science Statistics, Boston: Holbrook Press, 1974.

Renshon, Stanley Allen. Psychological Needs and Political Behavior: A Theory of Personality and Political Efficacy, New York: The Free Press, 1974.

Reynolds, H. T. Politics and the Common Man: An Introduction to Political Behavior, Homewood, II1.: Dorsey Press, 1974.

Robinson, John P., Rusk, Jerrold G., and Head, Kendra B. (eds.) Measures of Political Attitudes, Ann Arbor, Mich.: Survey Research Center, Institute for Social Research, University of Michigan, 1968.

Robinson, John P., and Shaver, Philip R. (eds.) Measures of SocialPsychological Attitudes, Ann Arbor, Mich.: Survey Research Center, Institute for Social Research, University of Michigan, 1969.

Ross, Murray G. Community Organization: Theory, Principles, and Practice, New York: Harper and Row, 1967.

Rothman, Jack. Planning and Organizing for Social Change: Action Principles from Social Science Research, New York, Columbia University Press, 1974.

Ruoss, Mery1. Citizen Power and Social Change, New York: Seabury Press, 1968. 
Schwartz, David C. Political Alienation and Political Behavior, Chicago: Aldine Publishing Co., 1973.

Spiege1, Hans B. C. (ed.) Citizen Participation in Urban Development: Cases and Programs, Vol. II, Washington: NTL Institute for Applied Behavioral Science, 1969.

- (ed.) Citizen Participation in Urban Development: Concepts and Issues, Vol. I, Washington: NTL Institute for Applied Behavioral Science, 1968.

- (ed.) Citizen Participation in Urban Development: Decentralization, Vol. III, Fairfax, Va.: Learning Resources Corporation/NTL, 1974.

Stone, William F. The Psychology of Politics, New York: The Free Press, 1974.

Stouffer, Samuel A. (ed.) Measurement and Prediction, (Studies in Social Psychology in World War II, Vol. IV), Princeton, N. J.: Princeton University Press, 1950.

Sundquist, James L. On Fightizg Poverty: Perspectives from Experience, New York: Basic Books, 1969 .

Tufte, Edward R. Data Analysis for Politics and Folicy, Englewood Cliffs, N. J.: Prentice-Ha1I, Inc., 1974.

Turner, John B. (ed.) Neighborhood Organization for Community Action, New York: National Association of Social Workers, 1969.

Unger, Irwin. (ed.) Populism: Nostalgic or Progressive?, Chicago: Rand McNa11y, 1964.

Verba, Sidney, and Nie, Norman H. Participation in America: Political Democracy and Social Equality, New York: Harper and Row, 1972.

Washnis, George J. Community Development Strategies: Case Studies of Major Mode1 Cities, New York: Praeger Publishers, 1974.

- Municipal Decentralization and Neighborhood Resources: Case Studies of Twelve New York Cities, New York: Praeger Publishers, 1972 .

Zurcher, Louis A. Poverty Warriors: The Human Experience of Planned Social Intervention, Austin, Texas, University of Texas Press, 1970 . 


\section{ARTICLES AND PERIODICALS}

Periodical Symposium Issues, Etc.

"Citizen Participation," Public Management, LI (July, 1969), entire issue.

Ferman, Louis A. (ed.) "Evaluating the War on Poverty," Annals of the Anerican Academy of Political and Social Science, CCCLXXXV (September, 1969), entire issue.

Frederickson, H. George. (ed.) "Curriculum Essays on Citizens, Politics, and Administration in Urban Neighborhoods," Public Administration Review, XXXII (Special Issue, October, 1972), entire issue.

Lynch, Thomas D. (ed.) "Symposium on Neighborhoods and Citizen Involvement," Public Administration Review, XXXII (May/June, 1972), entire issue.

"Planning and Citizen Participation," Journal of the American Institute of Planners, XXXV (July, 1969), entire issue.

Strange, John H. (ed.) Citizens Action in Model Cities and CAP Programs: Case Studies and Evaluation," Public Administration Review, XXXII (Special Issue, September, 1972), entire issue.

"Symposium on Alienation, Decentralization and Participation," Public Administration Review, XXIX (January/February, 1969), entire issue.

"Theme Articles: Participatory Democracy," Urban and Social Change Review, III (Spring, 1970), entire issue.

"Urban Decentralization and Community Participation," American Behavioral Scientist, XV (September/October, 1971), entire issue.

Individual Articles

Aberbach, Joel. "Alienation and Political Behavior," American Political Science Review, LXIII (March, 1969), Pp. 86-99.

Agger, Robert E., Goldstein, M. N., and Pear1, S. A. "Political Cynicism: Meaning and Measurement," Journal of Politics, XXIII (August, 1961), pp. 477-506.

Alinsky, Saul. "The War on Poverty: Political Pornography," Journal of Social Issues, XXI (January, 1965), pp. 41-47. 
Aronowitz, Stanley. "The Dialectics of Community Contro1," Social Policy, I (May/June, 1970), pp. 41-51.

Ashenfelter, Orley, and Kelley, Stanley, Jr. "Determinants of Participation in Presidential Elections," Journal of Law and Economics, XVIII (December, 1975), pp. 695-733.

Babcock, R., and Bosselman, F. "Citizen Participation: A Suburban Suggestion for the Central City," Law and Contemporary Problems, XXXIII (Spring, 1967), pp. 220-231.

Bachrach, Peter, Baratz, Morton S., and Levi, Margaret. "The Political Significance of Citizen Participation" in Bachrach, Peter and Baratz, Morton S., Power and Poverty: Theory and Practice, New York, Oxford University Press, 1970, Appendix, pp. 201-213.

Bellush, Jewel, and Hausknecht, Murray. "Planning, Participation and Urban Renewal," in Bellush, Jewel, and Hausknecht, Murray. (eds.) Urban Renewa1: People, Politics and Planning, Garden City, N. Y.: Anchor Books, 1967 pp. 278-286.

- "Urban Renewal: An Historical Perspective," in Bellush, Jewel, and Hausknecht, Murray. (eds.) Urban Renewal: People, Politics and Planning, Garden City, N. Y.: Anchor Books, 1967, pp. 3-16.

Bloomberg, Warner, Jr., and Rosenstock, Florence W. "Who Can Activate the Poor?: One Assessment of Maximum Feasible Participation," in Bloomberg, Warner, Jr., and Schmandt, Henry J. (eds.) Power, Poverty, and Urban Policy, Beverly Hills, Calif.: Sage Publications, 1968, pp. 313-354.

Blumenthal, Richard. "The Bureaucracy: Anti-Poverty and the Community Action Program," in Sindler, Alan P. (ed.) American Political Institutions and Public Policy: Five Contemporary Studies, Boston: Little, Brown and Company, 1969, pp. 128-179.

Brager, George, and Specht, Harry. "Mobilizing the Poor for Social Action," in Kramer, Ralph M., and Specht, Harry. (eds.) Readings in Community Organization Practice, Englewood Cliffs, N. J.: Prentice-Ha11, Inc., 1969, pp. 223-232.

Brokensha, David. "Maximum Feasible Participation (USA)," Community Development Journal, XIX (January, 1974), pp. 17-27.

Buchanan, William. "An Inquiry into Purposive Voting," Journal of Politics, XVIII (May, 1956), pp. 281-295.

Burke, Edmund. "Citizen Participation Strategies," Journal of the American Institute of Planners, XXXIV (September, 1968), pp. 287-294. 
Cary, Lee J. "The Role of the Citizen in the Community Development Process," in Cary, Lee J. (ed.) Community Development as a Process, Columbia, Mo.: University of Missouri Press, 1970, pp. 144-170.

Carmichael, Stokely, and Hamiltor, Charles. "Black Power," in Fainstein, Norman I., and Fainstein, Susan S. (eds.) The View From Below: Urban Politics and Social Policy, Boston: Little, Brown and Company, 1972, pp. 314-327.

Cole, Richard L. "Revenue Sharing: Citizen Participation and Social Service Aspects," Annals of the American Academy of Political and Social Science, CDXIX (May, 1975) pp. 63-74.

Cox, Fred M., and Garvin, Cnarles. "Community Organization Practice: 1865-1973," in Cox, Fred M., et al. (eds.) Strategies of Community Organization: A Book of Readings, 2nd. ed., Itasca, I11.: F. E. Peacock, 1974, pp. 29-59.

- "The Relevance of Social Forces to the Emergence of Community Organization Practice: 1865-1968," in Cox, Fred M., et al. (eds.) Strategies of Community Organization: A Book of Readings, 1st. ed., Itasca, III.: F. E. Peacock, 1970, Pp. 37-53.

Crenson, Matthew. "Organizational Factors in Citizen Participation," Journal of Politics, XXXVI (May, 1964), pp. 356-378.

Cunningham, Noble E. "The Jeffersonian Republican Party," in Schlesinger, Arthur M., Jr. (ed.) History of United States Political Parties, New York: Chelsea House Publishers, 1973, pp. 239-272.

Dahl, Robert. "The Rituals of Participation," in Bellush, Jewel, and Hausknecht, Murray. (eds.) Urban Renewal: People, Politics and Planning, Garden City, N. Y.: Anchor Books, 1967, pp. 302-311.

DeFleur, M. L., and Westie, F. R. "Verbal Attitudes and Overt Acts," American Sociological Review, XXIII (March, 1958), pp. 667-673.

Dixon, John. "How Can Public Participation Be Made Real?," Public Administration Review, XXXV (January/February, 1975), pp. 69-70.

Dubey, Sumati N. "Comanity Action Programs and Citizen Participation: Issues and Confusions," Social Work, XV (January, 1970), pp. 76-84.

Finiftner, Ada. "Dimensions of Political Alienation," American Political Science Review, LXIV (June, 1970), pp. 389-409.

Flacks, Richard. "On the Uses of Participatory Democracy," Dissent, XIII (November/December, 1966), pp. 701-708. 
Foard, Ashley A., and Fefferman, Hilbert. "Federal Urban Renewal Legislation," in Wilson, James Q. (ed.) Urban Renewal: The Record and the Controversy, Cambridge, Mass.: MIT Press, 1966, pp. 71-125.

Gamson, William A. "Rancorous Conflict in Community Politics," in Clark, Terry N. (ed.) Community Structure and Decision-Making: Comparative Analyses, San Francisco, Calif.: Chandler Publishing Co., 1968, pp. 197-214.

Gilbert, Neil, and Eaton, Joseph W. "Who Speaks for the Poor?," Journal of the American Institute of Planners, XXXVI (November, 1970), pp. 411-416.

Godshalk, David R. "The Circle of Urban Participation," in Eldredge, H. Wentworth. (ed.) Taming Megalopolis, II, Garden City, N. Y.: Anchor Books, 1967, pp. 971-979.

Gove, Walter, and Costner, Herbert I. "Organizing the Poor: An Evaluation of a Strategy," Social Science Quarterly, L (December, 1969), pp. 643-656.

Greenstein, Fred I. "The Impact of Personality on Politics: An Attempt to Clear Away the Underbrush," American Political Science Review, LXI (September, 1967), pp. 629-641.

Grosser, Charles. "Community Organization and the Grass Roots," Social Work, XII (October, 1967), pp. 61-67.

Hagedorn, R., and Labovitz, S. "Participation in Community Associations By Occupation: A Test of Three Theories," American Sociological Review, XXXIII (April, 1968), pp. 272-283.

Hawley, Amos H. "Community Power and Urban Renewal Success," in Clark, Terry N. (ed.) Community Structure and Decision-Making: Comparative Analyses, San Francisco, Calif.: Chandler Publishing Co., 1968, pp. 393-405.

Holt, Michael F. "The Democratic Party: 1828-1860," in Schlesinger, Arthur M., Jr. (ed.) History of United States Political Parties, New York: Chelsea House Publishers, 1973, pp. 497-536.

Hyman, Herbert H. "Planning With Citizens: Two Styles," Journal of the American Institute of Planners, XXXV (March, 1969), pp. 105112 .

Irland, Lloyd C. "Citizen Participation--A Tool for Conflict Management on the Public Lands," Public Administration Review, XXXV (May/ June, 1975), pp. 263-269.

Jackson, John S. III. "Alienation and Black Political Behavior," Journal of Politics, XXXV (ivovember, 1973), pp. 849-885. 
Jackson, John S. III, and Shade, William L. "Citizen Participation, Democratic Representation, and Survey Research," Urban Affairs Quarterly, IX (September, 1973), pp. 57-59.

Kravitz, Sanford. "The Community Action Program in Perspective," in Bloomberg, Warner, Jr., and Schmandt, Henry J. (eds.) Power, Poverty, and Urban Policy, Beverly Hills, Calif.: Sage Publications, 1968, pp. 259-283.

Lammers, C. J. "Power and Participation in Decision-Making," American Journal of Sociology, LXXIII (September, 1967), pp. 201-216.

Levens, Helene. "Organizational Affiliation and Powerlessness," Social Problems, XVI (Summer, 1968), Pp. 18-33.

Lipsky, Michael. "Protest as a Political Resource," American Political Science Review, LXVI (December, 1968), pp. 1144-1158.

- "Rent Strikes: Poor Man's Weapon," in Fainstein, Norman I., and Fainstein, Susan S. (eds.) The View From Below: Urban Politics and Social Policy, Boston: Little, Brown and Company, 1972, pp. 286-297.

Litt, Edgar. "Political Cynicism and Political Futility," Journal of Politics, XXV (May, 1963), pp. 312-323.

Lowi, Theodore. "The Public Philosophy: Interest Group Liberalism," American Political Science Review, LXI (March, 1967), pp. 4-24.

Leyden, Fremont James, and Thomas, Jerry V. "Citizen Participation in Policy-Making: A Study of a Community Action Program," Social Science Quarterly, L (December, 1969), pp. 631-642.

McDil1, Edward L., and Ridley, Jeanne Claire. "Status, Anomia, Political Alienation, and Political Participation," American Journal of Sociology, LXVIII (September, 1962), pp. 205-214.

Marshall, Dale R. "Who Participates in What?," Urban Affairs Quarterly, IV (December, 1968), pp. 201-216.

Marshall, Dale Rogers. "Public Participation and the Politics of Poverty," in Orleans, Peter, and Ellis, William R. (eds.) Race, Change, and Urban Society, Beverly Hills, Calif.: Sage Publications, 1971, pp. 451-482.

Maslow, Abraham Harold. "A Theory of Human Motivation," Psychological Review, L (July, 1943), pp. 370-396.

Mogulof, Melvin B. "Advocates for Themselves: Participation in Federal1y Supported Community Organizations," Community Mental Health Journal, X (Spring, 1974), pp. 66-76. 
- "Involving Low-income Neighborhoods in Antidelinquency Programs," Social Work, X (October, 1965), pp. 51-57.

Nie, N.H., Powell, G. B., Jr., and Prewitt, K. "Social Structure and Political Participation: Developmental Relationships," American Political Science Review, IXIII (June, 1969), pp. 361-378, and (September, 1969), pp. 808-832.

Onibokun, Adepoju G., and Curry, Martha. "An Ideology of Citizen Participation: The Metropolitan Seattle Transit Case Study," Public Administration Review, XXXVI (May/June, 1976), pp. 269-277.

Orum, Anthony M. "A Reappraisal of the Social and Political Participation of Negroes," in Edwards, John N., and Booth Alan. (eds.) Social Participation in Urban Society, Cambridge, Mass.: Schenkman Publishing Co., 1973, Pp. 97-109.

Peterson, Paul. "Forms of Representation: Participation of the Poor in Community Action Programs," American Political Science Review, LXIV (September, 1970). pp. 491-507.

Riessman, Frank. "Self Help Among the Poor," Trans-action, II (September, 1965), pp. 32-36.

- "Three Models of Community Organization Practice," in Cox, Fred M., et al. (eds.) Strategies of Community Organization: A Book of Readings, 2nd. ed., Itasca, I11.: F. E. Peacock, 1974, pp. 22-39.

Rubin, Lillian B. "Maximum Feasible Participation: The Origins and Implications," in Fainstein, Norman I., and Fainstein, Susan S. (eds.) The View From Below: Urban Politics and Social Policy, Boston: Little, Brown and Company, 1972, pp. 98-116.

Rusk, Jerrold G. "Political Participation in America: A Review Essay," American Political Science Review, LXX (June, 1976), pp. 583-591.

Salmon, Lester M., and Van Evera, Stephen. "Fear, Apathy, and Discrimination: A Test of Three Explanations of Political Participation," American Political Science Review, LXVII (December, 1973), pp. 1288-1306.

Scott, William A. "Attitude Measurement," in Lindzey, Gardner, and Aronson, Elliott. (eds.) Handbook of Social Psychology, II, 2nd. ed. , Cambridge, Mass." Addison-Wesley, 1968, pp. 204-266.

Seeman, Melvin, "On the Meaning of Alienation," American Sociological Review, XXivi (December, 1959), pp. 783-791.

Siege1, Roberta. "Citizen Committees--Advice vs Consent, "Trans-action, IV (May, 1967), pp. 47-52. 
Smith M. Brewster. "A Map for the Analysis of Personality and Politics," Journal of Social Issues, XXIV (July, 1968), pp.15-28.

Specht, Harry. "Community Development in Low Income Negro Areas," Social Work, II (October, 1966), pp.78-79.

Sproule-Jones, Mark. "Toward a Dynamic of Collective Action," Western Politica1 Quarterly, XXVI (September, 1973), pp. 414-426.

Thompson, Wayne, and Horton, John. "Political Alienation as a Force in Political Action, "Social Forces, XXXVIII (March, 1960), pp. 190-195.

U.S. Housing and Home Finance Agency. "Workable Program for Community Development," in Bellush, Jewe1, and Hausknecht, Murray. (eds.) Urban Renewal: People, Politics and Planning, Carden City, N.Y.: Anchor Books, 1967, pp. 276-277.

Vanecko, James J. "Community Mobilization and Institutional Change: The Influence of the Community Action Program in Large Cities," Social Science Quarterly, I (December, 1969), pp. 609-630.

Van Meter, Elena C. "Citizen Participation in the Policy Managment Process," Public Administration Review, XXXV (Special Issue, December, 1975), pp. 804-812.

Van Til, John, and Bould Sally. "Citizen Participation in Social Policy: The End of a Cycle?," Social Problems, XVII (Winter, 1970), pp. 313-323.

Verba, Sidney. "Democratic Participation," Annals of the American Academy of Political and Social Science, CCCLXXIII (September, 1967), pp. 53-78.

- "Political Participation and Strategies of Influence: A Comparative Study," in Barber, James David. (ed.) Readings in Citizen Politics: Studies of Political Behavior, Chicago: Markham Publishing Co., 1969, pp. 3-26.

Wachtel, Dawn Day. "Structures of Community and Strategies for Organization," in Cox, Fred M., et al (eds.) Strategies of Community Organization: A Book of Readings, 2nd. ed., Itasca, I11.: F. E. Peacock, 1974, pp. 177-182.

Warren, Roland L. "Types of Purposive Social Change at the Community Level," in Kramer, Ralph M., and Specht, Harry. (eds.) Readings in Community Organization Practice, Englewood Cliffs, N.J.: PrenticeHa11, Inc. 1969, pp. 205-222.

Warren, Roland L., and Hyman, Herbert H. "Purposive Community Change in Consensus and Dissensus Situations," in Clark, Terry N. (ed.) Community Structure and Decision-Making: Comparative Analyses San Francisco, Calif.: Chandler Publishing Co., 1968, pp. 407-424. 
Wi1son, James Q. "Planning and Politics: Citizen Participation in Urban Renewa1," in Wilson, James Q. (ed.) Urban Renewa1: The Record and the Controversy, Cambridge, Mass." MIT Press, 1966, pp. 407-421.

Woodward, Julian L., and Roper, Elmo. "Political Activity of American Citizens," American Political Science Review, XLIV (December, 1950), pp. $872-885$.

REPORTS AND PUBLIC DOCUMENTS

Advisory Commission on Intergovernmental Relations. Intergovernmental Relations in the Poverty Program: A Commission Report, Washington: U.S. Government Printing Office, 1966, Report No. A-29.

Citizen Participation in Community Development: A Selected Bibliography, Washington: National Association of Housing and Redevelopment Officials, 1975.

Citizen Participation Today, Proceedings of a Staff Conference, U.S. Department of Housing and Urban Development, Region IV, Chicago, June 3-4, 1968.

"Demonstration Cities and Metropolitan Development Act of 1966," United States Statutes at Large, LXXX (1967), pp. 1255-1296.

"Economic Opportunity Act of 1964," United States Statutes at Large, LXXVIII (1965), pp. 508-534.

Mogulof, Melvin B. Citizen Participation: A Review and Commentary on Federal Policies and Practices, Washington: The Urban Institute, 1970, Paper 102-1.

- Citizen Participation: The Local Perspective, Washington:

The Urban Institute, 1970, Paper 138-5.

National Data Program for the Social Sciences. Codebook for the Spring 1972 General Social Survey, Chicago: National Opinion Research Center, University of Chicago, July, 1972.

Report of the National Advisory Commission on Civil Disorders, New York: The New York Times Company, 1968.

U.S. Congress. Demonstration Cities and Metropolitan Development Act of 1966, Public Law 89-754, 89th Congress, 2nd Session, 1966.

- 88th Congress, 2nd Session, 1964. Economic Opportunity Act of 1964, Public Law 88-452.

- Juvenile Delinquency and Youth Offenses Control Act of 1961, Public Law 87-274, 37th Congress, lst Session, 1961.

U. S. Department of Commerce, Bureau of the Census, Census of Population and Housing: 1970, Census Tracts, Final Report PHC(1)165, Portland, Oreg.-Wash. SMSA. 
- Census of Housing: 1970, Block Statistics, Final Report HC(3) -195 , Portland, Oreg.-Wash. Urbanized area.

\author{
UNPUBLISHED MATERIAL
}

Brownlee, Thomas McCue. "Political Participation: Perceptions, Purposes, and Effects," (unpublished Ph.D. dissertation, University of Washirgton, 1971).

Howe11, Joseph T. "New Towns from the Point of View of the Ghetto Resident: Phase I--Developing a Kethod of Enquiry," Chapel Hill, N.C.: Center for Urban and Regional Studies, University of iNorth Carolina, 1969, (processed).

Knutson, Jeanne Nicke11. "Motivation and Political Behaviors: An Attempt at Synthesis," (unpublished Ph.D. dissertation, University of Oregon, 1968).

Larry, Maurice M., and Griggs, James. "Community Participation in Urban Development Projects," Chicago: Center for Urban Studies, University of Iilinois, July, 1969, Discussion Paper 10, (Processed).

Milne, James Stephen. "Feasibility in Poverty Politics: Participation or Paternalism?," (unpublished Ph.D. dissertation, Temple University, 1972).

Mittenthal, Stephen D., and Spiegel, Hans B. C. "Urban Confrontation: City Versus Neighborhood in the Model Cities Planning Process," New York: Institute for Urban Environment, School of Architecture, Columbia University, 1970, (Processed).

Paulson, Rick R. "A Comminity Congress for Southeast Portland," Portland, ore.: Portland Action Committees Together, Inc., 1970, (Processed).

"Results of Compilation from 'Bottom Up' Planning Returns," Portland, Ore.: Portland Action Committees Together, Inc., August, 1969, (Mimeographed).

"Social Impact--Woise," Field Interview Series, CPRC Study Number 42, Portland, Ore.: Urban Studies Center, Portland State University, 1972, (Processed).

Spiegel, Hans B. C., and Mittentha1, Stephen. "Neighborhood Power and Control," New York: Institute for Urban Environment, School of Architecture, Columbia University, 1968, (Processed).

Volkman, John. "An Overview of Decentralization and Citizen Participation," Portland, Ore.: Center for Urban Education, iNovember, 1976, (Processed). 
INTERVIEWS

Gilcrease, Cleveland, Director, Portland Metropolitan Steering Committee (EOA). Private interviews held at his office, May, June and July, 1974.

Hepburn, Irma, Assistant to the Director, Portland Metropolitan Steering Committee (EOA) Private Interviews held at her office, June and July, 1974.

Hintz, Margaret, Administrative Assistant, Portland Action Committees Together, Inc. Private Interviews held at her office, July and August, 1970, and November, 1975.

Lawwil, Hal, Director, Southeast Uplift Program. Private interviews held in his office, July and August, 1970.

Steward, Howard, Project Director, Portland Action Committees Together, Inc. Private interviews held in his office, July and August, 1970, June and November, 1975, and July, 1976.

Pedersen, Mary, Director, Bureau of Neighborhood Organizations, City of Portland, Oregon. Private interview held in her office, June, 1975. 
APPENDIX A

COMPARABILITY OF SURVEY AREAS

TABLE LIV

COMPARABILITY OF SURVEY AREAS

FOR SELECTED 1970 U.S.

CENSUS STATISTICS

\begin{tabular}{|c|c|c|}
\hline & \multicolumn{2}{|c|}{ SURVEY AREA } \\
\hline & $\begin{array}{c}\text { BLACK } \\
(\text { Tract } 34.02)\end{array}$ & $\begin{array}{l}\text { WHITE } \\
\text { (Tract 21) }\end{array}$ \\
\hline $\begin{array}{l}\text { TOTAI POPULATION } \\
\text { Percent Male } \\
\text { Percent Female } \\
\text { Percent Negro }\end{array}$ & $\begin{array}{l}2858 \\
47.9 \\
52.1 \\
84.1\end{array}$ & $\begin{array}{r}2551 \\
49.6 \\
50.4 \\
0.9\end{array}$ \\
\hline $\begin{array}{l}\text { POPULATION AGE GROUPS } \\
\text { Percent Less than } 5 \text { Years } \\
\text { Percent 5-19 Years } \\
\text { Percent 20-64 Years } \\
\text { Percent More than } 65 \text { Years }\end{array}$ & $\begin{array}{r}11.1 \\
29.0 \\
50.8 \\
9.2\end{array}$ & $\begin{array}{r}5.8 \\
16.9 \\
57.9 \\
19.4\end{array}$ \\
\hline $\begin{array}{l}\text { MARITAL STATUS ( } 14 \text { YEARS OLD AND OLDER) } \\
\text { Percent Single } \\
\text { Percent Married } \\
\text { Percent Separated, Widowed, Divorced }\end{array}$ & $\begin{array}{l}27.4 \\
43.4 \\
29.2\end{array}$ & $\begin{array}{l}26.5 \\
37.9 \\
35.6\end{array}$ \\
\hline $\begin{array}{l}\text { TYPE OF FAMILY } \\
\text { Percent Female Heads } \\
\text { Percent Households with Children } \\
\text { Percent Female Headed Households with } \\
\text { Childien }\end{array}$ & $\begin{array}{l}24.9 \\
54.3\end{array}$ & $\begin{array}{l}20.6 \\
35.2\end{array}$ \\
\hline $\begin{array}{l}\text { YEARS OF SCHOOL COMPLETED } \\
\text { Percent Completiing High School } \\
\text { Median School Years Completed }\end{array}$ & $\begin{array}{l}35.2 \\
10.0\end{array}$ & $\begin{array}{l}38.8 \\
10.7\end{array}$ \\
\hline $\begin{array}{l}\text { RESIDENCE IN } 1965 \text { (PERSONS } 5 \text { YEARS OR OLDER } \\
\text { IN 1970) } \\
\quad \text { Percent Same as } 1970\end{array}$ & 47.6 & 37.8 \\
\hline
\end{tabular}


SURVEY AREA

BLACK WHITE

(Tract 34.02) (Tract 21)

EMPLOYMENT STATUS

Percent Unemployed

Percent Males Over 16 Years Unemployed

12.9

11.6

Percent Females Over 16 Years Unemployed

11.0

10.6

15.9

13.1

\section{OCCUPATION}

Percent Professional, Technical

Percent Managers, Administrators

Percent Sales Workers

Percent Clerical

Percent Craftsmen, Foremen

Percent Operatives (Including Transport)

Percent Laborers (Including Farm)

Percent Service Workers

Percent Private Household Workers

\section{5}

5.4

0.8

16.0

7.5

17.2

9.8

32.1

5.7

13.0

6.1

7.8

20.1

13.1

16.0

7.7

15.8

0.5

CLASS OF WORKER

Percent Private Wage and Salary Workers

Percent Government Workers

Percent Self-Employed Workers

71.1

83.4

23.9

10.5

5.0

5.6

FAMILY INCOME

Median Family Income

Mean Family Income

Median Income for Families and Unrelated Individuals

Mean Income for Families and Unrelated Individuals

Percent of Family Incomes Below the Poverty Leve1

Percent of Family Incomes Less Than $\$ 3000$

30.8

15.2

27.3

20.7

\section{HOUSEHOLDS}

Percent Owner Occupied

Median Value of Housing Unit

37.3

$\$ 9400$

52.8

11.7

Percent Renter Occupied

$\$ 65$

Median Contract Rent

Median Gross Rent

\$ุ82

1.84

$\$ 10800$

80.5

$\$ 70$

$\$ 81$

Persons Per Household

$$
87.8
$$

93.8

Source: U.S. Bureau of the Census, Census of Population and Housing: 1970, CENSUS TRACTS, Final Report PHC(1)-165 Portland, Oreg.-Wash. SMSA. 
BLOCK MAPS OF SURVEY AREAS INDICATING STREETS AND BLOCK NUIBERS

I. BLACK NEIGHBORHOOD (Tract 34.02)

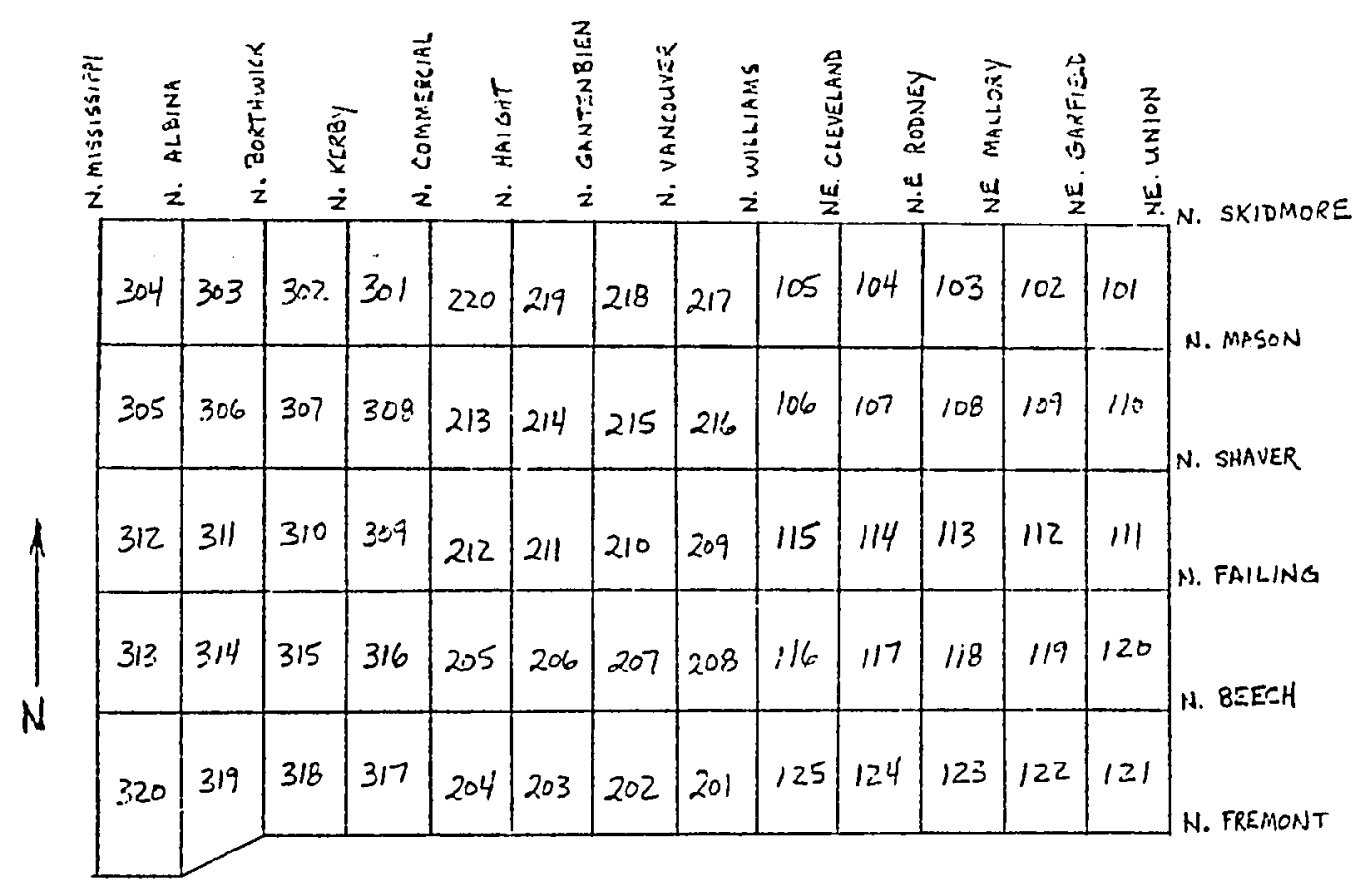




\section{WHITE NEIGHBORHOOD (TRACT 21)}

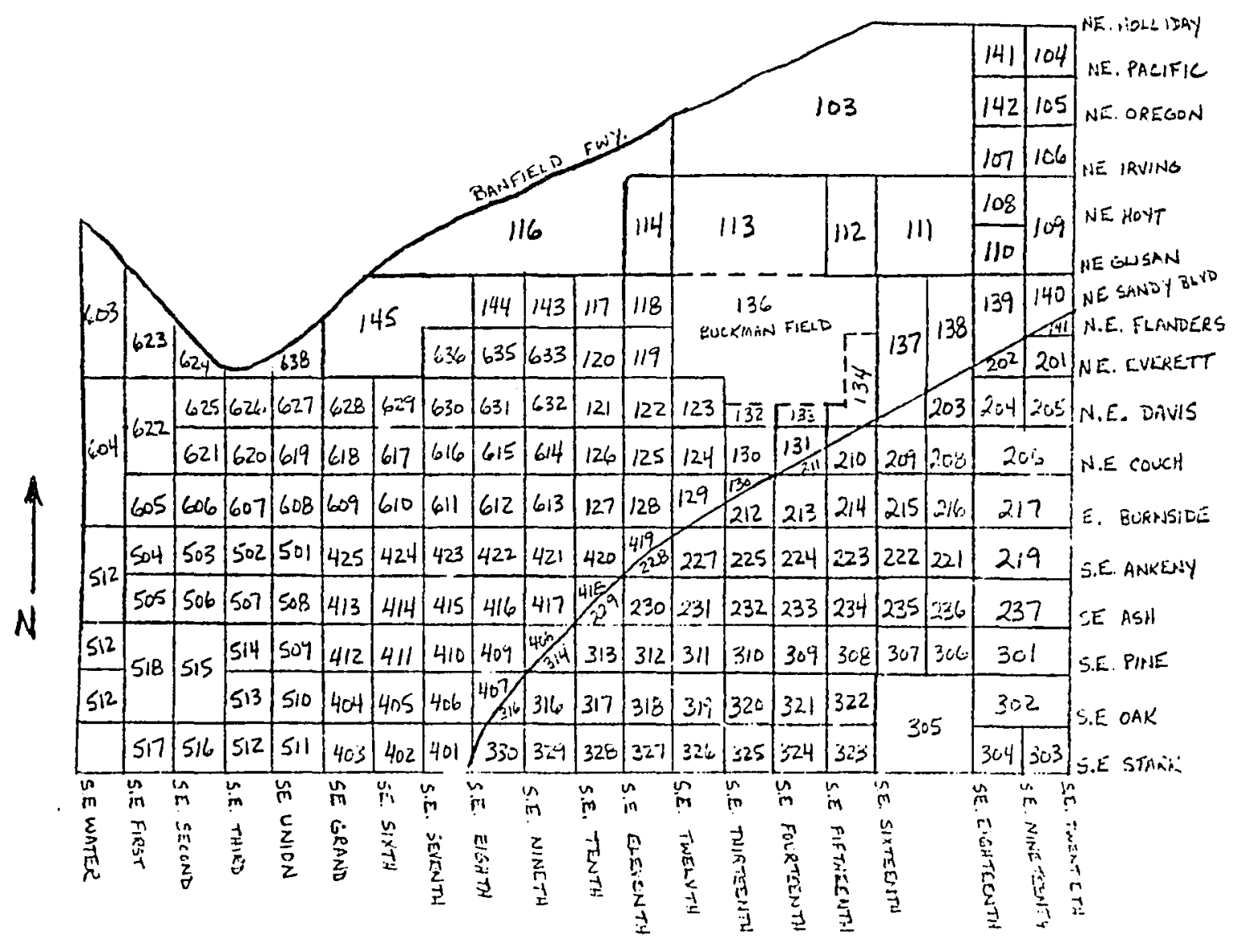


III. GEOGRAPHICAI RELATIONSHIPS BETWEEN SURVEY

NEIGHBORHOODS AND THE CENTRAL

BUSINESS DISTRICT

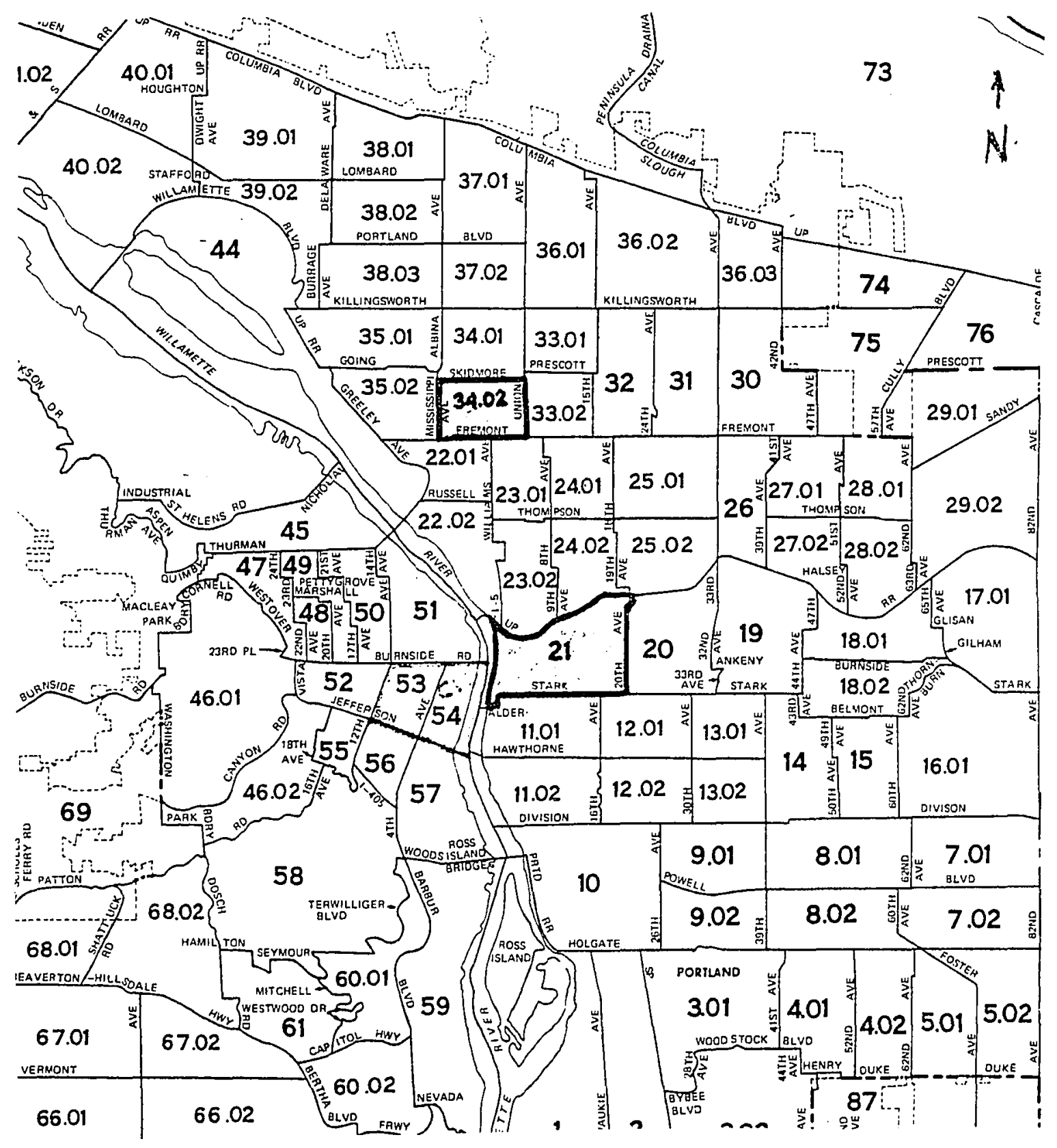


APPENDIX C

INTERVIEW SCHEDULE AND SUBSTITUTION

LISTS FOR SURVEY AREAS

I. BLACK NEIGHBORHOOD (TRACT 34.02)

SURVEY LIST

\begin{tabular}{|c|c|c|c|c|c|c|c|}
\hline BLOCK \# & $\begin{array}{l}\text { SURVEY } \\
\text { HOUSES } \\
\end{array}$ & BLOCK & 非 & $\begin{array}{l}\text { SURVEY } \\
\text { HOUSES } \\
\end{array}$ & BLOCK & 非 & $\begin{array}{l}\text { SURVEY } \\
\text { HOUSES } \\
\end{array}$ \\
\hline 304 & 5,15 & 202 & 8 , & 18,28 & 119 & 10 & 20,30 , \\
\hline 303 & 10 & 203 & 9 & & 118 & 9 & \\
\hline 302 & 12 & 204 & 3 , & 13 & 117 & 10 & \\
\hline 301 & 2,12 & 317 & 9 & & 116 & 10 & \\
\hline 220 & 4,14 & 318 & 6 & & 208 & 5 & 15,25 \\
\hline 219 & 6,16 & 319 & 8, & $18,28,38$ & 207 & 10 & \\
\hline 218 & 1,11 & 320 & 6 & $16,26,36$ & 206 & 6 & 16,26 \\
\hline 217 & 2 & 313 & & NONE & 205 & 7 & 17 \\
\hline 105 & 8 & 312 & 6 , & 16 & 316 & 9 & \\
\hline 104 & 6 & 305 & 2 , & 12 & 315 & 5, & 15 \\
\hline 103 & $2,12,22$ & 306 & 4 , & 14 & 314 & 4 , & 14 \\
\hline 102 & 8 & 307 & 9 , & $19,29,39,49$ & 311 & 9 , & 19,29 \\
\hline 101 & 1,11 & 308 & 10 & 20 & 310 & 8 , & 18,28 \\
\hline 110 & NONE & 213 & 9, & 19 & 309 & & NONE \\
\hline 111 & $4,14,24$ & 214 & 7 & 17,27 & 212 & & NONE \\
\hline 120 & 1,11 & 215 & 7 & 17 & 211 & 1 & \\
\hline 121 & NONE & 216 & 1 & 11 & 210 & 3 & 13 \\
\hline 122 & NONE & 106 & 6 & & 209 & 3 & 13 \\
\hline 123 & 3,13 & 107 & 2 , & 12 & 115 & 1 & 11 \\
\hline 124 & 7,17 & 108 & 8 & & 114 & 1 & 11 \\
\hline 125 & 1,11 & 109 & 1 , & 11 & 113 & 7 & \\
\hline 201 & 4 & 112 & 4 & 14 & & & \\
\hline 202 & $8,18,28$ & 207 & 10 & & & & \\
\hline 203 & & 206 & 6 , & 16,26 & & & \\
\hline 204 & 3,13 & 205 & 7 & 17 & & & \\
\hline 317 & 9 & 316 & 9 & & & & \\
\hline 318 & 6 & 315 & 5 & 15 & & & \\
\hline
\end{tabular}


II. BLACK NEIGHBORHOOD (TRACT 34.02)

\section{SUBSTITUTION LIST}

\begin{tabular}{|c|c|c|c|c|c|c|c|}
\hline BLOCK 非 & $\begin{array}{l}\text { SURVEY } \\
\text { HOUSES }\end{array}$ & BLOCK 非 & & $\begin{array}{l}\text { SURVEY } \\
\text { HOUSES } \\
\end{array}$ & BLOCK 非 & & $\begin{array}{l}\text { SURVEY } \\
\text { HOUSES }\end{array}$ \\
\hline 304 & 3,13 & 202 & 7, & 17,27 & 119 & 9, & $19,29,39$ \\
\hline 303 & 8 & 203 & 8 & & 118 & 8 & \\
\hline 302 & 3,13 & 204 & 2 , & 12 & 117 & 7 & \\
\hline 301 & 3,13 & 317 & 8 & & 116 & 8 & \\
\hline 220 & 5,15 & 318 & 5 & & 208 & 3, & 13,23 \\
\hline 219 & 7 & 319 & 7, & $17,27,37$ & 207 & 8 & \\
\hline 218 & 1,11 & 320 & 5, & $15,25,35$ & 206 & 4, & 14,24 \\
\hline 217 & 2 & 313 & & NONE & 205 & 5 , & 15 \\
\hline 105 & 8 & 312 & 5 , & 15 & 316 & 7 & \\
\hline 104 & 6 & 305 & 1, & 11 & 315 & 3, & 13 \\
\hline 103 & $2,12,22$ & 306 & 3 , & 13 & 314 & 2 , & 12 \\
\hline 102 & & 307 & 8 , & $18,28,38,48$ & 311 & 7 , & $17,27,37$ \\
\hline 101 & 1,11 & 308 & 9 , & 19 & 310 & 6 , & 16,26 \\
\hline 110 & NONE & 213 & 8 , & 18 & 309 & & NONE \\
\hline 111 & $4,14,24$ & 214 & 6 , & 16,26 & 212 & 2 & \\
\hline 120 & 10 & 215 & 6 , & 16,26 & 211 & & NONE \\
\hline 121 & NONE & 216 & 10 & & 210 & 1, & 11 \\
\hline 122 & NONE & 106 & 5 & & 209 & 1 & 11 \\
\hline 123 & 2,12 & 107 & 1 , & 11 & 115 & 1 & 11 \\
\hline 124 & $6,16,26$ & 108 & 7 & 17 & 114 & 10 & \\
\hline 125 & 10 & 109 & 10 & & 113 & 6 & \\
\hline 201 & 3 & 112 & 3 , & 13 & & & \\
\hline
\end{tabular}


III. WHITE NEIGHBORHOOD (TRACT 21) SURVEY LIST

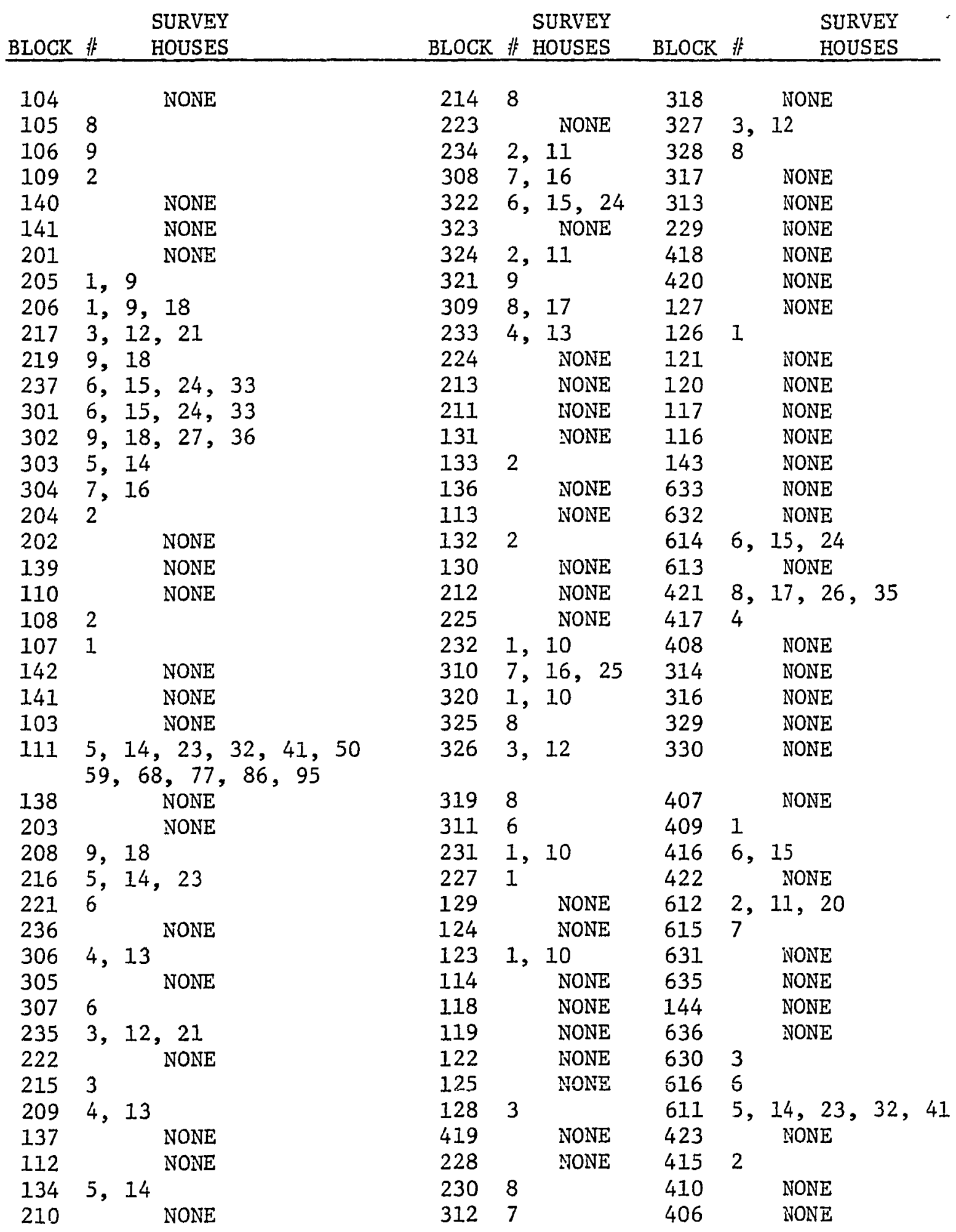


IV WHITE IVEIGHBORHOOD (TRACT 21) SUBSTITUTION LIST

\begin{tabular}{|c|c|c|c|c|c|c|c|c|}
\hline BLOCK & 非 & $\begin{array}{l}\text { SURVEY } \\
\text { HOUSES } \\
\end{array}$ & BLOCK & $\begin{array}{r}\text { SURVEY } \\
\text { 非 HOUSES } \\
\end{array}$ & BLOCK & \# & $\begin{array}{l}\text { SURVEI } \\
\text { HOUSES }\end{array}$ & \\
\hline 104 & & NONE & 214 & 9 & 318 & & NONE & \\
\hline 105 & 4 & & 233 & NONE & 327 & 6 & & \\
\hline 106 & 5 , & 14 & 234 & 3,12 & 328 & 2 & & \\
\hline 109 & & NONE & 308 & 8,17 & 317 & & NONE & \\
\hline 140 & & NONE & 322 & $7, \quad 16,25$ & 313 & & NONE & \\
\hline 141 & & NONE & 323 & NONE & 229 & 1 & & \\
\hline 201 & 4 & & 324 & 3 & 418 & & NONE & \\
\hline 205 & 6 & 15 & 321 & 1,10 & 420 & & NONE & \\
\hline 206 & 7 & 16 & 309 & 9,18 & 127 & & NONE & \\
\hline 217 & 4 , & 13 & 233 & 5,14 & 126 & 4 & & \\
\hline 219 & 1 , & 10,19 & 224 & NONE & 121 & & NONE & \\
\hline 237 & 7 & $16,25,34$ & 213 & NONE & 120 & & NONE & \\
\hline 301 & 7 & 16,25 & 211 & NONE & 117 & & NONE & \\
\hline 302 & 1 & $10,19,28,37$ & 131 & NONE & 116 & & NONE & \\
\hline 303 & 6 , & 15 & 133 & 3 & 143 & & NONE & \\
\hline 304 & 8 , & 17 & 136 & NONE & 633 & & NONE & \\
\hline 204 & 3 & & 113 & NONE & 632 & & NONE & \\
\hline 202 & & NONE & 132 & 6 & 614 & 9 , & 18 & \\
\hline 139 & & NONE & 130 & NONE & 613 & & NONE & \\
\hline 110 & & NONE & 212 & NONE & 421 & 2 , & 11,20 & $, 29,38$ \\
\hline 108 & 3 & & 225 & INONE & 417 & & NONE & \\
\hline 107 & 2 & & 232 & 5 & 408 & & NONE & \\
\hline 142 & & NONE & 310 & $2,11,20$ & 314 & & NONE & \\
\hline 141 & & NONE & 320 & 4 & 316 & & NONE & \\
\hline 103 & & NONE & 325 & 2,11 & 329 & & NONE & \\
\hline 111 & & $\begin{array}{r}15,24,33,42,51 \\
69,78,87\end{array}$ & 326 & 6 & 330 & & NONE & \\
\hline 138 & & NONE & 319 & 2,11 & 407 & & NONE & \\
\hline 203 & & NONE & 311 & 9 & 409 & 4 & & \\
\hline 208 & & 10,19 & 231 & 4,13 & 416 & 9, & 18 & \\
\hline 216 & 6 & 15,24 & 227 & NONE & 422 & & NONE & \\
\hline 221 & 7 & & 129 & NONE & 612 & 5 , & 14 & \\
\hline 236 & & NONE & 124 & NONE & 615 & 3 & & \\
\hline 306 & 5 & 14 & 123 & 3 & 631 & & NONE & \\
\hline 305 & & NONE & 114 & NONE & 635 & 1 & & \\
\hline 307 & 7 & & 118 & NONE & 144 & & NONE & \\
\hline 235 & 4 & 13,22 & 119 & NONE & 636 & & WNONE & \\
\hline 222 & & NONE & 122 & NONE & 630 & & NONE & \\
\hline 215 & 4 & & 125 & 1 & 616 & 2 & & \\
\hline 209 & 5 , & 14 & 128 & NONE & 611 & 1 , & 10,19 & $28, \quad 37$ \\
\hline 137 & & NONE & 419 & NONE & 423 & & NONE & \\
\hline 112 & & NONE & 228 & NONE & 415 & & LTONE & \\
\hline 134 & 6 & & 230 & 1,10 & 410 & & RNONE & \\
\hline 210 & 1 & & 312 & 1,10 & 406 & 1 & & \\
\hline
\end{tabular}




\section{APPENDIX D}

GENERAL INSTRUCTIONS FOR INTERVIEWERS

\section{Identifying Survey Households}

A. Each interviewer will receive the following items prior to the survey:

1. A numbered block map of the assigned survey area.

2. A list of assigned block numbers with the proper housenolds indicated for each block assigned.

3. A list of substitute households for each block assigned.

B. To locate the proper households to be surveyed in each block, always start in the NORTHWEST CORNER of the block and walk clockwise so that the buildings are always on your right. As you walk clockwise around the block, count housing units until you come to the first one indicated on your block list for that block. Interview an appropriate person in that house or apartment. Note: vacant lots and business do not count-only houses or apartments are counted.

In counting housing units, single family type units count one each. Duplexes and apartments are counted one for each unit in the complex. (You may have to check mailboxes or talk to the manager to find out the number of apartment units in some buildings--if you have to check with the manager, you should carefully explain your purpose so that you can get his or her cooperation). In counting units within an apartment structure always use the same order that the apartment units are numbered or lettered.

C. If nobody is home the first time, or if an appropriate person is not home, note the address and move on to the next housing unit indicated on the list for that block. There is to be one call-back in these cases before using substitute household.

D. Use the substitution list only in the following situations:

1. Where nobody is home, or an appropriate person is not at home after the call-back.

2. Where the house or apartment is obviously vacant or the structure is torn down. 
DO NOT UNDER ANY CIRCUMSTANCES USE THE SUBSTITUTION LIST IN CASES OF A REFUSAL TO BE INTERVIEWED!

When using the substitution list, use substitute households indicated for a particular block in the proper order. They are located in the same manner as the primary households. If there is no substitute listed, or you have used up all the substitutes for a particular block, move on to the next primary household on your list.

II. Whom to Interview

A. The survey is to be of adult residents of households. If the person who answers the door is obviously adult-no problem. If the person answering the door appears to be under 18 yrs. old, ask if either of the parents are home. If the parents are not home, ask the person if he or she is over 18 yrs. old. If not, note the address for a call-back. If yes, attempt to interview that person.

B. Try to get a feeling for the balance between males and females in the interviews you have completed. If both are present in a housenold, attempt to interview that person which will provide or maintain the balance. This is not a critical requirement for the study, however. In all cases, interview anyone you can rather than sacrifice an interview. (If both are present you should ask if you can interview one of them. If they agree but show no preference--choose one of them. If the first person you talk to does not agree to be interviewed do not approach another in the same household--treat it as a refusal.)

C. If the person who comes to the door is a babysitter, a friend, a neighbor, or a relative, try to determine whether an adult resident is available. If none is available, note the address for a call-back.

III. When to Interview

Try to arrange your schedule so that about half of your interviewing is done during the daytime and the other half is done in the evenings or on weekends. This will ensure a fair balance of working and non-working respondents.

IV. Introducing Yourself and the Study

A. When you first approach someone at the door, give them the following information (after first determining if you are talking to an appropriate person). This should be done in an informal and sincere manner. 
1. Identify yourself and show your letter of introduction.

2. Tell the person that you are interviewing a random sample of residents in their neighborhood as part of a PSU Urban Studies Program study and that their household has been selected.

3. Tell the person that the purpose of the study is to finc. out what people think about problems in their neighborhood and what people think about taking part in neighborhood affairs.

4. Assure them that you are not selling anything and that nobody will call on them to try to sell them anything.

5. Assure them that their responses will be completely confidential and that they will not be identified in any way.

6. Te11 them that the interview is not difficult and will take only about 25 minutes or maybe a little longer-depending on them.

7. Ask them if they will participate.

B. As you introduce yourself and the study, be sincere, polite, confident and persuasive. You have a right to be there--just as they have a right to refuse.

V. What to do if You Can't Complete the Interview

If there is an interruption, or the person runs out of time before the interview is completed, make every attempt to set a firm appointment to complete the balance of the interview. If this is impossible and there is no chance of completing the interview, note the circumstances on the final page of the questionnaire. If a person refuses to answer one or two questions only, do not terminate the interview. Simply note their refusal in the margin opposite the question and go on to the next question.

VI. Conducting the Interview

A. Instructions built into the questionnaire should present no problem. Read the questions slowly and clearly. Read exactly what is printed--do not ad 1ib. Read in a neutral manner but add emphasis where indicated. Watch for signs of confusion or misunderstanding and repeat questions or response choices where necessary. Do not try to interpret questions for the respondent.

B. The questionnaire is designed to force choices of preselected responscs. If a person indicates a response that is not one of the ones listed for a question, ask him or her which would be the choice if he or she had to pick one of the responses listed. If that still doesn't result in a choice, ask which way the person would lean if forced to make a choice. 
C. There should be no need for many margin comments. You may add comments where you think they are necessary. If you do comment, be as clear as possible.

D. Mark the questionnaire clearly by circling the number opposite the response chosen for each question. You may use either pencil or ink, but make sure that the marks are unmistakable.

VII. After the Interview

Before moving on to the next household on your list be sure to:

1. Complete the final page of the questionnaire which includes interviewer observations--including address. (Get a phone number if possible.)

2. Clearly print your name on the front cover page in the indicated place.

3. Number the questionnaire in the space provided on the front cover page. Each person should number consecutively beginning with number " 1 ".

VIII. Bookkeeping and Other Details

A. Keep a time and mileage log for each time period you are working. It should include:

1. The date.

2. The time you start out for the survey area.

3. The time you arrive at the survey area.

4. The time you stopped interviewing.

5. Mileage used.

6. The number of interviews completed.

B. I would like to have completed questionnaires returned to me at least every third day so that I can begin preliminary processing. I would like to review your time and mileage log covering those interviews at the same time.

C. Interviewers will be paid for their time and travel when they have completed their assigned number of interviews.

IX. Expectations

A. The interview itself takes from 25-45 minutes or so to complete. I am allowing in my budget a maximum of two hours for each completed interview on the average. Many interviews should be completed in much less time. Please be as accurate as you can in reporting your actual time. Since my funds are very limited, I would appreciate your attention to this detail.

B. I am not too concerned whether you work on a full-time basis for a short period of time or a part-time basis over a longer period. I do, however, expect a time commitment on the part 
of each interviewer that is sufficient to complete the assigned interviews on or before Monday, December 9th. (This means, for example, a time commitment of about 25-35 hours over the next twenty-one days on the basis of 17 or 18 assigned interviews). There will be extra interviewing opportunities available for those finishing their assigned interviews early. 


\section{APPENDIX E}

FIELD INTERVIEW QUESTIONNAIRE

I have a list of some of the things that people can do to help a political party, or a candidate for office, or a ballot measure win an election. I wonder if you could tell me whether you did any of these things during this last election campaign?

1. Did you talk to people and try to show them why they should vote for one of the political parties, candidates or ballot measures?

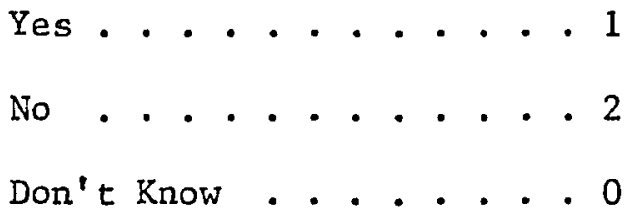

2. Did you give any money or buy tickets or anything to help the campaign for one of the political parties, candidates or ballot measures?

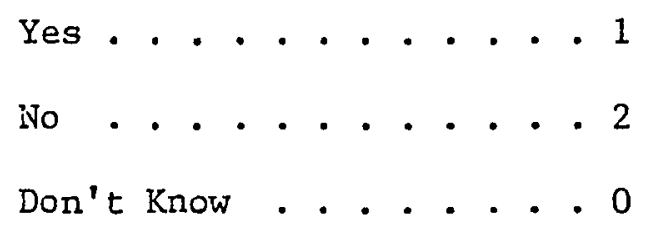

3. Did you go to any political meetings, rallies, dinners or anything like that where the candidates for office or the ballot measures were discussed?

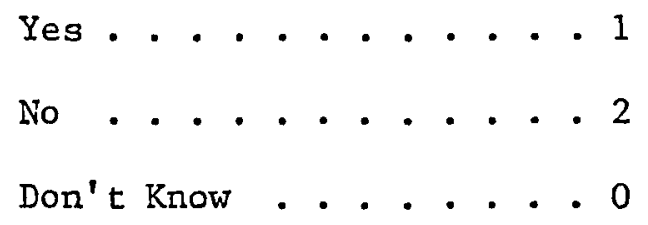


4. Did you do any other work for one of the political parties, candidates or ballot measures like telephoning, addressing envelopes or taking campaign literature door-to-door?

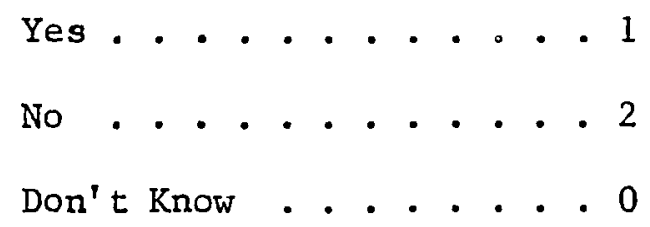

5. Do you belong to any political club or organization?

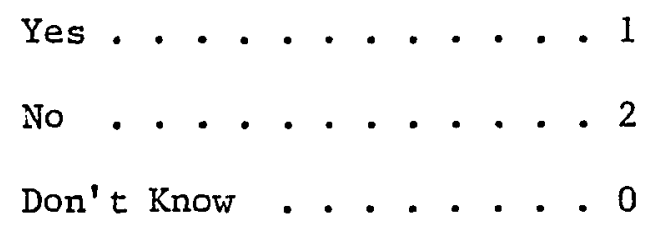

6. Did you wear a campaign button or put a bumper sticker on your car or put a sign on your lawn?

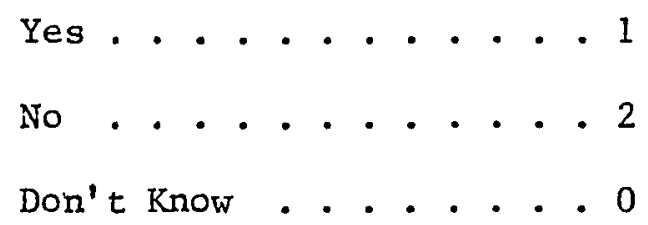

7. Are you registered to vote?

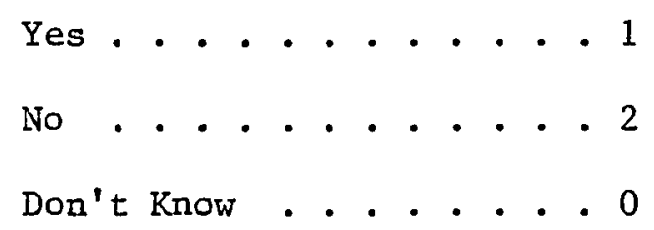

8. Have you voted in an election in the past four years?

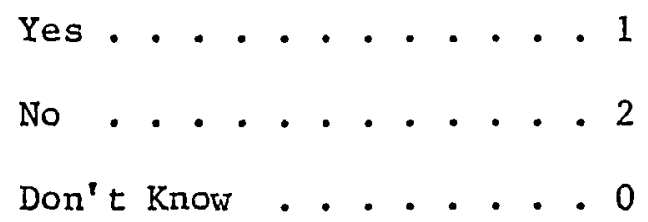

9. Did you vote in this last election?

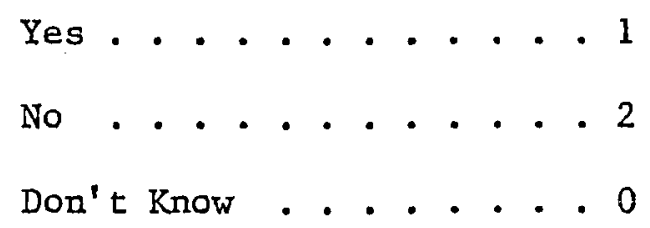


(READ THE FOLLOWING STATEMENT FOR INTERVIEWS IN THE WHITE NEIGHBORHOOD)

Another way people can take part in public affairs is to participate in community or neighborhood organizations. In the last four or five years, a number of neighborhood organizations and associations like: the Buckman Neighborhood Association; Portland Action Committees Together, Inc. (PACT, Inc.); Southeast Uplift; and so forth, have been in existence to help people get involved in solving problems in their own neighborhoods.

(READ THE FOLLOWING STATEMENT FOR INTERVIEWS IN THE BLACK NEIGHBORHOOD)

Another way people can take part in public affairs is to participate in community of neighborhood organizations. In the last four or five years, a number of neighborhood organizations and associations like: the Model Cities Program; the Albina Citizens' War on Poverty and Albina Action Center; and the Boise Citizen's Improvement Assoc. have been in existence to help people get involved in solving problems in their own neighborhoods.

10. Do you know about any of these groups or organizations?

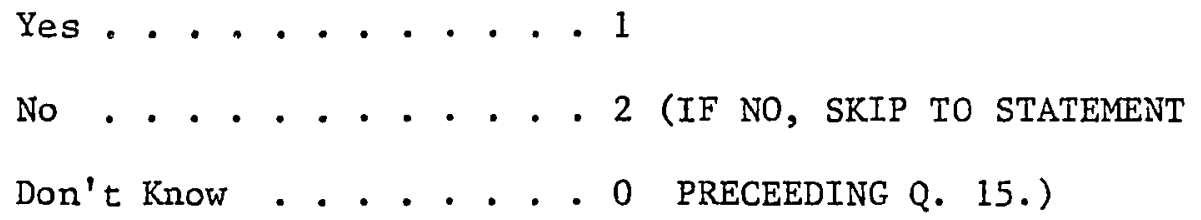

11. Have you attended meetings of any of these groups or organizations?

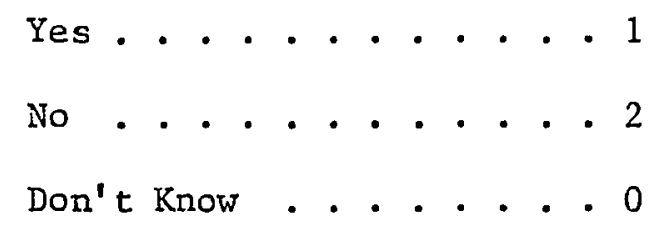

12. Have you taken part in activities or programs sponsored by any of these groups or organizations?

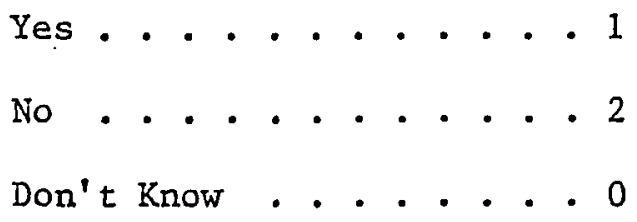


13. Have you voted in an election to choose the leaders of any of these groups or organizations?

$$
\begin{aligned}
& \text { Yes . . . . . . . } 1 \\
& \text { No . . . . . . . } 2 \\
& \text { Don't know . . . . } 0
\end{aligned}
$$

14. Have you been a leader, or have you served on a committee in any of these groups or organizations?

$$
\begin{aligned}
& \text { Yes . . . . . . } 1 \\
& \text { No . . . . . . . } 2 \\
& \text { Don't know . . . . } 0
\end{aligned}
$$

Another way people can take part in public affairs is to take an active part in some issue that arises. An active part means doing things to get a decision made in a particular way like: signing or collecting signatures on a petition; writing or talking to public officials; holding or attending special meetings; speaking to groups; attending public hearings, and things like that.

15. Have you taken an active part in any local government, community or neighborhood issue during the past two or three years?

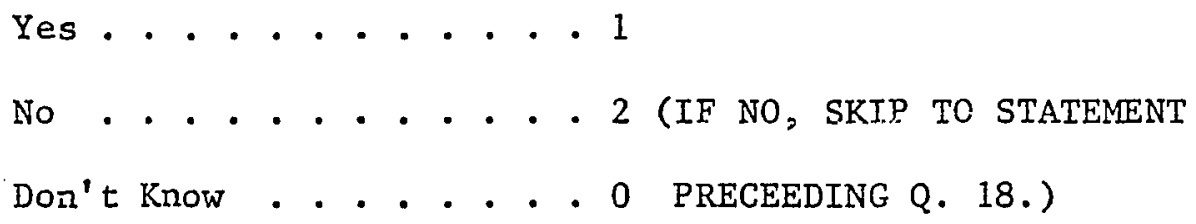

16. What was the issue?

17. What did you do?

Sign or Circulate a Petition . . . . . . . . . 1

Write or Talk to Public Officials . . . . . . 2

Hold or Attend Special Meetings . . . . . . . 3

Speak to Groups . . . . . . . . . . . . 4

Attend Public Hearings . . . . . . . . . . 5 
Over the past several years, a number of problems have been said to exist in this neighborhood. I would like to ask you some questions about how you see your neighborhood and its problems.

18. The first problem I would like to ask you about is housing. Housing problems might be described as things like: a lack of decent housing in this area; housing discrimination by landlords and real estate companies; poor enforcement of city building codes; lack of money to fix up housing; houses in bad condition because owners or landlords don't care about fixing them up; housing that costs too much, and so forth. Do you think any of these kinds of things are problems in your neighborhood?

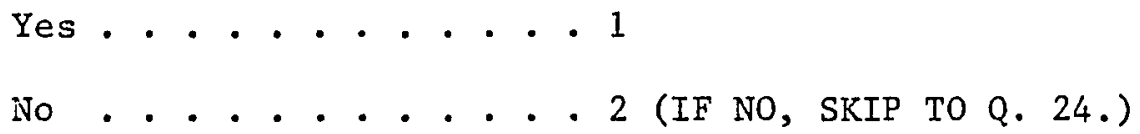

Now I would like to ask you five questions about how you see these problems.

19. Some people say these housing problems are personal problems that should be handled by the individual. Others say they are social problems that should be handled by government. If you had to choose one of four possibilities, would you say these nousing problems are: (READ POSSIBLE CHOICES BELOW)

$$
\begin{aligned}
& \text { Personal Problems . . . . . . . } 1 \\
& \text { Both, but more Personal. . . . } 2 \\
& \text { Both, but more Social. . . . . . } 3 \\
& \text { Social Problems . . . . . . . } 4
\end{aligned}
$$

20. Some people say these housing problems are local problems. Others say they are national problems. If you had to choose one of four possibilities, would you say these housing problems are: (READ POSSIBLE CHOICES BELOW)

$$
\begin{aligned}
& \text { Local Problems . . . . . . . . } 1 \\
& \text { Both, but more Local . . . . . . } 2 \\
& \text { Both, but more National . . . . } 3 \\
& \text { National Problems . . . . . . } 4
\end{aligned}
$$


21. Some people say these housing problems are not a political matter or responsibility. Others say they are a political matter or responsibility. If you had to choose one of four possibilities, would you say these housing problems are:

(READ POSSIBLE CHOICES BELOW)

$$
\begin{aligned}
& \text { Non-political Problems . . . . } 1 \\
& \text { Both, but more Non-political . . } 2 \\
& \text { Both, but more Political . . . . } 3 \\
& \text { Political Problems . . . . . } 4
\end{aligned}
$$

22. Are these housing problems the kinds of things you feel you can personally do something about as an individual?

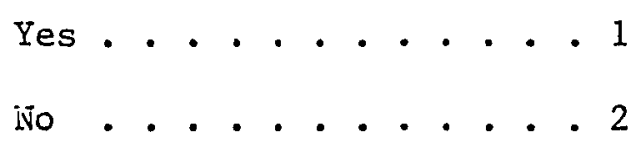

23. Are these housing problems the kinds of things you feel you could do sometining about as a part of a group of concerned neighbors working together?

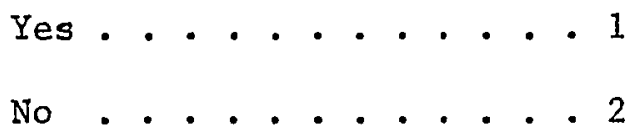

24. The second problem I would like to ask you about is education. Education problems might be described as things like: crowded classrooms; poor quality teachers; lack of vocational and job training; high drop-out rates; lack of parent concern; student unrest; school buildings and grounds in poor condition; lack of student interest in what is taught, and so forth. Do you think any of these kinds of things are problems in your neighborhood?

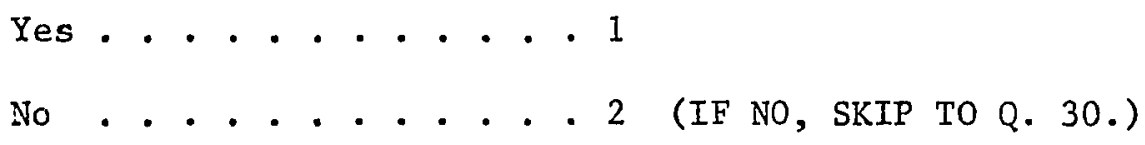

Now I would like to ask you five questions about how you see these problems. 
25. Some people say these education prcblems are personal problems that should be handled by the individual. Others say they are social problems that should be handled by government. If you had to choose one of four possibilities, would you say these education problems are: (READ POSSIBLE CHOICES BELOW)

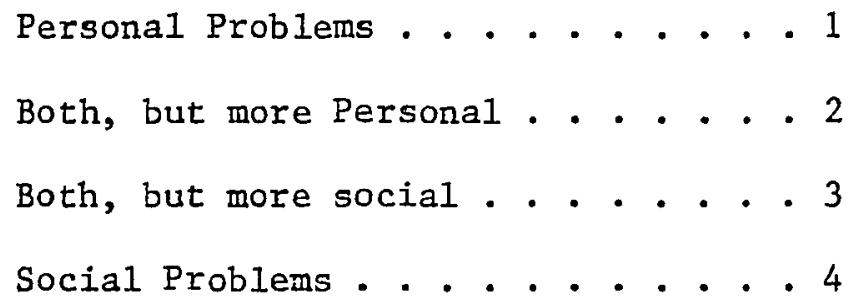

26. Some people say these education problems are local problems. others say they are national problems. If you had to choose one of four possibilities, would you say these education problems are: (READ POSSIBLE CHOICES BELOW)

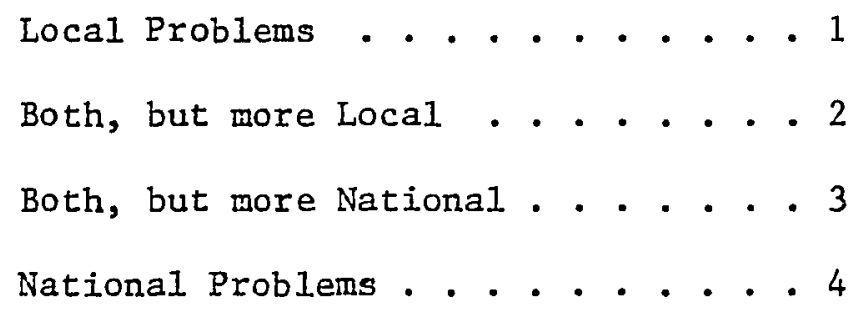

27. Some people say these education problems are not a political matter or responsibility. Others say they are a political matter or responsibility. If you had to choose one of four possibilities, would you say these education problems are: (READ POSSIBLE CHOICES BELOW)

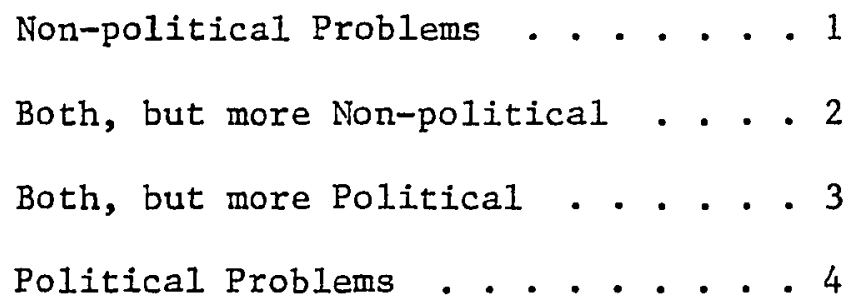

28. Are these education problems the kinds of things you feel you personally can do something about as an individual?

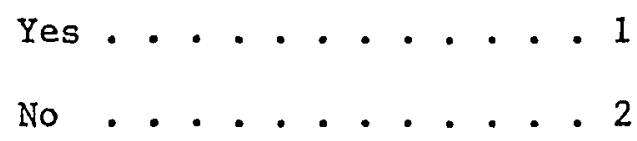


29. Are these education problems the kinds of things you feel you could do something about as a part of a group of concerned neighbors working together?

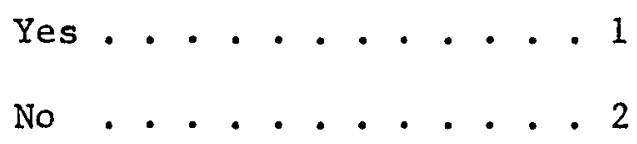

30. The next problem I would like to ask you about is employment. Employment problems might be described as things like: not enough jobs in the area; low paying jobs; people looking for work with low education and no job skills; job discrimination; lack of training programs; people with no desire to work; poor transportation to jobs; few day-care programs for working mothers, and so forth. Do you think any of these kinds of things are problems in your neighborhood?

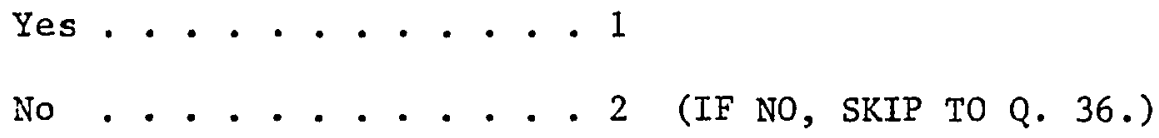

Now I would like to ask you five questions about how you see these problems.

31. Some people say these employment problems are personal problems that should be handled by the individual. Others say they are social problems that should be handled by government. If you had to choose one of four possibilities, would you say these employment problems are: (READ POSSIBLE CHOICES BELOW)

$$
\begin{aligned}
& \text { Personal Froblems . . . . . . . } 1 \\
& \text { Both, but more Personal . . . . } 2 \\
& \text { Both, but more Social . . . . . } 3 \\
& \text { Social Problems . . . . . . . } 4
\end{aligned}
$$

32. Some people say these employment problems are local problems. Others say they are national problems. If you had to choose one of four possibilities, would you say these employment problems are: (READ POSSIBLE CHOICES BELOW)

$$
\begin{aligned}
& \text { Local Problems . . . . . . . . } 1 \\
& \text { Both, but more Local . . . . . } 2 \\
& \text { Both, but more National . . . . } 3 \\
& \text { National Eroblems . . . . . . } 4
\end{aligned}
$$


33. Some people say these employment problems are not a political matter or responsibility. Others say they are a political matter or responsibility. If you had to choose one of four possibilities, would you say these employment problems are: (READ POSSIBLE CHOICES BELOW)

$$
\begin{aligned}
& \text { Non-political Problems . . . . . } 1 \\
& \text { Both, but more Non-political . . . } 2 \\
& \text { Both, but more Political . . . . } 3 \\
& \text { Political Problems . . . . . . } 4
\end{aligned}
$$

34. Are these employment problems the kinds of things you feel you can personally do something about as an individual?

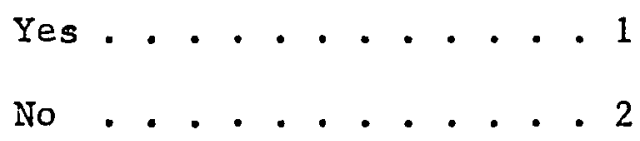

35. Are these employment problems the kinds of things you feel you could do something about as a part of a group of concerned neighbors working together?

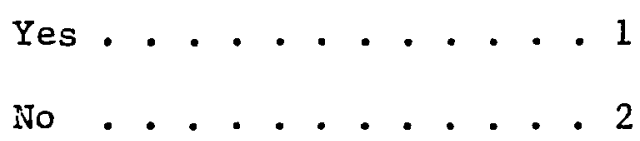

36. The fourth problem $I$ would like to ask you about is crime and delinquency. Problems of crime and delinquency might be described as things like: lack of respect for the property of others; 1ittle opportunity to make an honest living; poor law enforcement; too many people taking drugs; too much crime in the area to feel safe on the streets; too many kids running wild with no control by their parents, and so forth. Do you think any of these kinds of things are problems in your neighborhood?

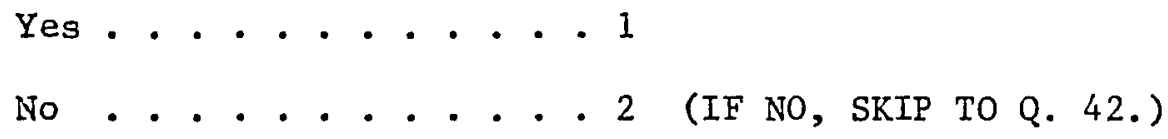

Now I would like to ask you five questions about how you see these problems. 
37. Some people say these problems of crime and delinquency are personal problems that should be handled by the individual. Others say they are social problems that should be handled by government. If you had to choose one of four possibilities, would you say these problems of crime and delinquency are: (READ POSSIBLE CHOICES BELOW)

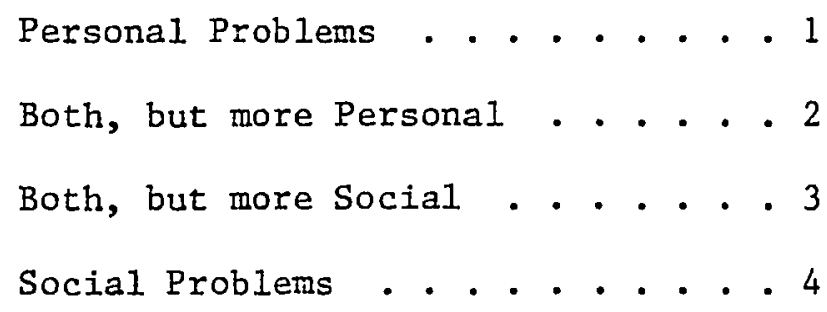

38. Some people say these problems of crime and delinquency are local problems. Others say they are national problems. If you had to choose one of four possibilities, would you say these problems of crime and delinquency are: (READ POSSIBLE CHOICES BELOW)

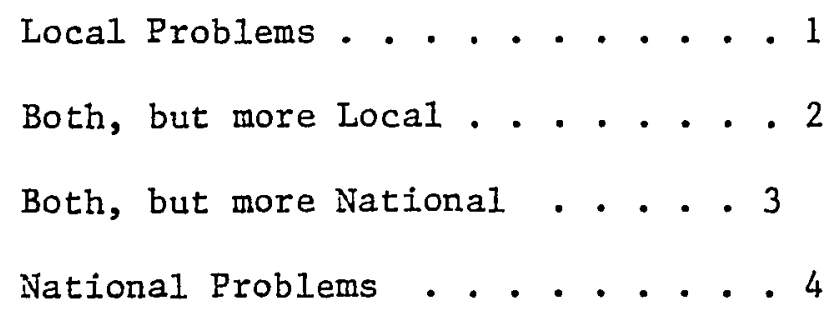

39. Some people say these problems of crime and delinquency are not a political matter or responsibility. Others say they are a political matter or responsibility. If you had to choose one of four possibilities, would you say these problems of crime and delinquency are: (READ POSSIBLE CHOICES BELOW)

$$
\begin{aligned}
& \text { Non-political Problems . . . . . } 1 \\
& \text { Both, but more Non-political . . } 2 \\
& \text { Both, but more Political . . . . } 3 \\
& \text { Political Problems . . . . . } 4
\end{aligned}
$$

40. Are these problems of crime and delinquency the kinds of things you feel you can personally do something about as an individual?

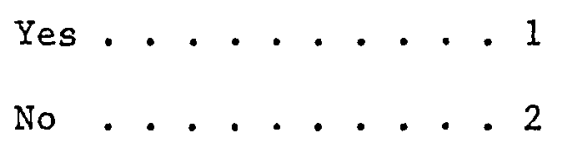


41. Are these problems of crime and delinquency the kinds of things you feel you could do something about as a part of a group of concerned neiginbors working together?

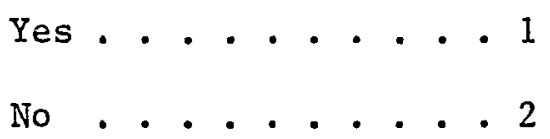

42. The final problem I would like to ask you about is policecommunity relations. Problems of police-community relations might be described as things like: police harassment and brutality; little trust between the police and the people; poor level of police protection; racial discrimination on the part of the police; little respect between the police and the people; unequal enforcenent of the law, and so forth. Do you think any of these kinds of things are problems in your neighborhood?

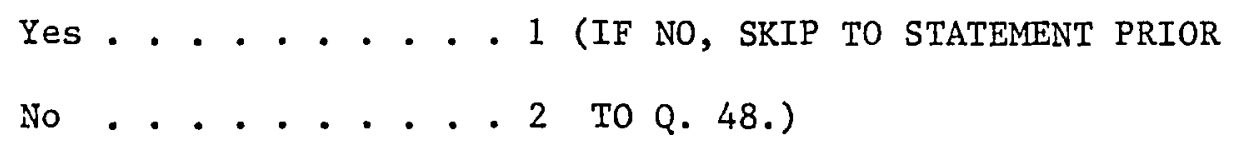

Now I would like to ask you five questions about how you see these problems.

43. Some people say these problems of police-community relations are personal problems that should be handled by the individual. Others say they are social problems that should be handled by government. If you had to choose one of four possibilities, would you say these problems of police-community relations are: (READ POSSIBLE CHOICES BELOW)

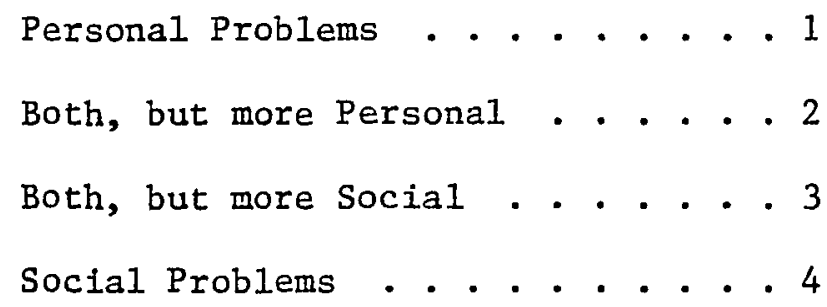


44. Some people say these problems of police-community relations are local problems. Others say they are national problems. If you had to choose one of four possibilities, would you say these problems of police-community relations are: (READ POSSIBLE CHOICES BELOW)

$$
\begin{aligned}
& \text { Local Problems . . . . . . . . } 1 \\
& \text { Both, but more Local . . . . . } 2 \\
& \text { Both, but more National . . . . } 3 \\
& \text { National Problems . . . . . . } 4
\end{aligned}
$$

45. Some people say these problems of police-community relations are not a political matter or responsibility. Cthers say they are a political matter or responsibility. If you had to choose one of four possibilities, would you say these problems of police-community relations are: (READ POSSIBLE CHOICES BELOW)

$$
\begin{aligned}
& \text { Non-political Problems . . . . . } 1 \\
& \text { Both, but more Non-Political . . } 2 \\
& \text { Both, but more Political . . . } 3 \\
& \text { Political Problems . . . . . } 4
\end{aligned}
$$

46. Are these problems of police-community relations the kinds of things you feel you can personally do something about as an individual?

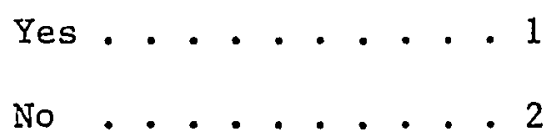

47. Are these problems of police-community relations the kinds of things you feel you could do something about as a part of a group of concerned neighbors working together?

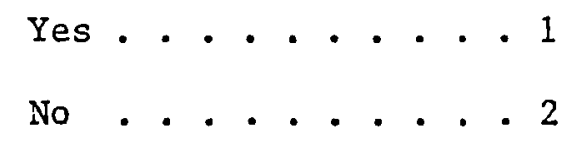

\section{(HAND RESPONDENT THE FIVE CARDS INDICATING PROBLEM AREAS)}

Here are five cards. Each card indicates one of the problem areas we have been talking about. I would like you to choose the three cards that indicate the problem areas that are the most important to you. 
(PAUSE WHILE RESPONDENT SELECTS THE THREE CARDS)

When you have made your choice, I would like you to put them in the order of their importance to you. The. card indicating the most important problem should be on top and the card indicating the least important of the three should be on the bottom.

48. (RETRIEVE CARDS FROM THE RESPONDENT AND RECORD RESPONSES)

First Choice

Second Choice

Third Choice

Now I would like to get some general background information about you and your family.

49. Who is the main wage earner in this household?

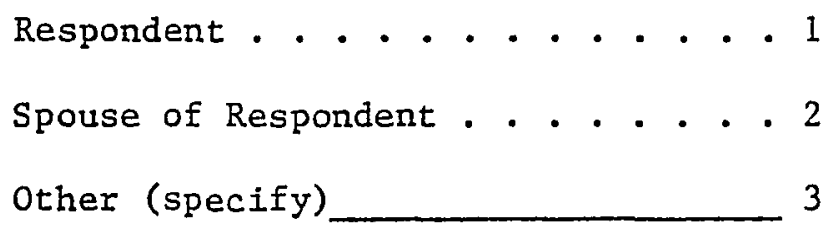

50. (Are you) (Is he/she) currently working: (READ POSSIBLE CHOICES BELOW)

$$
\begin{aligned}
& \text { Full-time . . . . . . . . . } 1 \\
& \text { Part-time .......... . } 2 \\
& \text { Unemployed or Temporarily Laid-off - } 3 \text { (IF } 3 \text { OR } 4 \text { READ: } \\
& \text { THIS NEXT QUESTION } \\
& \text { Retired .......... } 4 \text { ASKS ABOUT YOUR } \\
& \text { (HIS/HER) JOB. } \\
& \text { Other (specify) } \\
& 5 \text { ANSWER IT AS IF YOU } \\
& \text { (HE/SHE) WERE STILL } \\
& \text { WORKING.) }
\end{aligned}
$$

51. What is (your) (his/her) specific job where (you) (he/she) work(s)? What is it that (you) (he/she) do (does) there? 
52. Altogether, how many years of schooling did you complete?

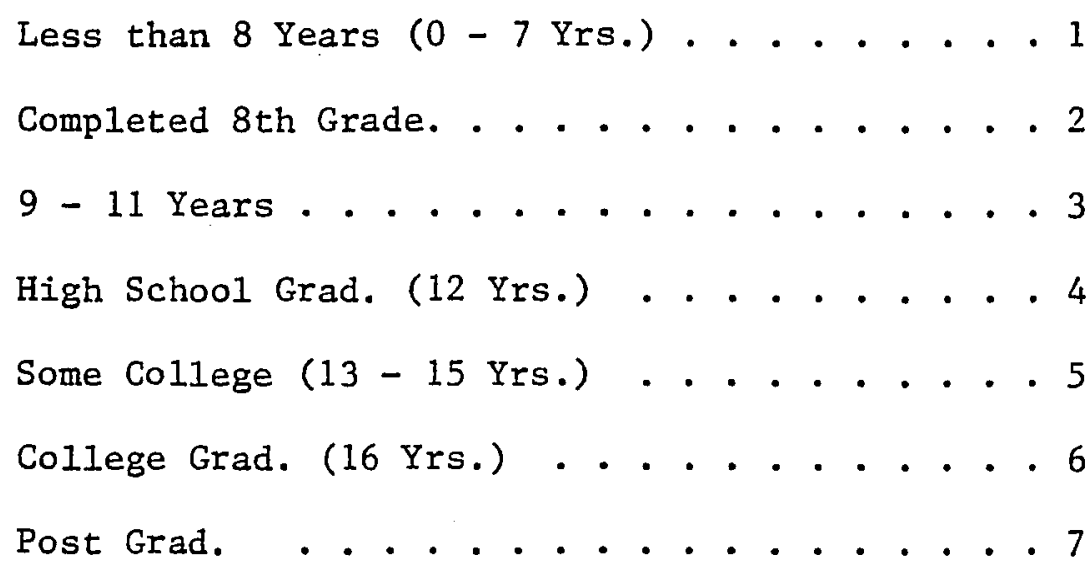

53. (ASK ONLY IF RESPONDENT IS NOT MAIN WAGE EARNER) Altogether, how many years of schooling did the main wage earner of the household complete?

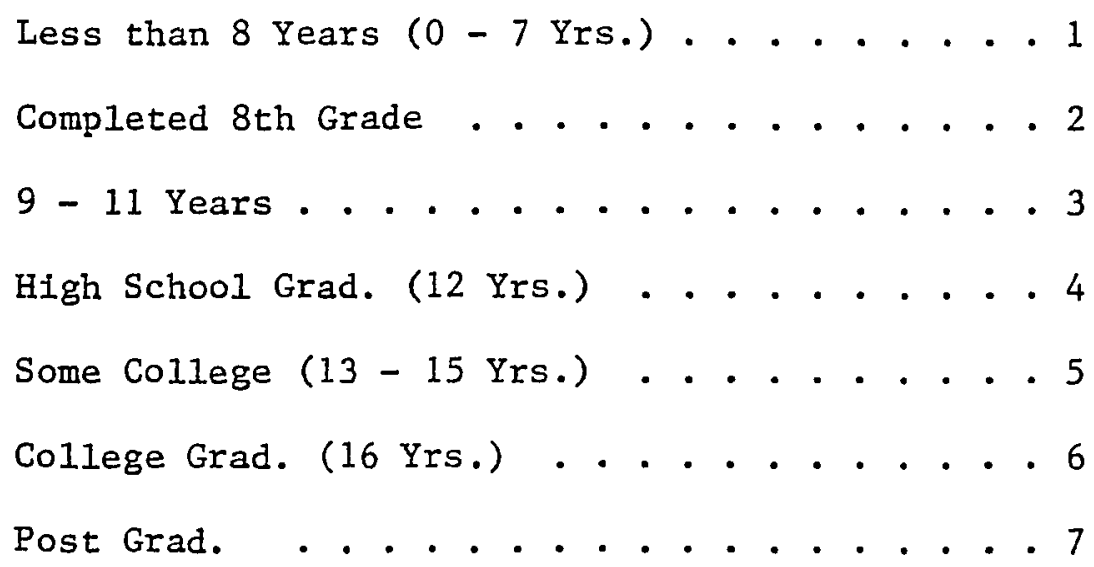

54. A household includes all persons who live together, cook together, and eat together as a separate group. How many people, including yourself, are there in this household?

(HAND RESPONDENT CARD INDICATING INCOME GROUPS)

I would like you look at this card and tell me the letter of the yearly income group that comes closest to the total amount that all members of this household combined received in the past year. 
55. (RECORD RESPONSE)
A..... $1 \quad(A=$ Less than $\$ 2,000)$
B.... 2 (B $=\$ 2,000-\$ 3,000)$
C.... $3 \quad(C=\$ 3,000-\$ 5,000)$
D.... $4 \quad(D=\$ 5,000-\$ 8,000)$
E..... $5 \quad(E=\$ 8,000-\$ 12,000)$
F..... $6 \quad(F=\$ 12,000-\$ 17,000)$
G.... $7 \quad(G=\$ 17,000-\$ 23,000)$
H..... 8 ( $\mathrm{H}=$ More than $\$ 23,000)$

(RETRIEVE CARD FROM RESPONDENT)

56. Do you own or rent your residence?

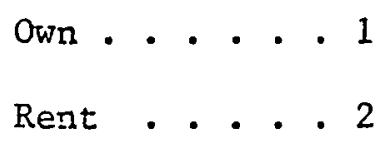

57. How long have you been living at this address?

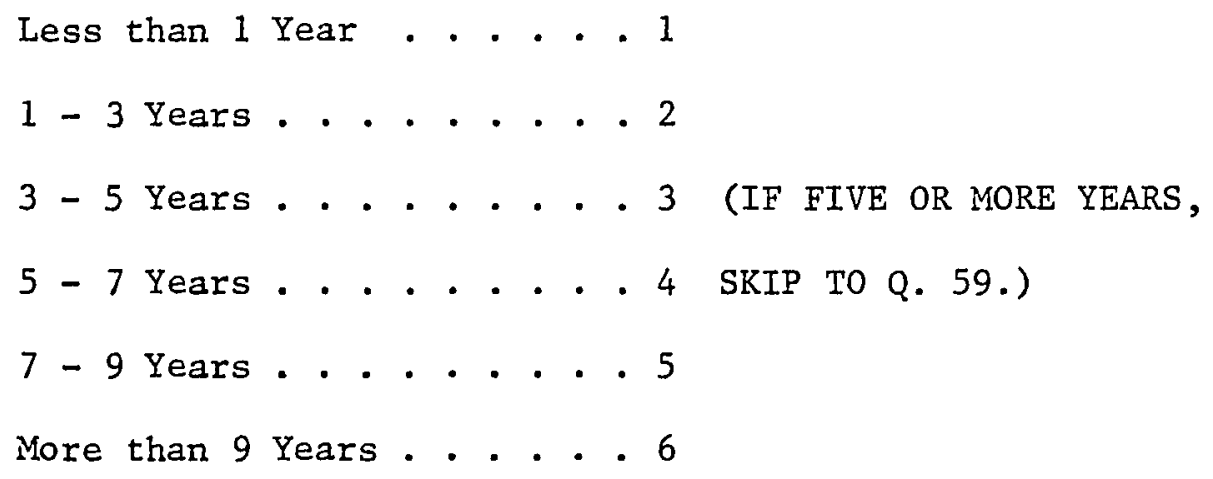

58. During the last five years, in about how many different places have you lived?

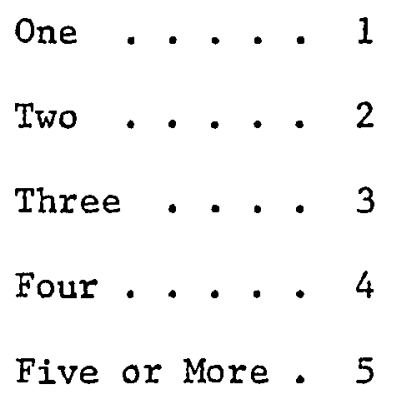


59. Where was your last residence prior to the one where you are now living? Was it: (READ POSSIBLE CHOICES BELOW)

A different place in the same neighborhood . . . . 1

A different place in Portland ........... 2

A different place in Oregon . . . . . . . . . 3

A different state.............. . 4

Other (specify) 5

60. On most issues, would you descrite youreelf as conservative, middle-of-the-road, liberal, radical, or something other?

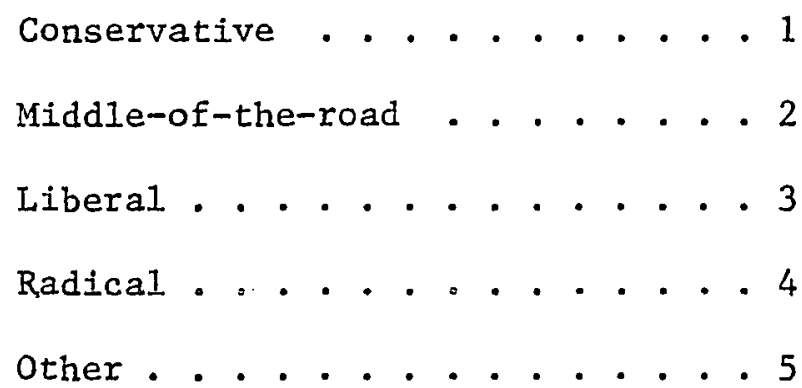

61. Do you get most of your information about the local community and your neighborhood from: (READ POSSIBLE CHOICES BELOW)

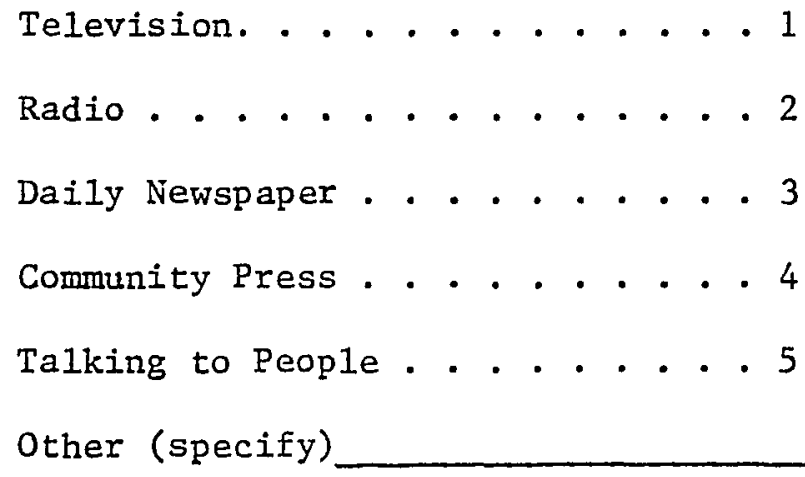

62. As you read, Iisten to, or watch the news these days, do you find you are paying a great deal of attention to things about the local community and your neighborhood, quite a bit of attention, only a little attention, or no attention at all?

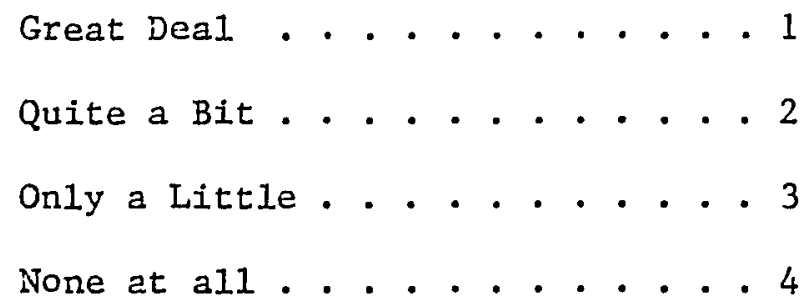


I am going to read you ten short statements. After I read each statement, I would like you to tell me whether you agree strongly, agree somewhat, agree slightly, disagree slightly, disagree somewhat, or disagree strongly.

63. In order to get nominated, most candidates for political office have to make basic compromises and undesirable commitments.

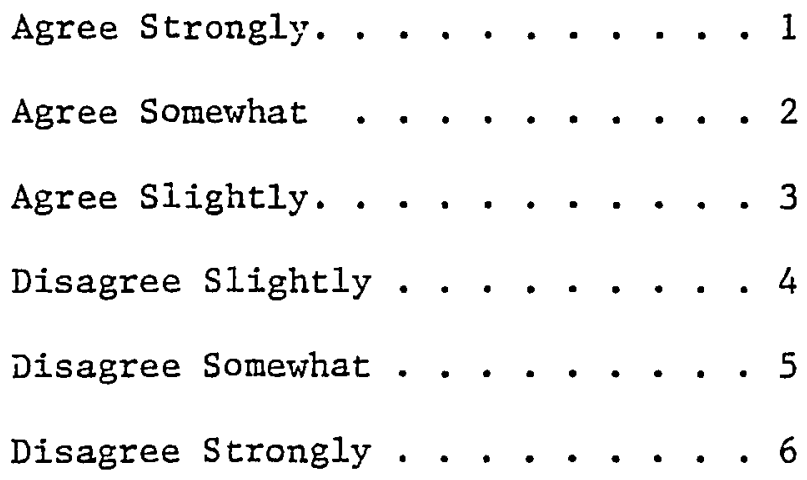

64. It is safest to assume that a11 people have a vicious streak and it will cone out when they are given a chance.

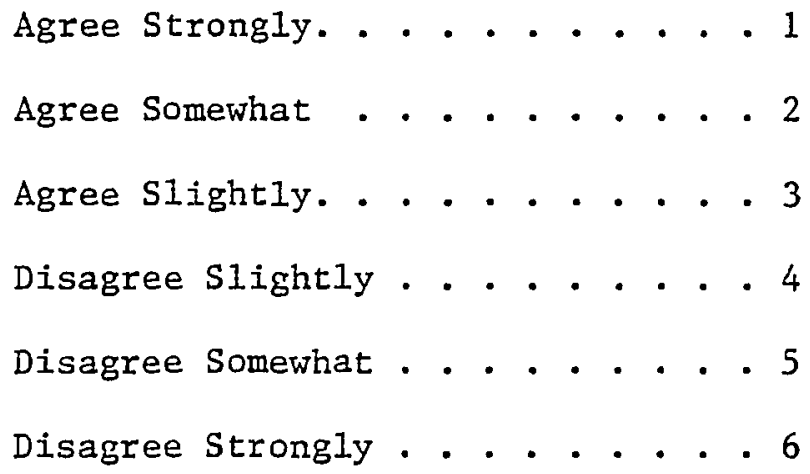

65. Money is the most important factor influencing public policies. Agree Strongly. . . . . . . 1 
66. Barnum was very wrong when he said there is a sucker born every minute.

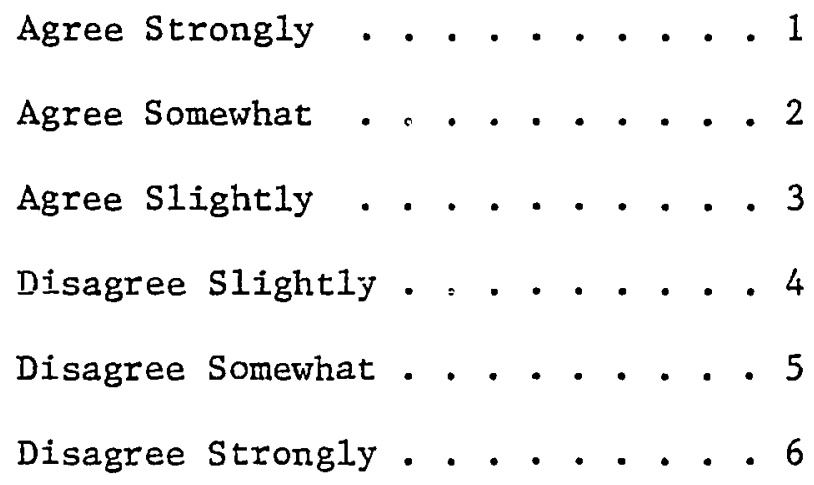

67. The biggest difference between most criminals and other people is that criminals are stupid enough to get caught.

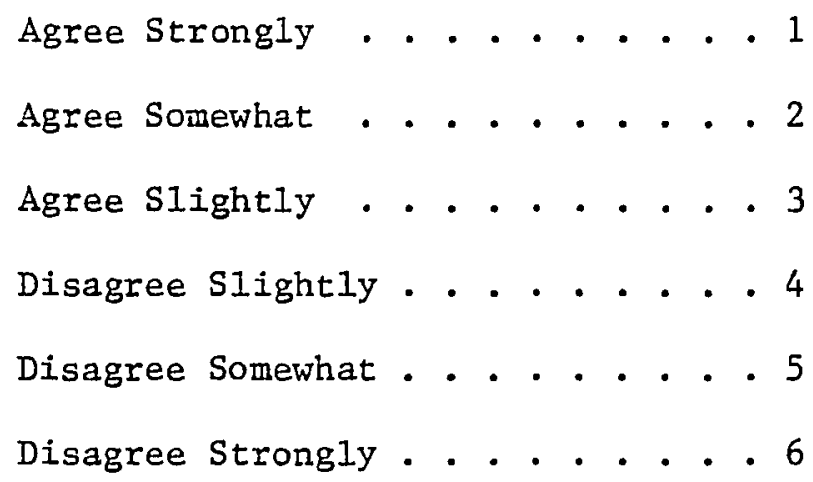

68. Generally speaking, people won't work hard unless they are forced to do so.

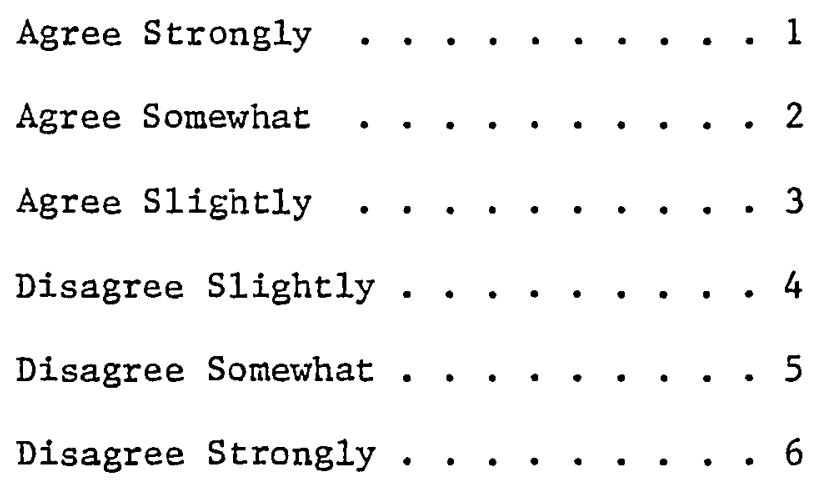


69. Politicians spend most of their time getting re-elected or re-appointed.

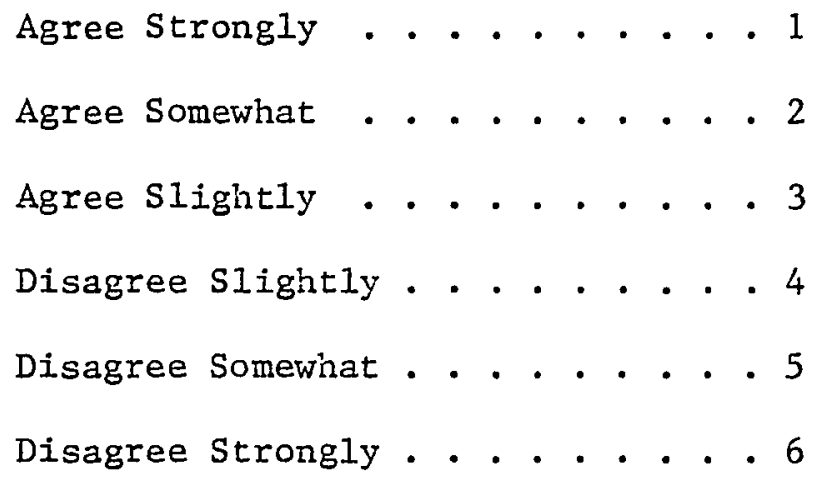

70. A large number of city and county politicians are political hacks.

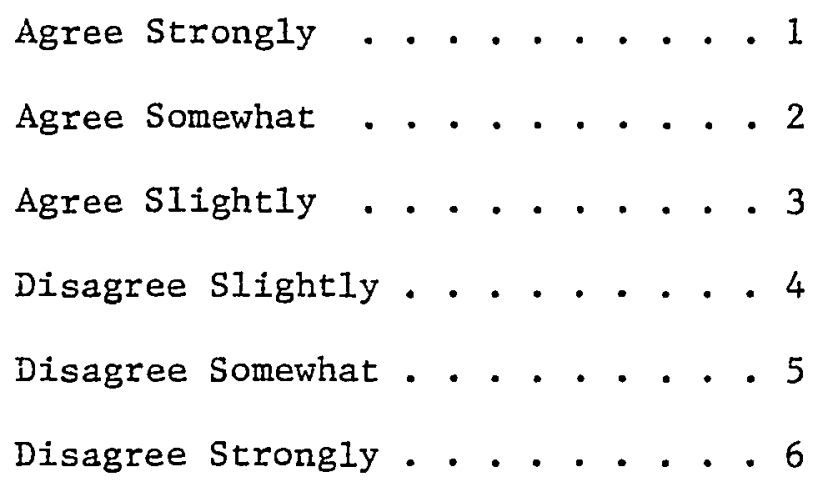

71. People are very frequently manipulated by politicians.

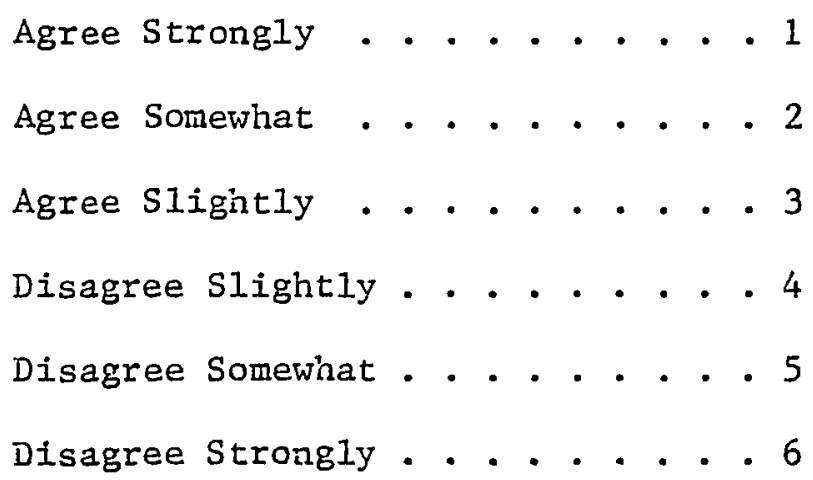


72. Politicans represent the general interest more frequently than they represent the special interests.

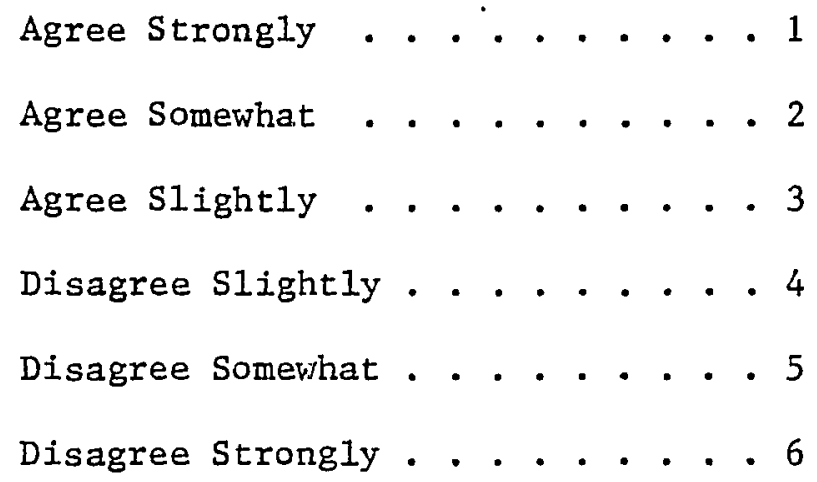

I am going to read you five more short statements. After I read each statement, I would like you to to tell me whether you agree strongly, agree somewhat, agree slightly, disagree slightly, disagree somewhat, or disagree strongly.

73. All citizens have a right to participate in deciding issues that affect them.

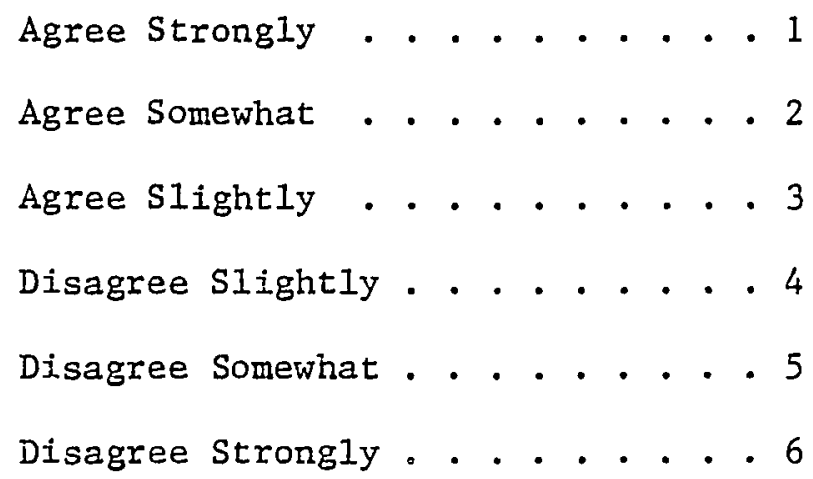

74. People should participate in deciding issues that are important to them.
Agree Strongly . . . . . . . . . 1
Agree Somewhat . . . . . . . 2
Agree Slightly . . . . . . . 3
Disagree Slightly . . . . . 4
Disagree Somewhat . . . . . 5
Disagree Strongly . . . . . 6 
75. Participation by people in decisions that affect them is more important than what decisions are made.

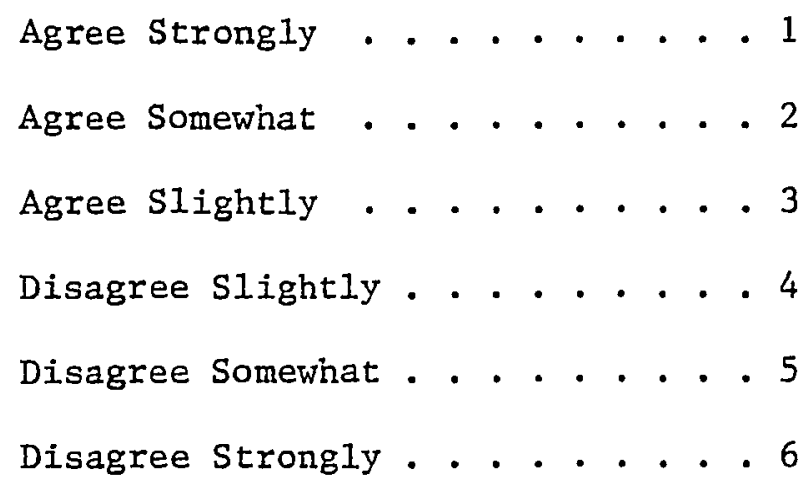

76. Participation by people in decisions that affect them is important even if the decisions are harder to make and might be delayed for longer periods of time.

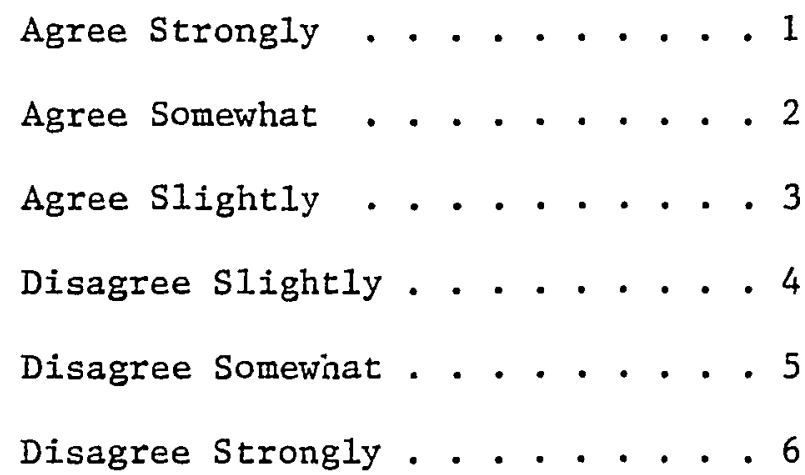

77. Participation by people in decisions that affect them is important even if the decisions made might be wrong.

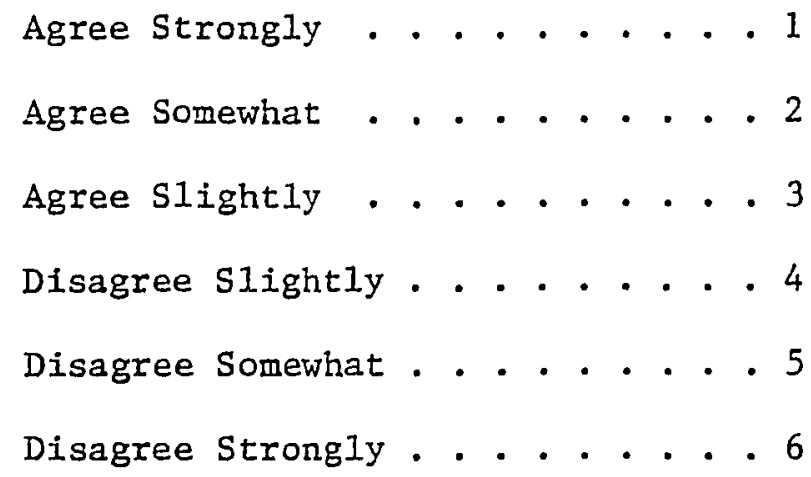

In order to solve neighborhood problems, decisions have to be made about what to do. There are many ways people can help get decisions made that they approve, and to stop decisions they are against. In the next five questions I would like you to tell me how effective you feel some of these ways are--regardless of whether you feel they are right or wrong. 
78. Some people feel voting is very effective. Others feel it is not effective at all. Do you feel voting is: (READ POSSIBLE CHOICES BELOW)

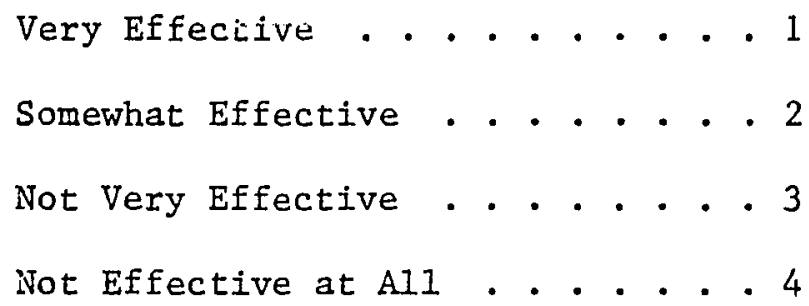

79. Some people feel that things like writing letters to officials, signing or circulating petitions, or speaking out at public hearings are very effective. Others feel these kinds of things are not effective at a1l. Do you feel these kinds of things are: (READ POSSIBLE CHOICES BELOW)

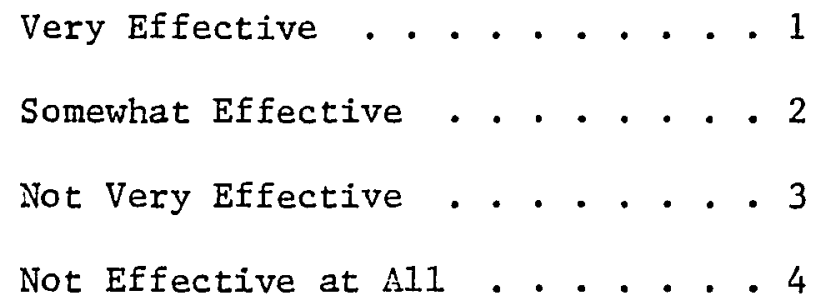

80. Some people feel joining with others and working together as a group is very effective. Others feel it is not effective at a11. Do you feel joining a group and working together is: (READ POSSIBLE CHOICES BELOW)

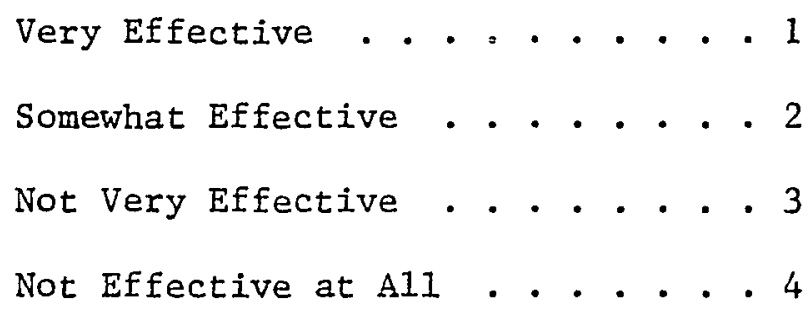

81. Some people feel organized, peaceful demonstrations and picketing are very effective. Others feel they are not effective at al1. Do you feel peaceful demonstrations and picketing are: (READ POSSIBLE CHOICES BELOW)

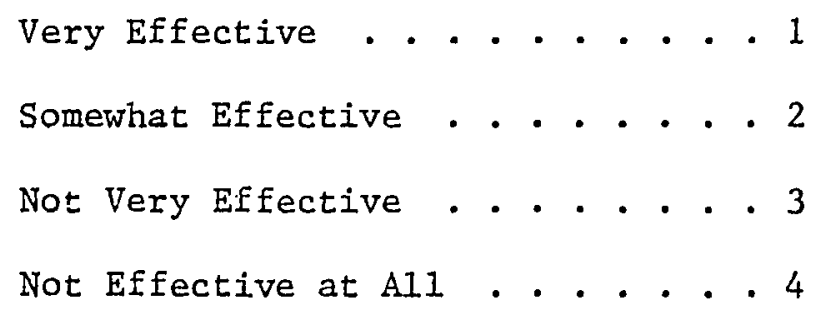


82. Some people feel violent demonstrations and rioting are very effective. Others feel they are not effective at all. Do you feel violent demonstrations and rioting are: (READ POSSIBLE CHOICES BELOW)

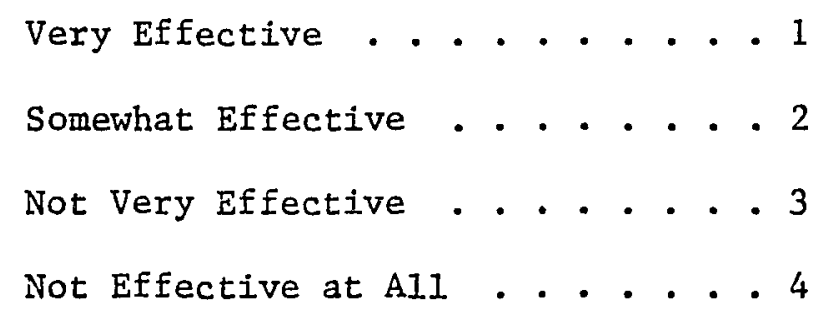

Just as you feel that some of these ways to help get decisions are more effective than others, you may also feel that some of them are right or wrong--regardiess of how effective you feel they are. In the next five questions I would like to ask you how strongly you approve or do not approve of these ways to get decisions made.

83. Some people approve of voting. Others do not. Do you approve very strongly, somewhat, very little, or not at ail?

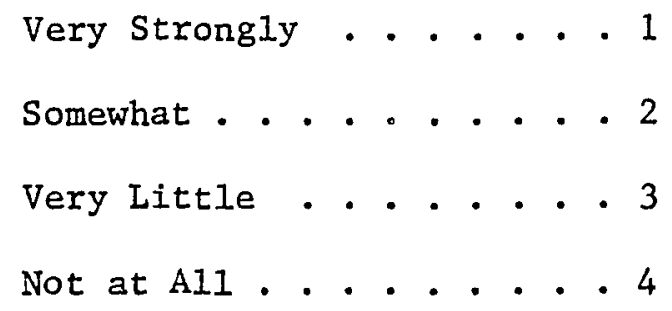

34. Some people approve of things like writing letters to officials, signing or circulating petitions, or speaking out at public hearings. Others do not. Do you approve of these kinds of things very strongly, somewhat, very little, or not at all?

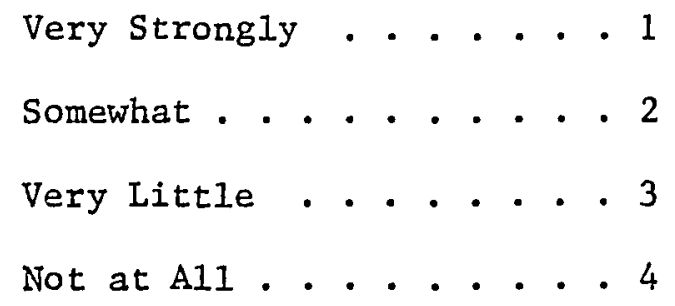


85. Some people approve of joining with others and working together as a group. Others do not. Do you approve of joining a group and working together very strongly, somewhat, very little, or not at all?

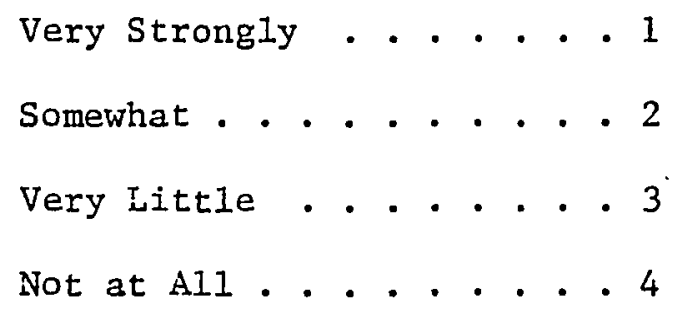

36. Some people approve of organized, peaceful demonstrations and picketing. Others do not. Do you approve of peaceful demonstrations and picketing very strongly, somewhat, very little, or not at all?

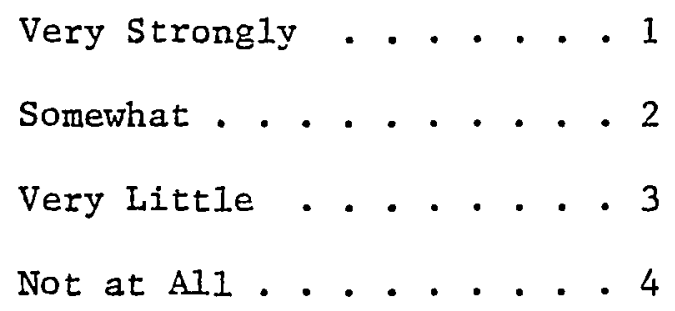

87. Some people approve of violent demonstrations and rioting. Others do not. Do you approve of violent demonstrations and rioting very strongly, somewhat, very little, or not at all?

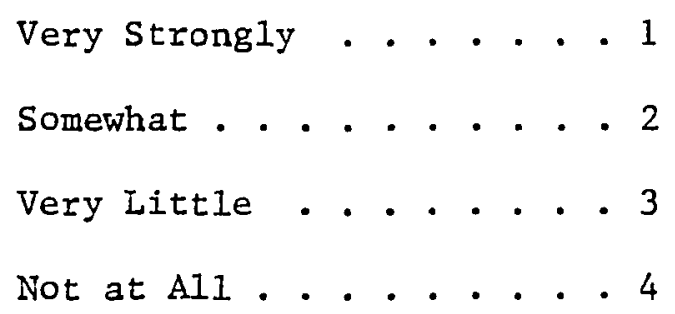

88. Do you feel that getting involved in community and neighborhood affairs is an effective way to improve yourself and increase your skil1s?

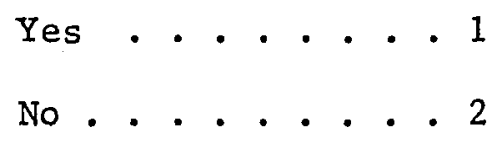


89. Do you approve of getting involved in community and neighborhood affairs as a way to improve yourself and increase your skills.

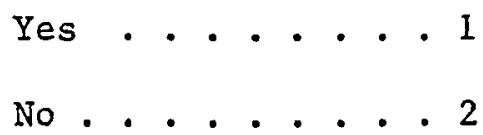

(END OF QUESTIONNAIRE)

(COMPIETE LAST PAGE AFTER LEAVING RESPONDENT'S HOME) 


$$
\text { (RECORD - DO NOT ASK) }
$$

Address

Phone

Race of Respondent

$$
\begin{aligned}
& \text { Black . . . . } 1 \\
& \text { White . . . . } 2 \\
& \text { Other ..... } 3
\end{aligned}
$$

Sex of Respondent

$$
\begin{aligned}
& \text { Fernale . . . . } 1 \\
& \text { Male . . . . . } 2
\end{aligned}
$$

Approximate Age of Respondent

Under 30 . . . . 1

$30-55$..... 2

Over $55 . . . . .3$

Other Persons Present During the Intarview

Yes. . . . . . 1

No . . . . . . 2

Rating of Respondent's Level of Articulation

$$
\begin{aligned}
& \text { Very Articulate . . } 1 \\
& \text { About Average . . . } 2 \\
& \text { Very Inarticulate . . } 3
\end{aligned}
$$

Date of the Interview

Time Interview Began: Time Completed

Reason for failure to complete interview:

Interviewer Comments: 
APPENDIX $F$

SURVEY COMPLETION RATES

\section{TABLE LV}

\section{INTERVIEW COMPLETION AND REFUSAI.} RATES IIN SURVEY NEIGHBORHOODS

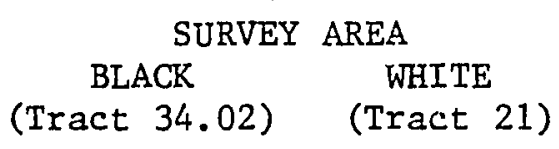

INTERVIEWS

Completed Interviews

$\begin{array}{cc}74 \%^{1} & 91 \%^{2} \\ 26 \% & 09 \% \\ 100 \% & 100 \% \\ 111 & 131 \\ 27 & 20\end{array}$

$\mathrm{N}=$

Houses Vacant or Missing

27

20

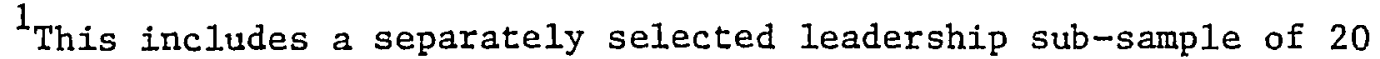
persons, 19 of whom were interviewed. Refer to Chapter $V$ for information concerning this leadership sub-sample.

2 This includes a separately selected leadership sub-sample of 25 persons, 24 of whom were interviewed. Refer to Chapter $V$ for information concerning this leadership sub-sample. 